\title{
Arsenic-72,77 as a Matched Pair Radiopharmaceutical for Imaging and Radiotherapy
}

A Dissertation presented to the Faculty of the Graduate School

at the University of Missouri-Columbia

In partial fulfillment of the requirements for the degree

Doctor of Philosophy

By

Yutian Feng

Professor Silvia S. Jurisson,

Dissertation Supervisor

MAY 2018 
(C) Copyright by Yutian Feng 2018

All Rights Reserved 
The undersigned, appointed by the dean of the Graduate School, have examined the dissertation entitled

\section{Arsenic-72, 77 as a Matched Pair Radiopharmace utical for Imaging and}

\section{Radiotherapy}

Presented by Yutian Feng, a candidate for the degree Doctor of Philosophy, and hereby certify that, in their opinion, it is worthy of acceptance.

Professor Silvia S. Jurisson

Professor Susan Z. Lever

Professor Timothy J. Hoffman

Professor Alan R. Ketring

Professor Kent S. Gates

Professor Cathy S. Cutler 


\section{Acknowledgments}

First and foremost, I give my utmost thankfulness to my graduate advisor Professor Silvia S. Jurisson for her great kindness, encouragement, support, patience and caring for me. Thanks to her I couldn't have enjoyed more my time as a graduate student. I'm fortunate and proud to have her as my mentor because of not only her expertise and wisdom, but also her hardworking attitude and persistence. Secondly I would like to thank my wife Jingjie Huang, without whom I couldn't have been able to survive the inevitable frustration from research and get back on my feet time and time again. Apart from that, I couldn't have done my work without the support from the University of Missouri Chemistry Department. I also want to thank Drs. Cathy Cutler and Alan Ketring for my

work at the MU Research Reactor and Dr. Tim Hoffman for my work at the Truman VA Hospital. I'm grateful for all the support and guidance I received. Collaborating with different institutes taught me invaluable communication skills and prepared me for my career. I'm grateful for the instruction, inspiration and insight provided by my graduate committee, Dr. Susan Lever and Dr. Kent Gates.

In addition, I would like to thank Dr. Anthony J. DeGraffenreid for all the help, advice and enlightenment when I first entered the field. I couldn't have done my work without his fundamental research. I would like to thank Dr. Wei Wycoff for all her help with the NMR facility, Dr. Fabio Gallazzi for the LC-MS facility, Dr. Charles Barnes for X-ray facility and Professor Michael Harmata for help in organic synthesis. I want to thank undergraduate Michael Phipps and graduate student Firouzeh Najafi Khosroshahi. Working as their trainer taught me how to give advice and work collaboratively. 
Finally I want to thank my friends and family for all the support over the years. My parents always support me to pursue my dream emotionally and financially and they have taught me to become a better person. 


\section{Table of Contents}

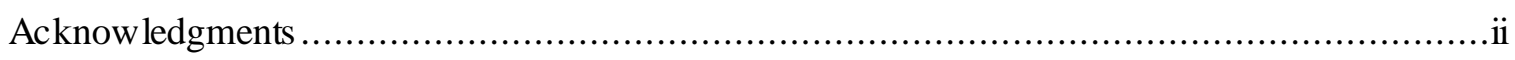

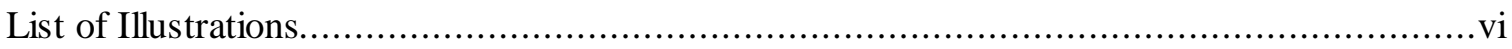

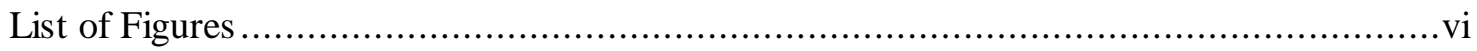

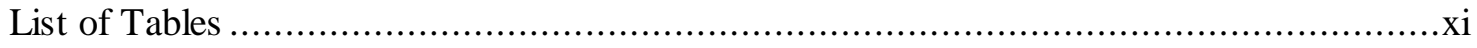

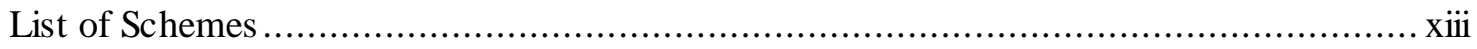

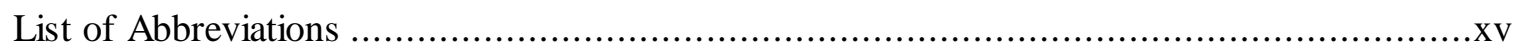

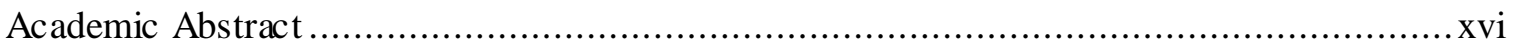

Chapter 1: Arsenic as a Matched Pair Radiopharmaceutical ............................................. 1

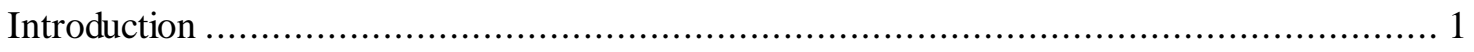

Nuclear Properties of Radionuclides and their Applications in Nuclear Medicine................. 5

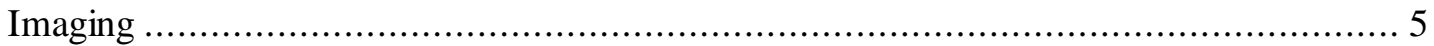

Therapy

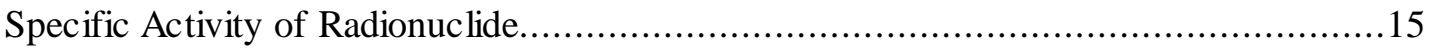

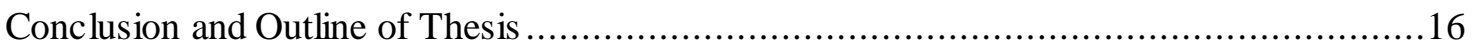

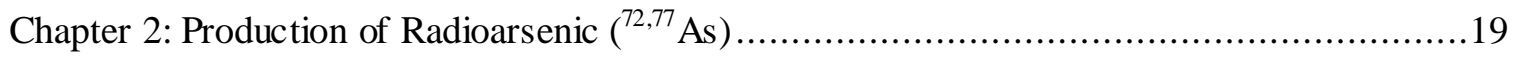

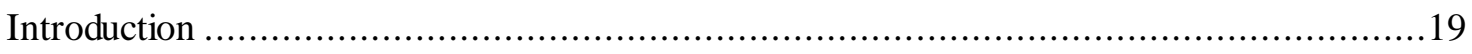

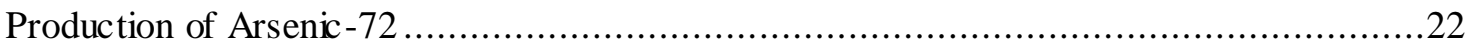

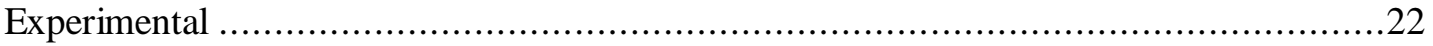

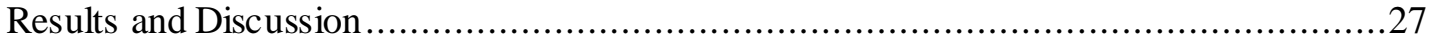

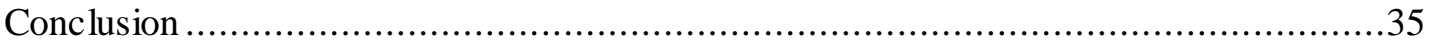

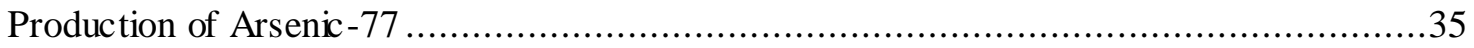

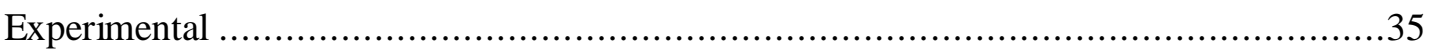

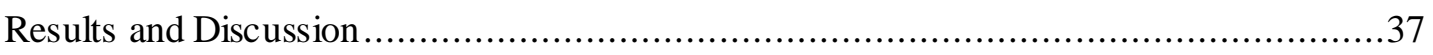

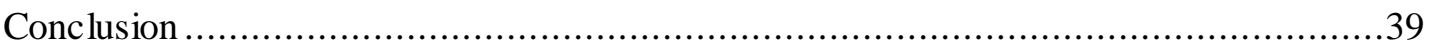

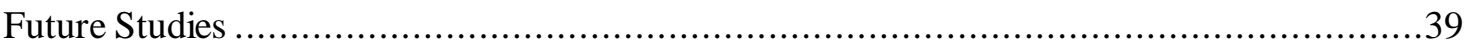

Chapter 3: Dithiol Aryl Arsenic Compounds as Potential Diagnostic and Therapeutic

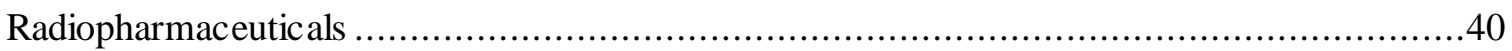

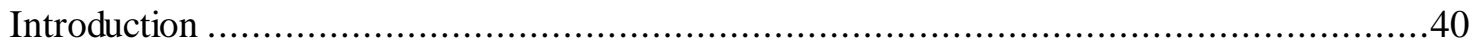

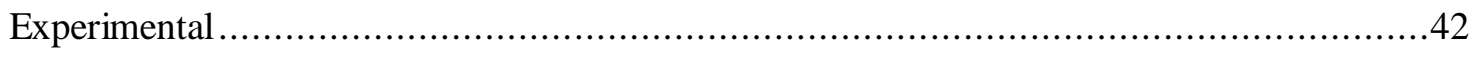

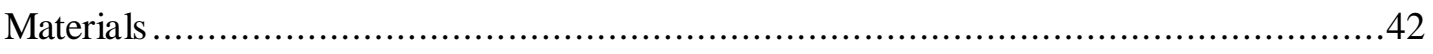

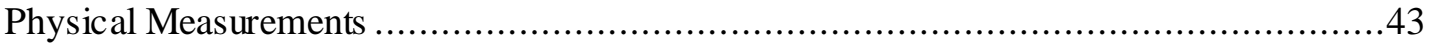

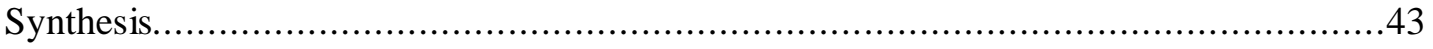




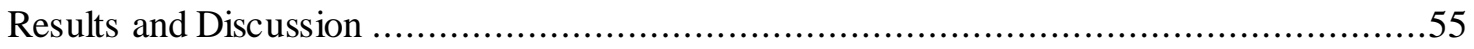

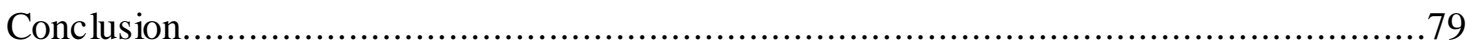

Chapter 4: Trithiol: a Potential Chelate for ${ }^{72,77}$ As Matched Pair Theranostic Complex with High

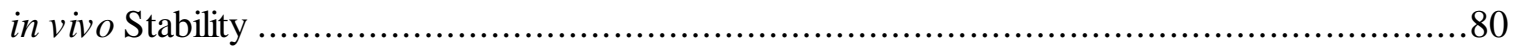

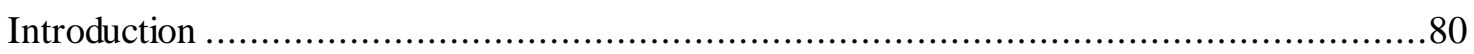

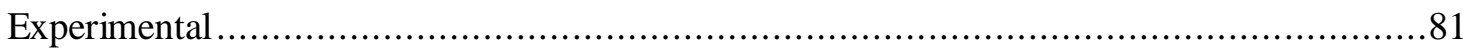

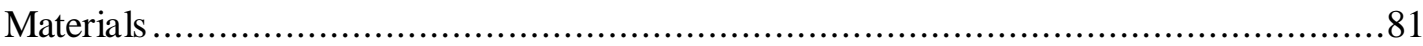

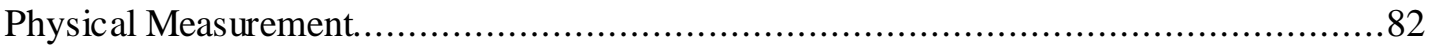

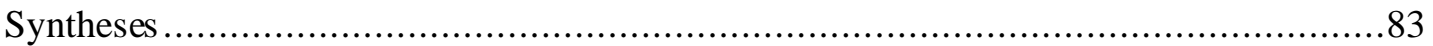

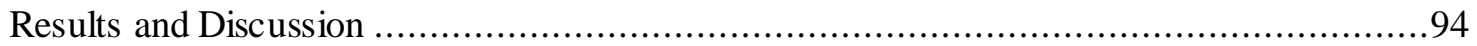

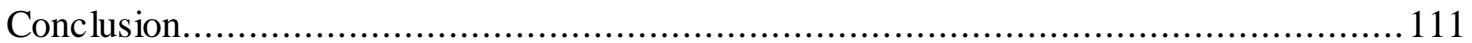

Synthesis of a linkable trithiol analogue with improved hydrophilicity .......................... 112

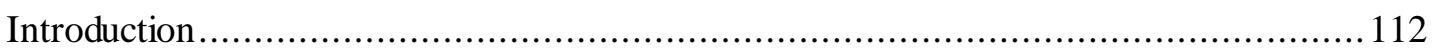

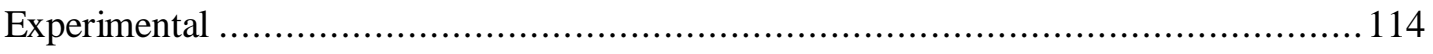

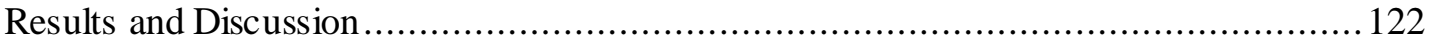

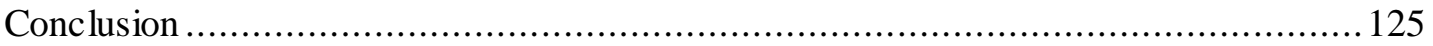

Structural and stability analysis of an arsenic trihydroxyl compound: 4-ethyl-2,6,7-trioxa-1-

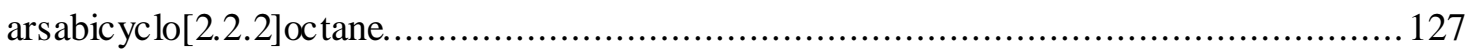

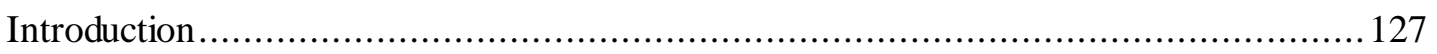

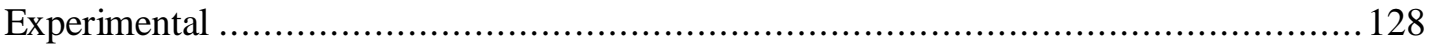

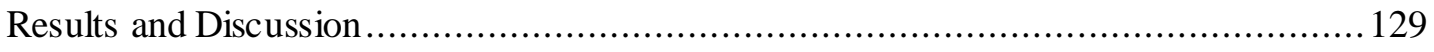

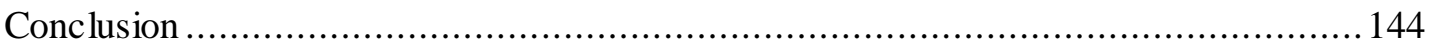

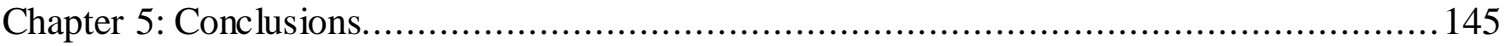

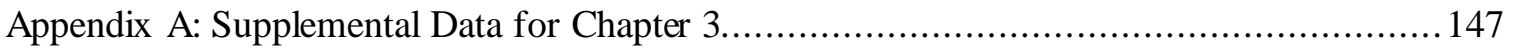

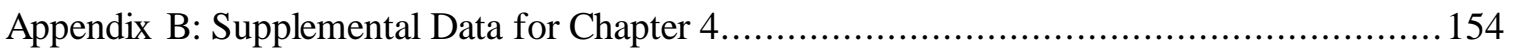

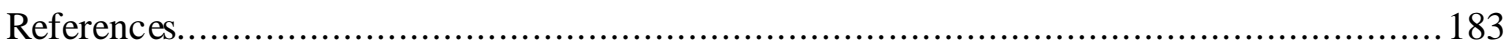

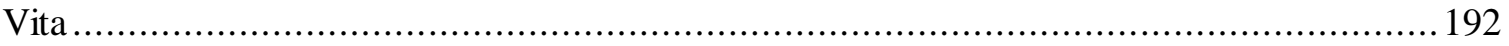




\section{List of Illustrations}

\section{List of Figures}

Figure 1.1. Structure of dithiolates used in treating arsenic poisoning.

Figure 1.2. The mechanism of single-photon emission computed tomography (SPECT) imaging.

Figure 1.3. The structure of ${ }^{99 \mathrm{~m}} \mathrm{Tc}$ Sestamibi (Cardiolite $\left.{ }^{\circledR}\right)$.

Figure 1.4. The mechanism of PET imaging.

Figure 1.5. The structure of ${ }^{18} \mathrm{~F}$ FDG.

Figure 2.1. The transient equilibrium of ${ }^{72} \mathrm{Se}$ and ${ }^{72} \mathrm{As}$.

Figure 2.2. Percentage counts of radionuclides in each fraction.

Figure 2.3. (a) Percentage of counts of radionuclides in each fraction in the second separation, column 1. (b) Percentage of counts of radionuclides in each fraction in the second separation, column 2.

Figure 2.4. PET Phantom data reconstructed. Phantom data collected on a Siemens Inveon® D-PET System using a Micro/Ultra Micro Jaszczak Phantom at 500 million counts.

Figure 3.1. Ethane- and propanedithioarylarsines showing the proton assignments from ${ }^{1} \mathrm{H}$ NMR spectrometry.

Figure 3.2. ORTEP representation of (1) with $50 \%$ probability ellipsoids.

Figure 3.3. ORTEP representation of $(3)$ with $50 \%$ probability ellipsoids.

Figure 3.4. ORTEP representation of (4) with $50 \%$ probability ellipsoids.

Figure 3.5. ORTEP representation of (6) with $50 \%$ probability ellipsoids.

Figure 3.6. ORTEP representation of (7) with $50 \%$ probability ellipsoids.

Figure 3.7. ORTEP representations of (8a and $\mathbf{8 b})$, obtained as the diammonium salt (omitted for clarity), with $50 \%$ probability ellipsoids.

Figure 3.8. ORTEP representation of (9) with $50 \%$ probability ellipsoids.

Figure 3.9. ORTEP representation of (10) (CCDC\# 1436766) with 50\% probability ellipsoids.

Figure 3.10. ORTEP representation of (12) with 50\% probability ellipsoids. 
Figure 3.11. HPLC chromatograms of (a) $\mathbf{1}$ (UV detection) and (b) nca $\left[{ }^{77} \mathrm{As}\right] \mathbf{1}$ (radionuclide detection) with both exhibiting retention times of $28.67 \mathrm{~min}$.

Figure 4.1. ORTEP representation of (3) with 50\% probability ellipsoids.

Figure 4.2. ORTEP representation of (6) with $50 \%$ probability ellipsoids.

Figure 4.3. ORTEP representation of $(8)$ with $50 \%$ probability ellipsoids.

Figure 4.4. The structure of trithiol-BBN(7-14) $\mathrm{NH}_{2}$ complex. (a) The structure of $\mathrm{BBN}(7-14) \mathrm{NH}_{2}$ peptide. (b) The structure of trithiol-linker-BBN(7-14) $\mathrm{NH}_{2}$.

Figure 4.5. The ${ }^{77}$ As-trithiol-BBN(7-14) $\mathrm{NH}_{2}$ was analyzed by RP-HPLC and its signals from both rad detector and UV detectors (wavelengths $220 \mathrm{~nm}$ and $280 \mathrm{~nm}$ ) were compared with trithiocyanate-BBN(7-14) $\mathrm{NH}_{2}$, trithiol-BBN(7-14) $\mathrm{NH}_{2}$ and As-trithiol$\mathrm{BBN}(7-14) \mathrm{NH}_{2}$ standards. Injections of $25 \mu \mathrm{L}$ were carried out for all the injections. Upper left diagram: rad peak of ${ }^{77}$ As-trithiol-BBN(7-14) $\mathrm{NH}_{2}$ (first line) matched the UV peak of As-trithiol-BBN(7-14) $\mathrm{NH}_{2}$ standard (second line); the UV peak of trithiol$\mathrm{BBN}(7-14) \mathrm{NH}_{2}$ standard (third line) was distinguished from As-trithiol-BBN(7-14) $\mathrm{NH}_{2}$ peaks (first and second line); the unlabeled trithiol-BBN(7-14) $\mathrm{NH}_{2}$ was also reduced (second and third line). Lower diagram: UV signals of monothiols and TCEP impurities were reduced after purification (second and third line); no UV signals related to the rad signals of ${ }^{77}$ As-trithiol-BBN(7-14) $\mathrm{NH}_{2}$ (first line) were observed, indicating the low concentration of ${ }^{77} \mathrm{As}$-trithiol-BBN(7-14) $\mathrm{NH}_{2}$ in the product solution.

Figure 4.6. Biodistribution of free ${ }^{77} \mathrm{As}\left(\left[{ }^{77} \mathrm{As}\right] \mathrm{H}_{2} \mathrm{AsO}_{4}{ }^{-}\right)$and ${ }^{77} \mathrm{As}-$ trithiol-BBN (714) $\mathrm{NH}_{2}$ in CF-1 normal mice. (A) Free ${ }^{77}$ As at $15 \mathrm{~min}, 1 \mathrm{~h}, 4 \mathrm{~h}$ and $24 \mathrm{~h}, \mathrm{n}=4$. (B) ${ }^{77} \mathrm{As}-$ trithiol-BBN(7-14) $\mathrm{NH}_{2}$ at $1 \mathrm{~h}$ and $4 \mathrm{~h}, \mathrm{n}=5$.

Figure 4.7. The structure of the linkable trithiol ligand containing a triazole unit.

Figure 4.8. The structure of the new trithiol chelate (trithiolYF1).

Figure 4.9. ORTEP representation of 4-ethyl-2,6,7-trioxa-1-arsabic yclo[2.2.2]octane with $50 \%$ probability ellipsoids.

Figure 4.10. The packing diagram of 4-ethyl-2,6,7-trioxa-1-arsabicyclo[2.2.2]octane.

Figure 4.11. ${ }^{1} \mathrm{H}$ NMR spectrum of 4-ethyl-2,6,7-trioxa-1-arsabicyclo[2.2.2] octane $\left(\mathrm{CDCl}_{3} \mathrm{~d}_{1} ; 500 \mathrm{MHz}\right)$.

Figure 4.12. ${ }^{13} \mathrm{C}$ NMR spectrum of 4-ethyl-2,6,7-trioxa-1-arsabicyclo[2.2.2]octane $\left(\mathrm{CDCl}_{3} \mathrm{~d}_{1} ; 500 \mathrm{MHz}\right)$. 
Figure 4.13. ${ }^{1} \mathrm{H}$ NMR spectrum of 2-ethyl-2-(hydroxymethyl)propane-1,3-diol $\left[\mathrm{C}_{6} \mathrm{H}_{14} \mathrm{O}_{3}\right]$ $\left(\mathrm{CDCl}_{3} \mathrm{~d}_{1} ; 500 \mathrm{MHz}\right)$.

Figure 4.14. ${ }^{13} \mathrm{C}$ NMR spectrum of 2-ethyl-2-(hydroxymethyl)propane-1,3-diol ( $\mathrm{CDCl}_{3}$ $\left.\mathrm{d}_{1} ; 500 \mathrm{MHz}\right)$.

Figure 4.15. ${ }^{1} \mathrm{H}$ NMR spectrum of a mixture of ethanethiol and triethylamine (stock solution $\mathrm{B}, 0.24 \mathrm{mmol}, 1: 1$ ratio, affording thiolates); this is the reference spectrum for the $\mathrm{t}=0 \mathrm{~h}$ time point $\left(\mathrm{CDCl}_{3} \mathrm{~d}_{1} ; 500 \mathrm{MHz}\right)$.

Figure 4.16. ${ }^{1} \mathrm{H}$ NMR spectrum of a mixture of ethanethiol, triethylamine and 4-ethyl2,6,7-trioxa-1-arsabicyclo[2.2.2] octane (thiol challenge study; free thiol: As complex 2.5: $1)$; this is the $\mathrm{t}=0 \mathrm{~h}$ time point spectrum.

Figure 4.17. (A) Proposed mechanism of a free thiol approaching the As metal center from As-O $\sigma^{*}$ orbital as a nucleophile, resulting in the As-O bond breaking and formation of a free hydroxyl group and As-S bonds. (B) ${ }^{1} \mathrm{H}$ NMR spectra ( $\delta$ from 3.5 to $4.2 \mathrm{ppm}$ ) showing the thiol challenge mixture at $\mathrm{t}=0 \mathrm{~h}, \mathrm{t}=4 \mathrm{~h}, \mathrm{t}=24 \mathrm{~h}$, and $\mathrm{t}=72 \mathrm{~h}$, respectively. a represents ${ }^{1} \mathrm{H}$ NMR signals of $\mathrm{CH}_{2} \mathrm{OAs}$, while $\mathbf{a}^{*}$ represents ${ }^{1} \mathrm{H}-\mathrm{NMR}$ signals for a free hydroxyl group $\mathrm{CH}_{2} \mathrm{OH}$. A singlet ( $\left.\mathbf{a}^{*}\right)$ grew in over time indicating the decompositon of the $\mathrm{As}(\mathrm{OR})_{3}$ bicyclic complex.

\section{Appendix A: Supplemental Data for Chapter 3}

Figure A-1. ${ }^{1} \mathrm{H}$ NMR of 2-(4-ethoxyphenyl)-1,3,2-dithiaarsolane $\left[\mathrm{CH}_{3} \mathrm{CH}_{2} \mathrm{OC}_{6} \mathrm{H}_{4} \mathrm{As}\left(\mathrm{SCH}_{2} \mathrm{CH}_{2} \mathrm{~S}\right)\right]$, compound 1.

Figure A-2. ${ }^{13} \mathrm{C}$ NMR of 2-(4-ethoxyphenyl)-1,3,2-dithiaarsolane $\left[\mathrm{CH}_{3} \mathrm{CH}_{2} \mathrm{OC}_{6} \mathrm{H}_{4} \mathrm{As}\left(\mathrm{SCH}_{2} \mathrm{CH}_{2} \mathrm{~S}\right)\right]$, compound 1.

Figure A-3. ${ }^{1} \mathrm{H}$ NMR of 2-(4-ethoxyphenyl)-1,3,2-dithiaarsolane-4,5-dicarboxylic acid, $\left(\mathrm{NH}_{4}\right)_{2}\left[\mathrm{CH}_{3} \mathrm{CH}_{2} \mathrm{O} \mathrm{C}_{6} \mathrm{H}_{4} \mathrm{As}(\mathrm{SCH}(\mathrm{COO}) \mathrm{CH}(\mathrm{COO}) \mathrm{S})\right]$, compound 2.

Figure A-4. ${ }^{13} \mathrm{C}$ NMR of 2-(4-ethoxyphenyl)-1,3,2-dithiaarsolane-4,5-dicarboxylic acid, $\left(\mathrm{NH}_{4}\right)_{2}\left[\mathrm{CH}_{3} \mathrm{CH}_{2} \mathrm{O} \mathrm{C}_{6} \mathrm{H}_{4} \mathrm{As}(\mathrm{SCH}(\mathrm{COO}) \mathrm{CH}(\mathrm{COO}) \mathrm{S})\right]$, compound 2.

Figure A-5. ${ }^{1} \mathrm{H}$ NMR of 2-(4-ethoxyphenyl)-1,3,2-dithiaarsinane $\left[\mathrm{CH}_{3} \mathrm{CH}_{2} \mathrm{OC}_{6} \mathrm{H}_{4} \mathrm{As}\left(\mathrm{SCH}_{2} \mathrm{CH}_{2} \mathrm{CH}_{2} \mathrm{~S}\right)\right]$, compound 3.

Figure A-6. ${ }^{13} \mathrm{C}$ NMR of 2-(4-ethoxyphenyl)-1,3,2-dithiaarsinane $\left[\mathrm{CH}_{3} \mathrm{CH}_{2} \mathrm{OC}_{6} \mathrm{H}_{4} \mathrm{As}\left(\mathrm{SCH}_{2} \mathrm{CH}_{2} \mathrm{CH}_{2} \mathrm{~S}\right)\right]$, compound 3.

\section{Appendix B: Supplemental Data for Chapter 4}


Figure B-1. ${ }^{1} \mathrm{H}$ NMR of (1-methyl-2,6,7-trioxa bicyc lo[2.2.2] octan-4-yl) methanol $\left[\mathrm{C}_{7} \mathrm{H}_{12} \mathrm{O}_{4}\right]$, compound 2 .

Figure B-2. ${ }^{13} \mathrm{C}$ NMR of (1-methyl-2,6,7-trioxabicyclo[2.2.2] octan-4-yl) methanol $\left[\mathrm{C}_{7} \mathrm{H}_{12} \mathrm{O}_{4}\right]$, compound 2 .

Figure B-3. ${ }^{1} \mathrm{H}$ NMR of 1-methyl-4-((prop-2-yn-1-yloxy)methyl)-2,6,7trioxabicyclo[2.2.2] octane $\left[\mathrm{C}_{10} \mathrm{H}_{14} \mathrm{O}_{4}\right]$, compound 3 .

Figure B-4. ${ }^{13} \mathrm{C}$ NMR of 1-methyl-4-((prop-2-yn-1-yloxy)methyl)-2,6,7trioxabicyclo[2.2.2] octane $\left[\mathrm{C}_{10} \mathrm{H}_{14} \mathrm{O}_{4}\right]$, compound 3 .

Figure B-5. ${ }^{1} \mathrm{H}$ NMR of 2-(hydroxymethyl)-2-((prop-2-yn-1-yloxy)methyl)propane-1,3diol $\left[\mathrm{C}_{8} \mathrm{H}_{14} \mathrm{O}_{4}\right]$, compound 4 .

Figure B-6. ${ }^{13} \mathrm{C}$ NMR of 2-(hydroxymethyl)-2-((prop-2-yn-1-yloxy)methyl) propane-1,3diol $\left[\mathrm{C}_{8} \mathrm{H}_{14} \mathrm{O}_{4}\right]$, compound 4 .

Figure B -7. ${ }^{1} \mathrm{H}$ NMR of 2-((prop-2-yn-1-yloxy)methyl)-2-((tosyloxy) methyl)propane1,3-diyl bis(4-methylbenzenesulfonate) $\left[\mathrm{C}_{29} \mathrm{H}_{32} \mathrm{O}_{10} \mathrm{~S}_{3}\right]$, compound 5 .

Figure B -8. ${ }^{13} \mathrm{C}$ NMR of 2-((prop-2-yn-1-yloxy)methyl)-2-((tosyloxy) methyl)propane1,3-diyl bis(4-methylbenzenesulfonate) $\left[\mathrm{C}_{29} \mathrm{H}_{32} \mathrm{O}_{10} \mathrm{~S}_{3}\right]$, compound 5 .

Figure B -9. ${ }^{1} \mathrm{H}$ NMR of 3-(3-thiocyanatomethyl)propoxy)prop-1-yne $\left[\mathrm{C}_{11} \mathrm{H}_{11} \mathrm{~N}_{3} \mathrm{OS}_{3}\right]$, compound 6.

Figure B-10. ${ }^{13} \mathrm{C}$ NMR of 3-(3-thiocyanatomethyl)propoxy)prop-1-yne $\left[\mathrm{C}_{11} \mathrm{H}_{11} \mathrm{~N}_{3} \mathrm{OS}_{3}\right]$, compound 6.

Figure B-11. ${ }^{1} \mathrm{H}$ NMR of ethyl 3-azidopropionate $\left[\mathrm{C}_{5} \mathrm{H}_{9} \mathrm{~N}_{3} \mathrm{O}_{2}\right]$, compound 9 .

Figure B-12. ${ }^{13} \mathrm{C}$ NMR of ethyl 3-azidopropionate $\left[\mathrm{C}_{5} \mathrm{H}_{9} \mathrm{~N}_{3} \mathrm{O}_{2}\right]$, compound 9.

Figure B-13. ${ }^{1} \mathrm{H}$ NMR of ethyl 3-(4-((3-thiocyanato-2,2-

bis(thiocyanatomethyl) propoxy) methyl)-1H-1,2,3-triazol-1-yl)propanoate $\left[\mathrm{C}_{16} \mathrm{H}_{20} \mathrm{~N}_{6} \mathrm{O}_{3} \mathrm{~S}_{3}\right]$, compound 7.

Figure B-14. ${ }^{13} \mathrm{C}$ NMR of ethyl 3-(4-((3-thiocyanato-2,2bis(thiocyanatomethyl) propoxy) methyl)-1H-1,2,3-triazol-1-yl)propanoate $\left[\mathrm{C}_{16} \mathrm{H}_{20} \mathrm{~N}_{6} \mathrm{O}_{3} \mathrm{~S}_{3}\right]$, compound 7.

Figure B-15. ${ }^{1} \mathrm{H}$ NMR of 3-(4-((3-thiocyanato-2,2-

bis(thiocyanatomethyl) propoxy)methyl)-1H-1,2,3-triazol-1-yl)propanoic acid $\left[\mathrm{C}_{14} \mathrm{H}_{16} \mathrm{~N}_{6} \mathrm{O}_{3} \mathrm{~S}_{3}\right]$, compound 8 . 
Figure B-16. ${ }^{13} \mathrm{C}$ NMR of 3-(4-((3-thiocyanato-2,2-

bis(thiocyanatomethyl) propoxy)methyl)-1H-1,2,3-triazol-1-yl)propanoic acid $\left[\mathrm{C}_{14} \mathrm{H}_{16} \mathrm{~N}_{6} \mathrm{O}_{3} \mathrm{~S}_{3}\right]$, compound 8 .

Figure B-17. ${ }^{1} \mathrm{H}$ NMR of dimethyl 5-(3-bromo-2,2bis(bromomethyl) propoxy) is ophthalate $\left[\mathrm{C}_{15} \mathrm{H}_{17} \mathrm{Br}_{3} \mathrm{O}_{5}\right]$, compound 9.

Figure B-18. ${ }^{13} \mathrm{C}$ NMR of dimethyl 5-(3-bromo-2,2bis(bromomethyl) propoxy)is ophthalate $\left[\mathrm{C}_{15} \mathrm{H}_{17} \mathrm{Br}_{3} \mathrm{O}_{5}\right]$, compound 9 .

Figure B-19. ${ }^{1} \mathrm{H}$ NMR of dimethyl 5-(3-(acetylthio)-2,2bis((acetylthio)methyl) propoxy) is ophthalate $\left[\mathrm{C}_{21} \mathrm{H}_{26} \mathrm{O}_{8} \mathrm{~S}_{3}\right]$, compound $\mathbf{1 0}$.

Figure B-20. ${ }^{13} \mathrm{C}$ NMR of dimethyl 5-(3-(acetylthio)-2,2bis((acetylthio)methyl) propoxy) is ophthalate $\left[\mathrm{C}_{21} \mathrm{H}_{26} \mathrm{O}_{8} \mathrm{~S}_{3}\right]$, compound $\mathbf{1 0}$.

Figure B-21a. ${ }^{1} \mathrm{H}$ NMR of 5-((4-(mercaptomethyl)-1,2-dithiolan-4yl)methoxy)is ophthalic acid $\left[\mathrm{C}_{13} \mathrm{H}_{14} \mathrm{O}_{5} \mathrm{~S}_{3}\right]$, compound 11 .

Figure B-21b. ${ }^{1} \mathrm{H}$ NMR of 5-((4-(mercaptomethyl)-1,2-dithiolan-4yl)methoxy)is ophthalic acid $\left[\mathrm{C}_{13} \mathrm{H}_{14} \mathrm{O}_{5} \mathrm{~S}_{3}\right]$, compound 11 .

Figure B-22. ${ }^{13} \mathrm{C}$ NMR of 5-((4-(mercaptomethyl)-1,2-dithiolan-4yl)methoxy)is ophthalic acid $\left[\mathrm{C}_{13} \mathrm{H}_{14} \mathrm{O}_{5} \mathrm{~S}_{3}\right]$, compound 11 .

Figure B-23. ${ }^{1} \mathrm{H}$ NMR of 5-(3-mercapto-2,2-bis(mercaptomethyl)propoxy) isophthalic acid $\left[\mathrm{C}_{13} \mathrm{H}_{16} \mathrm{O}_{5} \mathrm{~S}_{3}\right]$, compound 12 .

Figure B-24. ${ }^{1} \mathrm{H}$ NMR of 5-(3-mercapto-2,2-bis(mercaptomethyl)propoxy) isophthalic acid $\left[\mathrm{C}_{13} \mathrm{H}_{16} \mathrm{O}_{5} \mathrm{~S}_{3}\right]$, compound 12 .

Figure B-25. ${ }^{13} \mathrm{C}$ NMR of 5-(3-mercapto-2,2-bis(mercaptomethyl)propoxy)is ophthalic acid $\left[\mathrm{C}_{13} \mathrm{H}_{16} \mathrm{O}_{5} \mathrm{~S}_{3}\right]$, compound 12 .

Figure B-26. ${ }^{1} \mathrm{H}$ NMR of 5-((2,6,7-trithia-1-arsabicyclo[2.2.2] octan-4yl)methoxy)is ophthalic acid $\left[\mathrm{C}_{13} \mathrm{H}_{13} \mathrm{AsO}_{5} \mathrm{~S}_{3}\right]$, compound 14.

Figure B-27. ${ }^{13} \mathrm{C}$ NMR of 5-((2,6,7-trithia-1-arsabicyclo[2.2.2] octan-4yl)methoxy)is ophthalic acid $\left[\mathrm{C}_{13} \mathrm{H}_{13} \mathrm{AsO}_{5} \mathrm{~S}_{3}\right]$, compound 14. 


\section{List of Tables}

Table 1.1. Nuclear properties of arsenic radionuclides

Table 1.2. Commonly used positron emitting radionuclides and their nuclear properties.

Table 1.3. Commonly used $\beta^{-}$particles emitting radionuclides and their nuclear properties.

Table 1.4. Commonly used $\alpha$ emitting radionuclides and their nuclear properties.

Table 2.1. Nuclear properties of isotopes present in the target solution standard.

Table 3.1. ${ }^{1} \mathrm{H}$ and ${ }^{13} \mathrm{C}$ NMR alkyl dithiol proton and carbon chemical shifts for the aryldithioarsines $(\mathbf{1}-\mathbf{1 2})$ compared to the free ligands. Each methylene proton becomes unique on coordinating to the As(III).

Table 3.2. X-ray crystal data, data collection parameters, and refinement parameters for 1 and 3 .

Table 3.3. Selected bond distances $(\AA)$ and angles $\left({ }^{\circ}\right)$ for $\mathbf{1}$ and $\mathbf{3}$.

Table 3.4. X-ray crystal data, data collection parameters, and refinement parameters for 4, $6-10$ and 12.

Table 3.5. Selected bond distances $(\AA)$ and angles $\left(^{\circ}\right)$ for 4, 6-10 and 12 .

Table 3.6. Optimization of the reducing agent (ammonium mercaptoacetate) concentration for arsenate reduction $(n=2)$; conditions: 9:1 ACN:DI water, $60{ }^{\circ} \mathrm{C}, 30$ $\min$.

Table 3.7. Initial optimization of the ammonium mercaptoacetate concentration in the reduction of $\left[\mathrm{As}^{77}\right] p$-ethoxyphenylarsonic acid $(\mathrm{n}=3)$; conditions: 9:1 ACN:DI water, 60 
${ }^{\circ} \mathrm{C}, 45 \mathrm{~min}$., $30 \mathrm{mM}$ monothiol in the reduction step, $15 \mathrm{mg} p$-ethoxybenzenediazonium tetrafluoroborate.

Table 3.8. Initial optimization of the dithiol (1,2-ethanedithiol) concentration $(n=3)$; conditions: 9:1 ACN:DI water, $60{ }^{\circ} \mathrm{C}, 45 \mathrm{~min}$., $30 \mathrm{mM}$ monothiol in reduction step, 15 mg $p$-ethoxybenzenediazonium tetrafluoroborate, $270 \mathrm{mM}$ monothiol during incorporation step.

Table 4.1. X-ray crystal Data, data collection parameters, and refinement parameters for 3,6 , and 8 .

Table 4.2. Selected bond angles $\left({ }^{\circ}\right)$ and distances $(\AA)$ for $\mathbf{3 , 6}$, and $\mathbf{8}$.

Table 4.3. Biodistribution of free ${ }^{77} \mathrm{As}\left(\left[{ }^{77} \mathrm{As}\right] \mathrm{H}_{2} \mathrm{AsO}_{4}{ }^{-}\right)$in $\mathrm{CF}-1$ normal mice at $15 \mathrm{~min}, 1$ $\mathrm{h}, 4 \mathrm{~h}$ and $24 \mathrm{~h}$ post injection, $\mathrm{n}=4$. Data are presented as \%ID/g \pm SD.

Table 4.4. Biodistribution of ${ }^{77}$ As-trithiol-BBN(7-14) $\mathrm{NH}_{2}$ in $\mathrm{CF}-1$ normal mice at $1 \mathrm{~h}$ and $4 \mathrm{~h}$ post injection, $\mathrm{n}=5$. Data are presented as $\% \mathrm{ID} / \mathrm{g} \pm \mathrm{SD}$.

Table 4.5. X-ray crystal Data, data collection parameters, and refinement parameters for 4-ethyl-2,6,7-trioxa-1-arsabicyclo[2.2.2] octane.

Table 4.6. Selected bond angles $\left({ }^{\circ}\right)$ and distances $(\AA)$ for 4-ethyl-2,6,7-trioxa-1arsabicyclo[2.2.2] octane. 


\section{List of Schemes}

Scheme 1.1. Intermolecular and intramolecular binding of arsenic where $K_{d}=k_{o f f} / k_{o n}$.

Scheme 1.2. The decay scheme of ${ }^{99} \mathrm{Mo} /{ }^{99 \mathrm{~m}} \mathrm{Tc}$ generator.

Scheme 1.3. An example of high specific activity radionuclide $\left({ }^{77} \mathrm{As}\right.$ and $\left.{ }^{76} \mathrm{As}\right)$. v stands for anti-neutrino released from $\beta$ decay.

Scheme 1.4. Two approaches to radiolabel radioarsenic for increase under in vivo conditions.

Scheme 3.1. The synthesis of aryl-As compound via the Bart, Scheller and Bechamp reactions.

Scheme 3.2. The synthesis of dithioarylarsines.

Scheme 3.3. The structure of the dithioarylarsines (compound 1 to 12).

Scheme 3.4. The synthesis of the nca ${ }^{77}$ As 2-(4-ethoxyphenyl)-1,3,2-dithiaarsolane.

Scheme 3.5. Radio TLC data acquired from the Bioscan imager to evaluate the reaction yields. (a) Retention times of the radiolabeling species in methanol: acetone (10: 1). (b) Retention times of the radiolabeling species in dichloromethane: chloroform (1: 1).

Scheme 4.1. Synthetic scheme for the linkable trithiol precursor, compound $\mathbf{8}$.

Scheme 4.2. Synthesis of trithiol-BBN(7-14) $\mathrm{NH}_{2}$ complex. The trithiol-BBN(7-14) $\mathrm{NH}_{2}$ precursor was deprotected.

Scheme 4.3. Radiotracer synthesis of no carrier added ${ }^{77} \mathrm{As}$-trithiol-BBN(7-14) $\mathrm{NH}_{2}$.

Scheme 4.4. The synthesis of the new trithiol (trithiolYF1).

Scheme 4.5. Radiolabeling of nca ${ }^{77}$ As with the new trithiol (trithiolYF1).

Scheme 4.6. The deprotection of the linkablec trithiol and radiolabeling with nca ${ }^{77}$ As.

Scheme 4.7. The synthesis of the non-radioactive As-trithiol (As-trithiolYF1) complex. 
Scheme 4.8. The synthesis of the $\operatorname{As}\left(\mathrm{O}_{3} \mathrm{R}\right)$ complex 4-ethyl-2,6,7-trioxa-1arsabicyclo[2.2.2]octane. 


\section{List of Abbreviations}

$\alpha$ - alpha particle

$\beta^{+}$- positron

$\beta^{-}$- negatron

$\gamma$ - gamma photon

$\varepsilon$ - electron capture

ACN - acetonitrile

APL - acute promyelocytic leukemia

BAL - 2, 3-dimercaptopropanol or

British anti-lewisite

$\mathrm{BBN}$ - bombesin peptide

BBN(7-14) $\mathrm{NH}_{2}$ - bombesin peptide

residues 7 through 14 that is amidated on

the carboxy terminis

$\mathrm{BFC}$ - bifunctional chelator

BFCA - bifunctional chelate approach

BLIP - Brookhaven linac isotope

producer

BNL - Brookhaven national laboratory

BSA - bovine serum albumin

CCDC - Cambridge crystallographic

data centre

DIPEA - diisopropylamine

DMSA - 2, 3-dimercaptosuccinic acid

DMSO - dimethyl sulfoxide

ESI-MS - electrospray ionization mass

spectrometry

Fmoc - fluorenylmethyloxycarbonyl

protecting group

GRP receptors - gastrin-releasing

peptide receptors

HBTU - N,N,N',N'-tetramethyl-O- $(1 \mathrm{H}-$

benzotriazol-1-yl) uronium

hexafluorophosphate

HEPES - 4-(2-hydroxyethyl)-1-

piperazineethanesulfonic acid

HMQC - heteronuclear multiple

quantum coherence

$\mathrm{HPGe}$ - high purity germanium

HPLC - high performance liquid

chromatography

IC50 - Concentration of competing cell surface receptor binding necessary to

displace $50 \%$ of a standard bombesin peptide used as a gold

standard for binding studies

IT - isomeric transition

LD50 - dose or amount necessary to kill

$50 \%$ of a population

LED - light emitting diode

LET - linear energy transfer

$\mathrm{mAb}$ - monoclonal antibody

$m / z$ - mass to charge

$\mathrm{NaI}(\mathrm{Tl})$ - sodium iodide gamma ray

detector

NCA - no carrier added

NMR - nuclear magnetic resonance

PC-3 - prostate cancer cell line 3

PET - positron emission tomography

RP-HPLC - reversed phase high

performance liquid chromatography

SPECT - single-photon emission

computed tomography

$\mathrm{tBu}$ - tert-butanol protecting group

TFA - trifluoroacetic acid

TES - triethylsilane

TLC - thin layer chromatography 


\section{Academic Abstract}

Radiopharmaceuticals deliver radionuclides to specific target sites via the bifunctional chelate approach, where the radionuclides are chelated with a ligand and linked to a targeting biomolecule. They can be categorized as imaging or therapeutic agents based on the physical properties of the radionuclides. Matched pair radionuclides have advantages because of identical chemistry of the imaging and therapy counterparts and true matched pair radionuclides are rare (e.g., ${ }^{64,67} \mathrm{Cu},{ }^{44,47} \mathrm{Sc},{ }^{135,131} \mathrm{I}$ ). Radioimmunoimaging and therapy commonly use antibodies (or antibody fragments) as targeting biomolecules, and may take a few days to accumulate in tumor cells. Thus they require radionuclides with longer half-lives. Arsenic-72 ( $\beta+, 26$ hour half-life) and ${ }^{77} \mathrm{As}\left(\beta^{-}\right.$emitter, 38.8 hour half-life) have suitable physical properties as a true matched pair for radioimaging and therapy. This dissertation focuses on the development of ${ }^{72,77}$ As matched pair for potential PET imaging and radiotherapy.

The production and separation of no carrier added (nca) ${ }^{72,77}$ As will be discussed in Chapter 2 . No carrier added ${ }^{77}$ As separation was improved based on the reported method by decreasing the operation time and increasing capacity based on reported method.[1] The parameters for a

${ }^{72} \mathrm{Se} /{ }^{72}$ As generator were evaluated and nca ${ }^{72} \mathrm{Se}$ was produced via the ${ }^{70} \mathrm{Ge}(\alpha, 2 \mathrm{n}){ }^{72} \mathrm{Se}$ nuclear reaction, separated and loaded onto a generator column. Further evaluations are underway.

Radiochemistry of nca ${ }^{72,77}$ As will be discussed in Chapters 3 and 4 since two chelating approaches were evaluated. The aryl dithiol approach incorporates an aryl ring to nca radioarsenic and complexes it with dithiol ligands. After various modifications and optimizations, radiolabeling nca ${ }^{72,77}$ As affording dithioarylars ines were accomplished in high yields. The 
trithiol approach complexes nca ${ }^{72,77}$ As with a trithiol chelate. Its in vivo stability was evaluated by conjugating the trithiol chelate to a Bombesin receptor targeting peptide and investigating its biodistribution in normal mice. An improved trithiol chelate was proposed and synthesized based on the high in vivo stability but poor targeting efficacy of the initial trithiol complex. 


\section{Chapter 1: Arsenic as a Matched Pair Radiopharmaceutical}

\section{Introduction}

Radiopharmaceuticals contain radionuclides and are considered effective approaches to diagnosis and therapy of many diseases. In the 1940s, George de Hevesy was awarded the Nobel Prize for his contribution in establishing the radiotracer principal.[2] The radiotracer principal explains two conditions under which radiotracers could be taken advantage: (1) the concentration of radiotracers should be low enough to minimize the effect on human bodies; (2) at that concentration level, radiotracers should be able to be detected, or function therapeutically. Based on the nuclear properties of the radionuclides, radiopharmaceuticals can be categorized as imaging or therapeutic agents. Generally speaking, imaging radionuclides decay by emitting $\gamma$-rays $\left({ }^{99 \mathrm{~m}} \mathrm{Tc}\right)$ or positrons $\left({ }^{18} \mathrm{~F}\right)$ resulting in annihilation photons, which have high penetration and are detected external of the body to provide diagnostic information. Therapeutic radionuclides emit charged particles $\left(\beta^{-}\right.$, Auger electrons and $\alpha$ particles) depositing energy and causing damage to target tissues. [3]

The nuclear properties of radioarsenic $\left({ }^{72} \mathrm{As},{ }^{77} \mathrm{As}\right)$ led to the investigation of radiopharmaceuticals for combined radioimaging and radiotherapy using radioarsenic (Table 1.1). Arsenic-72 ( $\beta+$ emitter, $26 \mathrm{~h}$ half-life $)$ can potentially be used as a PET imaging agent while its therapeutic counterpart ${ }^{77} \mathrm{As}\left(\beta^{-}\right.$emitter, $38.8 \mathrm{~h}$ half-life) delivers a radiation dose via the emission of $\beta^{-}$particles. Because of the identical chemistry of the counterparts in a "matched pair", the imaging counterpart ${ }^{72}$ As provides accurate pharmacokinetics and biological distribution information to precisely guide the use of its therapy counterpart ${ }^{77} \mathrm{As}$ 


\section{Yutian Feng}

in both preclinical and clinical research. $[4,5]$ Arsenic-72 can be produced from the decay of its parent isotope ${ }^{72} \mathrm{Se}$, which can potentially be developed into a ${ }^{72} \mathrm{Se} /{ }^{72} \mathrm{As}$ generator because of the long half-life of ${ }^{72} \mathrm{Se}(8.4 \mathrm{~d})$.[6] Generally it is economically favorable to produce radionuclides from a generator since it can cut down the cost of transportation and provide a longer shelf-life for radionuclides of interest. Apart from that, the long half-lives of radioarsenic $\left({ }^{72} \mathrm{As},{ }^{77} \mathrm{As}\right)$ make them suitable for radiolabeling monoclonal antibodies (mAb), which usually take days to achieve maximum tumor uptake.[7] Compared to most commonly used positron emitters $\left(\right.$ e.g. $\left.,{ }^{18} \mathrm{~F},{ }^{11} \mathrm{C},{ }^{64} \mathrm{Cu},{ }^{68} \mathrm{Ga}\right),{ }^{72} \mathrm{As}$ has a half-life similar to the biological half-lives of antibodies and is capable of producing PET imaging 2 to 5 days after injections. Table 1.1. Nuclear properties of arsenic radionuclides (www.nndc.bnl.gov)

\begin{tabular}{|c|c|c|c|c|}
\hline Isotope & ${ }^{71} \mathrm{As}$ & ${ }^{72} \mathrm{As}$ & ${ }^{74} \mathrm{As}$ & ${ }^{77} \mathrm{As}$ \\
\hline Half-life (h) & 64.8 & 26.4 & 427.2 & 38.8 \\
\hline Mode of Decay (\%) & $\begin{array}{l}\text { EC (68); } \\
\beta^{+}(32)\end{array}$ & $\begin{array}{l}\text { EC (12.2); } \\
\beta^{+}(87.8)\end{array}$ & $\begin{array}{l}\text { EC (66); } \\
\beta^{+}(29)\end{array}$ & $\beta^{-(100)}$ \\
\hline $\mathbf{E}_{\beta \max }(\mathrm{MeV})$ & 2.01 & 2.50 & 0.940 & 0.683 \\
\hline $\begin{array}{c}\text { Gamma Emissions } \\
\text { (keV;\%) }\end{array}$ & $175.2 ; 32$ & $833.9 ; 80$ & $634.8 ; 15$ & $239.0 ; 1.7$ \\
\hline
\end{tabular}

Apart from the similarities in chemistry among group 15 pnictogens, arsenic sits on the border of metals and non-metals between germanium and selenium. It has an electron configuration of $3 d^{10} 4 s^{2} 4 p^{3}$. Arsenic is typically observed in two oxidation states, namely +3 (arsenite) and +5 (arsenate) and commonly has a coordination number of 3. Like phosphorous, arsenic is considered a soft Lewis acid or base depending on whether it is 


\section{Yutian Feng}

bonded to an electron withdrawing or donating group. Arsenic toxicity has been well discussed over the last few decades.[8] The high binding affinity between arsenic and thiols explains the in vivo arsenic accumulation in tissues with high cysteine content, and hence is the leading cause of arsenic toxicity.[9] Its thiophilic nature was also applied in the treatment of arsenic poisoning using dithiolates: 2,3-dimercaptopropanol (British Anti-lewisite, BAL), 2,3-dimercaptosuccinic acid (DMSA) and 2,3-dimercaptopropanesulfonate (DMPS) (Figure 1.1).[10]

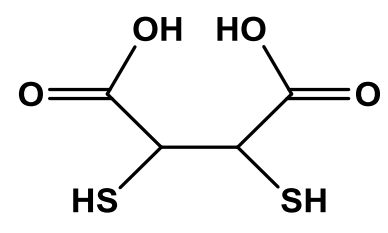

DMSA

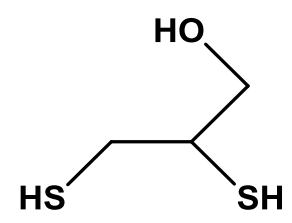

BAL

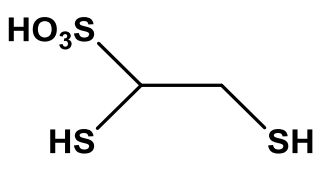

DMPS

Figure 1.1. Structure of dithiolates used in treating arsenic poisoning.

Recently the thiophilic nature of arsenic was used to develop potential no carrier added (nca) radioarsenic radiopharmaceuticals.[11-14] Monoclonal antibodies modified with SATA (Nsuccinimidyl S-acetylthioacetate) to increase the number of available thiol groups were directly radiolabeled with ${ }^{72,74}$ As with high radiolabeling yields achieved (>99\%).[11] Evaluation of the radioarsenic labeled antibodies showed they remained intact after incubation in serum for $72 \mathrm{~h}$, and biodistribution of radiolabeled bavituximab showed a tumor:liver ratio of 22 at $72 \mathrm{~h}$ in tumor bearing rats with minimal release of radioarsenic from radiolabeled antibodies.[12] More recently radioarsenic $\left({ }^{72} \mathrm{As}\right)$ labeling strategies using dithiol ligands and thiol-modified mesoporous silica nanoparticles were reported with 
reasonable yields. [14] Compared to the fast renal clearance of free ${ }^{72} \mathrm{As}$, the blood circulation lifetime of ${ }^{72}$ As labeled nanoparticles was enhanced providing a potential PET imaging radiopharmaceutical.

It has been demonstrated that arsenic conjugates are stable when arsenic binds to intramolecular thiols (Scheme 1.1).[8] This increased in vivo stability can be explained by the chelate effect. In Scheme 1.1, trivalent arsenic favors sulfur donors over hydroxyl donors and hence binds to thiols under in vivo conditions. Because of the chelate effect, monothiols that bind to arsenic are replaced with intramolecular thiols. This finding indicates that molecules with multiple thiols can potentially form As-S complexes with higher stability under in vivo conditions.

(A) Intermolecular<smiles>O[14CH2]O</smiles>

RSH

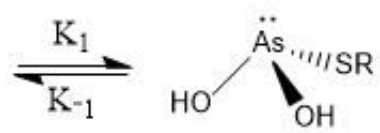

$\underset{\mathrm{K}-2}{\stackrel{\mathrm{K}_{2}}{\rightleftharpoons}}$

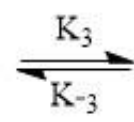

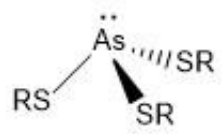

(B) Intramolecular<smiles>O[14C](O)(O)[14CH2]S</smiles>
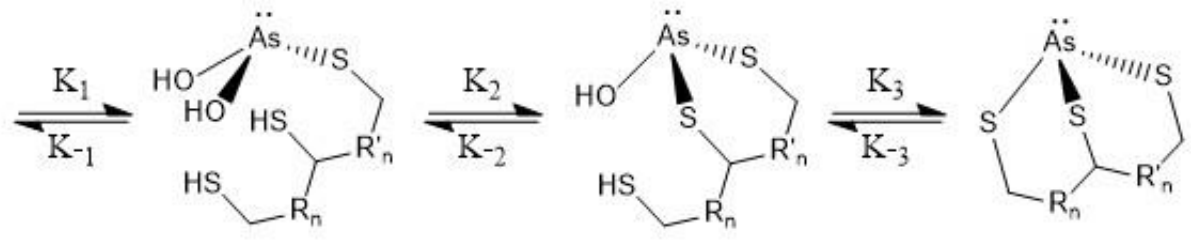

Scheme 1.1. Intermolecular and intramolecular binding of arsenic where $K_{d}=k_{o f f} / k_{o n} \cdot[15]$

Among all the successful examples of radiolabeling radioarsenic with thiol containing compounds, many of them suffer from low in vivo stability, and thus ligands with higher in vivo stability are required. 


\section{Nuclear Properties of Radionuclides and their Applications in Nuclear Medicine}

Radionuclides of interest can be used for imaging or therapy applications depending on their types of radioactive decay. Most radionuclides used for imaging decay either by positron $\left(\beta^{+}\right)$ emission, gamma ray $(\gamma)$ emission, electron capture (EC), and/or internal transition (IT). Commonly used imaging radionuclides include ${ }^{18} \mathrm{~F},{ }^{11} \mathrm{C},{ }^{68} \mathrm{Ga},{ }^{99 \mathrm{~m}} \mathrm{Tc},{ }^{89} \mathrm{Zr}$ and ${ }^{64} \mathrm{Cu}$. Therapeutic radionuclides decay emitting charged particles such as alpha $(\alpha)$, beta $\left(\beta^{-}\right)$and Auger electrons in order to deliver therapeutic efficacy. Commonly used therapeutic radionuclides include ${ }^{177} \mathrm{Lu},{ }^{153} \mathrm{Sm},{ }^{90} \mathrm{Y},{ }^{188} \mathrm{Re},{ }^{211} \mathrm{At},{ }^{212} \mathrm{~Pb}$ and ${ }^{225} \mathrm{Ac}$.

\section{Imaging}

There are two widely used non-invasive imaging technologies: single-photon emission computed tomography (SPECT) and positron emission tomography (PET). Generally speaking, SPECT imaging is economically more favorable than PET imaging because the most widely used SPECT imaging agent ${ }^{99 \mathrm{~m}} \mathrm{Tc}$ is readily available from the ${ }^{99} \mathrm{Mo} /{ }^{99 \mathrm{~m}} \mathrm{Tc}$ generator, while PET imaging provides great resolution (depending on $\mathrm{E}_{\beta+}$ ) and in vivo quantitation. The advantages and disadvantages of SPECT and PET imaging have been thoroughly discussed over the years.[16, 17] The mechanism, relevant radionuclides and examples of Food and Drug Administration (FDA) approved radiopharmaceuticals using the two imaging technologies will be briefly discussed here.

Single-photon emiss ion computed tomography (SPECT). Unlike diagnostic X-ray imaging, no external radiation sources are applied in SPECT imaging. Instead, a radioactive source is injected into a patient (normally through the blood stream), and $\gamma$-rays emitted by 
the radioactive source, usually from the particular radiopharmaceutical, are detected from external $\gamma$-ray detectors ( $\gamma$-ray cameras). The signals are then analyzed by a computer to form 3-D images to provide diagnostic information of the tissues or organs where the radiopharmaceutical are delivered (Figure 1.2).

\section{Component of SPECT}

\section{SPECT-CT}
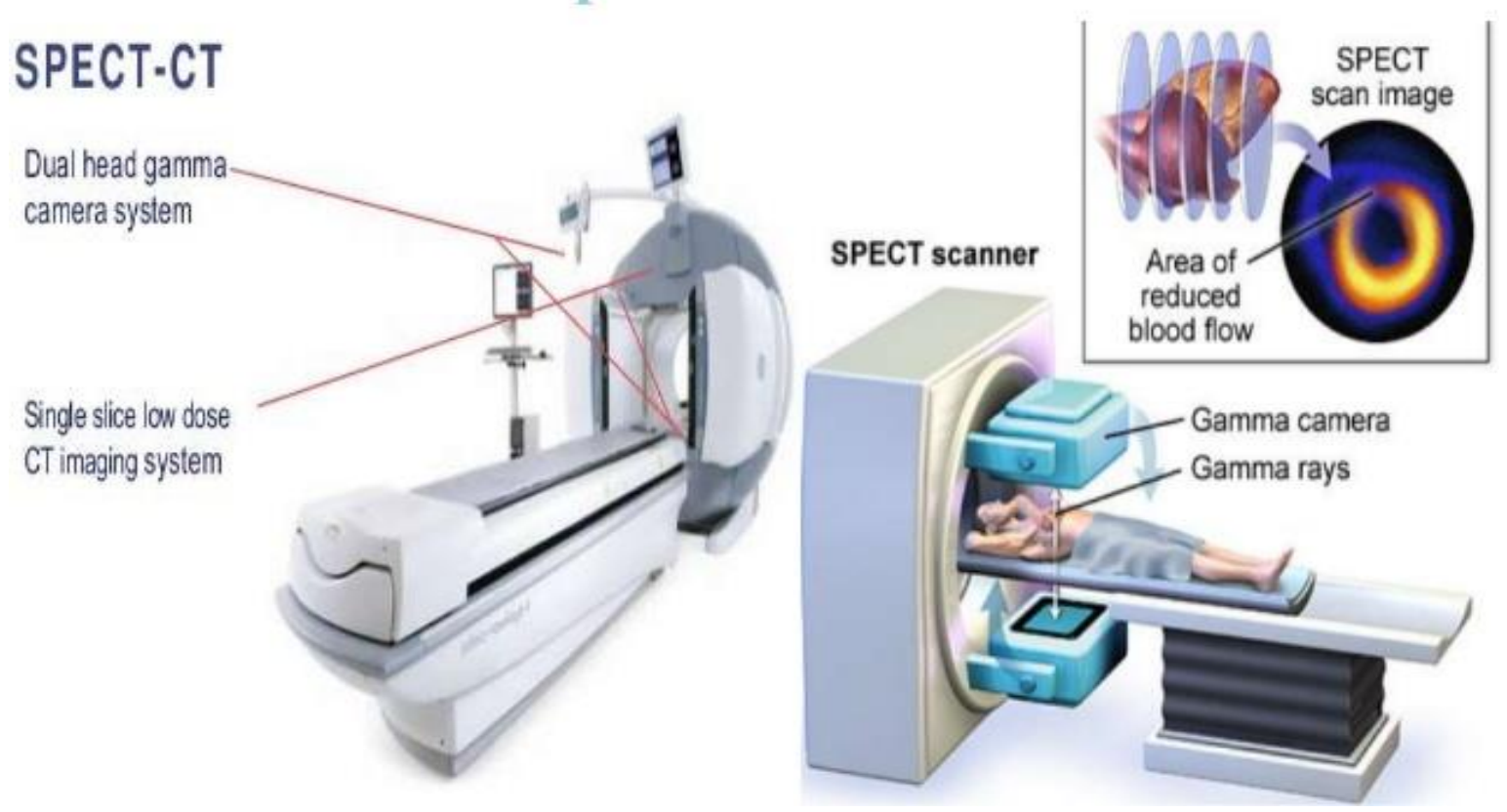

Figure 1.2. The mechanism of single-photon emission computed tomography (SPECT) imaging. (http//www.maropice.com/thyroid-and-parathyroid/thyroid-and-parathyroidawesome-spect-with-clinical-application/)

A great contributor to the wide usage of SPECT imaging is the development of ${ }^{99} \mathrm{Mo} /{ }^{99 \mathrm{~m}} \mathrm{Tc}$ generator. It was developed by Powell Richards at the Brookhaven National Laboratory in the 1960s.[18] The half-lives of ${ }^{99 \mathrm{~m}} \mathrm{Tc}$ and ${ }^{99} \mathrm{Mo}$ are $6 \mathrm{~h}$ and $66 \mathrm{~h}$, respectively. Molybdenum99 is adsorbed on an acid alumina $\left(\mathrm{Al}_{2} \mathrm{O}_{3}\right)$ resin in the chemical form of molybdate $\left(\mathrm{MoO}_{4}{ }^{2-}\right)$ 


\section{Yutian Feng}

as the parent isotope while the decay product of ${ }^{99} \mathrm{Mo}-{ }^{99 \mathrm{~m}} \mathrm{Tc}$ is readily produced and eluted from the resin (Scheme 1.2). One example of a ${ }^{99 m} \mathrm{Tc}$ radiopharmaceutical is Cardiolite ${ }^{\circledR}$, which is the kit to produce ${ }^{99 \mathrm{~m}}$ Tc Sestamibi for cardiac imaging (Figure 1.3). Normally two images are taken by injecting ${ }^{99 \mathrm{~m}} \mathrm{Tc}$ Sestamibi when patients are at rest and then at stress (by exercise or pharmacologically); by comparing the two images diagnostic information is acquired regarding the patients' coronary arteries.

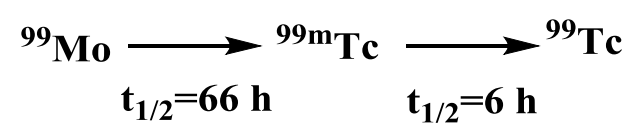

Scheme 1.2. The decay scheme of ${ }^{99} \mathrm{Mo} /{ }^{99 \mathrm{~m}} \mathrm{Tc}$ generator.

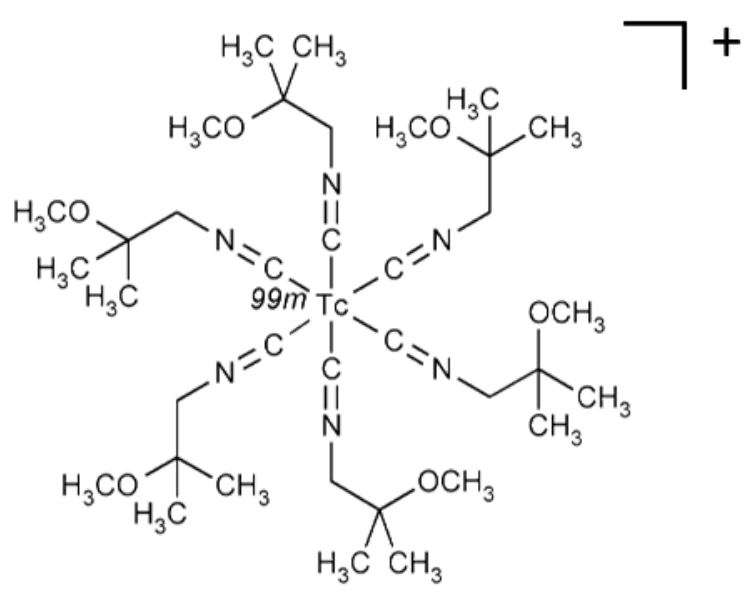

Figure 1.3. The structure of ${ }^{99 \mathrm{~m}} \mathrm{Tc}$ Sestamibi (Cardiolite $\left.\AA\right)$.

Positron emission tomography (PET). PET requires a positron emitting radionuclide to perform PET imaging (Figure 1.4). Similar to SPECT imaging, radiopharmaceuticals containing positron emitting radionuclides must be injected into a patient as an internal 


\section{Yutian Feng}

radiation source. The emitted positrons annihilate when they interact with electrons after depositing all their kinetic energy, and then emit two $511 \mathrm{keV}$ annihilation photons in opposite directions $\left(\sim 180^{\circ}\right)$. The external scintillators capture the signals but they are only taken into account when two coincident $511 \mathrm{keV}$ photons are detected to achieve high resolution and signal/noise ratio.
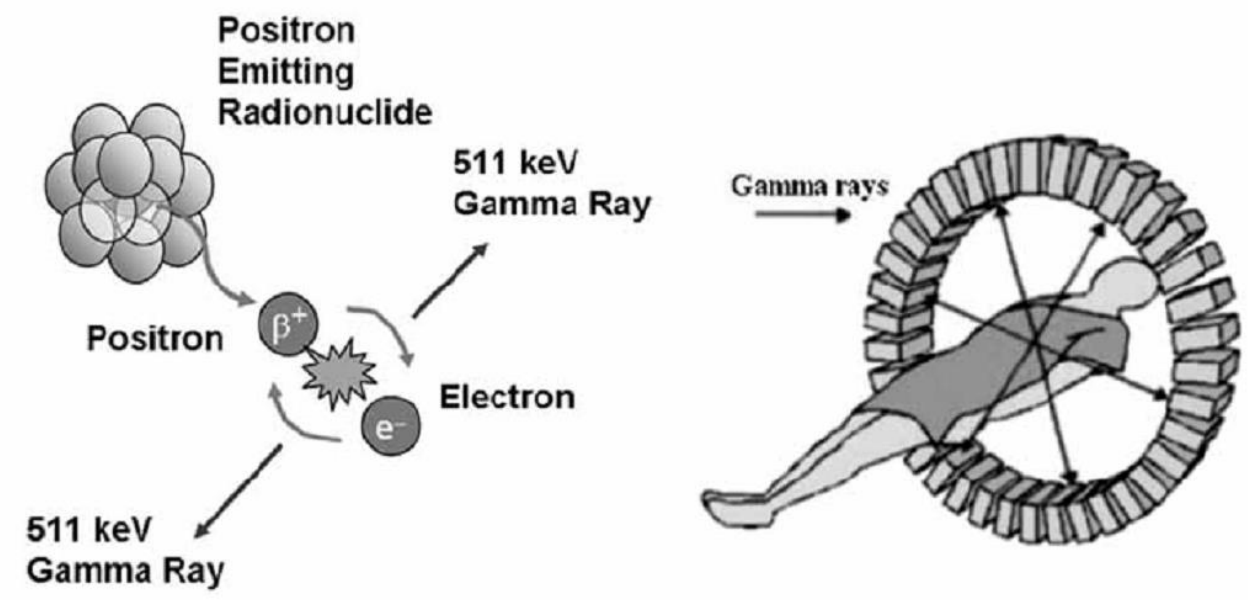

Figure 1.4. The mechanism of PET imaging.[19]

Fluorine-18 is the most commonly used radionuclide for PET imaging and ${ }^{18} \mathrm{~F}$ radiolabeled Fluorodeoxyglucose (FDG) is the most commonly used radiopharmaceutical for PET imaging. Structurally FDG is a glucose analog and ${ }^{18} \mathrm{~F}$ was labeled on the $\mathrm{C}-2$ position (Figure 1.5). 


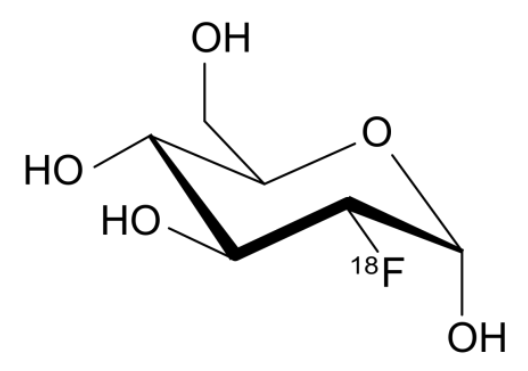

Figure 1.5. The structure of ${ }^{18} \mathrm{~F}$ FDG.

FDG is a suitable biomarker for tissues that have high glucose uptake and hence has been used for cancer imaging (most cancers are growing and metabolizing, and are thus high glucose uptake tissues), heart imaging and neuroimaging. Fluorine-18 has a half-life of 109.8 min and can be produced via the proton irradiation of enriched $\left[{ }^{18} \mathrm{O}\right] \mathrm{H}_{2} \mathrm{O}$ at a medical cyclotron facility. Nowadays ${ }^{18} \mathrm{~F}$ can be made in fairly large quantities in automatic systems and the labeling strategies for incorporating ${ }^{18} \mathrm{~F}$ into various molecules have been well discussed.[20] More recently another positron emitting radionuclide ${ }^{68} \mathrm{Ga}$ has drawn much attention since the success of the ${ }^{68} \mathrm{Ge} /{ }^{68} \mathrm{Ga}$ generator has made ${ }^{68} \mathrm{Ga}$ readily available. An imaging radiopharmaceutical using ${ }^{68} \mathrm{Ga}$ NETSPOT® $\left({ }^{68} \mathrm{Ga}\right.$ DOTATATE) has been approved by the FDA for neuroendocrine tumor detection. Commonly used positron emitting radionuclides are listed in Table 1.2. 
Table 1.2. Commonly used positron emitting radionuclides and their nuclear properties.

Highlighted radionuclides have Food and Drug Administration (FDA) approved radiopharmaceuticals. Data acquired from the Brookhaven National Laboratory National Nuclear Data Center. www.nndc.bnl.gov.

\begin{tabular}{cccc}
\hline Radionuclide & $\begin{array}{c}\mathbf{E}_{\boldsymbol{\beta}+\text { avg }} \text { in ke V; } \\
\text { \% abundance }\end{array}$ & $\begin{array}{c}\mathbf{E}_{\gamma} \text { in ke V; } \\
\text { \% abundance }\end{array}$ & $\begin{array}{c}\text { Half-life } \\
\text { (hours })\end{array}$ \\
\hline C-11 & $386 ; 100 \%$ & $511 ; 200 \%$ & 0.34 \\
Ga-68 & $836 ; 88 \%$ & $511 ; 176 \%$ & 1.13 \\
F-18 & $250 ; 97 \%$ & $511 ; 194 \%$ & 1.83 \\
Sc-44 & $632 ; 94 \%$ & $511 ; 188 \%$ & 4.0 \\
Cu-64 & $278 ; 17.6 \%$ & $511 ; 35.2 \%$ & 12.7 \\
Y-86 & $652 ; 0.44 \%$ & $511 ; 66 \%$ & 14.7 \\
As-72 & $1170 ; 88 \%$ & $511 ; 176 \%$ and $834 ; 80 \%$ & 26.0 \\
Zr-89 & $470 ; 22.7 \%$ & $511 ; 45.5 \%$ and $909 ;$ & 78.4 \\
I-124 & $820 ; 23 \%$ & $99 \%$ & 100.3 \\
\hline
\end{tabular}

\section{Therapy}

Radiopharmaceuticals are used in non-invasive radiotherapy based on the concept of the "magic bullet" developed by Paul Ehrlich, where radionuclides are delivered to target sites (e.g., tumors), emit charged particles to cause damage and ideally kill cancerous cells without collateral damage to normal cells.[21] In 1946, a radiopharmaceutical using ${ }^{131}$ I successfully diagnosed and cured thyroid cancer, which was the first demonstration of a true magic bullet 


\section{Yutian Feng}

in cancer treatment.[22] In 2018, Lutathera ${ }^{\circledR}\left({ }^{177} \mathrm{Lu}\right.$ oxodotreotide $)$ was approved for treating somatostatin receptor positive gastroenteropancreatic neuroendocrine tumors in adults in the US. Compared to chemotherapy, the advantages of deploying radiotherapy lie on the low concentrations of radiopharmaceuticals. Generally speaking the therapeutic radiopharmaceuticals are administrated to patients at nanomolar level, which will cause less pharmacokinetic side effects compared to chemotherapy (grams).[23] However, the side effects of radiation damage caused by radiopharmaceuticals can be problematic, and the decay of radiopharmaceuticals results in an inevitable short shelf-life, which adds to the cost of supply and transportation. Despite the disadvantages, therapeutic radiopharmaceuticals are being improved: radionuclides with better nuclear properties and bio-targeting vectors with improved selectivity are being investigated.

\section{Beta Decay, Auger Electrons and their The rapeutic Applications. Therapeutic} radionuclides can be categorized based on their types of emission. Neutron-rich radionuclides are likely to undergo $\beta^{-}$decay and emit $\beta^{-}$particles. The kinetic energy of the emitted $\beta^{-}$ particles varies from a few hundred $\mathrm{keV}\left({ }^{105} \mathrm{Rh}, \mathrm{E}_{\beta-\max } 566 \mathrm{keV}\right)$ to several MeV $\left({ }^{212} \mathrm{Bi}\right.$, $\mathrm{E}_{\beta-\max }$ 2.25 MeV, not commonly considered $\beta^{-}$emitters because of its daughter isotopes). This energy also determines the penetration range and thus determines the sizes of tumors the radionuclides are suitable for treatment. Commonly used $\beta$-particle emitting radionuclides are listed in Table 1.3. 
Table 1.3. Commonly used $\beta^{-}$particles emitting radionuclides and their nuclear properties.

The highlighted radionuclides have FDA approved radiopharmaceuticals. Data acquired from the Brookhaven National Laboratory National Nuclear Data Center. www.nndc.bnl.gov.

\begin{tabular}{|c|c|c|c|}
\hline Radionuclide & $\begin{array}{l}\mathbf{E}_{\beta} \text {-avg. in keV; } \\
\% \text { abundance }\end{array}$ & $\begin{array}{c}\mathbf{E}_{\gamma} \text { in } \mathrm{keV} \text {; } \\
\% \text { abundance }\end{array}$ & $\begin{array}{r}\text { Half-life } \\
\text { (hours) }\end{array}$ \\
\hline Cu-64 & $579 ; 38.5 \%$ & -- & 12.7 \\
\hline $\operatorname{Re}-188$ & $763 ; 100 \%$ & $155 ; 15.6 \%$ & 17.0 \\
\hline Но-166 & $665 ; 100 \%$ & $80.6 ; 6.6 \%$ & 26.8 \\
\hline Rh-105 & $152 ; 100 \%$ & $319 ; 19.1 \%$ & 35.4 \\
\hline As -77 & $226 ; 100 \%$ & $239 ; 1.7 \%$ & 38.8 \\
\hline Sm-153 & $224 ; 100 \%$ & $103 ; 29.3 \%$ & 46.5 \\
\hline Cu-67 & $141 ; 100 \%$ & $91.3 ; 7 \%, 93.3 ; 16.1 \%$, and $185 ; 49 \%$ & 61.9 \\
\hline Y-90 & $934 ; 100 \%$ & -- & 64.1 \\
\hline Au-198 & $312 ; 100 \%$ & $412 ; 95.6 \%$ & 64.7 \\
\hline Au-199 & $82 ; 100 \%$ & $158 ; 40 \%$ and $208 ; 8.7 \%$ & 75.3 \\
\hline Sc-47 & $162 ; 100 \%$ & $159 ; 68.3 \%$ & 80.4 \\
\hline Dy-166 & $119 ; 100 \%$ & $82.5 ; 13 \%$ & 81.6 \\
\hline $\operatorname{Re}-186$ & $347 ; 92.5 \%$ & $137 ; 9.5 \%$ & 89.2 \\
\hline Lu-177 & $134 ; 78.6 \%$ & $113 ; 6.2 \%$ and $208 ; 10.4 \%$ & 159.5 \\
\hline Tb-161 & $154 ; 100 \%$ & $75 ; 10.2 \%$ & 165.4 \\
\hline I-131 & $182 ; 100 \%$ & $284 ; 6.1 \% ; 365 ; 81.5 \%$, and $637 ; 7.2 \%$ & 192.5 \\
\hline
\end{tabular}

Compared to $\beta$-particle emitting radionuclides, Auger electron emitting radionuclides have their advantages and disadvantages. In electron capture decay, a proton-rich radionuclide absorbs one electron from the inner shell resulting in a vacancy, which will be filled by an 


\section{Yutian Feng}

electron from an outer shell with emission of X-rays. When the emitted photon (X-ray) transfers its energy to an electron, the electron is emitted as an Auger electron. Due to the nature of the Auger effect, there are multiple Auger electrons released from one decay and Auger electrons are likely to have significantly lower kinetic energy compared to $\beta^{-}$particles. The advantage of Auger electron emitters is that multiple emissions resulting from one decay possibly lead to more damage to cancerous cells. The lower average kinetic energy of Auger electrons limits their penetration, which means that Auger electron emitters are not suitable to treat large tumors and must be internalized in cancerous cells to be effective, and the possibility of damaging normal cells in the surroundings is quite low. Currently only a few Auger electron emitting radionuclides are being investigated (e.g., $\left.{ }^{67} \mathrm{Ga}\right)$.

Alpha de cay and its the rapeutic effect. Radionuclides generally have an atomic number bigger than 83 to undergo $\alpha$ decay emitting an $\alpha$ particle, which is the nucleus of helium -${ }_{2}^{4} \mathrm{He}^{+2}$. Alpha particles have two positive charges and a mass number of 4 , so they are over 7000 times the mass of $\beta^{-}$particles. Because of the high charge and mass, $\alpha$ particles have much less penetration but higher linear energy transfer (LET) compared to $\beta^{-}$particles. Recently $\alpha$-emitting radionuclides have drawn attention in the nuclear medicine community because of their low penetration and high LET, which is more likely to cause double strand damage to DNA in cancerous cells. Commonly used $\alpha$-emitting radionuclides are listed in Table 1.4. 


\section{Yutian Feng}

Table 1.4. Commonly used $\alpha$ emitting radionuclides and their nuclear properties. The highlighted radionuclide has FDA approved radiopharmaceuticals. Data acquired from the Brookhaven National Laboratory National Nuclear Data Center. www.nndc.bnl.gov.

\begin{tabular}{cccc}
\hline Radionuclide & $\begin{array}{c}\mathbf{E}_{\boldsymbol{\alpha}} \text { in MeV; } \% \\
\text { abundance }\end{array}$ & Half-lives & $\begin{array}{c}\mathbf{E}_{\boldsymbol{\gamma}} \text { in MeV; } \% \\
\text { abundance }\end{array}$ \\
\hline Bi-213 & $5.87 ; 2.2 \%$ & $45.6 \mathrm{~min}$ & $0.441 ; 26 \%$ \\
Bi-212 & $6.09 ; 35.9 \%$ & $60.6 \mathrm{~min}$ & $0.727 ; 6.5 \%$ \\
At-211 & $5.87 ; 41.8 \%$ & $7.21 \mathrm{~h}$ & $0.079 ; 20.7 \%$ \\
Ac-225 & $5.83 ; 100 \%$ & $9.92 \mathrm{~d}$ & -- \\
Ra-223 & $5.54 ; 9.0 \%$ & $11.4 \mathrm{~d}$ & $0.27 ; 13.9 \%$ \\
& $5.61 ; 25.2 \%$ & & \\
& $5.72 ; 51.6 \%$ & & \\
\hline
\end{tabular}

Research on developing radiopharmaceuticals using $\alpha$-emitting radionuclides is driven by their promising nuclear properties. However the problems to be overcome are clear: 1) the lack of availability of $\alpha$-emitting radionuclides limits the development of radiopharmaceuticals; 2) since most of the $\alpha$-emitting radionuclides undergo multiple decays, chelates of high binding affinity and in vivo stability are required because the radionuclides that break free from the targeting vector will lead to radiation toxicity in normal tissues and organs; 3 ) the chemistry and radiochemistry of some $\alpha$-emitting radionuclides are unknown and difficult due to the lack of stable isotopes. More effort and optimization are still needed in developing $\alpha$-emitting radiopharmaceuticals. 


\section{Specific Activity of Radionuclide}

Specific activity is an important factor in terms of selecting suitable radionuclides for developing radiopharmaceuticals. Specific activity is defined as the radioactivity per mass unit of a certain radiopharmaceutical. High specific activity indicates high efficacy in imaging or therapy applications because when administrated the same mass, high specific activity radiopharmaceuticals have both a higher percentage of radioactive atoms and radiation dose. For example, ${ }^{76}$ As can be produced from an ${ }^{75}$ As target via neutron irradiation while ${ }^{77} \mathrm{As}$ is produced from the decay of ${ }^{77} \mathrm{Ge}$, which is produced by neutron irradiation of a ${ }^{76}$ Ge target (Sche me 1.3).

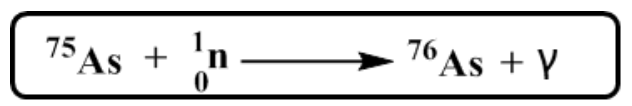

$$
{ }^{76} \mathrm{Ge}+{ }_{0}^{1} \mathrm{n} \longrightarrow{ }^{77} \mathrm{Ge}+\mathrm{Y} \longrightarrow{ }^{77} \mathrm{As}+\mathrm{B}-+\tilde{\mathrm{v}}
$$

Scheme 1.3. An example of high specific activity radionuclide $\left({ }^{77} \mathrm{As}\right.$ and $\left.{ }^{76} \mathrm{As}\right)$. $\tilde{\mathrm{v}}$ stands for anti-neutrino released from $\beta$ decay.[24]

In Scheme 1.3, ${ }^{76}$ As cannot be chemically separated from the ${ }^{75}$ As target because of their identical chemistry, while ${ }^{77}$ As produced from a germanium target can be chemically separated from the target material. It is worth mentioning that in the production of ${ }^{77} \mathrm{As}$ all the arsenic atoms are radioactive, hence called a no carrier added (nca) radionuclide. On the other hand, only a small percentage (less than $1 \%$ ) of arsenic atoms is present as ${ }^{76}$ As while the majority of the arsenic atoms are non-radioactive ${ }^{75} \mathrm{As}$, namely carrier added. The carrier is the non-radioactive and chemically inseparable isotope. 
For radiopharmaceuticals using the bifunctional chelate approach, normally high specific activity is important because the number of receptors at the targeting site maybe limited. The more receptors occupied by the non-radioactive molecule, the less radioactive molecules can accumulate in the target site.

\section{Conclusion and Outline of Thesis}

The chemistry of arsenic has been extensively discussed in the 1940s, but the translation of arsenic chemistry at the macroscopic level to the nca $(\mathrm{nM})$ level needs to be developed. The majority of this dissertation will focus on the radiochemistry of arsenic at the nca level, namely low concentrations.

Radioarsenic $\left({ }^{72,77} \mathrm{As}\right)$ is considered a true matched pair radionuclide because of their identical chemistry and yet different nuclear properties, while true matched pair radionuclides are rare (e.g., $\left.{ }^{64,67} \mathrm{Cu},{ }^{125,131} \mathrm{I},{ }^{44,47} \mathrm{Sc},{ }^{203,212} \mathrm{~Pb}\right)$. Apart from the true matched pairs, there are a few radiotherapeutic agents and their imaging counter parts that are also considered matched pairs because of their similar yet different chemistry. Technetium- $99 \mathrm{~m}$ and its therapeutic counterpart ${ }^{186,188}$ Re are both in VIIB group and hence behave alike in terms of chemistry and radiochemistry. However their redox chemistry and coordination chemistry are distinguishable. Even among the true matched pairs, radioarsenic has comparably long and similar half-lives which make them promising candidates for combined imaging and radiotherapy.[5]

The production of nca ${ }^{72,77}$ As has been reported, but many of the reported methods require extreme chemical conditions (distillation, aqua regia, etc.) or human handling, which leads to 


\section{Yutian Feng}

unnecessary radiation doses.[11, 14, 25-28] One of the main issues in separating nca radioarsenic is that at $\mathrm{nM}$ concentrations, arsenic is readily oxidized to the +5 oxidation state (arsenate) while arsenite ( +3 state) is active to coordination. A fast and straightforward method of producing nca ${ }^{77}$ As has been reported.[1] The upgrade and improved separation based on this method will be discussed in Chapter 2. For ${ }^{72} \mathrm{As}$, two production approaches have been reported: the one time production from ${ }^{72} \mathrm{Ge}$ via ${ }^{72} \mathrm{Ge}(\mathrm{p}, \mathrm{n}){ }^{72} \mathrm{As}$ nuclear reaction; a generator production of ${ }^{72} \mathrm{As}$ via the ${ }^{72} \mathrm{Se} /{ }^{72} \mathrm{As}$ transient equilibrium. [6, 14, 28-30] The production of ${ }^{72} \mathrm{Se}$ for ${ }^{72} \mathrm{Se} /{ }^{72}$ As generators will be discussed in Chapter 2.

Due to the thiophilic nature of arsenic, thiol based ligands and chelates are required in order to stabilize radioarsenic under in vivo conditions. Two chelate approaches were carried out: an aryl dithiol approach and a trithiol approach (Scheme 1.4).[31, 32] In the aryl dithiol approach, an aryl group was incorporated onto the arsenic and a dithiol ligand was coordinated to increase the stability. Different methods of incorporating a phenyl ring to arsenic were evaluated and optimized by synthesizing several dithioarylarsines at the macroscopic level. This chemistry was then translated to radioarsenic at nca level. Optimization was carried out to achieve optimal radiolabeling yield. This will be discussed in Chapter 3. For the trithiol approach, a simple trithiol ligand was synthesized and radiolabeled with radioarsenic to optimize its radiochemistry. A linkable trithiol ligand was synthesized and radiolabeled with radioarsenic. Based on the high in vitro stability of the As-trithiol complex, a bifunctional chelate as developed and conjugated to the bombesin(7-14) $\mathrm{NH}_{2}$ peptide, which targets Gastrin-Releasing Peptide (GRP) receptors highly expressed in prostate cancer cells.[33] The trithiol approach stabilizing radioarsenic will be discussed in Chapter 4. 
Chapter 5 discusses the conclusions of the research discussed in the dissertation and future work.

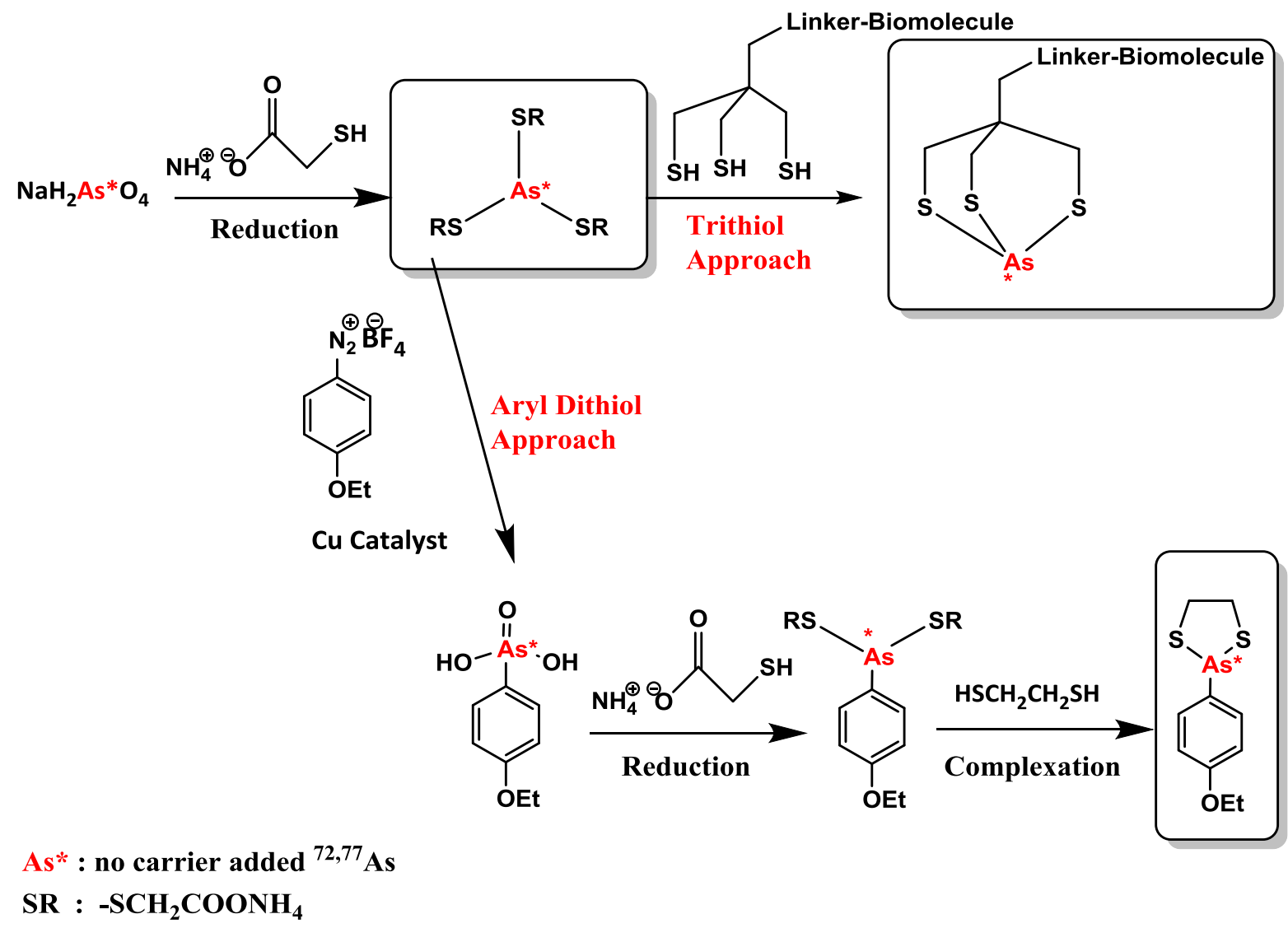

Scheme 1.4. Two approaches to radiolabel radioarsenic for increasing stability under in vivo conditions. The starting material of radioarsenic was $\mathrm{NaH}_{2} \mathrm{AsO}_{4}$ based on the first pKa of arsenic acid (2.19) and the $\mathrm{pH}$ of the solution ( 4).[34] 


\section{Chapter 2: Production of Radioarsenic $\left({ }^{72,77} \mathrm{As}\right)$}

\section{Introduction}

Reactor production of Arsenic-77. Nuclear reactors produce neutron fluxes as a product of the nuclear fission reaction. For nuclear power plants, the thermal energy produced from fission reactions are transformed to electric energy while the neutrons are considered as side products. For research reactors, the neutron flux is utilized for various research purposes. The University of Missouri Research Reactor (MURR) is the largest research reactor in the United States, operating at $10 \mathrm{MW}$. Traditionally radionuclides produced at nuclear reactors are carrier-added such as Lu-177, Sm-153 and Re-186. Lutetium-177 is a $\beta^{-}$emitting radionuclide with a $6.65 \mathrm{~d}$ half-life. It can be produced at a nuclear reactor by irradiating an enriched Lu-176 target (2.599\% natural abundance) with a neutron flux via the ${ }^{176} \mathrm{Lu}(\mathrm{n}, \gamma)$ ${ }^{177} \mathrm{Lu}$ reaction. Because of the high cross section of the nuclear reaction, the percentage of ${ }^{177} \mathrm{Lu}$ converted from ${ }^{176} \mathrm{Lu}$ is comparatively high, resulting in a fairly high specific activity (as high as $25 \mathrm{Ci} / \mathrm{mg}$ ).[35] Quadramet ${ }^{\circledR}$ is a radiotherapeutic agent for bone palliation and was first developed at the MURR using Sm-153, which was produced via ${ }^{152} \mathrm{Sm}(\mathrm{n}, \gamma){ }^{153} \mathrm{Sm}$ from an enriched ${ }^{152} \mathrm{Sm}$ target $(26.75 \%$ natural abundance).[36, 37] High specific activity radionuclides have advantages when it comes to medical applications because the number of receptors, that radiopharmaceuticals target, is limited.

One of the current research focuses at the MURR is to produce high specific activity radionuclides for medical applications, and the production of nca ${ }^{77}$ As is one of them.[38] Arsenic-77 is the decay product of ${ }^{77} \mathrm{Ge}$, which has an $11.2 \mathrm{~h}$ half-life and can be produced via the ${ }^{76} \mathrm{Ge}(\mathrm{n}, \gamma){ }^{77} \mathrm{Ge}$ reaction from an enriched ${ }^{76} \mathrm{Ge}$ target. Because the half-life of the 


\section{Yutian Feng}

daughter nuclide $\left({ }^{77} \mathrm{As}, 38.8 \mathrm{~h}\right)$ is longer than that of the parent nuclide $\left({ }^{77} \mathrm{Ge}, 11.2 \mathrm{~h}\right)$, a separation is required after the maximum growth time of ${ }^{77} \mathrm{As}$ (approximately $26 \mathrm{~h}$ ) to produce nca ${ }^{77}$ As. A chromatographic separation of nca ${ }^{77}$ As from the germanium target was reported previously using silica gel as the stationary phase and methanol as the mobile phase.[1] Improvements were necessary because ${ }^{77} \mathrm{Ge}$ breakthrough might occur when the loading volume exceeded $250 \mu \mathrm{L}$. Different mobile phases and bed volumes of the silica gel resin were evaluated to improve the scale of the separation and produce nca ${ }^{77}$ As with optimal radiochemical yield.

Production of ${ }^{72} \mathrm{Se} /{ }^{72}$ As generator. No carrier added ${ }^{72}$ As can potentially be produced through several different pathways. One of them is via the decay of ${ }^{72} \mathrm{Se}(\mathrm{EC}, 8.5$ day halflife). The transient equilibrium of ${ }^{72} \mathrm{Se} /{ }^{72} \mathrm{As}$ is similar to commercially available ${ }^{99} \mathrm{Mo} /{ }^{99 \mathrm{~m}} \mathrm{Tc}$ generators and the comparatively long half-life of ${ }^{72} \mathrm{Se}$ makes ${ }^{72} \mathrm{Se} /{ }^{72}$ As generators economically favorable.[6, 11, 25, 28, 39] In the transient equilibrium of ${ }^{72} \mathrm{Se}$ and ${ }^{72} \mathrm{As},{ }^{72} \mathrm{As}$ reaches maximum ingrowth at approximately $3.5 \mathrm{~d}$ and can be eluted from the generator (Figure 2.1). The ${ }^{72}$ As radioactivity will reach maximum growth $3.5 \mathrm{~d}$ later while approximately $50 \%$ and $70 \%$ of ${ }^{72}$ As radioactivity growth are achieved after 1 day and 2 days, respectively. Several methods have been described for the production of nca ${ }^{72} \mathrm{Se}$. Irradiating an enriched ${ }^{70} \mathrm{Ge}$ target with high energy $\alpha$ beam to produce nca ${ }^{72} \mathrm{Se}$ via ${ }^{70} \mathrm{Ge}(\alpha, 2 \mathrm{n}){ }^{72} \mathrm{Se}$ nuclear reaction is being investigated.[30, 39, 40] The drawback for this production route is that there are only a few facilities in the world that are capable of producing high energy $\alpha$ beams (University of Washington, Duke University and TRIUMF). Another production route is to irradiate a natural arsenic target with a proton beam from a cyclotron via ${ }^{75} \mathrm{As}(\mathrm{p}, 4 \mathrm{n})$ ${ }^{72}$ Se nuclear reaction. [30, 39, 40] This production route enjoys the advantage of the low cost 


\section{Yutian Feng}

of the target material due to the $100 \%$ natural abundance of ${ }^{75}$ As. However some of the byproducts (e.g. ${ }^{75} \mathrm{Se}, 120 \mathrm{~d}$ half-life) cannot be chemically separated from ${ }^{72} \mathrm{Se}$, which could be problematic. Additionally, ${ }^{72} \mathrm{Se}$ can also be produced by bombarding a $\mathrm{NaBr}$ target with high energy proton beam via ${ }^{79,81} \mathrm{Br}(\mathrm{p}, \mathrm{x}){ }^{72} \mathrm{Se}$.[28] All of the production routes of ${ }^{72} \mathrm{Se}$ involve target dissolution, separation of ${ }^{72} \mathrm{Se}$ from the target and generator chromatography, and chromatography methods for ${ }^{72} \mathrm{Se} /{ }^{72} \mathrm{As}$ generators have been reported.[6] Production from a $\mathrm{NaBr}$ target has the advantage of target dissolution due to the nature of the target, while for the separation of ${ }^{72} \mathrm{Se}$, several methods have been reported for separating ${ }^{72} \mathrm{Se}$ from both germanium and arsenic.[11, 30, 39] Apart from that, direct production of ${ }^{72}$ As has been reported from a germanium target using the ${ }^{72} \mathrm{Ge}(\mathrm{p}, \mathrm{n}){ }^{72}$ As nuclear reaction.[14] The production was followed by a 3-step separation resulting in a reasonable radiochemical yield $(50 \%)$ of nca ${ }^{72}$ As. Compared to the production of ${ }^{72} \mathrm{Se}$, this direct route offers a feasible production and separation on a medical cyclotron, however it does not enjoy the sustainability of ${ }^{72} \mathrm{Se} /{ }^{72} \mathrm{As}$ generators.

Using a separation method that was developed in our group previously, radiochemically pure ${ }^{72} \mathrm{Se}$ (selenate) and ${ }^{72} \mathrm{As}$ (arsenate) were separated from alpha beam irradiated enriched ${ }^{70} \mathrm{Ge}$ metal target, and a ${ }^{72} \mathrm{Se} /{ }^{72} \mathrm{As}$ generator was established.[41] No carrier added ${ }^{72} \mathrm{As}$ as arsenate ( $\sim \mathrm{nM}$ concentration) was continuously eluted from the generator and characterized in a phantom study for its imaging potential, and its radiolabeling methods were carried out following procedures developed previously in our group. 


\section{${ }^{72} \mathrm{Se} /{ }^{72}$ As Decay}

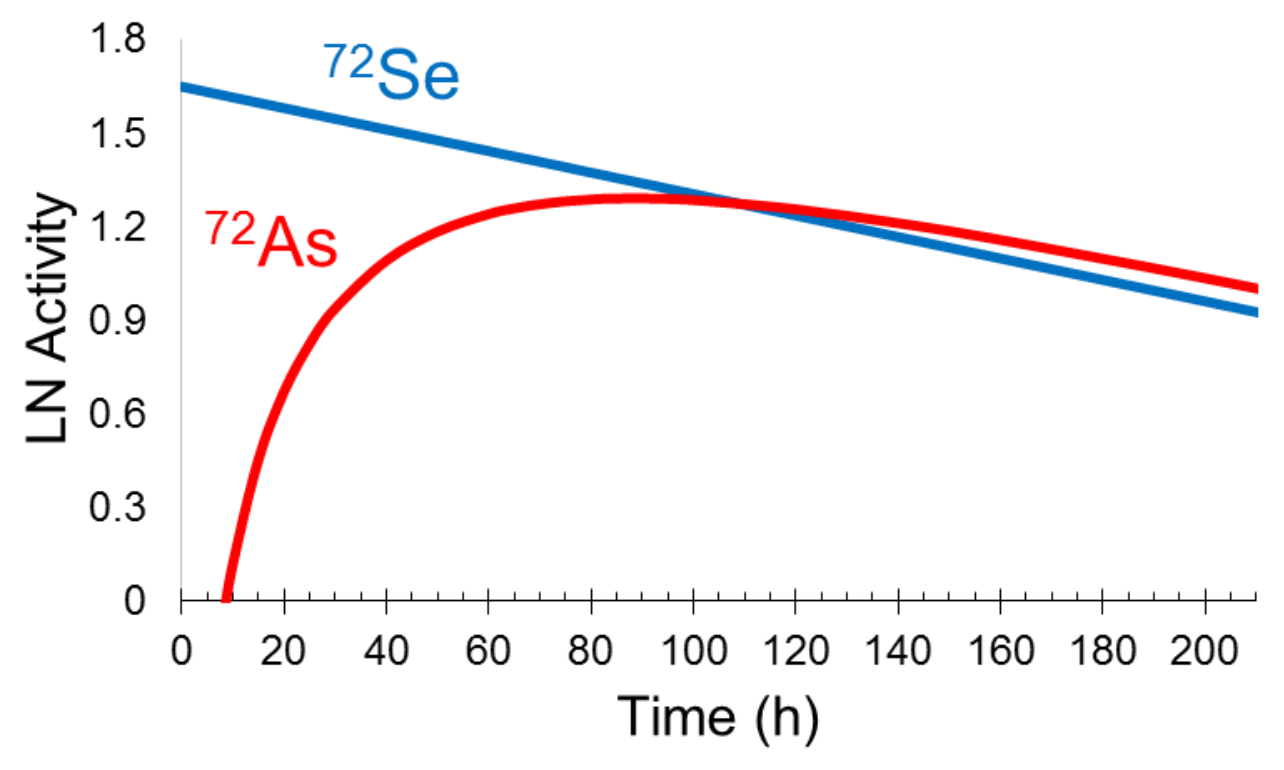

Figure 2.1. The transient equilibrium of ${ }^{72} \mathrm{Se}$ and ${ }^{72} \mathrm{As}$.

\section{Production of Arsenic-72}

\section{Experimental}

Physical Measurements and Materials. Caution! Selenium-72 $\left({ }^{72} \mathrm{Se}\right),{ }^{71,72,74} \mathrm{As}$ and ${ }^{71} \mathrm{Ge}$ are radioactive and all work involving these radionuclides was carried out in approved laboratories following the appropriate radiation safety procedures. Selenium-72 $\left(\mathrm{t}_{1 / 2}=8.40 \mathrm{~d}\right)$ used in ${ }^{72} \mathrm{Se} /{ }^{72}$ As separation studies was produced at the University of Washington (UW) via the ${ }^{70} \mathrm{Ge}(\alpha, 2 \mathrm{n}){ }^{72} \mathrm{Se}$ reaction of an enriched ${ }^{70} \mathrm{Ge}$ metal target $(98 \%$ enrichment $) .{ }^{70} \mathrm{Ge}$ metal powder (250 mg) was firmly pressed in aluminum can in a graphite-germanium-graphite "sandwich" form. The target was bombarded with a $48 \mathrm{MeV}$ alpha beam at $20 \mu \mathrm{A}$. Upon receipt at the MURR, 68.64 MBq $(1.855 \mathrm{mCi})$ As-72 $\left(\mathrm{t}_{1 / 2}=26.0 \mathrm{~h}\right)$ was measured in a Capentec NaI well detector, and a radiation dose of $280 \mathrm{mR} / \mathrm{hr}$ six inches over the target 


\section{Yutian Feng}

sample was measured at the University of Missouri Research Reactor. Germanium-71, as a decay product of ${ }^{71}$ As was present as well as ${ }^{71,74}$ As as impurities from the target bombardment. Reagents and solvents were purchased from Alfa Aesar (WardHill, MA), Fisher Scientific (Pitts burg, PA), Mallinckrodt (St. Louis,MO), and Sigma-Aldrich (St. Louis, MO) and used as received. Dowex anion exchange resin was obtained from Bio-Rad Corporation (Hercules, CA) and Sigma-Aldrich (St. Louis, MO). All water used was purified on-site (deionized water from a Millipore system to $>18 \mathrm{M} \Omega \mathrm{cm}$ ).

Target Dissolution. Two dissolution experiments were carried out prior to handling the irradiated target. Natural germanium metal powder $(250 \mathrm{mg})$ was prepared in an identical way with the graphite-germanium-graphite "sandwich" target. In the first run, the target was separated from the backing with a spatula and placed into a beaker. The target material was then transferred to a $100 \mathrm{~mL}$ 3-necked round bottom flask. $25 \mathrm{~mL}$ of $6 \% \mathrm{H}_{2} \mathrm{O}_{2}$ and $200 \mu \mathrm{L}$ of $10 \mathrm{M} \mathrm{NaOH}$ were added to the flask and the resultant mixture was refluxed at $100{ }^{\circ} \mathrm{C}$ while stirring for $40 \mathrm{~min}$. Then $25 \mathrm{~mL}$ of $30 \% \mathrm{H}_{2} \mathrm{O}_{2}$ was added to the mixture and it was refluxed at $100{ }^{\circ} \mathrm{C}$ for $20 \mathrm{~min}$. Small black flakes $(5 \mathrm{~mm}$ in diameter) were observed, one of which was taken out by a spatula. Germanium metal was observed underneath the graphite surface. In the second practice run, the target was dissociated from the backing and crushed into small pieces in a beaker, and then transferred to a $100 \mathrm{~mL}$ 3-necked round bottom flask. $15 \mathrm{~mL}$ of $20 \% \mathrm{H}_{2} \mathrm{O}_{2}$ solution was added to the flask and another $5 \mathrm{~mL}$ of $20 \% \mathrm{H}_{2} \mathrm{O}_{2}$ was added to the beaker and combined in the flask after rinsing. $100 \mu \mathrm{L}$ of $10 \mathrm{M} \mathrm{NaOH}$ was added to the flask and the mixture refluxed at $100{ }^{\circ} \mathrm{C}$ while stirring for 20 min until no big pieces of Ge metal were observed. $20 \mathrm{~mL}$ of $6 \% \mathrm{H}_{2} \mathrm{O}_{2}$ and $38 \mu \mathrm{L}$ of $10 \mathrm{M} \mathrm{NaOH}$ were added to the flask and reflux continued for $20 \mathrm{~min}$. 


\section{Yutian Feng}

The irradiated target was placed onto a watch glass in a glove box. The germanium metal along with the graphite was separated from the aluminum backing and placed into a beaker, and crushed with a grass rod. It was then transferred to a $100 \mathrm{~mL} \mathrm{3-necked} \mathrm{round} \mathrm{bottom}$ flask. $20 \mathrm{~mL}$ of $30 \% \mathrm{H}_{2} \mathrm{O}_{2}$ was added with $138 \mu \mathrm{L}$ of $10 \mathrm{M} \mathrm{NaOH}$ to the flask. The mixture was refluxed at $100{ }^{\circ} \mathrm{C}$ while stirring for $40 \mathrm{~min}$, and $20 \mathrm{~mL}$ of $6 \% \mathrm{H}_{2} \mathrm{O}_{2}$ was added. The reflux continued for 1 hour and then the mixture was cooled to room temperature. The solution was suctioned into four $10 \mathrm{~mL}$ vacuum vials through a syringe filter. The 4 vials containing target solution were each counted on a Capentec $\mathrm{NaI}$ well detector, and the total activity of ${ }^{72} \mathrm{As}$ was measured to be $63.68 \mathrm{MBq}(1.721 \mathrm{mCi}$, approximately $93 \%$ of total radioactivity). $200 \mu \mathrm{L}$ of the target solution was taken out and diluted to $1 \mathrm{~mL}$ volume with DI water as a standard.

Column Separation of ${ }^{72}$ Se and ${ }^{72}$ As. Radiochemically pure ${ }^{72}$ Se and ${ }^{72}$ As were separated from the target solution via column chromatography using Dowex 1-X8 resins. Approximately $40 \mathrm{~mL}$ of target solution was separated on two columns. In the first separation, $1.26 \mathrm{~g}$ of Dowex 1-X8 resin was packed in a Bio-Rad column with a bed volume of $1.8 \mathrm{~mL}$. It was then preconditioned with concentrated nitric acid, and washed to neutral $\mathrm{pH}$ with DI water. $20 \mathrm{~mL}$ of target solution $\left(0.92 \mathrm{mCi}\right.$ of $\left.{ }^{72} \mathrm{Se}\right)$ was loaded onto the column in 2 $\mathrm{mL}$ fractions, and $2 \mathrm{~mL}$ fractions were collected. Germanate was eluted with DI water (4* 5 $\mathrm{mL})$. Arsenate $\left({ }^{71,72,74} \mathrm{As}\right)$ was eluted with $0.015 \mathrm{M} \mathrm{HNO}_{3}(\mathrm{pH}=1.82)(16 * 5 \mathrm{~mL}$, then $23 *$ $10 \mathrm{~mL}$ ) until only ${ }^{72} \mathrm{As}$ and ${ }^{72} \mathrm{Se}$ were observed in the eluent. Selenate breakthrough was observed at fraction 39. Then the remaining arsenate and selenate was eluted with $0.6 \mathrm{M}$ $\mathrm{HNO}_{3}(7 * 10 \mathrm{~mL})$. An arsenic-71 impurity was observed along with ${ }^{72} \mathrm{Se}$. 


\section{Yutian Feng}

In the second separation, $10 \mathrm{~mL}$ of target solution $\left(0.22 \mathrm{mCi}\right.$ of $\left.{ }^{72} \mathrm{Se}\right)$ was loaded onto a concentrated $\mathrm{HNO}_{3}$ preconditioned Dowex 1-X8 column $(1 \mathrm{~g}, 1.43 \mathrm{~mL}$ bed volume $)$ with a small piece of glass wool on top of resin to prevent disturbing the resin. $5 \mathrm{~mL}$ fractions were collected. Germanate was eluted with DI water $(3 * 5 \mathrm{~mL})$, and then arsenate $\left({ }^{71,72,74} \mathrm{As}\right)$ was eluted with $0.015 \mathrm{M} \mathrm{HNO}_{3}(\mathrm{pH}=1.82)(9 * 5 \mathrm{~mL})$ to the point only ${ }^{72}$ As was observed. The selenate and remaining arsenate was eluted with $0.6 \mathrm{M} \mathrm{HNO}_{3}(3 * 10 \mathrm{~mL})$. The rest of the target solution $(10 \mathrm{~mL})$ was separated with the identical method. Fractions containing ${ }^{72} \mathrm{Se}$ and ${ }^{72}$ As were combined, $100 \mu \mathrm{L}$ of which was added to a vial and diluted with DI water to $10 \mathrm{~mL}$ volume. It was then counted on High Purity Germanium Detector (HPGe Detector) as a quality control. No other radionuclides were observed.

${ }^{72} \mathrm{Se} /{ }^{72} \mathrm{As}$ Generators. The solution containing ${ }^{72} \mathrm{Se}$ and ${ }^{72} \mathrm{As}$ was boiled to dryness, and reconstituted with $10 \mathrm{~mL}$ of $10 \% \mathrm{H}_{2} \mathrm{O}_{2} .1 \mathrm{M} \mathrm{NaOH}$ solution was added to adjust the $\mathrm{pH}$ to 8 . The solution was then heated at $50{ }^{\circ} \mathrm{C}$ for $30 \mathrm{~min}$. This solution was loaded onto a concentrated $\mathrm{HCl}$ preconditioned Dowex 1-X8 column ( $0.6 \mathrm{~g}, 1 \mathrm{~mL}$ bed volume). Selenium72 breakthrough was observed immediately. Then selenate and arsenate on the column was eluted with $0.6 \mathrm{M} \mathrm{HNO}_{3}(2 * 5 \mathrm{~mL})$. All fractions containing ${ }^{72} \mathrm{Se}$ and ${ }^{72} \mathrm{As}$ were combined and adjusted $\mathrm{pH}$ to 8 with $10 \mathrm{M} \mathrm{NaOH}$. The solution was heated at $80{ }^{\circ} \mathrm{C}$ for $30 \mathrm{~min}$ and then loaded onto a concentrated $\mathrm{HCl}$ preconditioned Dowex 1-X8 column $(1 \mathrm{~g}, 1.43 \mathrm{~mL}) .13 \%$ ${ }^{72} \mathrm{Se}$ breakthrough was observed, adjusted $\mathrm{pH}$ to 8 and was loaded to another Dowex 1-X8 column $(1 \mathrm{~g}, 1.43 \mathrm{~mL})$. No breakthrough was observed.

${ }^{72}$ As Elution. The column was counted on a Capentec NaI well detector and $1.55 \mathrm{MBq}$ (42 uCi) of ${ }^{72} \mathrm{As} \mathrm{had} \mathrm{grown} \mathrm{in.} \mathrm{Arsenate}\left({ }^{72} \mathrm{As}\right)$ was eluted with $0.027 \mathrm{M} \mathrm{HCl}(\mathrm{pH}=1.56)(3 * 5$ $\mathrm{mL})$. The amount of ${ }^{72} \mathrm{As}$ was measured to be $1.41 \mathrm{MBq}(38 \mu \mathrm{Ci})$ in the first 2 fractions. Less 


\section{Yutian Feng}

than $0.074 \mathrm{MBq}(2 \mu \mathrm{Ci})$ of ${ }^{72} \mathrm{As}$ was observed in the third fraction, and minor ${ }^{72} \mathrm{Se}$ breakthrough was detected. Arsenate was eluted from the generator 3 days after the first elution with $5 \mathrm{~mL}$ of $0.027 \mathrm{M} \mathrm{HCl}(\mathrm{pH}=1.56) .0 .56 \mathrm{MBq}(15 \mu \mathrm{Ci}){ }^{72} \mathrm{As}$ was eluted while approximately $0.19 \mathrm{MBq}(5 \mu \mathrm{Ci}){ }^{72} \mathrm{As}$ was left on the generator. 12 days later the generator was evaluated with $0.37 \mathrm{MBq}(10 \mu \mathrm{Ci})$ of ${ }^{72} \mathrm{As}$ and arsenate was eluted with $5 \mathrm{~mL}$ of 0.027 $\mathrm{M} \mathrm{HCl}(\mathrm{pH}=1.56) .0 .17 \mathrm{MBq}(4.6 \mu \mathrm{Ci})$ of ${ }^{72} \mathrm{As}$ was detected in the eluent. ${ }^{72}$ As Phantom Study. Eluents from the ${ }^{72} \mathrm{Se} /{ }^{72}$ As generator containing $1.41 \mathrm{MBq}(38 \mu \mathrm{Ci})$ of ${ }^{72}$ As were sent to the Harry S. Truman Memorial Veterans' Hospital to evaluate PET imaging capabilities. A Micro Deluxe Jaszczak phantom (Model ECT/DLX/MMP, Data Spectrum Corporation, Durham, North Carolina, USA), with rod diameters 1.2, 1.6, 2.4, 3.2, 4.0, and $4.8 \mathrm{~mm}$, was filled with ${ }^{72} \mathrm{As}(0.3 \mathrm{MBq}, 9 \mu \mathrm{Ci})$. Maximum intensity projection micropositron emission tomography images were obtained using a Siemens INVEON small-animal, dedicated PET system (Siemens Medical Solutions, Malvern, PA, USA). The phantom was imaged in a three-dimensional (3D) volume with emission acquisition mode set to acquire 500 million counts. Image reconstruction was obtained using an OSEM2D (ordered subset expectation maximization-two dimensional) algorithm without scatter correction, Fourier rebinning applying four interactions, in a $128 \times 128$ matrix. The microPET data was loaded into Inveon Research Workstation (IRW) software for image analysis and a Gaussian full width at half maximum filter was applied. Previously acquired PET phantom data for ${ }^{18} \mathrm{~F}$, ${ }^{64} \mathrm{Cu}$, and ${ }^{68} \mathrm{Ga}$ using the same phantom geometry, acquisition parameters, and similar image processing was provided for reference. 


\section{Yutian Feng}

\section{Results and Discussion}

Target Dissolution. Two non-radioactive germanium metal targets were assembled for evaluation in the identical fashion to the irradiated Ge metal target using natural germanium metal powder. Due to the nature of the graphite-metal-graphite "sandwich" target, the germanium metal target was removed from the backing along with graphite powder. In the first attempt of target dissolution, dark flakes ( $5 \mathrm{~mm}$ diameter) were observed after heating at $100{ }^{\circ} \mathrm{C}$ for $1 \mathrm{~h}$. The dark flakes were covered by graphite powder causing difficulties to visually distinguish germanium metal from graphite. One of the dark flakes was taken out with a spatula and the graphite powder adherent on the surface was removed to reveal the metal. In the second run, the target material was crushed in a beaker for better dissolution. A higher concentration of $\mathrm{H}_{2} \mathrm{O}_{2}$ was used because the solubility of germanium metal is dependent on both $\mathrm{H}_{2} \mathrm{O}_{2}$ concentration and $\mathrm{pH}$. The $\mathrm{pH}$ of the target solution was adjusted to 8 with $\mathrm{NaOH}$. Target dissolution was completed in $1 \mathrm{~h}$ and no germanium metal was observed visually.

The irradiated target was counted in a NaI well detector before dissolution. $68.8 \mathrm{MBq}(1.86$ $\mathrm{mCi})$ of ${ }^{72} \mathrm{As}$ was measured. Due to the low energy $\gamma(46 \mathrm{keV})$ from ${ }^{72} \mathrm{Se}$, the amount of ${ }^{72} \mathrm{Se}$ could not be measured accurately with a NaI well detector, and hence the radioactivity of

${ }^{72} \mathrm{Se}$ was calculated based on the measurement of ${ }^{72} \mathrm{As}$ using the Bateman equation.

$$
A_{D}=\frac{\lambda_{D}}{\lambda_{D}-\lambda_{P}} \times A_{P 0}\left(e^{-\lambda_{P} \times t}-e^{-\lambda_{D} \times t}\right)
$$

$A_{D}$ indicates the radioactivity of the daughter isotope $\left({ }^{72} \mathrm{As}\right)$ and $\mathrm{A}_{\mathrm{P} 0}$ indicates the initial radioactivity of the parent isotope $\left({ }^{72} \mathrm{Se}\right) . \lambda$ indicates the decay constants of both the parent and daughter isotopes, and $\mathrm{t}$ indicates in-growth time.[42] 


\section{Yutian Feng}

A radiation dose of $280 \mathrm{mR} / \mathrm{hr}$ was read with a dosimeter at 6 inches over the target, which required the target dissolution to be carried out in a lead shielded glove box to reduce the radiation dose as low as reasonably achievable. After dissociation from the backing, the target material was broken into smaller pieces before transferring to a round bottom flask, where it was dissolved in $30 \% \mathrm{H}_{2} \mathrm{O}_{2}$ at $\mathrm{pH}$. The addition of $6 \% \mathrm{H}_{2} \mathrm{O}_{2}$ was to assure full oxidation to selenate and arsenate. The dissolution was continued for over $2 \mathrm{~h}$ and then filtered into 4 vacuum vials for future use. $200 \mu \mathrm{L}$ of target solution was counted as a standard on an HPGe detector. Radionuclides present in the standard included ${ }^{72} \mathrm{Se},{ }^{71,72,74} \mathrm{As}$ and ${ }^{71} \mathrm{Ge}$ (Table 2.1).

Table 2.1. Nuclear properties of isotopes present in the target solution standard. Data acquired from the Brookhaven National Laboratory National Nuclear Data Center. www.nndc.bnl.gov.

\begin{tabular}{cccc}
\hline Isotope & Half-life & Decay Mode & $\begin{array}{c}\text { Decay } \\
\text { Product }\end{array}$ \\
\hline Se-72 & $8.4 \mathrm{~d}$ & $\varepsilon(100 \%)$ & As-72 \\
As-71 & $65.3 \mathrm{~h}$ & $\varepsilon(100 \%)$ & Ge-71 \\
As-72 & $26.0 \mathrm{~h}$ & $\varepsilon(12 \%)$, & Ge-72 \\
& & $\beta^{+}(88 \%)$ & \\
As-74 & $17.77 \mathrm{~d}$ & $\varepsilon(66 \%)$, & Ge-74, Se-74 \\
Ge-71 & $11.43 \mathrm{~d}$ & $\varepsilon(100 \%)$ & $\mathrm{Ga}-71$ \\
\hline
\end{tabular}

Optimization of Se paration Parameters. All fractions from the column separation were counted on an HPGe detector with identical settings, and the distance between the detector and the samples was adjusted to the fraction that had the highest radioactivity to avoid high dead times resulting in systematic errors in the measurements. Based on our previous findings, by loading $\mathrm{pH} 8$ target solution, selenate and arsenate, which were in their ionic 


\section{Yutian Feng}

form, were retained on the anion exchange resin and reached their maximum equilibrium distribution ratios, while germanate passed through without any interactions with the resin (Figure 2.2). The first $\mathrm{pK}_{\mathrm{a}}$ value of selenous acid $\left(\mathrm{H}_{2} \mathrm{SeO}_{3}, \mathrm{pK}_{\mathrm{a}}\right.$ 2.62) is close to that of arsenic acid $\left(\mathrm{H}_{3} \mathrm{AsO}_{4}, \mathrm{pK}_{\mathrm{a}}\right.$ 2.19) while the first $\mathrm{pK}_{\mathrm{a}}$ value of selenic acid $\left(\mathrm{H}_{2} \mathrm{SeO}_{4}\right)$ is -3 , thus oxidizing selenium to $\mathrm{Se}(\mathrm{VI})$ is vital for the separation.[34] $7.33 \%$ of ${ }^{72} \mathrm{Se}$ breakthrough was observed during loading. Possible explanations are: 1) the excess $\mathrm{H}_{2} \mathrm{O}_{2}$ loaded on the column decomposed upon interaction with the anion exchange resin producing $\mathrm{O}_{2}$ gas, which formed channeling in the column, affecting the efficiency of the selenate being retained on the anion exchange resin; 2) the target solution was stored at room temperature for over 60 hours before being loaded on the resin, which could lead to the reduction from selenate to selenite.

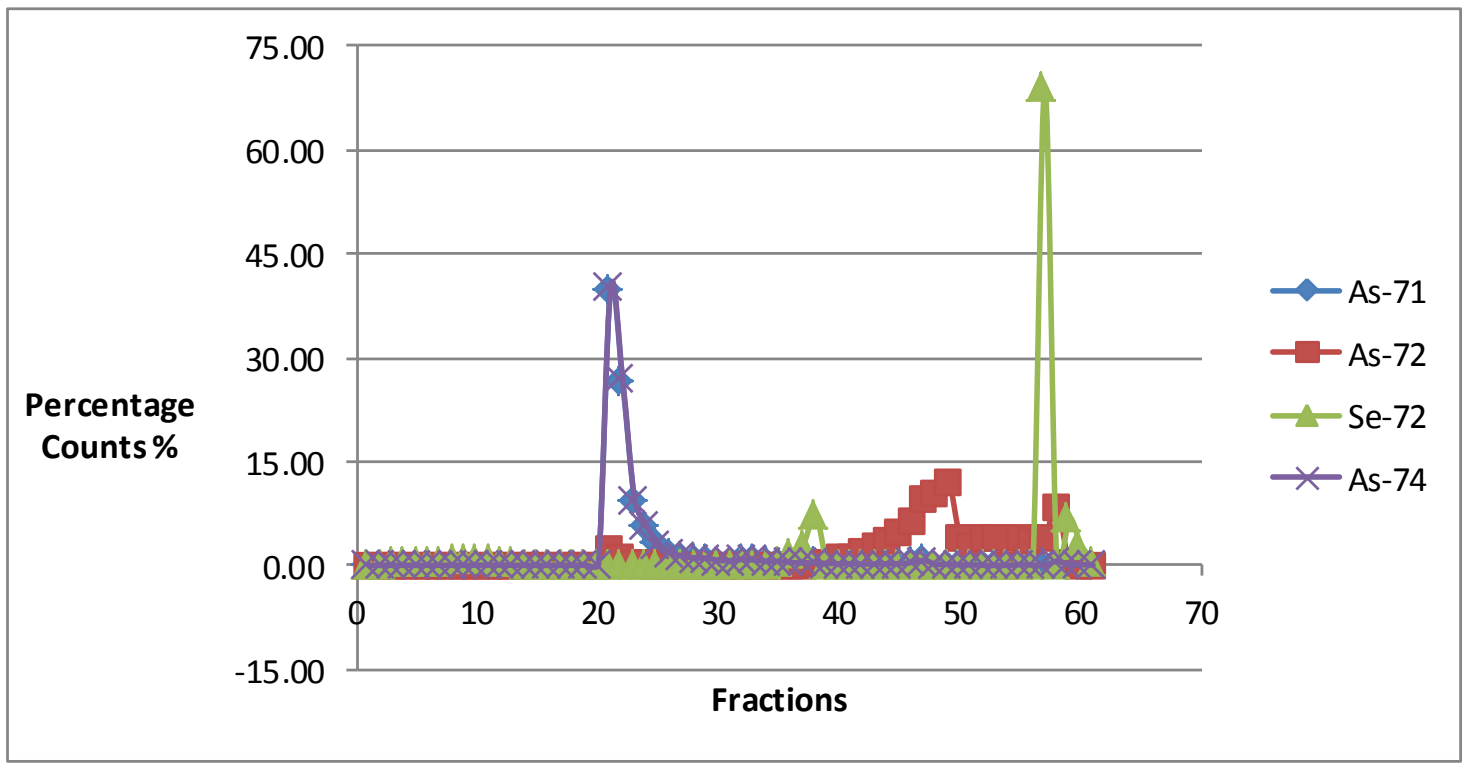

Figure 2.2. Percentage counts of radionuclides in each fraction. The counts of each isotope were measured on High Purity Germanium Detector (HPGe Detector) and decay corrected. The percentages were calculated by counts of a radioisotope/total count of the same radioisotope. All radioactivity was eluted from the column and the total counts of each 


\section{Yutian Feng}

radionuclide were calculated by combining all counts of each radionuclide in all fractions after decay corrected.

Arsenate $\left({ }^{71,72,74} \mathrm{As}\right)$ started eluting with $0.015 \mathrm{M} \mathrm{HNO}_{3}(\mathrm{pH}=1.82)$, and kept eluting since under $\mathrm{pH}=1.82$, arsenate was fully protonated to form arsenic acid $\left(\mathrm{H}_{3} \mathrm{AsO}_{4}\right)$ which no longer associated with the anion exchange column. Selenium-72 breakthrough was observed later in the washing process, which possibly resulted from: 1) $\left[{ }^{72} \mathrm{Se}\right]$ selenate was partially reduced to $\left[{ }^{72} \mathrm{Se}\right]$, protonated to form selenous acid $\left(\mathrm{H}_{2} \mathrm{SeO}_{3}\right)$, and eluted with arsenate; 2$)$ the large volume of $0.015 \mathrm{M} \mathrm{HNO}_{3}$ added to the column; 2) adding solvent to the anion exchange resin disturbed the resin packing. Apart from that, it was possible that the anion exchange column was over loaded, which could lead to breakthrough.

The anion exchange column was eluted with $0.015 \mathrm{M} \mathrm{HNO}_{3}$ until only ${ }^{72} \mathrm{Se}$ and ${ }^{72}$ As were observed in the fractions. $0.6 \mathrm{M} \mathrm{HNO}_{3}$ was added to the resin under which conditions selenate was fully protonated in the form of selenic acid and eluted from the resin. However, a small percentage (1\% each) of ${ }^{71}$ As and ${ }^{74}$ As co-eluted with the selenate.

According to our findings in the first separation, the amount of anion exchange resin was increased in the second separation. $10 \mathrm{~mL}$ of target solution $\left(0.22 \mathrm{mCi}\right.$ of $\left.{ }^{72} \mathrm{Se}\right)$ was added to a preconditioned Dowex 1-X8 column (1 g, $1.43 \mathrm{~mL}$ bed volume) (Figure 2.3). Two columns were prepared and loaded in the same method. Little to none of germanium isotopes were observed in the fractions and could not be measured accurately. Hence they were not included. In the loading process only a small amount of ${ }^{72}$ As was observed possibly because of the increase in resin bed volume compared to the radioactivity added. Arsenate $\left({ }^{71,72,74} \mathrm{As}\right)$ was eluted by adding $0.015 \mathrm{M} \mathrm{HNO}_{3}(\mathrm{pH}=1.82)$ solution. $1.4 \%{ }^{72}$ Se breakthrough was observed in the first column while no ${ }^{72}$ Se breakthrough was observed in the second column. 
When only a small amount of ${ }^{72}$ As was observed in the fractions, the column was counted on an HPGe detector as a quality control assuring that other radionuclides of arsenic $\left({ }^{71,74} \mathrm{As}\right)$ were eluted. $0.6 \mathrm{M} \mathrm{HNO}_{3}$ was added to elute ${ }^{72} \mathrm{Se}$ and the remaining ${ }^{72} \mathrm{As}$.
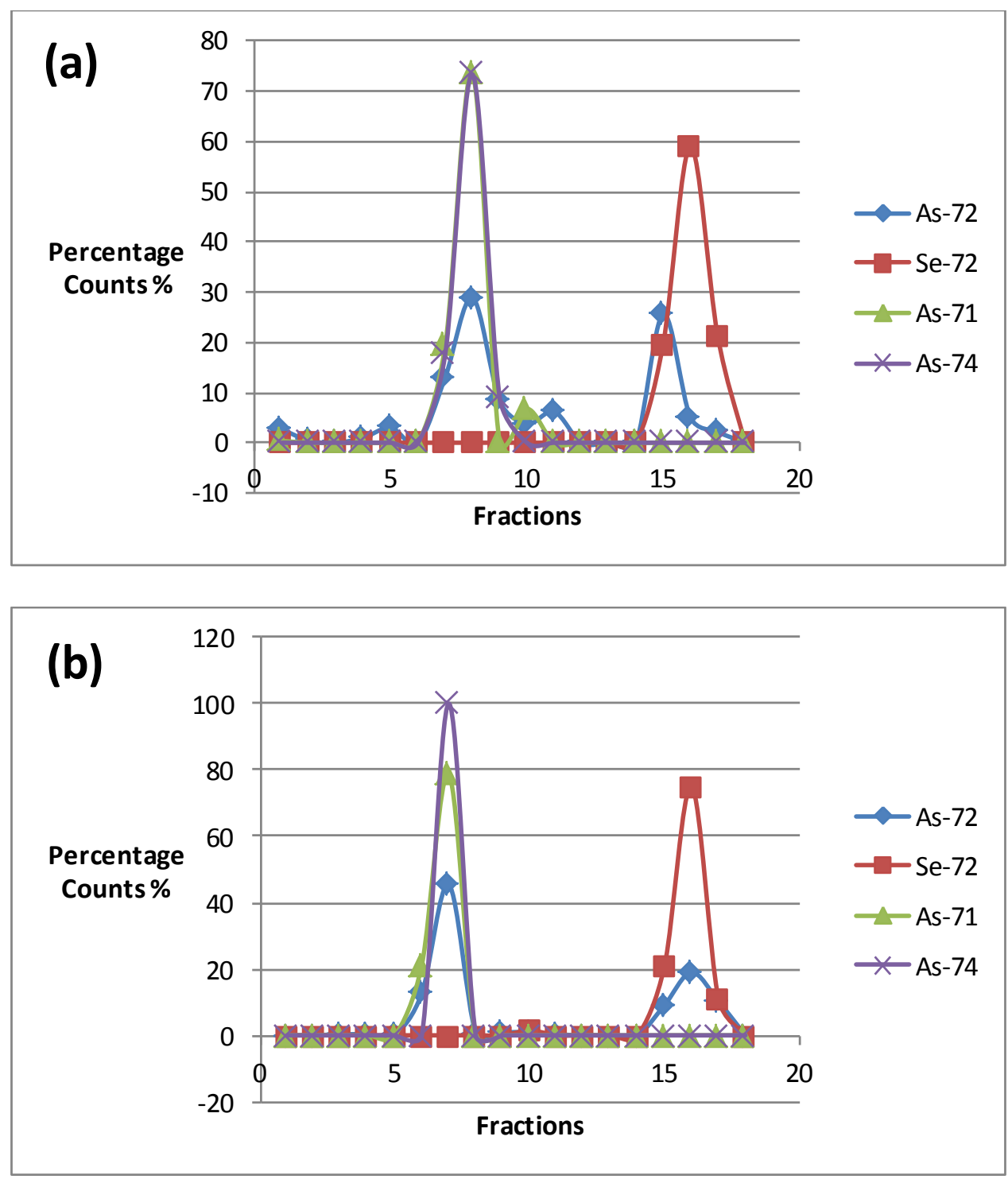

Figure 2.3. (a) Percentage of counts of radionuclides in each fraction in the second separation, column 1. (b) Percentage of counts of radionuclides in each fraction in the second separation, column 2. The counts of each radionuclide were measured on an HPGe detector 


\section{Yutian Feng}

and decay corrected based on their half-lives. The percentages were calculated by counts of one radionuclide/total counts of the same radionuclide. All radioactivity was eluted from the column and the total counts of each radionuclide were calculated by combining all counts of each radionuclide in all fractions after decay correction.

Determination of ${ }^{72} \mathrm{Se} /{ }^{72} \mathrm{As}$ Generator Parameters. Fractions containing selenate $\left({ }^{72} \mathrm{Se}\right)$ and arsenate $\left({ }^{72} \mathrm{As}\right)$ were combined. $100 \mu \mathrm{L}$ of the eluent from the generator was counted on the HpGe detector as a quality control sample. Only a small aliquot of the eluent was counted instead of the whole eluent because with lower radioactivity, the sample could be counted at a position that has higher efficiency without being affected by high dead time leading to inaccurate counts. Since only ${ }^{72} \mathrm{Se}$ and ${ }^{72}$ As were detected, the eluent was boiled to dryness in a beaker. Selenate (Se (VI)) was readily converted to $\mathrm{Se}(\mathrm{IV})$ when the volume was reduced due to radiolytic reduction. Therefore it is vital to oxidize selenium with a sufficient amount of $\mathrm{H}_{2} \mathrm{O}_{2}$. The radioactivity was reconstituted with $10 \mathrm{~mL}$ of $10 \% \mathrm{H}_{2} \mathrm{O}_{2}$ and heated at $50{ }^{\circ} \mathrm{C}$ for $30 \mathrm{~min}$, and then the $\mathrm{pH}$ was adjusted to 8 with $1 \mathrm{M} \mathrm{NaOH}$. Selenium breakthrough was detected immediately when this solution was loaded on the resin. This could result from several causes: 1) since the generator column had a bed volume of $1 \mathrm{~mL}$, it was likely affected by the bubbles and gaps produced from $\mathrm{H}_{2} \mathrm{O}_{2}$ decomposition, which could potentially lead to selenium breakthrough; 2) reoxidizing conditions were insufficient to convert all selenium to $\mathrm{Se}(\mathrm{VI})$. The selenium was then eluted with $0.6 \mathrm{M} \mathrm{HNO}_{3}$, and the $\mathrm{pH}$ was adjusted to 8 with $10 \mathrm{M} \mathrm{NaOH}$. It was heated at $80{ }^{\circ} \mathrm{C}$ for 30 min and then loaded onto a concentrated $\mathrm{HCl}$ preconditioned Dowex 1-X8 column (1g, $1.43 \mathrm{~mL})$. The generator resins were preconditioned with $\mathrm{HCl}$ solution instead of $\mathrm{HNO}_{3}$ because the presence of $\mathrm{HNO}_{3}$ in the 


\section{Yutian Feng}

eluents will affect the radiolabeling of ${ }^{72}$ As. $13 \%$ of selenium breakthrough was observed in the loading. After loading, the column was eluted with $0.027 \mathrm{M} \mathrm{HCl}(\mathrm{pH}=1.56)$.

Radiochemical pure ${ }^{72}$ As was eluted from the generator. Minor selenium breakthrough occurred when the generator was eluted with $0.027 \mathrm{M} \mathrm{HCl}(\mathrm{pH}=1.56)$ after $90 \%$ of arsenate had been eluted.

${ }^{72}$ As Phantom Study. The ${ }^{72} \mathrm{Se} /{ }^{72}$ As generator was eluted with $0.027 \mathrm{M} \mathrm{HCl}(\mathrm{pH}=1.56) 72$ hours after set up for ${ }^{72}$ As to grow in. The fractions were counted on an HPGe detector to assure the production of radiochemically pure ${ }^{72} \mathrm{As}$, boiled to dryness and reconstituted with $1 \mathrm{~mL}$ of DI water. The $\mathrm{pH}$ of that solution was $2 \sim 3$, where the dominant chemical form of arsenate was $\mathrm{NaH}_{2} \mathrm{AsO}_{4}$.[34] The sample was sent to the Harry S. Truman Memorial Veterans' Hospital for a phantom study (Figure 2.4) on the PET camera system. 


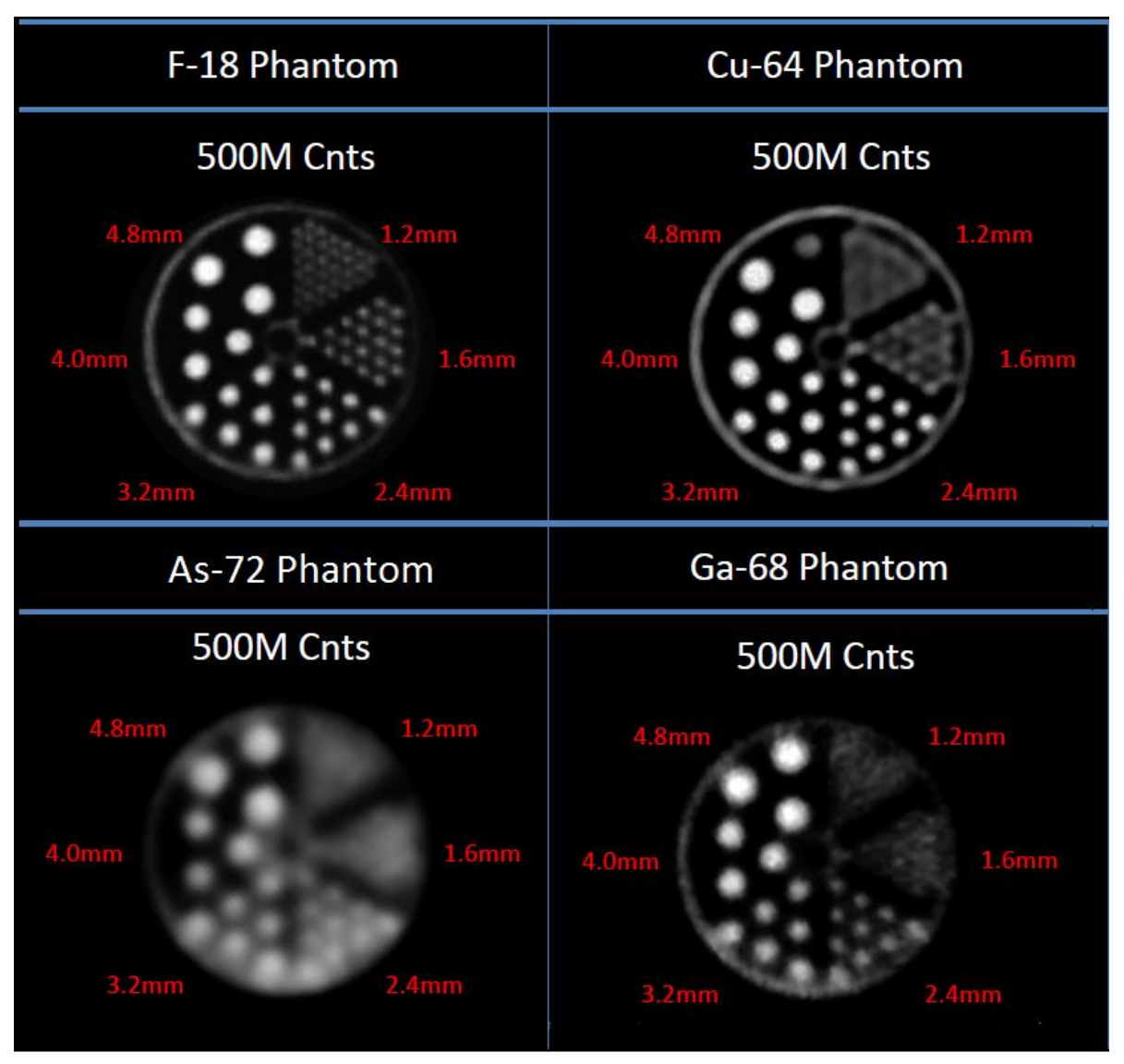

Figure 2.4. PET Phantom data reconstructed. Phantom data collected on a Siemens Inveon®

D-PET System using a Micro/Ultra Micro Jaszczak Phantom at 500 million counts.

Fluorine-18 has been considered as the "gold standard" for PET imaging and is the most widely used isotope for PET imaging. Due to the low positron energy $(0.63 \mathrm{MeV})$ of ${ }^{18} \mathrm{~F}$, positrons emitted by ${ }^{18} \mathrm{~F}$ decay travel a relatively short distance before depositing their kinetic energy $(0.63 \mathrm{MeV})$ and undergoing annihilation. Compared to ${ }^{18} \mathrm{~F},{ }^{64} \mathrm{Cu}\left(\beta^{+} 0.65\right.$ $\mathrm{MeV}),{ }^{68} \mathrm{Ga}\left(\beta^{+} 1.89 \mathrm{MeV}\right)$ and ${ }^{72} \mathrm{As}\left(\beta^{+} 2.50 \mathrm{MeV}\right)$ have higher positron energies and increased image blurring occurs (i.e. decreasing image resolution) as a function of positron energy.[43] Arsenic-72 emits $2.50 \mathrm{MeV}$ energy positrons, which results in significant source blurring and lower resolution than observed with ${ }^{18} \mathrm{~F}$. In addition, ${ }^{72} \mathrm{As}$ has an $834 \mathrm{keV}(80 \%)$ 
gamma emission which can further add to the background of spurious coincidences, thereby increasing image blurring. [44]

\section{Conclusion}

Arsenic-72 and ${ }^{77}$ As as a "matched pair" is a potential theranostic radionuclides for radiopharmaceuticals. In order to develop an efficient ${ }^{72} \mathrm{As}$ production, ${ }^{72} \mathrm{Se} /{ }^{72} \mathrm{As}$ generator production was established. A graphite-germanium metal-graphite "sandwich" target was designed to tackle the difficulties in high energy $\alpha$ beam irradiation, which produces nca ${ }^{72} \mathrm{Se}$ via the ${ }^{70} \mathrm{Ge}(\alpha, 2 \mathrm{n}){ }^{72}$ Se reaction, followed by a novel and environmentally friendly target dissolution method. Approximately $93 \%$ of the radioactivity from the irradiation was recovered from the dissolution. Anion exchange column chromatography was used to separate no carrier added ${ }^{72} \mathrm{Se}$ and ${ }^{72} \mathrm{As}$ from the germanium target. $\mathrm{A}{ }^{72} \mathrm{Se} /{ }^{72}$ As generator was set up and radiochemically pure ${ }^{72}$ As was readily eluted, and characterized by phantom PET imaging study.

\section{Production of Arsenic-77}

\section{Experimental}

Physical Meas urements and Mate rials. All reagents and solvents were purchased from Alfa Aesar (WardHill, MA) and Fisher Scientific (Pittsburg, PA). Enriched ${ }^{76} \mathrm{GeO}_{2}(98.5 \%$ enrichment) was purchased from Trace Sciences International (Richmond Hill, ON, Canada). Analytical grade silica gel was purchased from Mallinckrodt (St. Louis, MO). Commercial $60 \AA$ A silica gel was purchased from Acros Organics (Geel, Belgium). Poly-prep columns (0.8 
cm ID; $10 \mathrm{~mL}$ reservoir) were purchased from Bio-Rad Corporation (Hercules, CA). All materials were used as received without further purification. All water used was purified onsite (deionized water from a Millipore system to greater than $18 \mathrm{M} \Omega \mathrm{cm}$ ). An ORTEC HPGe detector outfitted with Genie multichannel analysis software was used to assay ${ }^{77} \mathrm{Ge}$ and ${ }^{77} \mathrm{As}$ liquid samples.

Target dissolution. The glass vial containing target material was placed on a hot plate. A stir bar was placed inside of the vial, and $450 \mu \mathrm{L}$ of $0.1 \mathrm{M} \mathrm{NaOH}$ solution was added to the vial. The temperature was set at $40{ }^{\circ} \mathrm{C}$ and stir rate was set at $350 \mathrm{rpm}$. The dissolution was finished in 15 min. After that $450 \mu \mathrm{L}$ of $0.1 \mathrm{M} \mathrm{HCl}$ was added to the vial. $\mathrm{H}_{2} \mathrm{O}_{2}(100 \mu \mathrm{L}$, $30 \%$ ) was added to the vial and it was heated at $80{ }^{\circ} \mathrm{C}$ for $30 \mathrm{~min}$. The target solution was cooled to room temperature and placed in a lead shield for further use.

Column Preconditioning. Silica gel (1 g) was weighed and placed in a chromatographic column (1.8 $\mathrm{mL}$ bed volume). Methanol $(6 \mathrm{~mL})$ was added to the column and stirred with the silica gel to form a uniform mixture. The column was washed with another $6 \mathrm{~mL}$ of methanol and a piece of glass wool $(1 \times 1 \mathrm{~cm})$ was placed on top of the silica gel to prevent the disturbance of the silica gel bed. An ethanol solution of $0.1 \mathrm{M} \mathrm{HCl}$ was prepared by diluting optimal grade concentrated $\mathrm{HCl}(12.1 \mathrm{M}, 100 \mu \mathrm{L}, 1.21 \mathrm{mmol})$ with ethanol $(12 \mathrm{~mL})$. The 0.1 $\mathrm{M} \mathrm{HCl}$ in ethanol solution (5 mL) was added to wash the column.

Separation. The target solution $(1 \mathrm{~mL})$ was added to the column and allowed to sit for 2 min for column equilibration. After that the first $1 \mathrm{~mL}$ fraction was collected into a glass vial. Fractions with volumes of $1 \mathrm{~mL}$ were collected by adding $1 \mathrm{~mL}$ of $0.1 \mathrm{M} \mathrm{HCl}$ in ethanol to the column each time before collection. Radiochemically pure As-77 was collected in the first 5 fractions (over $90 \%$ of the total radioactivity) and Ge-77 breakthrough was observed in 


\section{Yutian Feng}

the 6th fraction. Germanium can be recovered by eluting the column with DI water followed by $0.01 \mathrm{M} \mathrm{NaOH}$ solution. Fractions containing As-77 were combined and the vials were rinsed with methanol to ensure maximum transfer of radioactivity. The solution was dried down by blowing air over the vial and reconstituted with $1 \mathrm{~mL}$ of DI water. The solution was ready for further use.

\section{Results and Discussion}

It is important to note that radiochemical separations can be problematic since the mass of the target ( $\sim \mathrm{mg})$ is normally in a huge excess compared to the mass of the product ${ }^{77} \mathrm{As}(\sim \mathrm{ng})$. In the previous method[1] using silica gel and methanol, nca ${ }^{77}$ As was eluted at a reasonable yield $(74 \pm 11 \%)$ in $4 \mathrm{~mL}$ and the loading capacity was $210.9 \mathrm{MBq}(5.7 \mathrm{mCi})$ of ${ }^{77} \mathrm{As} /{ }^{76,77} \mathrm{Ge}$ resulting in $74 \mathrm{MBq}\left(2 \mathrm{mCi}\right.$ ) of nca ${ }^{77} \mathrm{As}$ while little to no ${ }^{77} \mathrm{Ge}$ breakthrough was observed.[1] Currently at the University of Missouri Research Reactor (MURR), approximately $444 \mathrm{MBq}$ (12 mCi) of ${ }^{77} \mathrm{As}$ is produced from enriched ${ }^{76} \mathrm{GeO}_{2}$ targets (98\% enrichment, $3 \sim 5 \mathrm{mg}$ of size) per target per irradiation (1 week irradiation time). Potential production scale-up can be achieved with increased target sizes. An improved separation was developed to enhance the separation capacity from $74 \mathrm{MBq}(2 \mathrm{mCi})$ to $444 \mathrm{MBq}(12 \mathrm{mCi})$ of ${ }^{77} \mathrm{As}$ production in each separation.

Target dissolution. The separation of nca ${ }^{77}$ As from the germanium target was done following a described procedure and carried out at approximately $26 \mathrm{~h}$ post irradiation to allow the ${ }^{77}$ As to grow to its maximum amount.[1] After being transferred from a sealed quartz vial to a glass vial, the ${ }^{76} \mathrm{GeO}_{2}$ target appeared as a black powder. $\mathrm{NaOH}$ solution was added to dissolve the target with gentle heat $\left(\sim 40^{\circ} \mathrm{C}\right)$, and the dissolution lasted $15 \mathrm{~min}$. 


\section{Yutian Feng}

Initially the concentration of the $\mathrm{NaOH}$ solution was $1 \mathrm{M}$. A lower concentration $\mathrm{NaOH}$ solution $(0.1 \mathrm{M})$ was used to reduce the concentration of $\mathrm{Na}^{+}$, which could potentially affect the radiolabeling step. $\mathrm{NaOH}$ solution $(0.01 \mathrm{M})$ was also tested but poor results were observed for the dissolution. The target solution remained cloudy and black powder precipitation was observed, which also affected the separation yield due to incomplete dissolution. Higher temperature and longer dissolution times were carried out but were ineffective. The target solution was neutralized with $\mathrm{HCl}$ solution at room temperature. $30 \%$ $\mathrm{H}_{2} \mathrm{O}_{2}$ solution was added to oxidize ${ }^{77}$ As to the +5 oxidation state. Because of the low concentration of nca ${ }^{77} \mathrm{As}$, it could be readily oxidized to the +5 oxidation state by oxygen in the air or in solution. Other methods have kept arsenic reduced in the +3 oxidation state $\left(\mathrm{AsCl}_{3}, \mathrm{AsI}_{3}\right)$.[45] However, fully oxidizing arsenic to the +5 oxidation state was more experimentally doable.

Column Separation. A column chromatographic separation using silica gel resin was developed to produce nca ${ }^{77}$ As with high radiochemical yield.[1] It was found that under acidic conditions germanium is retained on the silica gel column. At the same time $\left[{ }^{77} \mathrm{As}\right]$ arsenate was protonated to form $\mathrm{H}_{3} \mathrm{AsO}_{4}\left(\mathrm{pKa}_{1}=2.19\right)$. Separation could be achieved by eluting the resin with ethanol solution. The resin volume and column preconditioning parameters were optimized. The amount of silica gel was increased to $1 \mathrm{~g}$ to meet the requirements because the loading volume increased from $250 \mu \mathrm{L}$ to $1 \mathrm{~mL}$ (total target solution volume). When the target solution was loaded on the preconditioned silica gel resin, germanium was retained on the resin while ${ }^{77}$ As was eluted with $12 \mathrm{M} \mathrm{HCl:EtOH} \mathrm{(1:1200)}$ solution as a mobile phase. Different eluents were evaluated and it was found that by 
controlling the amount of water present in the eluent to a minimum, germanium breakthrough was not observed.

\section{Conclusion}

With this separation method, $94 \%$ of total ${ }^{77}$ As radioactivity was isolated within 4 hours. No carrier added ${ }^{77} \mathrm{As}(444 \mathrm{MBq}, 12 \mathrm{mCi}, 94 \%$ radiochemical yield) can be produced from an $98 \%$ enriched $\left[{ }^{76} \mathrm{Ge}\right] \mathrm{GeO}_{2}$ target $(\sim 3 \mathrm{mg})$ after one week of irradiation and $26 \mathrm{~h}$ growth time post irradiation.

\section{Future Studies}

For the development of ${ }^{72} \mathrm{Se} /{ }^{72} \mathrm{As}$ generator, efforts are needed to improve the production of nca ${ }^{72} \mathrm{Se}$ on a larger scale. The conditions of separating nca ${ }^{72}$ Se from its germanium target and loading it on a generator were evaluated and established. Future studies include conducting a large production of ${ }^{72} \mathrm{Se}$ from ${ }^{70} \mathrm{Ge}$ metal target and optimization of the separation parameters.

The production and separation of nca ${ }^{77}$ As have been optimized and are performed on a regular basis. However the current production capacity is limited due to the target size. A production capacity scale-up can be potentially achieved by increasing the target size. However the separation conditions will require modifications to meet the production need. 


\section{Chapter 3: Dithiol Aryl Arsenic Compounds as Potential Diagnostic and Therapeutic Radiopharmaceuticals}

\section{Introduction}

Radionuclides of arsenic have the potential to be used as imaging and therapeutic radionuclides.[5] Two promising arsenic radionuclides, As-72 and As-77, are considered a "matched pair" due to their useful nuclear properties for PET imaging and radiotherapy, respectively.[31] In order to utilize arsenic radionuclides, ligands stabilizing As(III) at high dilution under in vivo conditions are required. Sulfur donors are commonly observed in arsenic chemistry based on the metalloid nature of arsenic. Arsenic has a strong affinity for thiol-containing molecules such as dimercaptosuccinic acid and British anti-Lewisite, which are approved to treat arsenic poisoning.[46] Arsenic toxicity is believed to involve binding to thiols in proteins. The total thiol concentration in the body has been estimated to be $0.4-0.5$ $\mathrm{mM}$ in plasma, and 8-10 $\mu \mathrm{M}$ in cells; these concentrations are fairly high compared to the concentration of radiopharmaceuticals (nM).[47, 48] Radiopharmaceuticals must survive the complex in vivo environment to be effective.

Incorporating an aryl group to arsenic is believed to add stability to arsenic and studies show that dithioarylarsine compounds have high stability for different applications.[49, 50] Dithioarylarsine compounds have the potential to stabilize trivalent radioarsenic at tracer levels to survive the comparatively high thiol concentration under in vivo conditions. There are three reported methods to introduce an aryl-As bond to arsenic, namely the Bart, Scheller and Bechamp reactions (Scheme 3.1).[51] To evaluate the synthesis conditions and translate 


\section{Yutian Feng}

the synthesis of dithioarylarsines to the tracer level with nca ${ }^{77}$ As, several dithioarylarsines were synthesized and characterized as macroscopic standards. It is necessary to acknowledge that many of the dithioarylarsines were synthesized and characterized by Dr. Anthony J.

DeGraffenreid and hence included in his thesis previously.[52] The synthesis was carried out with nca ${ }^{77}$ As and the radiolabeling yield was optimized using the macroscopic standards. [31]

The Bart Reaction

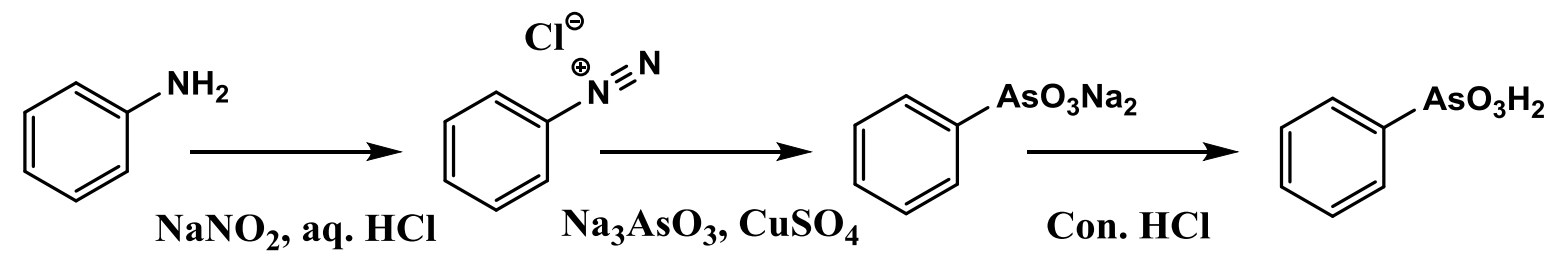

The Scheller Reaction

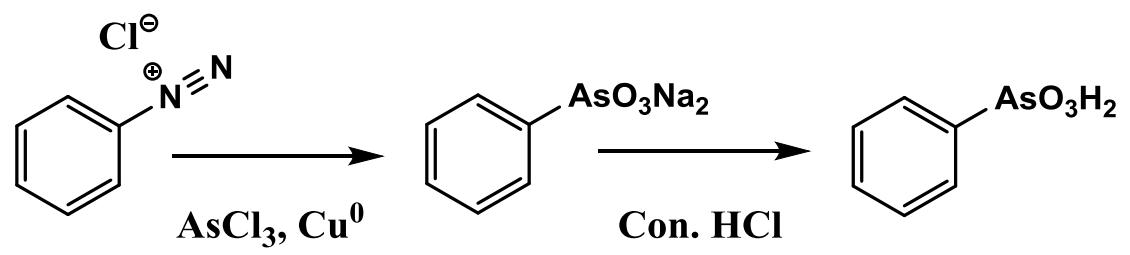

\section{The Bechamp Reaction}

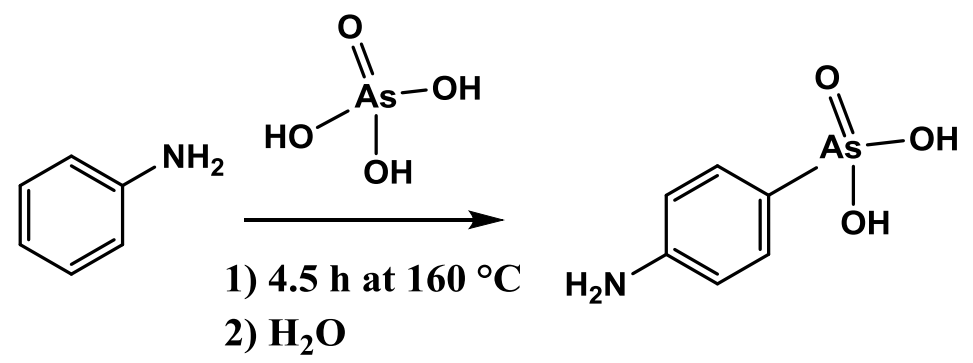

Scheme 3.1. The synthesis of aryl-As compound via the Bart, Scheller and Bechamp reactions. 


\section{Yutian Feng}

\section{Experimental}

\section{Materials}

Arsenic trioxide (CAUTION! Arsenic is highly toxic and should be handled with care), mercaptoacetic acid, dimercaptosuccinic acid (DMSA), 1,2-ethane dithiol, 1,3-propane dithiol, 4-amino-phenyl arsonic acid ( $p$-arsanilic acid), and phenyl arsonic acid were purchased from Sigma Aldrich, Acros, or Alfa Aesar, and used as received. All solvents and acids were reagent grade and purchased from Fisher Scientific or Sigma Aldrich and used without further purification. $\mathrm{Cu}^{0}$ nanoparticles $(<20 \mathrm{~nm}$ in acetone at $100 \mathrm{mg} / \mathrm{mL}$ (surfactant and reactant-free)) were purchased from Strem Chemicals, Inc. SORBTECH Silica Gel TLC plates were purchased from Sorbtech (Norcross, GA) and used as received. $p$ Aminophenyldichloroarsine, $p$-nitrophenylarsonic acid, $p$-ethoxyphenyldiazonium tetrafluoroborate, and, $p$-ethoxyphenylarsonic acid were prepared using literature methods.[49, 51, 53, 54]

CAUTION! ${ }^{77}$ As and ${ }^{77} \mathrm{Ge}(2.7 \mathrm{MeV} \beta-211,215$ and $264 \mathrm{keV} \gamma, 11.3 \mathrm{~h}$ half-life $)$ are radioactive and must be handled in laboratories outfitted and approved for work with radioactive materials. Arsenic-77 was produced by neutron irradiation of $96.2 \%$ or $98.6 \%$ enriched ${ }^{76} \mathrm{GeO}_{2}$ (Trace Sciences International, Richmond Hill, ON) in the flux trap at a thermal flux of $\sim 2.4 \times 10^{14} \mathrm{n} / \mathrm{cm}^{2}$-s at the University of Missouri Research Reactor Center (MURR). Arsenic-77 $\left(\mathrm{NaH}_{2}{ }^{77} \mathrm{AsO}_{4}\right)$ was provided in a methanol solution $\left({ }^{77}\right.$ As stock solution, $1 \mathrm{ml}, \sim 177.6 \mathrm{MBq}(4.8 \mathrm{mCi}), 5.9 \times 10^{-11} \mathrm{~mol}$ or $4 \mathrm{ng}$ based on measured activity), separated as discussed in Chapter 2. 


\section{Yutian Feng}

\section{Physical Measurements}

${ }^{1} \mathrm{H}$ and ${ }^{13} \mathrm{C}$ NMR spectra were obtained in $\mathrm{D}_{2} \mathrm{O}, \mathrm{CDCl}_{3},\left(\mathrm{CD}_{3}\right)_{2} \mathrm{SO}$ or $\mathrm{CD}_{3} \mathrm{CN}$ on either a Bruker ARX-300 or $500 \mathrm{MHz}$ spectrometer. Electrospray Ionization Mass Spectra (ESI-MS) were collected on a Thermo Finnigan TSQ7000 triple-quadrupole instrument with an API2 source. Elemental analyses were performed by Atlantic Microlab, Inc. (Norcross, GA). An ORTEC high purity germanium (HPGe) detector coupled to a Canberra amplifier, analog to digital converter, and HV power supply system using PROcount 2000 software was used to assay ${ }^{77}$ As samples. A Shimadzu Prominence HPLC system equipped with a pump, controller, Prominence UV-Vis detector (model SPD20-AV) set to $254 \mathrm{~nm}$ and coupled to a Beckman $170 \mathrm{NaI}(\mathrm{Tl})$ radionuclide detector with a Thermo Scientific Beta Basic column $\left(\mathrm{C} 18,5 \mu \mathrm{m}, 150 \mathrm{~mm} \times 4.6 \mathrm{~mm}\right.$ ) was used to analyze ${ }^{77}$ As dithioarylarsines, with a linear gradient from $100 \%$ A to $65 \% \mathrm{~B}(\mathrm{~A}=$ water with $0.1 \%$ TFA, and $\mathrm{B}=\mathrm{ACN}$ with $0.1 \%$ TFA $)$ with a flow rate of $1 \mathrm{~mL} / \mathrm{min}$ over 65 min. An Eckert \& Ziegler Bioscan AR-2000 Imager using LabLogic Win-Scan imaging scanner software (Version 2.2(11)) was used for scanning radioTLC plates.

\section{Synthesis}

Syntheses of a series of dithioarylarsines at the macroscopic le vel. The syntheses were carried out using a modified Bart reaction and described in Scheme 3.2. The structures of the dithioarylarsines were described in Scheme 3.3. Different phenylarsonic acids were prepared following literature procedures using $\mathrm{As}_{2} \mathrm{O}_{3}$ as a starting material.[51] The phenylarsonic acids were reduced with ammonium mercaptoacetate to afford dimonothioarylarsines, which were then complexed with different dithiols. 
<smiles>[R]c1ccc([As](=O)(O)O)cc1</smiles><smiles>[R7]c1ccc([As]([R])[R5])cc1</smiles>

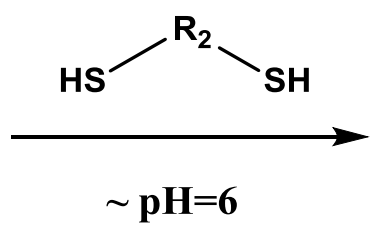<smiles>[R]S[As](S[R])c1ccc([R])cc1</smiles>

\section{$\mathrm{R}=\mathrm{SCH}_{2} \mathrm{COONH}_{4}$}

$\mathrm{R}_{1}=-\mathrm{OEt}, \mathrm{NH}_{2}, \mathrm{H}, \mathrm{NO}_{2}$

$\mathrm{R}_{2}=\mathrm{CH}_{2} \mathrm{CH}_{2}, \mathrm{CH}(\mathrm{COO}) \mathrm{CH}(\mathrm{COO}), \mathrm{CH}_{2} \mathrm{CH}_{2} \mathrm{CH}_{2}$.

Scheme 3.2. The synthesis of dithioarylarsines.<smiles>CCOc1ccc([As]2SCCS2)cc1</smiles>

1
$\mathrm{H}_{4} \mathrm{NOOC}$<smiles>CC1S[Ge]SC1C(=O)NO</smiles><smiles>CCOc1ccc([As])cc1</smiles>

2<smiles>CCOc1ccc([As]2SCCCS2)cc1</smiles>

3<smiles>NC(=O)C1S[As](c2ccccc2)SC1C(=O)ON1CCS[As]1c1ccccc1</smiles>

Scheme 3.3. The structure of the dithioarylarsines (compound 1 to 12). 
Compound 5,7 -9,11 and 12 were synthesized and characterized by Dr. Anthony DeGraffenreid and hence were reported in his dissertation. Those compounds are included in this dissertation because they are necessary for the discussion and conclusions. [52] 2-(4-Ethoxyphenyl)-1,3,2-dithiaarsolane $\left[\mathrm{CH}_{3} \mathrm{CH}_{2} \mathrm{OC}_{6} \mathrm{H}_{4} \mathrm{As}\left(\mathrm{SCH}_{2} \mathrm{CH}_{2} \mathrm{~S}\right)\right]$, 1. p-

Ethoxyphenylarsonic acid (200 mg, $0.81 \mathrm{mmol})$ was dissolved in ethanol $(100 \%, 20 \mathrm{~mL})$ in a round bottom flask equipped with a stir bar, and heated to $55{ }^{\circ} \mathrm{C}$ in a water bath. Aqueous ammonium mercaptoacetate $(5.5 \mathrm{M}, 890 \mu \mathrm{L}, 4.9 \mathrm{mmol})$ was added, and heating continued with vigorous stirring. After 60 minutes, the flask was removed from heat and 1,2ethanedithiol ( $69 \mu \mathrm{L}, 77 \mathrm{mg}, 0.82 \mathrm{mmol})$ was added. The resultant reaction mixture was stirred for 30 minutes, at which time water $(\sim 50 \mathrm{~mL})$ was added to precipitate the product. After cooling in the freezer $\left(-15^{\circ} \mathrm{C}\right)$ for $2 \mathrm{~h}$, the solids were collected by vacuum filtration, washed with cold ethanol, and dried in vacuo to obtain the product as a light yellow powder. Yield: 47\%, $110 \mathrm{mg} .{ }^{1} \mathrm{H}-\mathrm{NMR}\left(\mathrm{CDCl}_{3}\right.$; $\left.500 \mathrm{MHz}\right) \delta \mathrm{ppm}: 1.41$ (t, 3H, $\left.\mathrm{CH}_{3}\right), 3.19(\mathrm{~m}, 2 \mathrm{H}$, $\mathrm{SCH}_{2}$ ), 3.35 (m, 2H, SCH$), 4.02$ (q, 2H, OCH $), 6.88$ (d, 2H, ArH), 7.54 (d, 2H, ArH). ${ }^{13} \mathrm{C}-$ $\operatorname{NMR}\left(\mathrm{CDCl}_{3} ; 125.8 \mathrm{MHz}\right) \delta$ ppm: $14.92\left(\mathrm{CH}_{3}\right), 41.84\left(\mathrm{SCH}_{2}\right), 63.57\left(\mathrm{OCH}_{2}\right), 114.66(\mathrm{ArC})$, 132.24 (ArC), 133.21 (ArC), 160.05 (ArC). Elem. Anal. Calcd (found) for $\mathrm{C}_{10} \mathrm{H}_{13} \mathrm{OS}_{2}$ As: C, 41.67 (41.84); H, 4.55 (4.45); S, 22.24 (22.40). ESI/APCI MS ( $\mathrm{m} / \mathrm{z}): 305.11$ (304.96 calcd for $\left.\left[\mathrm{C}_{10} \mathrm{H}_{14} \mathrm{O}_{2} \mathrm{~S}_{2} \mathrm{As}\right][\mathrm{M}+\mathrm{OH}]^{+}\right)$.

2-(4-Ethoxyphenyl)-1,3,2-dithiaarsolane-4,5-dicarboxylic acid, $\left(\mathrm{NH}_{4}\right)_{2}\left[\mathrm{CH}_{3} \mathrm{CH}_{2} \mathrm{O}\right.$ $\left.\boldsymbol{C}_{6} \mathrm{H}_{4} \mathbf{A s}(\mathbf{S C H}(\mathrm{COO}) \boldsymbol{C H}(\mathrm{COO}) S)\right], 2$. p-Ethoxyphenylarsonic acid (200 mg, $\left.0.81 \mathrm{mmol}\right), 5.5$ M ammonium mercaptoacetate ( $890 \mu \mathrm{L}, 4.9 \mathrm{mmol})$, and meso-2,3-dimercaptosuccinic acid (149 $\mathrm{mg}, 0.82 \mathrm{mmol})$ were reacted in ethanol $(100 \%, 10 \mathrm{~mL})$ as described above for $\mathbf{1}$. The product began to precipitate shortly after the addition of DMSA. After stirring for 30 


\section{Yutian Feng}

minutes, the reaction mixture was placed in the freezer at $-15^{\circ} \mathrm{C}$ to further precipitate the product. Solids were collected by vacuum filtration, washed with cold ethanol, and dried in vacuo to obtain the product as a light yellow powder. Yield: $32.8 \%, 100 \mathrm{mg} .{ }^{1} \mathrm{H}$ NMR $\left(\mathrm{D}_{2} \mathrm{O}\right.$ $\left.\mathrm{d}_{2} ; 500 \mathrm{MHz}\right) \delta$ ppm: $1.41\left(\mathrm{t}, 3 \mathrm{H}, \mathrm{CH}_{3}\right), 4.18\left(\mathrm{q}, 2 \mathrm{H}, \mathrm{OCH}_{2}\right), 4.45(\mathrm{~s}, 2 \mathrm{H}, \mathrm{SCH}), 7.08(\mathrm{~d}, 2 \mathrm{H}$, $\operatorname{ArH}), 7.77(\mathrm{~d}, 2 \mathrm{H}, \mathrm{ArH}) .{ }^{13} \mathrm{C}$ NMR $\left(\mathrm{D}_{2} \mathrm{O} \mathrm{d} \mathrm{d}_{2} ; 125.8 \mathrm{MHz}\right) \delta \mathrm{ppm}: 13.83\left(\mathbf{C H}_{3}\right), 63.33\left(\mathbf{C H}_{2}\right)$, 64.33 (SCH), 115.04 (ArC), 132.38.66 (ArC), 134.36 (ArC), 159.08 (ArC), 175.11 (COOH). Elem. Anal. Calcd (found) for $\mathrm{C}_{12} \mathrm{H}_{19} \mathrm{AsN}_{2} \mathrm{O}_{5} \mathrm{~S}_{2}$ : C, 35.13 (34.72); H, 4.67 (4.36); N, 6.83 (6.25); S, 15.63 (15.64). ESI/APCI MS ( $m / z): 393.15$ (393.16 calcd for $\left[\mathrm{C}_{12} \mathrm{H}_{14} \mathrm{O}_{6} \mathrm{~S}_{2} \mathrm{As}\right]$ $\left.[\mathrm{M}+\mathrm{OH}]^{+}\right)$.

2-(4-Ethoxyphenyl)-1,3,2-dithiaarsinane $\left[\mathrm{CH}_{3} \mathrm{CH}_{2} \mathrm{OC}_{6} \mathrm{H}_{4} \mathrm{As}\left(\mathrm{SCH}_{2} \mathrm{CH}_{2} \mathrm{CH}_{2} \mathrm{~S}\right)\right]$, 3. pEthoxyphenylarsonic acid $(200 \mathrm{mg}, 0.81 \mathrm{mmol}), 5.5 \mathrm{M}$ ammonium mercaptoacetate $(890 \mu \mathrm{L}$, $4.9 \mathrm{mmol})$, and 1,3-propanedithiol $(82 \mu \mathrm{L}, 88 \mathrm{mg}, 0.82 \mathrm{mmol})$ were reacted in ethanol (100\%, $10 \mathrm{~mL})$ as described above for $\mathbf{1}$. The reaction mixture was treated with water $(\sim 50 \mathrm{~mL})$ to precipitate the product and cooled in the freezer $\left(-15^{\circ} \mathrm{C}\right)$ for $2 \mathrm{~h}$. Solids were collected by vacuum filtration, washed with cold ethanol, and dried in vacuo to obtain the product as a light yellow powder. Yield: 61.3\%, $150 \mathrm{mg} .{ }^{1} \mathrm{H}-\mathrm{NMR}\left(\mathrm{CDCl}_{3} ; 500 \mathrm{MHz}\right) \delta \mathrm{ppm}: 1.44(\mathrm{t}, 3 \mathrm{H}$, $\left.\mathrm{CH}_{3}\right), 2.14\left(\mathrm{~m}, 1 \mathrm{H}, \mathrm{CH}_{2} \mathrm{CH}_{2} \mathrm{CH}_{2}\right), 2.17\left(\mathrm{~m}, 1 \mathrm{H}, \mathrm{CH}_{2} \mathrm{CH}_{2} \mathrm{CH}_{2}\right), 2.71(\mathrm{~m}, 2 \mathrm{H}, \mathrm{SCH}$ ), 2.87 (m, 2H, SCH 2$), 4.08$ (q, 2H, OCH $), 7.01(\mathrm{~d}, 2 \mathrm{H}, \mathrm{ArH}), 7.78(\mathrm{~d}, 2 \mathrm{H}, \operatorname{ArH}) .{ }^{13} \mathrm{C}-\mathrm{NMR}\left(\mathrm{CDCl}_{3}\right.$; $125.8 \mathrm{MHz}) \delta$ ppm: $14.96\left(\mathrm{CH}_{3}\right), 26.32\left(\mathrm{SCH}_{2} \mathrm{CH}_{2}\right), 28.67\left(\mathrm{SCH}_{2}\right), 63.62\left(\mathrm{OCH}_{2}\right), 115.44$ (ArC), 128.66 (ArC), 134.01 (ArC), 160.12 (ArC). Elem. Anal. Calcd (found) for $\mathrm{C}_{11} \mathrm{H}_{15} \mathrm{AsOS}_{2}$ : C, 41.67 (41.84); H, 4.55 (4.45); S, 22.24 (22.40). ESI/APCI MS ( $\left.\mathrm{m} / z\right)$ : 317.15 (317.98 calcd for $\left.\left[\mathrm{C}_{11} \mathrm{H}_{15} \mathrm{O}_{2} \mathrm{~S}_{2} \mathrm{As}\right][\mathrm{M}+\mathrm{O}]^{+}\right)$. 


\section{Yutian Feng}

4-(1,3,2-Dithiaarsolan-2-yl)aniline [ $\left.\mathrm{NH}_{2} \mathrm{C}_{6} \mathrm{H}_{4} \mathrm{As}\left(\mathrm{SCH}_{2} \mathrm{CH}_{2} \mathrm{~S}\right)\right]$, 4. p-Arsanilic acid (109.5 $\mathrm{mg}, 0.504 \mathrm{mmol})$ was dissolved in ethanol $(95 \%, 20 \mathrm{~mL})$ in a $100 \mathrm{~mL}$ round bottom flask equipped with a stir bar, and heated to $55^{\circ} \mathrm{C}$ in a water bath. Aqueous ammonium mercaptoacetate $(5.5 \mathrm{M}, 458 \mu \mathrm{L}, 2.52 \mathrm{mmol})$ was added, and heating continued while stirring vigorously. After 60 minutes, the flask was removed from the heat and 1,2-ethane dithiol (47.5 mg, $42.4 \mu \mathrm{L}, 0.504 \mathrm{mmol}$ ) was added. The resultant reaction mixture was stirred for 30 minutes, at which time water $(\sim 50 \mathrm{~mL})$ was added until the reaction turned milky white. After standing overnight in the freezer $\left(-15^{\circ} \mathrm{C}\right)$, crystalline product was isolated by vacuum filtration, washed with water, and dried in vacuo. X-ray quality crystals were obtained by slow evaporation from methanol. Yield: $60 \%, 151 \mathrm{mg} .{ }^{1} \mathrm{H}-\mathrm{NMR}\left(\mathrm{CDCl}_{3} ; 500 \mathrm{MHz}\right) \delta \mathrm{ppm}$ : $3.21\left(\mathrm{~m}, 2 \mathrm{H}, \mathrm{SCH}_{2}\right), 3.34\left(\mathrm{~m}, 2 \mathrm{H}, \mathrm{SCH}_{2}\right), 3.78\left(\mathrm{~s}, 2 \mathrm{H}, \mathrm{NH}_{2}\right), 6.66(\mathrm{~d}, 2 \mathrm{H}, \operatorname{ArH}), 7.42(\mathrm{~d}, 2 \mathrm{H}$, ArH). ${ }^{13} \mathrm{C}-\mathrm{NMR}\left(\mathrm{CDCl}_{3} ; 125.8 \mathrm{MHz}\right) \delta$ ppm: $41.76\left(\mathrm{CH}_{2}\right), 115.06(\mathrm{ArC}), 131.49$ (ArC), 132.27 (ArC), 147.73 (ArC). ESI/APCI MS ( $m / z) 259.90$ (259.96 calcd for $\left[\mathrm{C}_{8} \mathrm{H}_{10} \mathrm{NS}_{2} \mathrm{As}\right]$ $(\mathrm{M}+\mathrm{H})^{+}$). Elem. Anal. Calcd (found) for $\mathrm{C}_{8} \mathrm{H}_{10} \mathrm{NS}_{2}$ As: C, 37.07 (37.15): H, 3.89 (3.94); N, 5.40 (5.34); S, 24.74 (24.95).

\section{2-(4-Aminophenyl)-1,3,2-dithiaarsolane-4,5-dicarboxylic acid,}

$\left(\mathrm{NH}_{4}\right)_{2}\left[\mathrm{NH}_{2} \mathrm{C}_{6} \mathrm{H}_{4} \mathrm{As}(\mathrm{SCH}(\mathrm{COO}) \mathrm{CH}(\mathrm{COO}) \mathrm{S})\right]$, 5. [52] $p$-Arsanilic acid (106.5 mg, 0.490 mmol), 5.5 M ammonium mercaptoacetate (419 $\mu \mathrm{L}, 2.30 \mathrm{mmol})$ and dimercaptosuccinic acid (DMSA; $84.6 \mathrm{mg}, 0.464 \mathrm{mmol})$ in ethanol $(95 \%, 20 \mathrm{~mL})$ were reacted as described above for 4. A white precipitate began to form shortly after the addition of DMSA. The product was collected via vacuum filtration, washed with cold ethanol and cold diethyl ether, and dried in

vacuo. Yield: $68 \%, 109.6 \mathrm{mg} .{ }^{1} \mathrm{H}$ NMR $\left(\mathrm{D}_{2} \mathrm{O} ; 500 \mathrm{MHz}\right) \delta \mathrm{ppm}: 4.41(\mathrm{~s}, 2 \mathrm{H}, \mathrm{SCH}), 6.78(\mathrm{~d}$, $2 \mathrm{H}, \mathrm{ArH}), 7.49(\mathrm{~d}, 2 \mathrm{H}, \mathrm{ArH}) .{ }^{13} \mathrm{C} \mathrm{NMR}\left(\mathrm{CD}_{3} \mathrm{OD}+\mathrm{D}_{2} \mathrm{O} ; 125.8 \mathrm{MHz}\right) \delta$ ppm: 64.82 
(SCHCOOH), 116.77 (ArC), $132.06(\operatorname{ArC}), 133.0(\operatorname{ArC}), 149.43(\mathrm{ArC}), 176.85(\mathbf{C O O H})$. ESI/APCI MS $(m / z): 345.72$ (345.92 calcd for $\left.\left[\mathrm{C}_{8} \mathrm{H}_{10} \mathrm{NS}_{2} \mathrm{As}\right][\mathrm{M}-\mathrm{H}]^{-}\right)$. Elem. Anal. Calcd (found) for $\mathrm{C}_{10} \mathrm{H}_{16} \mathrm{~N}_{3} \mathrm{O}_{4} \mathrm{~S}_{2} \mathrm{As}$ : C, 31.50 (31.39); $\mathrm{H}, 4.23$ (4.09); N, 11.02 (10.03); S, 16.82 (17.42).

4-(1,3,2-Dithiaarsinan-2-yl)aniline [ $\left.\mathrm{NH}_{2} \mathrm{C}_{6} \mathrm{H}_{4} \mathrm{As}\left(\mathrm{SCH}_{2} \mathrm{CH}_{2} \mathrm{CH}_{2} \mathrm{~S}\right)\right]$, 6. p-Arsanilic acid (101.4 mg, $0.467 \mathrm{mmol}$ ), 5.5 M ammonium mercaptoacetate (419 $\mu \mathrm{L}, 2.30 \mathrm{mmol})$ and 1,3propane dithiol ( $49.7 \mathrm{mg}, 46 \mu \mathrm{L}, 0.46 \mathrm{mmol})$ in ethanol $(95 \% ; 20 \mathrm{~mL}$ ) were reacted and isolated as described above for 4 . X-ray quality crystals were obtained by slow evaporation from methanol. Yield: 80\%, $100.6 \mathrm{mg} .{ }^{1} \mathrm{H}$ NMR $\left(\mathrm{CDCl}_{3} ; 500 \mathrm{MHz}\right) \delta \mathrm{ppm}: 1.93(\mathrm{~m}, 1 \mathrm{H}$, $\left.\mathbf{C H}_{2}\right), 2.14\left(\mathrm{~m}, 1 \mathrm{H}, \mathbf{C} \mathbf{H}_{2}\right), 2.72\left(\mathrm{~m}, 2 \mathrm{H}, \mathbf{S C H} \mathbf{H}_{2}\right), 2.90\left(\mathrm{~m}, 2 \mathrm{H}, \mathbf{S C H} \mathbf{H}_{2}\right), 6.78(\mathrm{~d}, 2 \mathrm{H}, \mathrm{ArH}), 7.65$ $(\mathrm{d}, 2 \mathrm{H}, \mathrm{ArH}) .{ }^{13} \mathrm{C} \mathrm{NMR}\left(\mathrm{CDCl}_{3} ; 125.8 \mathrm{MHz}\right) \delta \mathrm{ppm}: 26.57\left(\mathrm{SCH}_{2} \mathrm{CH}_{2}\right), 28.84\left(\mathrm{SCH}_{2}\right)$, 115.78 (ArC), 125.85 (ArC), 133.93 (ArC), 147.65 (ArC). ESI/APCI MS (m/z): 314.58 (315.00 calcd for $\left[\mathrm{C}_{11} \mathrm{H}_{15} \mathrm{~N}_{2} \mathrm{~S}_{2} \mathrm{As}\right]\left[\mathrm{M}+\mathrm{CH}_{3} \mathrm{CN}+\mathrm{H}\right]^{+}$). Elem. Anal. Calcd (found) for $\left[\mathrm{C}_{9} \mathrm{H}_{12} \mathrm{NS}_{2} \mathrm{As}: \mathrm{C}, 39.56\right.$ (38.80); H, 4.43 (4.33); N, 5.13 (4.94); S, 23.47 (23.05).

2-Phenyl-1,3,2-dithiaarsolane $\left[\mathrm{C}_{6} \mathrm{H}_{5} \mathrm{As}\left(\mathrm{SCH}_{2} \mathrm{CH}_{2} \mathrm{~S}\right)\right]$, 7.[52] Phenyl arsonic acid (101.0 mg, $0.5 \mathrm{mmol}), 5.5 \mathrm{M}$ ammonium mercaptoacetate $(2.48 \mathrm{mmol}, 450 \mu \mathrm{L})$ and 1,2-ethane dithiol (46.6 mg, $41.7 \mu \mathrm{L}, 0.495 \mathrm{mmol})$ in ethanol $(95 \%, 20 \mathrm{~mL}$ ) were reacted and isolated as above for 4. The desired product, a white solid, was collected via vacuum filtration, washed with water, and dried in vacuo. X-ray quality crystals were obtained by slow evaporation from methanol. Yield: 53\%, $64.1 \mathrm{mg} .{ }^{1} \mathrm{H} \mathrm{NMR}\left(\mathrm{CDCl}_{3} ; 500 \mathrm{MHz}\right) \delta \mathrm{ppm}: 3.17\left(\mathrm{~m}, 2 \mathrm{H}, \mathrm{SCH}_{2}\right)$, $3.37\left(\mathrm{~m}, 2 \mathrm{H}, \mathrm{SCH}_{2}\right), 7.31(\mathrm{t}, 1 \mathrm{H}, p-\operatorname{ArH}), 7.36(\mathrm{t}, 2 \mathrm{H}, \mathrm{ArH}), 7.65(\mathrm{~d}, 2 \mathrm{H}, \mathrm{ArH}) .{ }^{13} \mathrm{C} N M R$ $\left(\mathrm{CDCl}_{3} ; 125.8 \mathrm{MHz}\right) \delta$ ppm: $41.97\left(\mathrm{SCH}_{2}\right), 128.57$ (ArC), 129.18 (ArC), $130.74(\mathrm{ArC})$, 


\section{Yutian Feng}

143.80 (ArC). ESI/APCI MS ( $/ 2 / z)$ : $261.05\left(260.94\right.$ calcd for $\left.\left[\mathrm{C}_{8} \mathrm{H}_{10} \mathrm{~S}_{2} \mathrm{AsO}\right][\mathrm{M}+\mathrm{OH}]^{+}\right)$.

Elem. Anal. Calcd (found) for $\mathrm{C}_{8} \mathrm{H}_{9} \mathrm{~S}_{2} \mathrm{As}$ : C, 39.35 (39.56); H, 3.71 (3.73); S, 26.26 (26.39).

2-Phenyl-1,3,2-dithiaarsolane-4,5-dicarboxylic acid,

$\left(\mathrm{NH}_{4}\right)_{2}\left[\mathrm{C}_{6} \mathrm{H}_{5} \mathrm{As}(\mathrm{SCH}(\mathrm{COO}) \mathrm{CH}(\mathrm{COO}) \mathrm{S})\right], 8$. [52] Phenyl arsonic acid (101.2 mg, $\left.0.5 \mathrm{mmol}\right)$,

5.5 M ammonium mercaptoacetate (2.48 mmol, $450 \mu \mathrm{L})$, and dimercaptosuccinic acid (89.8

$\mathrm{mg}, 0.493 \mathrm{mmol})$ in ethanol $(95 \%, 20 \mathrm{~mL})$ were reacted as described above for 4 . Water was not needed to initiate precipitation and thus was not added. The product was collected as a white solid by vacuum filtration, washed with cold acetone, and dried in vacuo. X-ray quality crystals were obtained by slow evaporation from a mixture of water and acetone. Yield: 78\%, $127.8 \mathrm{mg} .{ }^{1} \mathrm{H}$ NMR $\left(\mathrm{D}_{2} \mathrm{O} ; 500 \mathrm{MHz}\right) \delta \mathrm{ppm}: 4.15$ (s, 2H, SCH), 7.44 (t, $1 \mathrm{H}, p-$ $\operatorname{ArH}), 7.49(\mathrm{~d}, 2 \mathrm{H}, \mathrm{ArH}), 7.84(\mathrm{~d}, 2 \mathrm{H}, \mathrm{ArH}) .{ }^{13} \mathrm{C} \mathrm{NMR}\left(\mathrm{CD}_{3} \mathrm{OD}+\mathrm{D}_{2} \mathrm{O} ; 125.8 \mathrm{MHz}\right) \delta \mathrm{ppm}:$ $64.80(\mathrm{SCH}), 129.53(\mathrm{ArC}), 130.06(\mathrm{ArC}), 131.69(\mathrm{ArC}), 144.53(\mathrm{ArC}), 176.42(\mathbf{C O O H})$. ESI/APCI MS ( $\mathrm{m} / \mathrm{z}$ ): 331.25 (330.92 calcd for $\left[\mathrm{C}_{10} \mathrm{H}_{9} \mathrm{O}_{4} \mathrm{~S}_{2} \mathrm{As}\right][\mathrm{M}-\mathrm{H}]$ ). Elem. Anal. Calcd (found) for $\mathrm{C}_{10} \mathrm{H}_{15} \mathrm{~N}_{2} \mathrm{O}_{4} \mathrm{~S}_{2} \mathrm{As}$ : C, 32.79 (32.67); $\mathrm{H}, 4.13$ (4.11); N, 7.65 (7.27); $\mathrm{S}, 17.51$ (18.20).

2-Phenyl-1,3,2-dithiaarsinane $\left[\mathrm{C}_{6} \mathrm{H}_{5} \mathrm{As}\left(\mathrm{SCH}_{2} \mathrm{CH}_{2} \mathrm{CH}_{2} \mathrm{~S}\right)\right]$, 9. [52] Phenyl arsonic acid (99.8 $\mathrm{mg}, 0.494 \mathrm{mmol}), 5.5 \mathrm{M}$ ammonium mercaptoacetate $(2.48 \mathrm{mmol}, 450 \mu \mathrm{L})$, and 1,3-propane dithiol $(53.6 \mathrm{mg}, 49.7 \mu \mathrm{L}, 0.495 \mathrm{mmol})$ in ethanol $(95 \%, 20 \mathrm{~mL})$ were reacted as above for 4 . Following the water addition, ethanol was removed by rotary evaporation to facilitate precipitation of the product, and the reaction mixture was placed in the freezer $\left(-15^{\circ} \mathrm{C}\right)$ for an hour. The product, a white solid, was isolated via vacuum filtration, washed with water, and dried in vacuo. X-ray quality crystals were obtained by slow evaporation from methanol. Yield: 45\%, $57.5 \mathrm{mg} .{ }^{1} \mathrm{H}$ NMR $\left(\mathrm{CDCl}_{3} ; 500 \mathrm{MHz}\right) \delta \mathrm{ppm}: 1.94\left(\mathrm{~m}, 1 \mathrm{H}, \mathrm{CH}_{2}\right), 2.17(\mathrm{~m}, 1 \mathrm{H}$, 


\section{Yutian Feng}

$\left.\mathrm{CH}_{2}\right), 2.69\left(\mathrm{~m}, 2 \mathrm{H} \mathrm{SCH} \mathbf{H}_{2}\right), 2.84\left(\mathrm{~m}, 2 \mathrm{H}, \mathbf{S C} \mathbf{H}_{2}\right), 7.40(\mathrm{t}, 1 \mathrm{H}, p-\operatorname{ArH}), 7.49(\mathrm{t}, 2 \mathrm{H}, \mathrm{ArH}), 7.91$

$(\mathrm{d}, 2 \mathrm{H}, \mathrm{ArH}) .{ }^{13} \mathrm{C}$ NMR $\left(\mathrm{CDCl}_{3} ; 125.8 \mathrm{MHz}\right) \delta \mathrm{ppm}: 26.11\left(\mathrm{SCH}_{2} \mathrm{CH}_{2}\right), 28.49\left(\mathrm{SCH}_{2}\right)$, 129.16 (ArC), $129.36(\operatorname{ArC}), 132.56(\operatorname{ArC}), 138.73$ (ArC). ESI/APCI MS $(m / z): 275.02$ (274.95 calcd for $\left[\mathrm{C}_{9} \mathrm{H}_{12} \mathrm{~S}_{2} \mathrm{AsO}\right][\mathrm{M}+\mathrm{OH}]^{+}$). Elem. Anal. Calcd (found) for $\mathrm{C}_{9} \mathrm{H}_{11} \mathrm{~S}_{2} \mathrm{As}$ : C, 41.86 (41.62); H, 4.29 (4.09).

2-(4-Nitrophenyl)-1,3,2-dithiaarsolane [ $\left.\mathrm{NO}_{2} \mathrm{C}_{6} \mathrm{H}_{4} \mathrm{As}\left(\mathrm{SCH}_{2} \mathrm{CH}_{2} \mathrm{~S}\right)\right]$, 10. p-Nitro phenyl arsonic acid (102 mg, $0.411 \mathrm{mmol}), 5.5 \mathrm{M}$ ammonium mercaptoacetate $(2.02 \mathrm{mmol}, 368 \mu \mathrm{L})$, and 1,2-ethane dithiol (38.1 mg, $34.0 \mu \mathrm{L}, 0.411 \mathrm{mmol})$ in $\mathrm{H}_{2} \mathrm{O} / \mathrm{EtOH}(1: 1 ; 10 \mathrm{~mL})$ were reacted as described above for $\mathbf{4}$. The reaction mixture was removed from heat and 1,2ethane dithiol in a 50/50 mix of ethanol and acetone ( $10 \mathrm{~mL}$ total) was added. After stirring for 30 minutes, organic solvents were removed via vacuum distillation and cooled to give the crude product as a light yellow precipitate. The solids were isolated via vacuum filtration, washed with cold water, and dried in vacuo to give the pure product. X-ray quality crystals were obtained by slow evaporation from methanol. Yield: 69\%, $91.8 \mathrm{mg} .{ }^{1} \mathrm{H} \mathrm{NMR}\left(\mathrm{CDCl}_{3}\right.$; $500 \mathrm{MHz}) \delta$ ppm: $3.11\left(\mathrm{~m}, 2 \mathrm{H}, \mathrm{SCH} \mathbf{H}_{2}\right), 3.42\left(\mathrm{~m}, 2 \mathrm{H}, \mathrm{SCH}_{2}\right), 7.85(\mathrm{~d}, 2 \mathrm{H}, \operatorname{ArH}), 8.17(\mathrm{~d}, 2 \mathrm{H}$, ArH). ${ }^{13} \mathrm{C} \mathrm{NMR}\left(\mathrm{CDCl}_{3} ; 125.8 \mathrm{MHz}\right) \delta \mathrm{ppm}: 42.42\left(\mathrm{SCH}_{2}\right), 123.09$ (ArC), $131.81(\mathrm{ArC})$, 148.43 (ArC), $153.31(\mathrm{ArC})$. ESI/APCI MS $(\mathrm{m} / \mathrm{z}): 287.93$ (287.91 calcd for $\left[\mathrm{C}_{8} \mathrm{H}_{8} \mathrm{NO}_{2} \mathrm{~S}_{2} \mathrm{As}\right]$ [M-H]'). Elem. Anal. Calcd (found) for $\mathrm{C}_{8} \mathrm{H}_{8} \mathrm{NO}_{2} \mathrm{~S}_{2} \mathrm{As}: \mathrm{C}, 33.22$ (33.49); H, 2.79 (2.69); N, 4.84 (4.75); S, 22.17 (22.43).

2-(4-Nitrophenyl)-1,3,2-dithiaarsolane-4,5-dicarboxylic acid, $\left(\mathrm{NH}_{4}\right)_{2}\left[\mathrm{NO}_{2} \mathrm{C}_{6} \mathrm{H}_{4} \mathrm{As}(\mathrm{SCH}(\mathrm{COO}) \mathrm{CH}(\mathrm{COO}) \mathrm{S})\right], 11$. [52] $p$-Nitro phenyl arsonic acid (100 mg, $0.405 \mathrm{mmol}), 5.5 \mathrm{M}$ ammonium mercaptoacetate $(368 \mu \mathrm{L}, 2.02 \mathrm{mmol})$, and dimercaptosuccinic acid (74.4 mg, $0.408 \mathrm{mmol})$ in EtOH/acetone $(1: 1 ; 10 \mathrm{~mL})$ and $\mathrm{H}_{2} \mathrm{O}(1$ 


\section{Yutian Feng}

\section{Chapter 3}

$\mathrm{mL}$ ) were reacted as above for $\mathbf{4}$. A light yellow precipitate began to form shortly after the addition of DMSA. After 30 minutes, acetone $(5 \mathrm{~mL})$ was added to further precipitate the product. The reaction mixture was cooled to, $-15{ }^{\circ} \mathrm{C}$, and filtered via vacuum filtration. The solids were washed with acetone, diethyl ether, and dried in vacuo to obtain the product.

Yield: 71\%, $108.3 \mathrm{mg} .{ }^{1} \mathrm{H} \mathrm{NMR}\left(\mathrm{D}_{2} \mathrm{O} / \mathrm{CD}_{3} \mathrm{OD} ; 500 \mathrm{MHz}\right) \delta \mathrm{ppm}: 4.31$ (s, 2H, SCH), 8.04 $(\mathrm{d}, 2 \mathrm{H}, \mathrm{ArH}), 8.22(\mathrm{~d}, 2 \mathrm{H}, \mathrm{ArH}) .{ }^{13} \mathrm{C} \mathrm{NMR}\left(\mathrm{CD}_{3} \mathrm{OD}+\mathrm{D}_{2} \mathrm{O} ; 125.8 \mathrm{MHz}\right) \delta \mathrm{ppm}: 65.51$ (SCH), 123.79 (ArC), 133.16 (ArC), 149.46 (ArC), 155.19 (ArC), 176.19 (COOH). ESI/APCI MS (m/z): 375.72 (375.89 calcd for $\left.\left.\left[\mathrm{C}_{10} \mathrm{H}_{8} \mathrm{NO}_{6} \mathrm{~S}_{2} \mathrm{As}\right][\mathrm{M}-\mathrm{H}]\right]^{-}\right)$. Elem. Anal. Calcd (found) for $\mathrm{C}_{10} \mathrm{H}_{14} \mathrm{~N}_{3} \mathrm{O}_{6} \mathrm{~S}_{2} \mathrm{As} \cdot \mathrm{CH}_{3} \mathrm{CH}_{2} \mathrm{OH}$ : C, 31.51 (31.34); H, 4.41 (4.27); N, 9.19 (9.04); S, $14.02(14.54)$.

2-(4-Nitrophenyl)-1,3,2-dithiaarsinane [ $\left.\mathrm{NO}_{2} \mathrm{C}_{6} \mathrm{H}_{4} \mathrm{As}\left(\mathrm{SCH}_{2} \mathrm{CH}_{2} \mathrm{CH}_{2} \mathrm{~S}\right)\right]$, 12. [52] p-Nitro phenyl arsonic acid (103.7 mg, $0.402 \mathrm{mmol}), 5.5 \mathrm{M}$ ammonium mercaptoacetate (2.02 mmol, $368 \mu \mathrm{L})$ and 1,3-propane dithiol (43.8 $\mathrm{mg}, 40.7 \mu \mathrm{L}, 0.405 \mathrm{mmol})$ in ethanol $(95 \%, 20 \mathrm{~mL})$ were reacted as above for 4 . The product, a light yellow solid, precipitated upon removal of the ethanol by rotary evaporation. The solids were collected by vacuum filtration, washed with water, and dried in vacuo. X-ray quality crystals were obtained by slow evaporation from a 50/50 mixture of chloroform and acetonitrile. Yield: $66 \%, 80.5 \mathrm{mg} .{ }^{1} \mathrm{H} \mathrm{NMR}\left(\mathrm{CDCl}_{3}\right.$ $\left.\mathrm{d}_{1} ; 500 \mathrm{MHz}\right) \delta$ ppm: $1.97\left(\mathrm{~m}, 1 \mathrm{H}, \mathbf{C H}_{2}\right), 2.18\left(\mathrm{~m}, 1 \mathrm{H}, \mathbf{C H}_{2}\right), 2.72(\mathrm{~m}, 4 \mathrm{H}, \mathrm{SCH}), 8.13(\mathrm{~d}$, $2 \mathrm{H}, \mathrm{ArH}), 8.21(\mathrm{~d}, 2 \mathrm{H}, \mathrm{ArH}) .{ }^{13} \mathrm{C}$ NMR $\left(\mathrm{CDCl}_{3} \mathrm{~d}_{1} ; 125.8 \mathrm{MHz}\right) \delta \mathrm{ppm}: 25.84\left(\mathbf{C H}_{2}\right), 27.77$ $\left(\mathrm{SCH}_{2}\right), 123.87$ (ArC), 133.66 (ArC), 148.65 (ArC), 148.49 (ArC). ESI/APCI MS ( $\left.m / z\right)$ : 302.69 (302.94 calcd for $\left.\left[\mathrm{C}_{9} \mathrm{H}_{10} \mathrm{NO}_{2} \mathrm{~S}_{2} \mathrm{As}\right]\left[\mathrm{M}^{+*}\right]\right)$. Elem. Anal. Calcd (found) for $\mathrm{C}_{9} \mathrm{H}_{10} \mathrm{NO}_{2} \mathrm{~S}_{2} \mathrm{As}: \mathrm{C}, 35.65$ (35.57); H, 3.32 (3.32); N, 4.62 (4.52); S, 21.15 (21.26). 
No carrier added radiotracer synthesis. The translation of the synthesis to nca ${ }^{77}$ As was accomplished using $\left[{ }^{77} \mathrm{As}\right]$ arsenate as a starting material. The synthesis is described in Scheme 3.4.
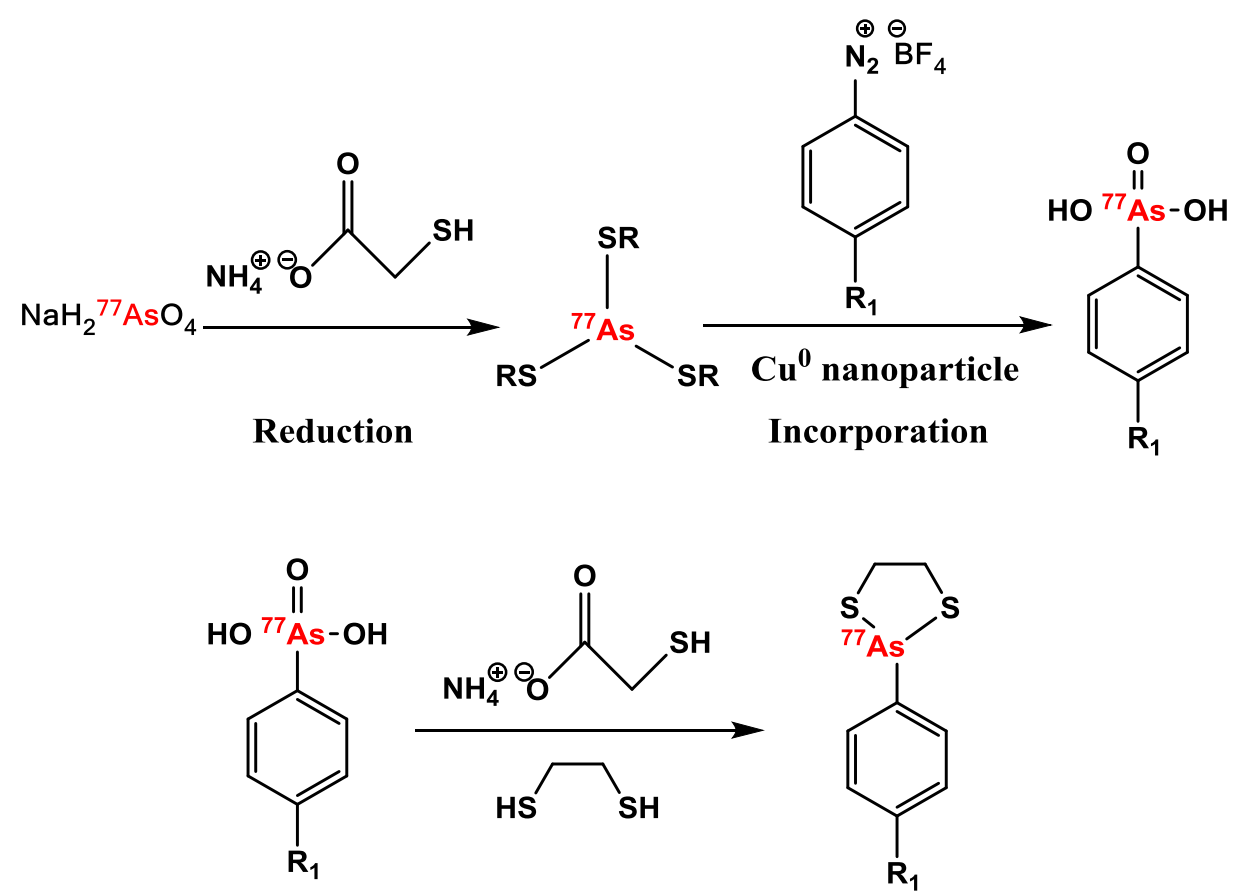

Complexation

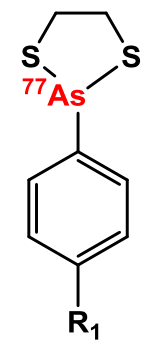

$$
\begin{aligned}
& \mathbf{R}=-\mathrm{SCH}_{2} \mathrm{COONH}_{4} \\
& \mathbf{R}_{\mathbf{1}}=-\mathrm{OEt}
\end{aligned}
$$

Scheme 3.4. The synthesis of the nca ${ }^{77}$ As 2-(4-ethoxyphenyl)-1,3,2-dithiaarsolane.

\section{Synthesis of No Carrier added ${ }^{77}$ As 2-(4-ethoxyphenyl)-1,3,2-dithiaarsolane}

$\left[\mathrm{CH}_{3} \mathrm{CH}_{2} \mathrm{OC}_{6} \mathrm{H}_{4}{ }^{77} \mathrm{As}\left(\mathrm{SCH}_{2} \mathrm{CH}_{2} \mathrm{~S}\right)\right],\left[{ }^{77} \mathrm{As}\right]$, 1. [ $\left.{ }^{77} \mathrm{As}\right]$ 2-(4-ethoxyphenyl)-1,3,2-dithiaarsolane was synthesized at the nca radiotracer level from $\left[{ }^{77}\right.$ As]arsenate, by optimizing the amounts of reducing agent (mercaptoacetate, $1-550 \mathrm{mM}$ ), aryldiazonium salt ( $p$ -

ethoxybenzenediazaonium tetrafluoroborate, 20-85 mM), dithiol (1,2-ethanedithiol, 9.8-100 $\mathrm{mM}$ ), $\mathrm{Cu}$ catalyst (polished $\mathrm{Cu}$ (pieces ( $5 \mathrm{~mm} \times 5 \mathrm{~mm} \times 2 \mathrm{~mm}$ ) or $\mathrm{Cu}$ nanoparticles), solvent (ethanol, acetonitrile), temperature and time. Each parameter was optimized independently 


\section{Yutian Feng}

and then the final formulation was fine-tuned. The optimal synthesis is as follows: Acetonitrile $(650 \mu \mathrm{L})$ was added to a screw cap vial containing $250 \mu \mathrm{L}$ of the aqueous nca ${ }^{77}$ As stock solution $\left(38.9 \mathrm{MBq}, 1.05 \mathrm{mCi}, 1.3 \times 10^{-11} \mathrm{~mol}, \sim 1 \mathrm{ng}\right.$ (mass calculated based on activity only) followed by addition of ammonium mercaptoacetate (50 $\mu \mathrm{L}$ of $500 \mathrm{mM})$ while stirring in a $60^{\circ} \mathrm{C}$ water bath. After $30 \mathrm{~min}$, a $10 \mu \mathrm{L}$ aliquot of $\mathrm{Cu}^{0}$ nanoparticle solution (100 $\mathrm{mg} / \mathrm{mL}$ in acetone) was added, followed by $100 \mu \mathrm{L}$ of $p$-ethoxybenzenediazonium tetrafluoroborate $(0.1 \mathrm{mg} / \mu \mathrm{L})$ in acetonitrile. The reaction mixture was removed from the water bath and stirred at room temperature for $45 \mathrm{~min}$. Ammonium mercaptoacetate $(100 \mu \mathrm{L}$ of $5.5 \mathrm{M})$ was added and the reaction mixture was placed in a $60^{\circ} \mathrm{C}$ water bath $(45 \mathrm{~min})$. Ethanedithiol $(10 \mu \mathrm{L} ; 1.123 \mathrm{~g} / \mathrm{mL})$ was added and the reaction mixture stirred at room temperature for $30 \mathrm{~min}$. Silica gel TLC using 9\% acetone in methanol and radionuclide detection (Bioscan AR-2000) was used to determine yield and follow the progress of the reaction: ${ }^{77} \mathrm{AsO}_{4}{ }^{3-}(\mathrm{V}), \mathrm{R}_{\mathrm{f}}=0 ;{ }^{77} \mathrm{As}(\text { mercaptoacetate })_{3}, \mathrm{R}_{\mathrm{f}}=0.64 ;\left[\mathrm{Ass}^{77}\right] p-$ ethoxyphenylars onic acid, $\mathrm{R}_{\mathrm{f}}=0.24$; (2-(4-ethoxyphenyl) $)-{ }^{77} \mathrm{As}(\text { mercaptoacetate })_{2}, \mathrm{R}_{\mathrm{f}}=0.44$; $\left[{ }^{77} \mathrm{As}\right] p$-ethoxyphenyl-1,2-ethanedithioarsine, $\mathrm{R}_{\mathrm{f}}=0.72 .\left[{ }^{77} \mathrm{As}\right] p$-ethoxyphenyl-1,2ethanedithioarsine was analyzed by an additional radioTLC method (silica gel, 50/50 $\mathrm{CHCl}_{3} / \mathrm{CH}_{2} \mathrm{Cl}_{2}$ ): $\mathrm{R}_{\mathrm{f}}=0.93$; no other species migrated from the origin. The radiochemical yield of $\left[{ }^{77} \mathrm{As}\right] p$-ethoxyphenyl-1,2-ethanedithioarsine was determined to be $95 \%$ by radioTLC. Reversed phase HPLC comparison of the non-radioactive standard and $\left[{ }^{77} \mathrm{As}\right] p$ ethoxyphenyl-1,2-ethanedithioarsine confirmed that the desired product had been synthesized (both had retention times of $28.35 \mathrm{~min}$ ) in $95 \%$ radiolabeling yield.

Synthesis of No Carrier added ${ }^{72}$ As 2-(4-ethoxyphenyl)-1,3,2-dithiaarsolane $\left[\mathrm{CH}_{3} \mathrm{CH}_{2} \mathrm{OC}_{6} \mathrm{H}_{4}{ }^{77} \mathrm{As}\left(\mathrm{SCH}_{2} \mathrm{CH}_{2} \mathrm{~S}\right)\right],\left[{ }^{72} \mathrm{As}\right], 1$. Eluent from the ${ }^{72} \mathrm{Se} /{ }^{72}$ As generator was boiled 


\section{Yutian Feng}

to dryness and reconstituted with $500 \mu \mathrm{L}$ of DI water $(0.17 \mathrm{MBq}, 4.6 \mu \mathrm{Ci}$ in $500 \mu \mathrm{L})$ as the ${ }^{72}$ As stock solution (the production of nca ${ }^{72}$ As was discussed in Chapter 2). Acetonitrile $(650 \mu \mathrm{L})$ was added to a screw cap vial containing $250 \mu \mathrm{L}$ of the aqueous nca ${ }^{72}$ As stock solution $\left(0.085 \mathrm{MBq}, 2.3 \mu \mathrm{Ci}, 1.9 \times 10^{-14} \mathrm{~mol}, \sim 1 \mathrm{pg}\right.$ (mass calculated based on activity only) followed by addition of ammonium mercaptoacetate $(50 \mu \mathrm{L}$ of $500 \mathrm{mM})$ while stirring in a $60^{\circ} \mathrm{C}$ water bath. After $30 \mathrm{~min}$, a $10 \mu \mathrm{L}$ aliquot of $\mathrm{Cu}^{0}$ nanoparticle solution $(100 \mathrm{mg} / \mathrm{mL}$ in acetone) was added, followed by $100 \mu \mathrm{L}$ of $p$-ethoxybenzenediazonium tetrafluoroborate $(0.1 \mathrm{mg} / \mu \mathrm{L})$ in acetonitrile. The reaction mixture was removed from the water bath and stirred at room temperature for $45 \mathrm{~min}$. Ammonium mercaptoacetate $(100 \mu \mathrm{L}$ of $5.5 \mathrm{M})$ was added and the reaction mixture was placed in a $60^{\circ} \mathrm{C}$ water bath (45 min). Ethanedithiol (10 $\mu \mathrm{L} ; 1.123 \mathrm{~g} / \mathrm{mL}$ ) was added and the reaction mixture stirred at room temperature for $30 \mathrm{~min}$. Silica gel TLC using 9\% acetone in methanol and radionuclide detection (Bioscan AR-2000) was used to determine the yield and follow the progress of the reaction: ${ }^{72} \mathrm{AsO}_{4}{ }^{3-}(\mathrm{V}), \mathrm{R}_{\mathrm{f}}=0$; ${ }^{72} \mathrm{As}$ (mercaptoacetate $)_{3}, \mathrm{R}_{\mathrm{f}}=0.64 ;\left[\mathrm{As}^{72}\right] p$-ethoxyphenylarsonic acid, $\mathrm{R}_{\mathrm{f}}=0.24 ;(2-(4-$ ethoxyphenyl $)-{ }^{72} \mathrm{As}(\text { mercaptoacetate })_{2}, \mathrm{R}_{\mathrm{f}}=0.44 ;\left[{ }^{72} \mathrm{As}\right] p$-ethoxyphenyl-1,2ethanedithioarsine, $\mathrm{R}_{\mathrm{f}}=0.72 .\left[{ }^{72} \mathrm{As}\right] p$-ethoxyphenyl-1,2-ethanedithioarsine was analyzed by an additional radioTLC method (silica gel, 50/50 $\mathrm{CHCl}_{3} / \mathrm{CH}_{2} \mathrm{Cl}_{2}$ ): $\mathrm{R}_{\mathrm{f}}=0.93$; no other species migrated from the origin. The radiochemical yield of $\left[{ }^{72} \mathrm{As}\right] p$-ethoxyphenyl-1,2ethanedithioarsine was determined to be $80 \%$ by radioTLC.

X-ray Crystal Structures. The crystallographic data of compound 7-9, and 12 were acquired by Dr. Anthony DeGraffenreid and hence reported in his dissertation. [52] Intensity data for compounds $\mathbf{1}$ and $3,4,6-10$ and 12 were obtained at $-100{ }^{\circ} \mathrm{C}$ or $-173{ }^{\circ} \mathrm{C}$ on a Bruker SMART CCD Area Detector system using the $\omega$ scan technique with Mo K $\alpha$ 


\section{Yutian Feng}

radiation from a graphite monochromator. Intensities were corrected for Lorentz and polarization effects. Equivalent reflections were merged, and absorption corrections were made using the multi-scan method. The structures were solved by direct methods with fullmatrix least-squares refinement, using the SHELX package.[55] All non-hydrogen atoms were refined with anisotropic thermal parameters. The hydrogen atoms were placed at calculated positions and included in the refinement using a riding model, with fixed isotropic $U$. Data were corrected for decay and absorption using the program SADABS. [56] The final difference maps contained no features of chemical significance.

\section{Results and Discussion}

Both the Bart and Scheller reactions involve the use an aryldiazonium intermediate, which is then reacted with $\mathrm{As}(\mathrm{III})$ arsenite in the presence of a $\mathrm{Cu}$ catalyst. In the original syntheses, $\mathrm{Cu}$ (II) catalyst was deployed but the reaction was carried out in a copper metal container, which could potentially make $\mathrm{Cu}(\mathrm{I})$. It was unknown which copper species functioned as the catalyst. Phenylarsonic acid was produced in both the Bart and Scheller reactions. The Bechamp reaction took another approach: using an aromatic amine and $\mathrm{As}(\mathrm{V})$ arsenate as starting materials, incorporating aryl-As bond on the para position of the aryl ring was accomplished through heating at high temperature.

The Bart reaction was believed to be a suitable approach for the aryl group incorporation, and a few modifications were applied. In Scheller reaction, $\mathrm{AsCl}_{3}$ was used as a starting material. However, it is important to note that the boiling point of $\mathrm{AsCl}_{3}$ is $130.2{ }^{\circ} \mathrm{C}$, which makes the Scheller reaction impractical when translated to nca ${ }^{77}$ As synthesis due to safety concerns besides the fact that $\mathrm{AsCl}_{3}$ is difficult to produce from $\mathrm{AsO}_{4}{ }^{3-}$. As for the Bechamp reaction, 


\section{Yutian Feng}

since it requires heating at $160{ }^{\circ} \mathrm{C}$ for $4.5 \mathrm{~h}$, it was neither economically favorable because of the time required, nor practical for safety reasons. Modifications were applied because the starting material in the Bart reaction was As(III) arsenite, which would readily be oxidized to $\operatorname{As}(\mathrm{V})$ arsenate at the nca level. A monothiol (ammonium mercaptoacetate) was used to reduce the nca $\left[{ }^{77} \mathrm{As}\right]$ arsenate to the +3 oxidation state. Instead of using a diazonium chloride, a diazonium tetrafluoroborate was used due to its enhanced stability and longer shelf life. Synthesis and Characterization of Dithioarylarsines. Macroscopic standards were required to evaluate the stability of dithioarylarsines in aqueous solutions and identify the yield before the synthesis could be translated to the tracer level. Several dithioarylarsines were synthesized via the reaction in Scheme 3.2 and the ir structures described in Scheme 3.3. Many of the dithioarylarsines were synthesized by Dr. Anthony J. DeGraffenreid and their crystallographic data were acquired by Dr. Charles Barnes and reported.[52] Those dithioarylarsines (compounds $\mathbf{4 - 1 2}$ ) are included in this thesis to better discuss the synthesis and structures of the dithioarylarsines. However, when translated to the tracer level, synthesis of $\left[{ }^{77} \mathrm{As}\right] \mathbf{1}$ was the most successful and optimized to reach high radiochemical yield. Thus the discussion focuses on compounds $\mathbf{1}-\mathbf{3}$.

Commercially available phenylarsonic acids were used as starting materials except for two arylarsonic acids ( $p$-nitro, $p$-ethoxy), which were prepared following a modified procedure from the literature.[51] In the original Bart reaction, the reaction was carried out in copper metal tank while $\mathrm{CuSO}_{4}$ was deployed as a catalyst. In the synthesis of the two arylarsonic acids ( $p$-nitro, $p$-ethoxy), the copper tank was avoided but a piece of polished copper metal was used. $\mathrm{No} \mathrm{Cu}(\mathrm{II})$ catalyst was added. As the first step in the synthesis, ammonium mercaptoacetate was used to reduce and complex the arylarsonic acids to afford the 


\section{Yutian Feng}

intermediate bis(mercaptoacetato)arylarsines. However the separation and characterization of the intermediate was unsuccessful because it decomposed to related arylarsonic acids when separated from the excess of ammonium mercaptoacetate in the aqueous solution.

Electrospray Ionization Mass Spectrometry (ESI-MS) and elemental analyses confirmed the compositions and purities of the various dithioarylarsines.

The ${ }^{1} \mathrm{H}$ NMR spectra of the dithioarylarsines were consistent with literature values (Table 3.1).[50, 57-59] Each of the dithiolate backbone protons displayed unique signals in ${ }^{1} \mathrm{H}$ NMR spectra because of the constraints resulting from binding to arsenic (Figure 3.1), and showed as multiplets. Compared to free dithiols, their chemical shift moved downfield (Table 3.1). The ${ }^{13} \mathrm{C}$ NMR spectra of the dithioarylarsines were consistent with literature values (Table 3.1).[50, 57-59] Similarly, the alkyl $\mathrm{C}$ on the dithiolate backbones displayed a downfield shift because of binding to As. The arylarsine-DMSA complexes exhibited a 22-25 ppm downfield chemical shift relative to DMSA, dependent on the particular arylarsine. Similarly, the ethane dithiol complexes exhibited a downfield ${ }^{13} \mathrm{C}$ shift of $12-14 \mathrm{ppm}$ relative to the free dithiol, while the propane dithiol complexes displayed downfield shifts ranging from 2-4 ppm for the central carbon and upfield shifts of 8-10 ppm for the carbon adjacent to sulfur. 


\section{Yutian Feng}
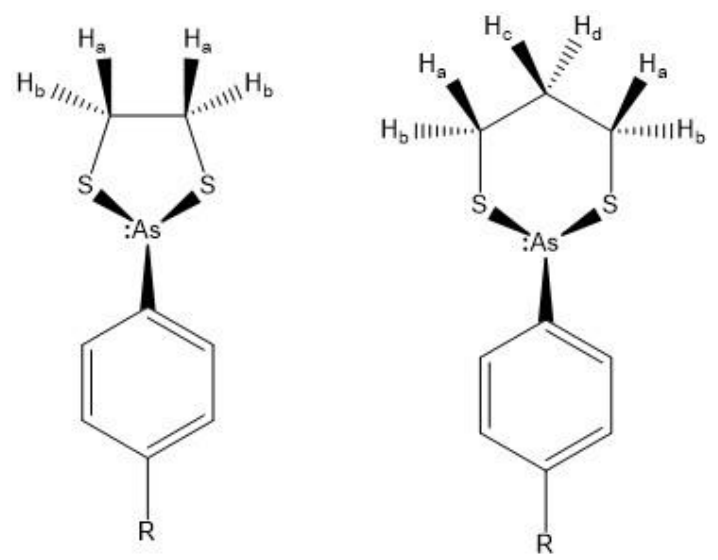

Figure 3.1. Ethane- and propanedithioarylarsines showing the proton assignments from ${ }^{1} \mathrm{H}$ NMR spectrometry. 


\section{Yutian Feng}

Table 3.1. ${ }^{1} \mathrm{H}$ and ${ }^{13} \mathrm{C}$ NMR alkyl dithiol proton and carbon chemical shifts for the aryldithioars ines $(\mathbf{1}-\mathbf{1 2})$ compared to the free ligands. Each methylene proton becomes unique on coordinating to the As(III). The aryl substituent is noted in parentheses following the compound number $(\mathbf{1}-\mathbf{1 2})$.

\begin{tabular}{|c|c|c|c|c|c|}
\hline \multicolumn{3}{|c|}{${ }^{1} \mathrm{H}-\mathrm{NMR}$ Chemical Shifts $(\delta, \mathrm{ppm})$} & \multicolumn{3}{|c|}{${ }^{13} \mathrm{C}-\mathrm{NMR}$ Chemical Shifts $(\delta, \mathrm{ppm})$} \\
\hline & $\mathrm{SCH}_{2}$ & $\mathrm{CH}_{2}$ & & $\mathrm{SCH}_{2}$ & $\mathrm{CH}_{2}$ \\
\hline $\begin{array}{c}1,2- \\
\text { ethanedithiol }\end{array}$ & 2.75 & & 1,2-ethanedithiol & 28.84 & \\
\hline $1(\mathrm{p}-\mathrm{OEt})$ & $3.19,3.35$ & & 1 (p-OEt) & 41.84 & \\
\hline $4\left(\mathrm{p}-\mathrm{NH}_{2}\right)$ & $3.21,3.34$ & & $4\left(\mathrm{p}-\mathrm{NH}_{2}\right)$ & 41.76 & \\
\hline $7(\mathrm{p}-\mathrm{H})$ & $3.17,3.37$ & & $7(\mathrm{p}-\mathrm{H})$ & 41.97 & \\
\hline $10\left(\mathrm{p}-\mathrm{NO}_{2}\right)$ & $3.11,3.42$ & & $10\left(\mathrm{p}-\mathrm{NO}_{2}\right)$ & 42.42 & \\
\hline DMSA & 3.59 & & DMSA & 41.23 & \\
\hline $2(\mathrm{p}-\mathrm{OEt})$ & 4.45 & & $2(p-O E t)$ & 63.33 & \\
\hline $5\left(\mathrm{p}-\mathrm{NH}_{2}\right)$ & 4.41 & & $5\left(\mathrm{p}-\mathrm{NH}_{2}\right)$ & 64.82 & \\
\hline $8(\mathrm{p}-\mathrm{H})$ & 4.15 & & $8(\mathrm{p}-\mathrm{H})$ & 64.80 & \\
\hline $11\left(\mathrm{p}-\mathrm{NO}_{2}\right)$ & 4.31 & & $11\left(\mathrm{p}-\mathrm{NO}_{2}\right)$ & 65.51 & \\
\hline $\begin{array}{c}1,3- \\
\text { propanedithiol }\end{array}$ & 2.68 & 1.91 & 1,3-propanedithiol & 37.43 & 23.00 \\
\hline $3(\mathrm{p}-\mathrm{OEt})$ & $2.71,2.87$ & $2.14,2.17$ & $3(\mathrm{p}-\mathrm{OEt})$ & 28.67 & 26.32 \\
\hline $6\left(\mathrm{p}-\mathrm{NH}_{2}\right)$ & $2.72,2.90$ & $1.92,2.14$ & $6\left(\mathrm{p}-\mathrm{NH}_{2}\right)$ & 28.84 & 26.57 \\
\hline $9(\mathrm{p}-\mathrm{H})$ & $2.69,2.84$ & $1.94,2.17$ & $9(\mathrm{p}-\mathrm{H})$ & 28.49 & 26.11 \\
\hline $12\left(\mathrm{p}-\mathrm{NO}_{2}\right)$ & 2.72 & $1.97,2.18$ & $12\left(\mathrm{p}-\mathrm{NO}_{2}\right)$ & 27.62 & 25.68 \\
\hline
\end{tabular}

Structural Studies: X-ray Crystallography. Compounds 1, 3, 4, 6-10, and 12 were characterized by X-ray crystallography. Crystal refinement data, bond angles and distances are summarized in Tables 3.2 - 3.5. These structures contain either five or six-membered rings on chelation of two sulfurs to the arsenic, resulting in a trigonal pyramidal geometry (Figure 3.2). Comparison of the observed values with literature reports is limited to only two other structures reported, one with British Anti-Lewisite $\left(\mathrm{HSCH}_{2} \mathrm{CH}\left(\mathrm{CH}_{2} \mathrm{OH}\right) \mathrm{SH}, \mathrm{BAL}\right)$ 


\section{Yutian Feng}

\section{Chapter 3}

to form a 5-membered dithioarylarsine chelate ring and one with dihydrolipoic acid to form a 6-membered dithioarylars ine chelate ring. [50, 59]

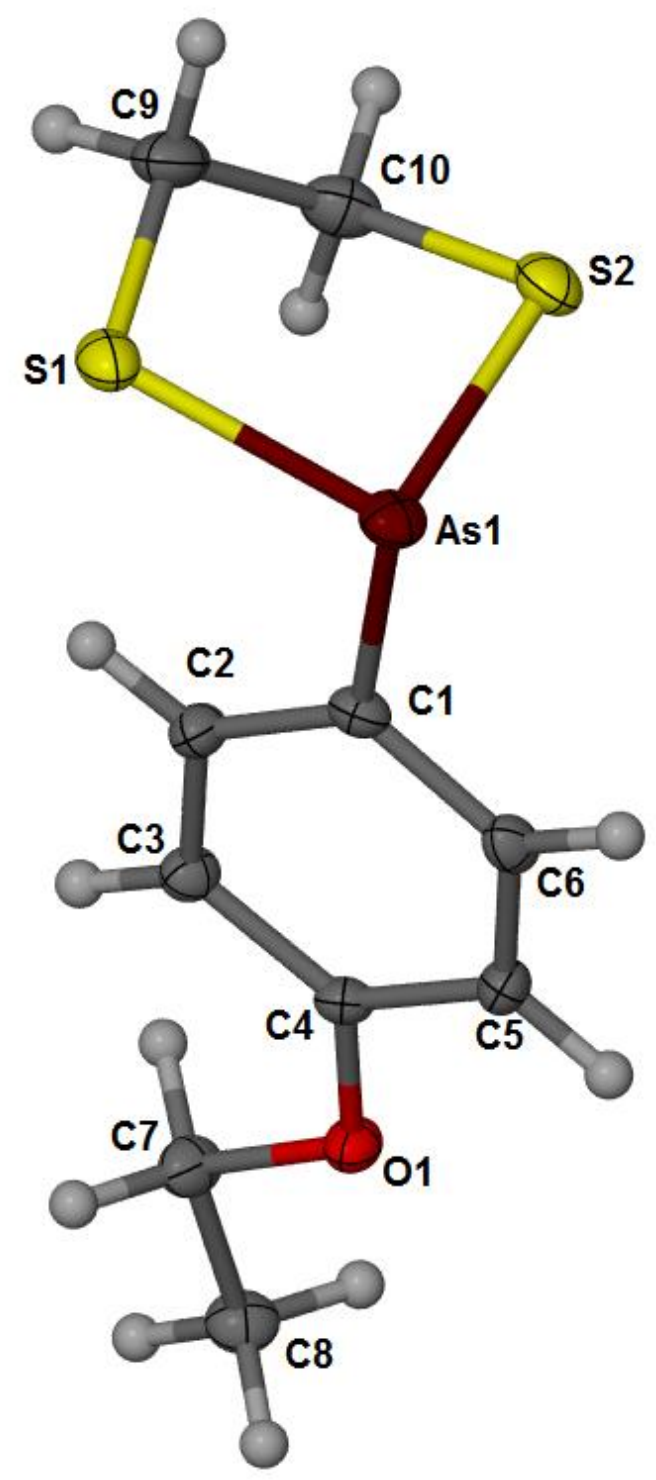

Figure 3.2. ORTEP representation of (1) (CCDC\# 1436768) with 50\% probability ellipsoids. 


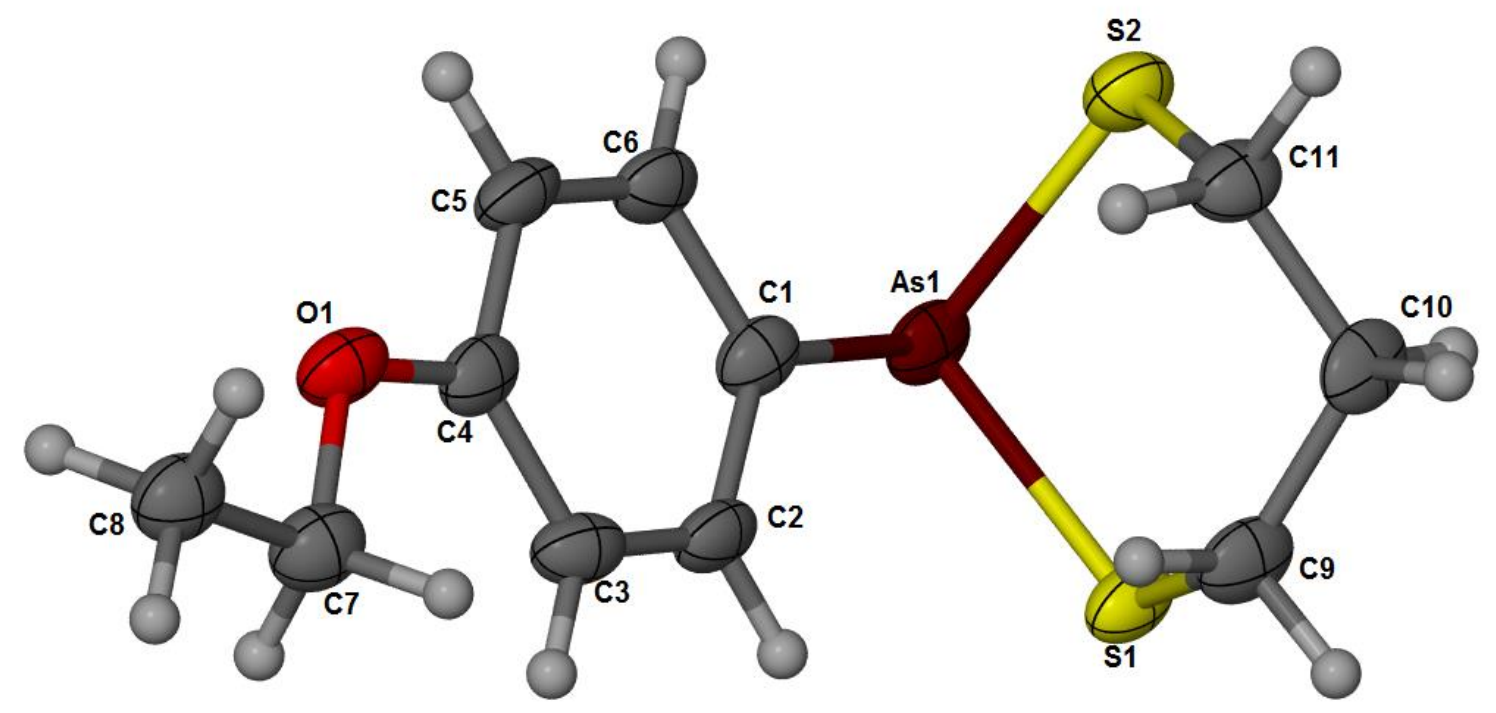

Figure 3.3. ORTEP representation of (3) (CCDC\# 1436769) with 50\% probability ellipsoids.

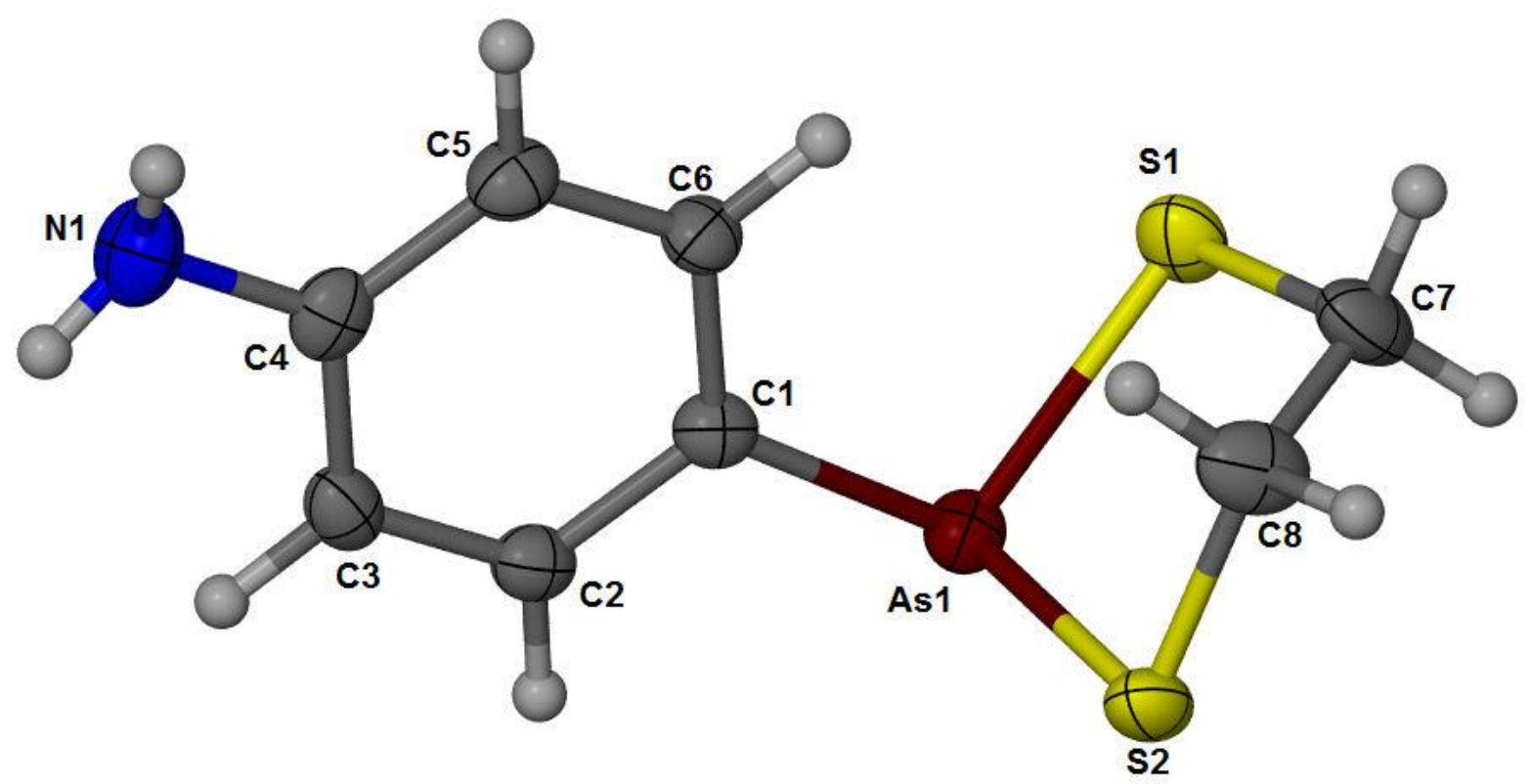

Figure 3.4. ORTEP representation of (4) (CCDC 1436762) with 50\% probability ellipsoids. 


\begin{tabular}{l|l} 
Yutian Feng & Chapter 3 \\
\hline
\end{tabular}

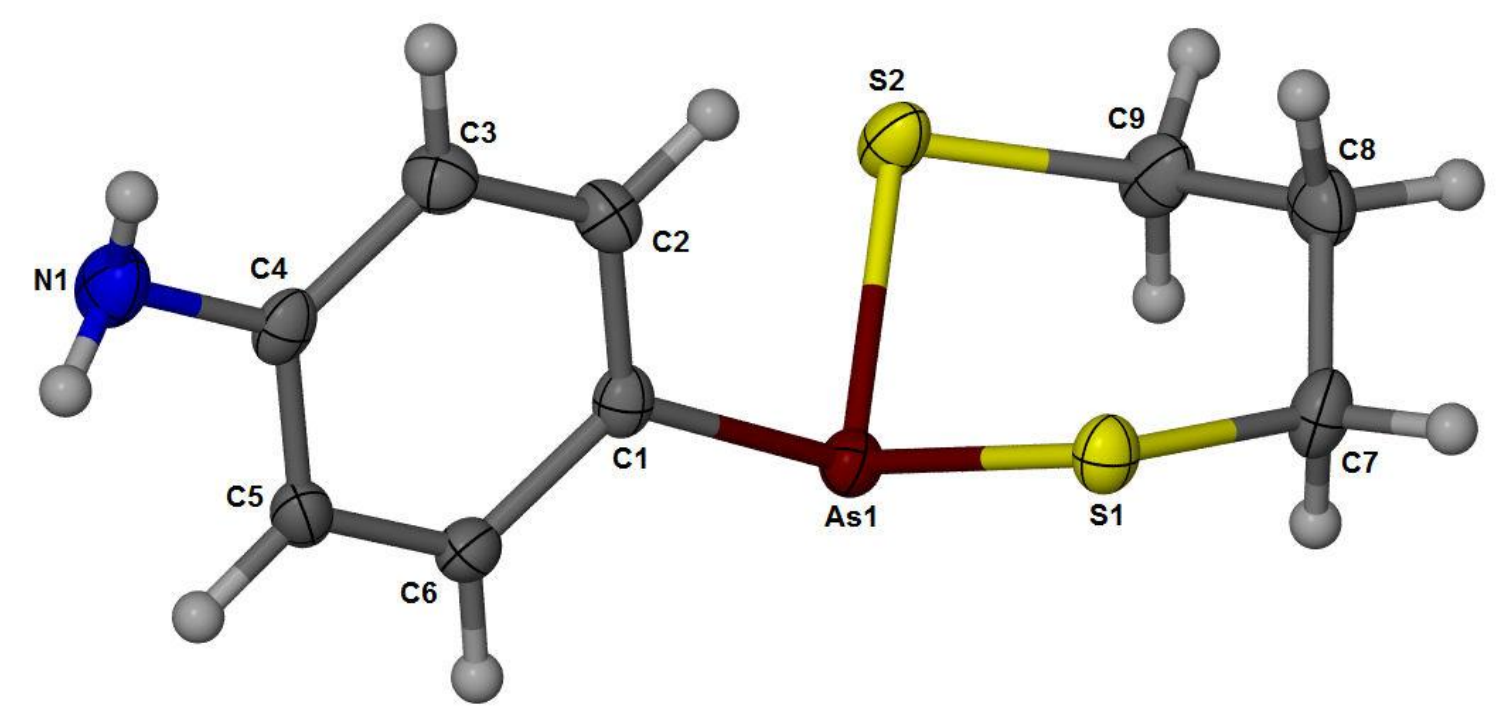

Figure 3.5. ORTEP representation of (6) (CCDC\# 1436763) with 50\% probability ellipsoids.

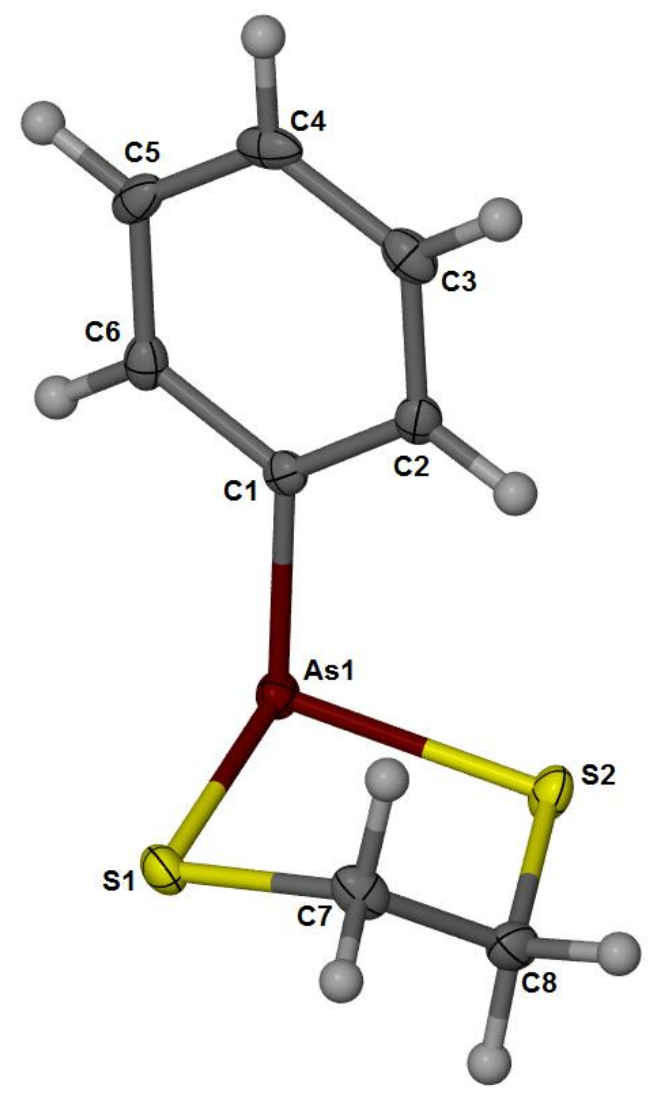

Figure 3.6. ORTEP representation of (7) (CCDC\# 1437260) with 50\% probability ellipsoids.[52] 


Yutian Feng $\quad$ Chapter 3
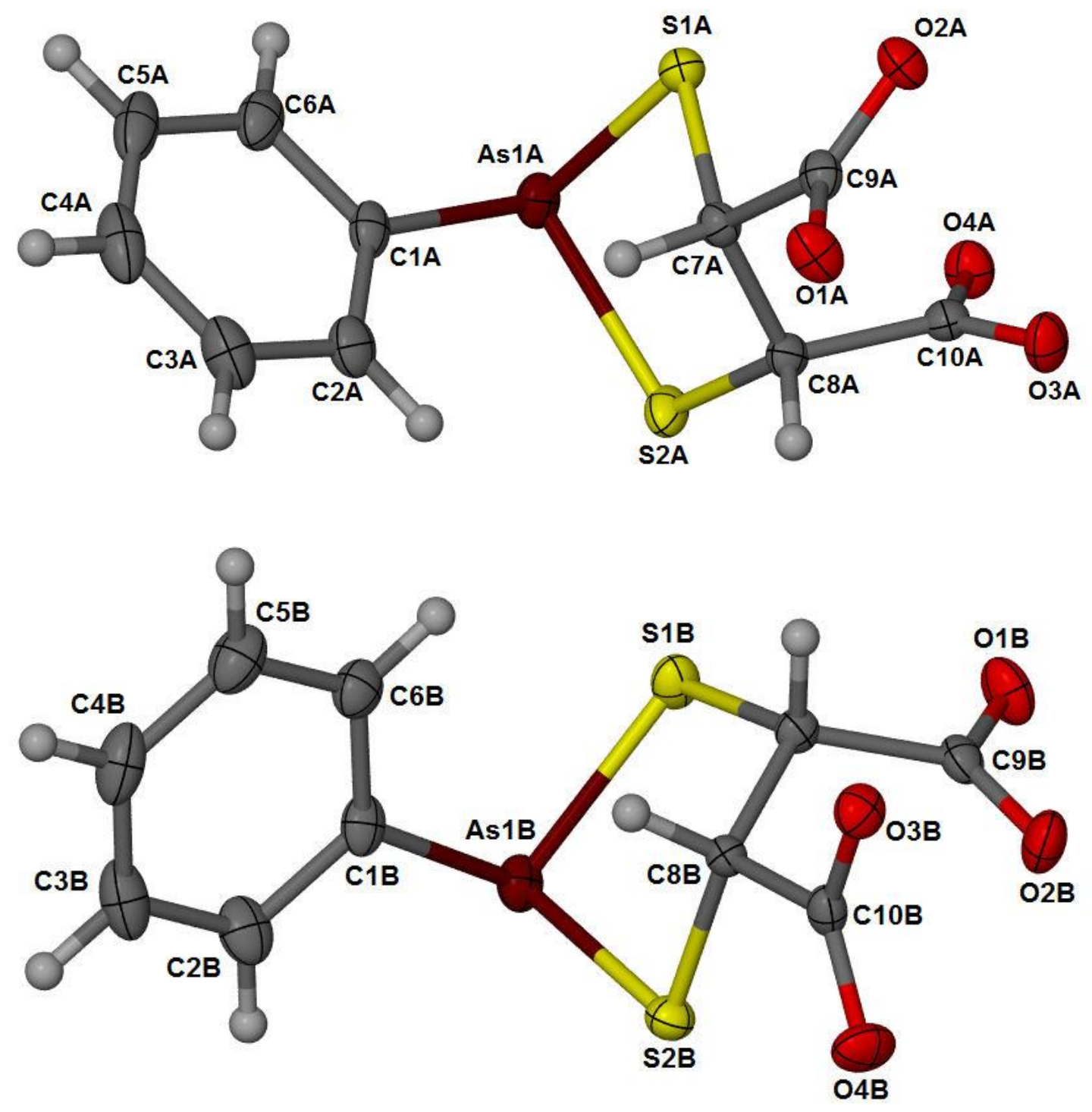

Figure 3.7. ORTEP representations of (8a and $\mathbf{8 b})$, obtained as the diammonium salt (omitted for clarity), (CCDC\# 1436764) with 50\% probability ellipsoids.[52] 

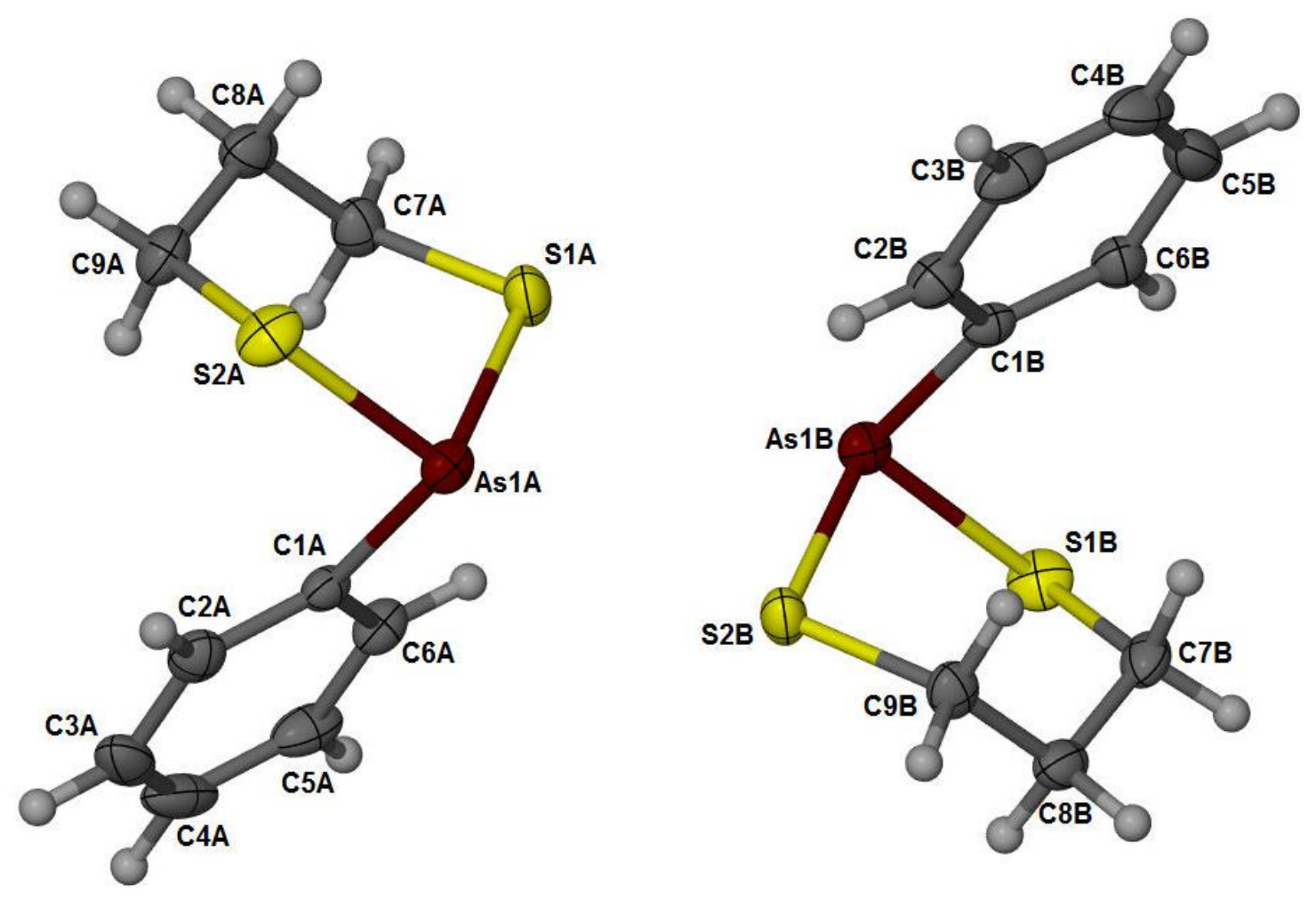

Figure 3.8. ORTEP representation of (9) (CCDC\# 1436765) with 50\% probability ellipsoids.[52] 


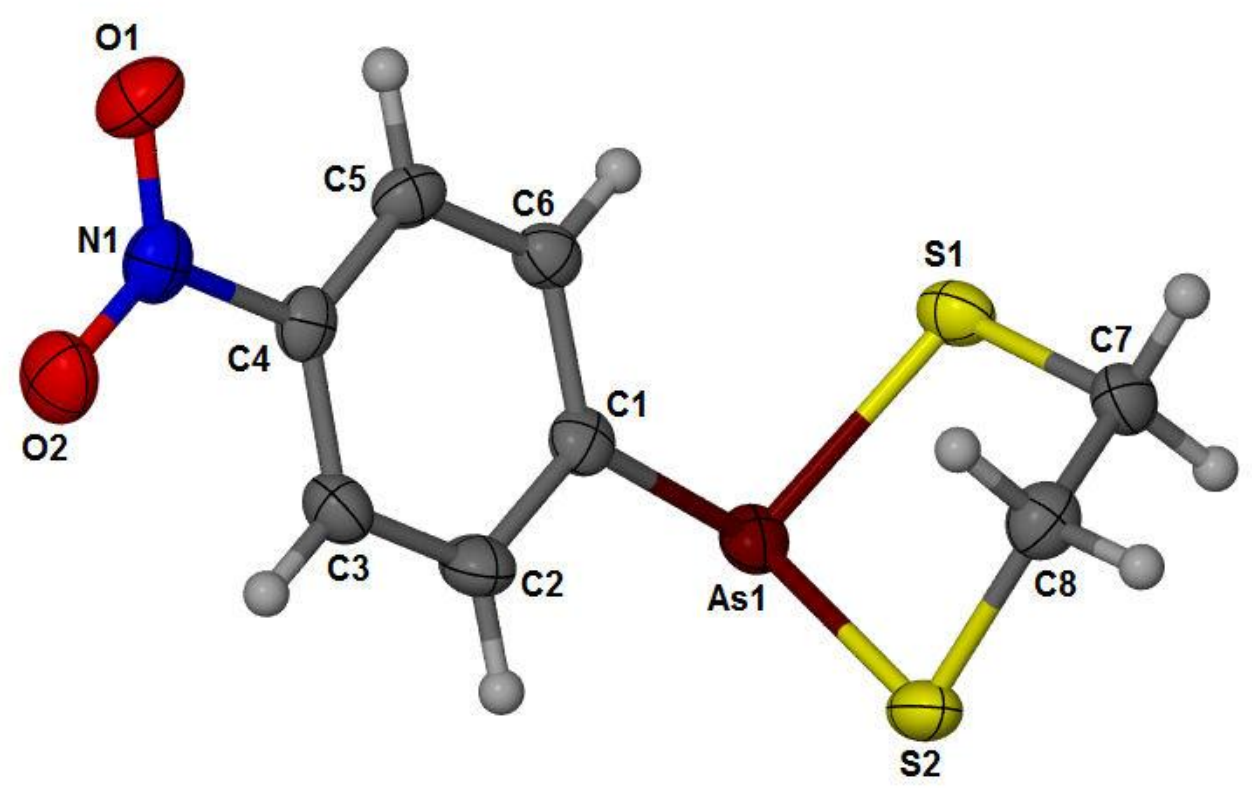

Figure 3.9. ORTEP representation of (10) (CCDC\# 1436766) with 50\% probability ellipsoids. 


\begin{tabular}{l|l} 
Yutian Feng & Chapter 3 \\
\hline
\end{tabular}

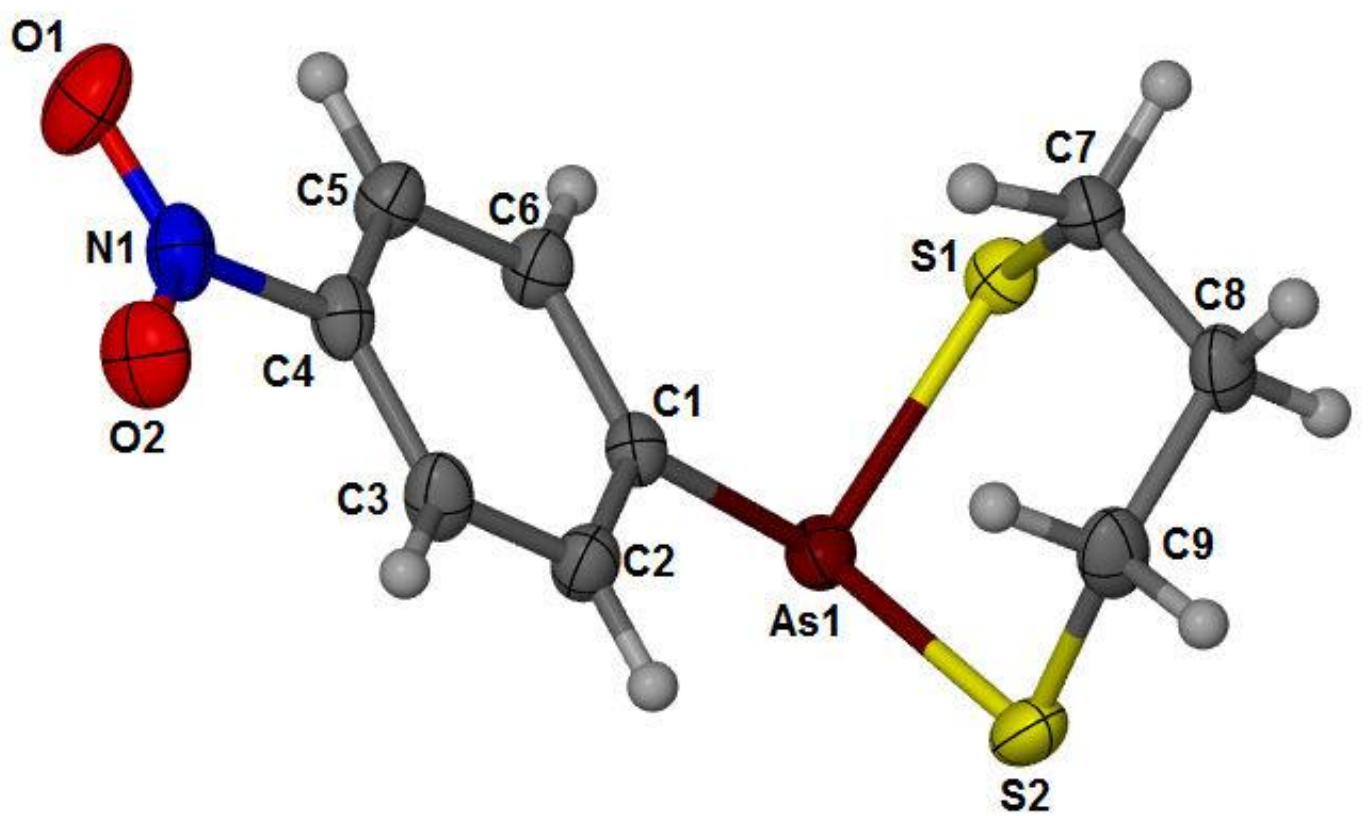

Figure 3.10. ORTEP representation of (12) (CCDC\# 1436767) with 50\% probability ellipsoids.[52] 
Table 3.2. X-ray crystal data, data collection parameters, and refinement parameters for $\mathbf{1}$ and 3 .

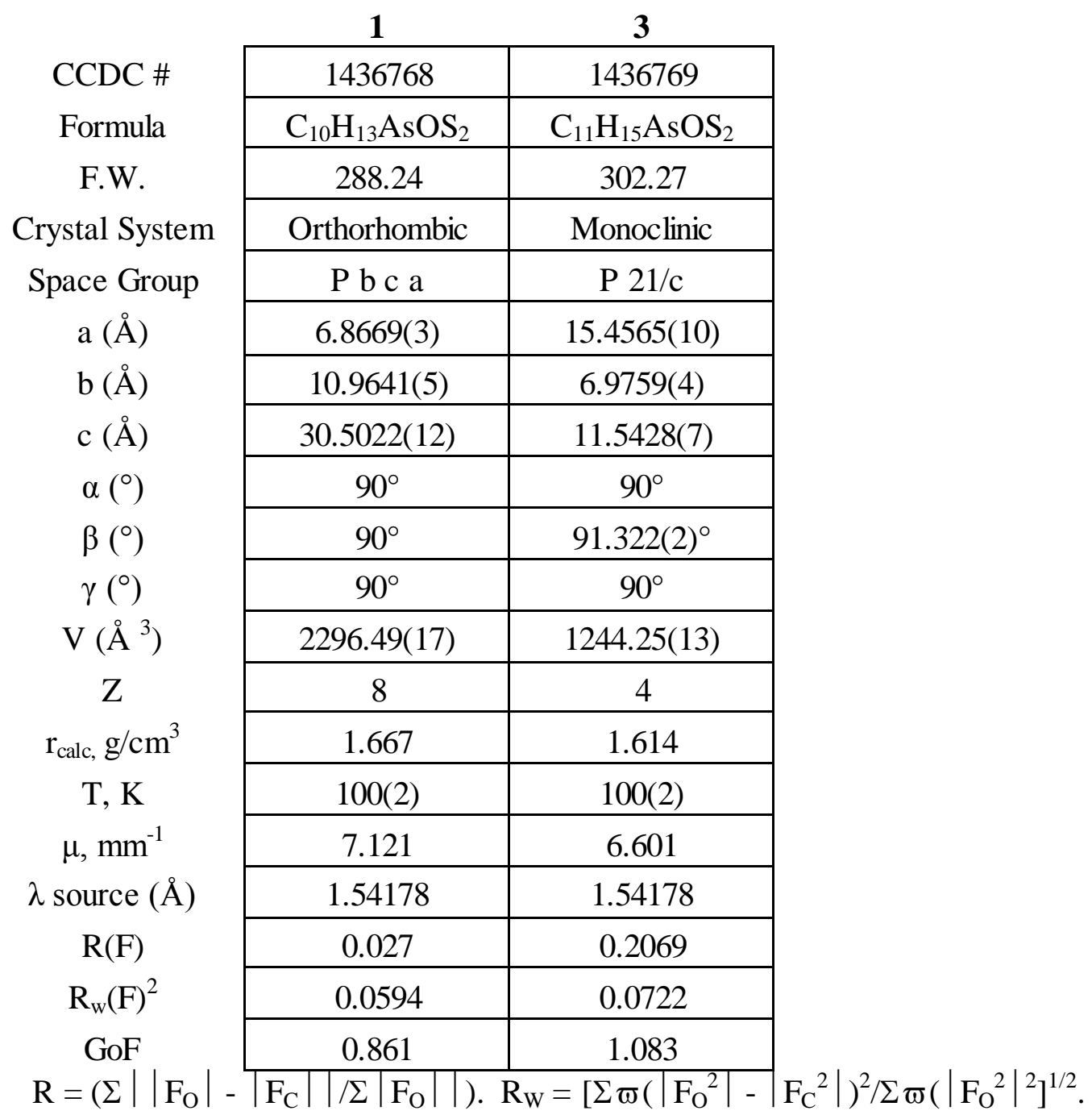




\section{Yutian Feng}

Table 3.3. Selected bond distances $(\AA)$ and angles $\left(^{\circ}\right)$ for $\mathbf{1}$ and $\mathbf{3}$.

\begin{tabular}{|c|c|c|}
\hline & $\mathbf{1}$ & $\mathbf{3}$ \\
\hline aryl & $p$-OEt & $p$-OEt \\
\hline dithiol & ethyl & propyl \\
\hline As-S1 & $2.2476(7)$ & $2.2224(15)$ \\
\hline As-S2 & $2.2409(7)$ & $2.2274(16)$ \\
\hline As-C1 & $1.961(2)$ & $1.958(6)$ \\
\hline & & \\
\hline S1-As-S2 & $92.62(3)$ & $100.95(6)$ \\
\hline S1-As-C1 & $101.56(8)$ & $102.11(17)$ \\
\hline S2-As-C1 & $100.67(8)$ & $100.03(18)$ \\
\hline
\end{tabular}




\section{Yutian Feng}

Table 3.4. X-ray crystal data, data collection parameters, and refinement parameters for 4, 6

-10 and 12.

\begin{tabular}{|c|c|c|c|}
\hline & $\mathbf{4}$ & $\mathbf{6}$ & $\mathbf{7}$ \\
\hline $\mathrm{CCDC} \#$ & 1436762 & 1436763 & 1437260 \\
\hline Formula & $\mathrm{C}_{8} \mathrm{H}_{10} \mathrm{AsNS}_{2}$ & $\mathrm{C}_{9} \mathrm{H}_{12} \mathrm{AsNS}_{2}$ & $\mathrm{C}_{8} \mathrm{H}_{9} \mathrm{AsS}_{2}$ \\
\hline $\mathrm{F} . \mathrm{W}$. & 259.21 & 273.24 & 244.19 \\
\hline $\begin{array}{c}\text { Crystal } \\
\text { System }\end{array}$ & Monoclinic & Orthorhombic & Orthorhombic \\
\hline Space Group & $\mathrm{P} 21 / \mathrm{n}$ & $\mathrm{P} 212121$ & $\mathrm{P} 212121$ \\
\hline $\mathrm{a}(\AA)$ & $12.346(5)$ & $5.6626(9)$ & $8.3948(7)$ \\
\hline $\mathrm{b}(\AA)$ & $6.184(2)$ & $7.915(1)$ & $9.8742(8)$ \\
\hline $\mathrm{c}(\AA)$ & $13.254(5)$ & $23.987(4)$ & $11.0466(9)$ \\
\hline$\alpha\left({ }^{\circ}\right)$ & 90 & 90 & 90 \\
\hline$\beta\left({ }^{\circ}\right)$ & $95.594(4)$ & 90 & 90 \\
\hline$\gamma\left({ }^{\circ}\right)$ & 90 & 90 & 90 \\
\hline $\mathrm{V}\left(\AA{ }^{3}\right)$ & $1007.1(7)$ & $1075.1(3)$ & $915.67(13)$ \\
\hline $\mathrm{Z}$ & 4 & 4 & 4 \\
\hline $\mathrm{r}_{\mathrm{calc}} \mathrm{g} / \mathrm{cm}^{3}$ & 1.71 & 1.688 & 1.771 \\
\hline $\mathrm{T}, \mathrm{K}$ & $173(2)$ & $173(2)$ & $100(2)$ \\
\hline$\mu, \mathrm{mm}{ }^{-1}$ & 3.734 & 3.503 & 4.098 \\
\hline$\left.\lambda \mathrm{source}^{3} \AA\right)$ & 0.71073 & 0.71073 & 0.71073 \\
\hline $\mathrm{R}(\mathrm{F})$ & 0.0249 & 0.0163 & 0.0131 \\
\hline $\mathrm{R}_{\mathrm{w}}(\mathrm{F})^{2}$ & 0.0668 & 0.0413 & 0.0303 \\
\hline $\mathrm{GoF}$ & 1.069 & 1.049 & 1.037 \\
\hline
\end{tabular}

\begin{tabular}{|c|c|c|c|c|}
\hline & $\mathbf{8 a , b}$ & $\mathbf{9 a , b}$ & $\mathbf{1 0}$ & $\mathbf{1 2}$ \\
\hline CCDC \# & 1436764 & 1436765 & 1436766 & 1436767 \\
\hline Formula & $\mathrm{C}_{10} \mathrm{H}_{17} \mathrm{AsN}_{2} \mathrm{O}_{4} \mathrm{~S}_{2}$ & $\mathrm{C}_{9} \mathrm{H}_{11} \mathrm{AsS}_{2}$ & $\mathrm{C}_{8} \mathrm{H}_{8} \mathrm{AsNO}_{2} \mathrm{~S}_{2}$ & $\mathrm{C}_{9} \mathrm{H}_{10} \mathrm{AsNO}_{2} \mathrm{~S}_{2}$ \\
\hline F.W. & 384.3 & 258.22 & 289.19 & 303.22 \\
\hline
\end{tabular}




\section{Yutian Feng}

\begin{tabular}{|c|c|c|c|c|}
\hline Crystal System & Triclinic & Monoclinic & Monoclinic & Monoclinic \\
\hline Space Group & $\mathrm{p}^{-1}$ & $\mathrm{P} 21 / \mathrm{n}$ & $\mathrm{P} 21 / \mathrm{n}$ & $\mathrm{C} 2 / \mathrm{c}$ \\
\hline $\mathrm{a}(\AA)$ & $6.2774(9)$ & $12.144(4)$ & $11.234(3)$ & $28.493(7)$ \\
\hline $\mathrm{b}(\AA)$ & $16.094(2)$ & $10.175(3)$ & $6.3996(19)$ & $7.1817(18)$ \\
\hline $\mathrm{c}(\AA)$ & $16.875(2)$ & $17.227(5)$ & $14.612(4)$ & $11.623(3)$ \\
\hline$\alpha\left(^{\circ}\right)$ & $115.1390(10)$ & 90 & 90 & 90 \\
\hline$\beta\left(^{\circ}\right)$ & $100.345(2)$ & $106.308(3)$ & $98.793(3)$ & $107.713(3)$ \\
\hline$\gamma\left(^{\circ}\right)$ & $93.488(2)$ & 90 & 90 & 90 \\
\hline $\mathrm{V}\left(\AA^{3}\right)$ & $1500.2(4)$ & $2043.1(1)$ & $1038.1(5)$ & $2265.6(10)$ \\
\hline $\mathrm{Z}$ & 4 & 8 & 4 & 8 \\
\hline $\mathrm{r}_{\text {calc. } \mathrm{g} / \mathrm{cm}^{3}}$ & 1.047 & 1.679 & 1.85 & 1.778 \\
\hline $\mathrm{T}, \mathrm{K}$ & $173(2)$ & $173(2)$ & $173(2)$ & $173(2)$ \\
\hline$\mu, \mathrm{mm}^{-1}$ & 2.563 & 3.678 & 3.647 & 3.347 \\
\hline$\lambda$ source $(\AA)^{(\AA)}$ & 0.71073 & 0.71073 & 0.71073 & 0.71073 \\
\hline $\mathrm{R}(\mathrm{F})$ & 0.0256 & 0.0234 & 0.0227 & 0.0229 \\
\hline $\mathrm{R}_{\mathrm{w}}(\mathrm{F})^{2}$ & 0.0615 & 0.0539 & 0.0491 & 0.0546 \\
\hline $\mathrm{GoF}$ & 1.047 & 1.044 & 1.027 & 1.02 \\
\hline
\end{tabular}

$\mathrm{R}=\left(\Sigma|| \mathrm{F}_{\mathrm{O}}|-| \mathrm{F}_{\mathrm{C}}|| / \Sigma\left|\mathrm{F}_{\mathrm{O}}\right| \mid\right) . \mathrm{R}_{\mathrm{W}}=\left[\Sigma \varpi\left(\left|\mathrm{F}_{\mathrm{O}}^{2}\right|-\left|\mathrm{F}_{\mathrm{C}}{ }^{2}\right|\right)^{2} / \Sigma \varpi\left(\left|\mathrm{F}_{\mathrm{O}}{ }^{2}\right|^{2}\right]^{1 / 2}\right.$. 
Table 3.5. Selected bond distances $(\AA)$ and angles $\left({ }^{\circ}\right)$ for 4, 6-10 and 12 .

\begin{tabular}{|c|c|c|c|c|c|c|c|c|c|}
\hline & $\mathbf{4}$ & $\mathbf{6}$ & $\mathbf{7}$ & \multicolumn{2}{|c|}{$\mathbf{8}$} & \multicolumn{2}{|c|}{$\mathbf{9}$} & $\mathbf{1 0}$ & $\mathbf{1 2}$ \\
\hline aryl & $p$ - $\mathrm{NH}_{2}$ & $p$ - $\mathrm{NH}_{2}$ & $p$-H & \multicolumn{2}{|c|}{$p$-H } & \multicolumn{2}{|c|}{$p$-H } & $p$ - $\mathrm{NO}_{2}$ & $p$ - $\mathrm{NO}_{2}$ \\
\hline dithiol & ethyl & propyl & ethyl & \multicolumn{2}{|c|}{ DMSA } & \multicolumn{2}{|c|}{ propyl } & ethyl & propyl \\
\hline \multirow{2}{*}{} & & & & Molecule a & Molecule b & Molecule a & Molecule b & & \\
& & & & & & & & & \\
\hline As-S1 & $2.2516(1)$ & $2.2452(5)$ & $2.2394(6)$ & $2.2418(5)$ & $2.2470(6)$ & $2.2310(8)$ & $2.2301(7)$ & $2.2369(8)$ & $2.2279(7)$ \\
\hline As-S2 & $2.2422(8)$ & $2.2536(6)$ & $2.2540(6)$ & $2.2573(6)$ & $2.2414(5)$ & $2.2341(7)$ & $2.2296(7)$ & $2.2290(9)$ & $2.2321(8)$ \\
\hline As-C1 & $1.940(2)$ & $1.940(2)$ & $1.972(2)$ & $1.9657(2)$ & $1.9644(2)$ & $1.9615(2)$ & $1.9699(2)$ & $1.986(2)$ & $1.9712(2)$ \\
\hline & & & & & & & & & \\
\hline S1-As-S2 & $92.56(2)$ & $97.27(2)$ & $93.34(2)$ & $92.480(2)$ & $91.94(2)$ & $99.28(3)$ & $99.78(3)$ & $93.91(2)$ & $100.87(2)$ \\
\hline S1-As-C1 & $100.75(6)$ & $97.71(5)$ & $100.29(6)$ & $97.49(5)$ & $101.28(6)$ & $100.04(6)$ & $99.76(6)$ & $100.33(6)$ & $98.53(6)$ \\
\hline S2-As-C1 & $100.60(7)$ & $97.05(6)$ & $100.82(7)$ & $100.68(6)$ & $98.48(6)$ & $99.91(6)$ & $100.38(6)$ & $98.99(6)$ & $99.96(6)$ \\
\hline
\end{tabular}

The As- $\mathrm{S}_{\mathrm{x}}$, and As- $\mathrm{C}_{1}$ bond lengths in these compounds range from 2.2224(15) $\AA$ to 2.2573(6) $\AA$, and $1.940(2) \AA$ to $1.986(2) \AA$, respectively, with no significant difference between the five and six-membered chelate ring complexes (Table 3.3 and Table 3.5). Angles observed around the As center, $\mathrm{S}_{\mathrm{x}}-\mathrm{As}-\mathrm{S}_{\mathrm{y}}$ and $\mathrm{S}_{\mathrm{x}}-\mathrm{As}-\mathrm{C}_{\mathrm{x}}$, range from $91.94(2)^{\circ}$ to $93.91(2)^{\circ}$ and $97.49(5)^{\circ}$ to $101.56(8)^{\circ}$, respectively, for the five-membered chelate ring complexes and from $97.27(2)^{\circ}$ to $100.95(6)^{\circ}$ and $97.05(6)^{\circ}$ to $102.11(17)^{\circ}$, respectively, for the six-membered chelate ring complexes. As expected, the six-membered chelate ring complexes have a larger S-As-S bite angle. The lengths and angles observed are typical and fall within or near the range reported for other dithioarylarsine complexes.[50, 59, 60] 


\section{Yutian Feng}

Optimization of No Carrier Added ${ }^{77}$ As 2-(4-Ethoxyphenyl)-1,3,2-dithiarsolane

$\left[\mathrm{CH}_{3} \mathrm{CH}_{2} \mathrm{OC}_{6} \mathrm{H}_{5}{ }^{77} \mathrm{As}\left(\mathrm{SCH}_{2} \mathrm{CH}_{2} \mathbf{S}\right)\right]$. The synthesis was carried out in 4 stages: reduction of

$\left[{ }^{77}\right.$ As]arsenate, incorporation of the aryl group, second reduction of the arylarsonic acid and dithiol complexation and various conditions were evaluated to optimize the radiochemical yield accordingly (Scheme 3.4). The optimization was conducted using a radioTLC system. Each reaction solution was spotted on silica gel TLC plates using a micro capillary tube, and then the TLC plates were placed in TLC chambers to develop in the mobile phase. The developed TLC plates were counted on the BioScan imager to evaluate the radiochemical yields (Scheme 3.5). Two mobile phases were developed to distinguish all the species in the reaction solution: methanol: acetone (10:1) and dichloromethane: chloroform (1:1). 


\section{Yutian Feng}

(a)
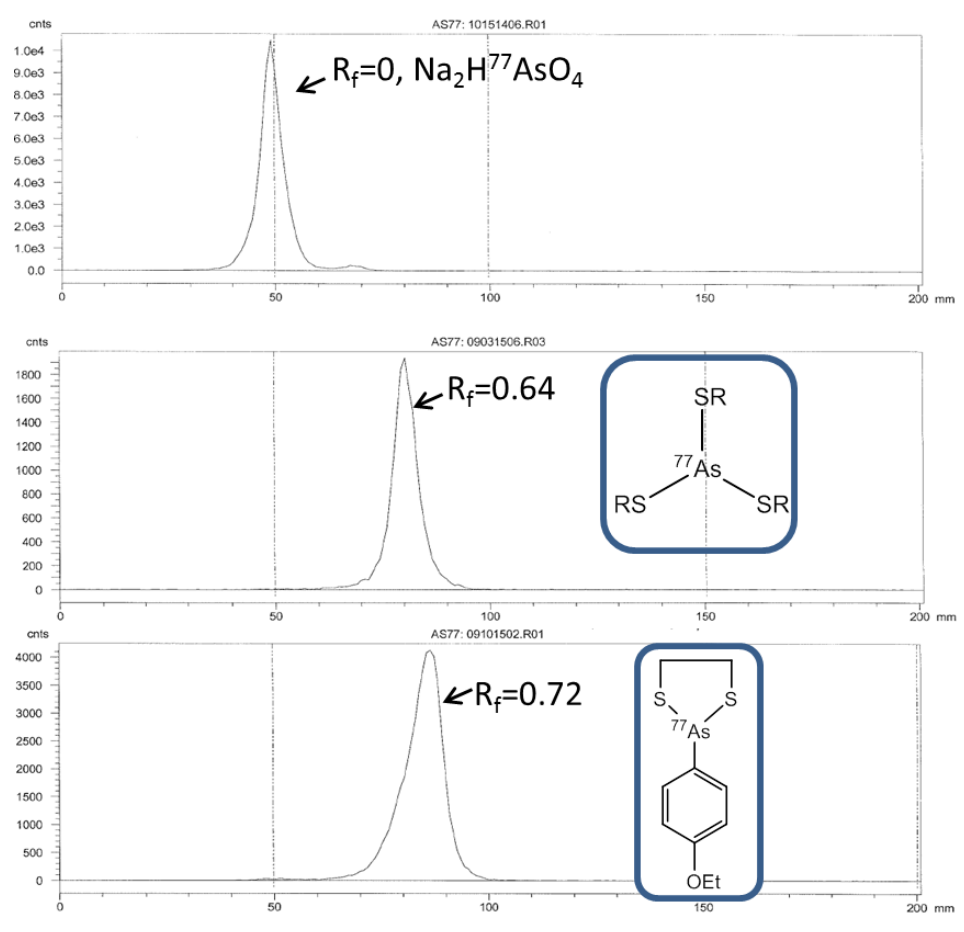

(b)
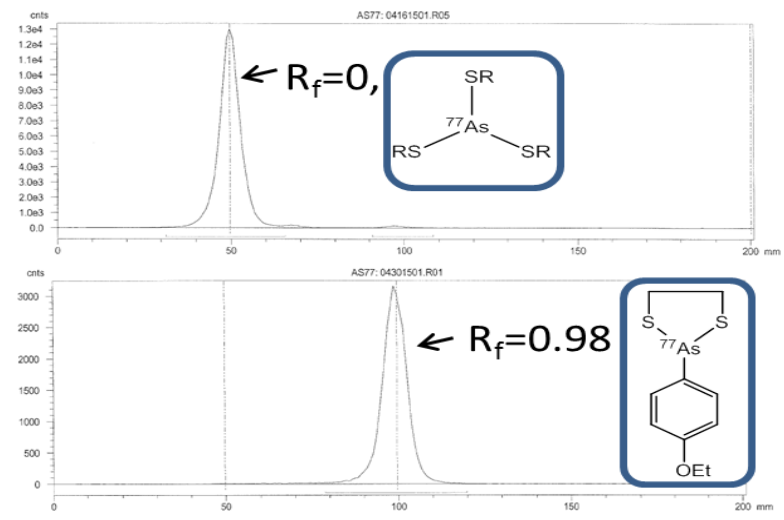

Scheme 3.5. Radio TLC data acquired from the Bioscan imager to evaluate the reaction yields. (a) Retention times of the radiolabeling species in methanol: acetone (10: 1). (b) Retention times of the radiolabeling species in dichloromethane: chloroform (1: 1). 


\section{Yutian Feng}

An aqueous ammonium mercaptoacetate (monothiol) solution was used to reduce and complex nca ${ }^{77}$ As. Various monothiol concentrations were evaluated because compared to the $\mathrm{nM}$ concentration of nca ${ }^{77} \mathrm{As}$, the monothiol would present an excess and potentially affect the following incorporation step (Table 3.6), even though higher monothiol concentrations would assure reduction yield. The reduction yield reached $99 \%$ at $20 \mathrm{mM}$ and fell to $36 \%$ at $1 \mathrm{mM}$. To assure the reduction of $\mathrm{As}(\mathrm{V})$ to $\mathrm{As}(\mathrm{III})$, which was critical in the following steps, $30 \mathrm{mM}$ mercaptoacetate was used while higher concentrations of monothiol were avoided.

Table 3.6. Optimization of the reducing agent (ammonium mercaptoacetate) concentration for arsenate reduction $(\mathrm{n}=2)$; conditions: 9:1 ACN:DI water, $60{ }^{\circ} \mathrm{C}, 30 \mathrm{~min}$.

\begin{tabular}{cc}
\hline $\begin{array}{c}\text { Concentration of } \\
\text { Reducing Agent }(\mathrm{mM})\end{array}$ & Yield (\%) \\
\hline 40 & $99 \pm 5$ \\
30 & $100 \pm 6$ \\
20 & $99 \pm 8$ \\
10 & $94 \pm 7$ \\
1 & $36 \pm 6$ \\
\hline
\end{tabular}

In the second stage, an aryl group was incorporated to $\left[{ }^{77} \mathrm{As}\right] \mathrm{As}(\mathrm{SR})_{3}$, with the copper catalyst added prior to the addition of the diazonium salt. As discussed before, the functioning species of $\mathrm{Cu}(\mathrm{Cu}$ metal, $\mathrm{Cu}(\mathrm{I})$ or $\mathrm{Cu}(\mathrm{II}))$ was unclear, but the usage of copper cations, namely $\mathrm{Cu}(\mathrm{I})$ or $\mathrm{Cu}(\mathrm{II})$ should be avoided due to their concentration excess and potential interference to radiolabeling. Both polished copper metal and copper nanoparticle solution (acetone as solvent) were evaluated and found to be good catalysts. The copper 


\section{Yutian Feng}

nanoparticle solution was used as the catalyst to simplify procedures and consistently add a known amount of $\mathrm{Cu}$.

The amount of $p$-ethoxybenzenediazonium tetrafluoroborate was varied from 5-20 mg, in 5 $\mathrm{mg}$ increments, in the optimization. The yield increased up to $10 \mathrm{mg}$ and then remained constant after that point.

On the macroscopic level, incorporation of the aryl group generates the arylarsonic acid, which has the arsenic in oxidation state +5 . At the nca ${ }^{77}$ As radiotracer level, both the arylarsonic acid and a reduced arylarsine, likely the bis(monothio)arylarsine, were formed. An additional reduction with mercaptoacetate was necessary to ensure all arsenic was present as As(III) and allow incorporation of the dithiol. The reducing agent (mercaptoacetate) and 1,2-ethanedithiol concentrations were individually varied to optimize the product yield (Tables 3.7 and 3.8). Dithiol alone did not yield the desired product at the radiotracer level and poor yields were observed at the macroscopic level.

Table 3.7. Initial optimization of the ammonium mercaptoacetate concentration in the reduction of $\left[\mathrm{As}^{77}\right] p$-ethoxyphenylarsonic acid $(\mathrm{n}=3)$; conditions: 9:1 ACN:DI water, $60{ }^{\circ} \mathrm{C}$, $45 \mathrm{~min} ., 30 \mathrm{mM}$ monothiol in the reduction step, $15 \mathrm{mg}$-ethoxybenzenediazonium tetrafluoroborate.

\begin{tabular}{cc}
\hline $\begin{array}{c}\text { Concentration of } \\
\text { Reducing Agent (mM) }\end{array}$ & Yield (\%) \\
\hline 108 & $26 \pm 3$ \\
160 & $36 \pm 4$ \\
210 & $50 \pm 5$ \\
260 & $54 \pm 3$ \\
\hline
\end{tabular}




\section{Yutian Feng}

Table 3.8. Initial optimization of the dithiol $(1,2$-ethanedithiol) concentration $(n=3)$; conditions: 9:1 ACN:DI water, $60{ }^{\circ} \mathrm{C}, 45 \mathrm{~min} ., 30 \mathrm{mM}$ monothiol in reduction step, $15 \mathrm{mg} p$ ethoxybenzenediazonium tetrafluoroborate, $270 \mathrm{mM}$ monothiol during incorporation step.

\begin{tabular}{cc}
\hline $\begin{array}{c}\text { Concentration of 1,2- } \\
\text { ethanedithiol }(\mathrm{mM})\end{array}$ & Yield $(\%)$ \\
\hline 9.8 & $26 \pm 2$ \\
19.3 & $36 \pm 3$ \\
28.3 & $50 \pm 5$ \\
37.5 & $54 \pm 3$ \\
100 & $57 \pm 1$ \\
\hline
\end{tabular}

As discussed in Chapter 2, nca ${ }^{77}$ As was separated from the target solution, dried down and reconstituted in water. It is believed that there was a certain concentration of $\mathrm{NaCl}$ present in the nca ${ }^{77}$ As stock solution.

The acetonitrile-water solvent ratio also played an important role during the reduction, incorporation and complexation reactions. The initial optimizations were carried out in 9:1 acetonitrile-water (Tables 3.6- 3.8). However, two layers were observed in the reaction vials, a pale yellow organic layer above a clear aqueous layer. As discussed in Chapter 2, nca ${ }^{77}$ As was separated from the target solution, dried down and reconstituted in water. It is believed that was concentration of $\mathrm{NaCl}$ present in nca ${ }^{77} \mathrm{As}$ stock solution interfered and resulted in 2 layers.

Analysis of the 2 layers showed the aqueous phase contained more ${ }^{77}$ As activity but less product while the organic phase contained less ${ }^{77}$ As but with more product. Modifying the acetonitrile-water ratio to 7:3 maintained a single homogeneous reaction and increased the product yields. 


\section{Yutian Feng}

Various temperatures and times were evaluated to optimize the reduction, aryl incorporation, and dithiol complexation steps. During the first reduction step (Scheme 3.4), yields reached a plateau after $30 \mathrm{~min}$.; at $30 \mathrm{mM}$ ammonium mercaptoacetate and $60{ }^{\circ} \mathrm{C}$, the reduction yield was over $90 \%$ after $30 \mathrm{~min}$. In terms of temperature effects, the yield for the first reduction step increased when the reaction temperature was increased from $50{ }^{\circ} \mathrm{C}$ to $60{ }^{\circ} \mathrm{C}$. However, the higher temperature $\left(60^{\circ} \mathrm{C}\right)$ for this reduction step led to discoloration (dark brown color) and a significant decrease in yield during the aryl incorporation in the following step (Scheme 3.4). For the aryl incorporation step, the reaction mixture is removed from heat reaching $90 \%$ yield after 45 min, with no further change observed at longer reaction times. Temperature had no significant effect on the second mercaptoacetate reduction or the dithiol complexation (final step), and they were run at room temperature (Scheme 3.4); 95\% yield was observed during the dithiol complexation after $30 \mathrm{~min}$.

The optimal conditions involved a single vial, multistep aqueous synthesis involving reduction of ${ }^{77} \mathrm{As}(\mathrm{V})$-arsenate $\left(\sim 37 \mathrm{MBq}, 1 \mathrm{mCi}, \sim 1 \times 10^{-11} \mathrm{~mol}, \sim 1 \mathrm{ng}\right)$ with the water soluble mercaptoacetate as the first step. Following the reduction to ${ }^{77} \mathrm{As}(\mathrm{III})$, the aryl group was incorporated by addition of $p$-ethoxybenzenediazonium tetrafluorborate in the presence of $\mathrm{Cu}^{0}$ nanoparticles to generate the aryl arsonic acid. A second reduction step was required to form the aryl bis(mercaptoacetato)arsine, and finally dithiol substitution of the monothiols yielded the desired product. The synthesis of nca $\left[{ }^{77} \mathrm{As}\right] 2$-(4-ethoxyphenyl)-1,3,2dithiarsolane $\left(\left[{ }^{77} \mathrm{As}\right] \mathbf{1}\right)$ was successfully optimized to $>95 \%$ yield, and it eluted with the same HPLC retention time as its non-radioactive standard 1 (Figure 3.11).

The synthesis of nca $\left[{ }^{72} \mathrm{As}\right] 2$-(4-ethoxyphenyl)-1,3,2-dithiarsolane $\left(\left[{ }^{72} \mathrm{As}\right] \mathbf{1}\right)$ was carried out in the same fashion as the procedure of nca ${ }^{77}$ As. The radiolabeling synthesis followed 


\section{Yutian Feng}

optimized conditions and the radiochemical yields were determined to be $80 \%$ by a Bioscan gas proportional detector. Because of the low radioactivity of the nca ${ }^{72}$ As, the signal/background ratio on the Bioscan detector was low, which was the possible cause for the comparatively low radiochemical yield (80\% compared to $95 \%$ ).
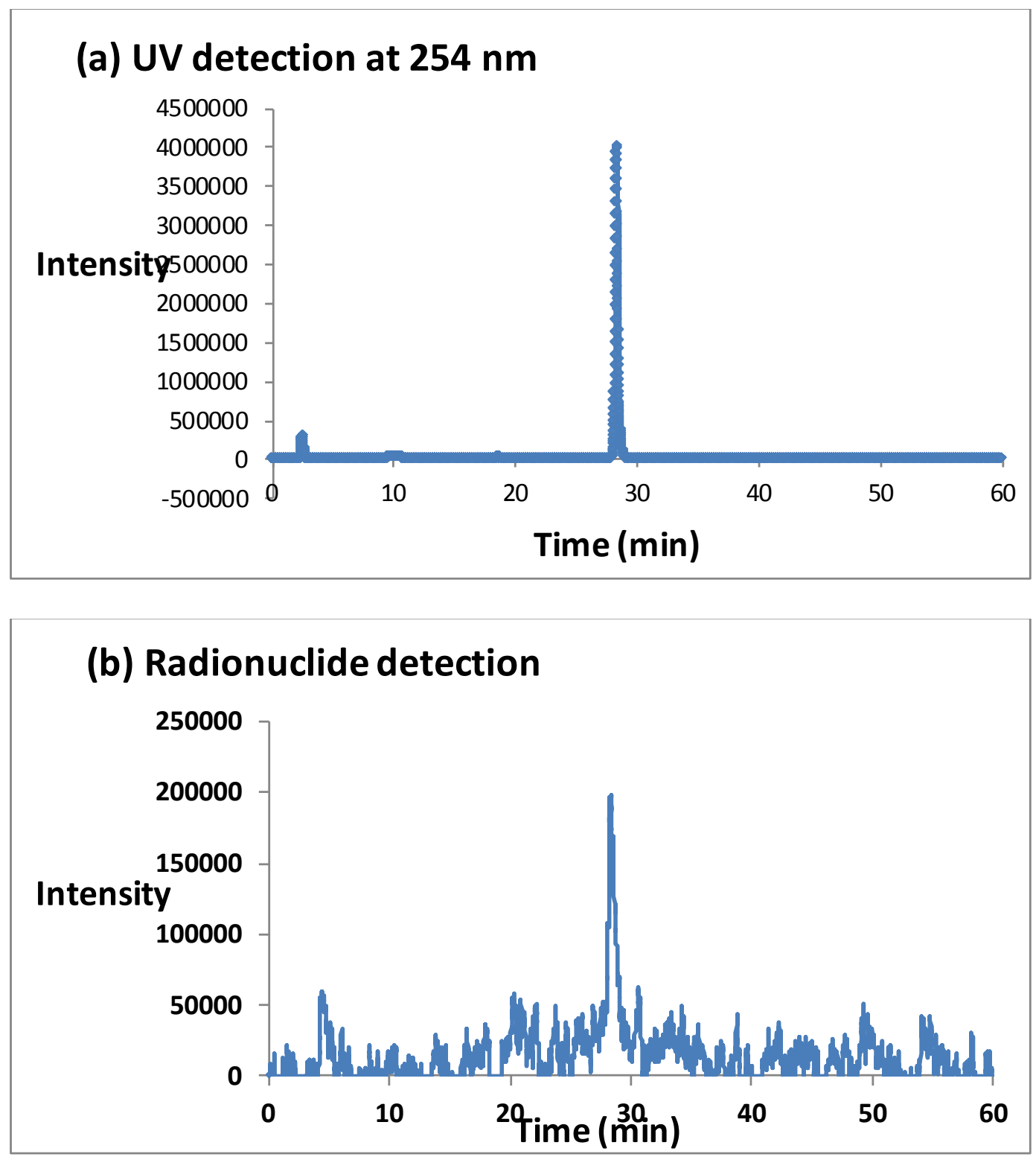

Figure 3.11. HPLC chromatograms of (a) $\mathbf{1}$ (UV detection) and (b) nca $\left[{ }^{77} \mathrm{As}\right] \mathbf{1}$ (radionuclide detection) with both exhibiting retention times of $28.6 \mathrm{~min}$. 


\section{Yutian Feng}

\section{Conclusion}

Several dithioarylarsines were synthesized and fully characterized (including their crystal structures) as macroscopic standards for the nca ${ }^{77}$ As chemistry. Successful incorporation of an aryl group onto nca ${ }^{77} \mathrm{As}$, beginning with arsenate $\left({ }^{77} \mathrm{AsO}_{4}{ }^{3-}\right)$, was achieved in close to quantitative yield with various modifications to the Bart reaction to optimize the production of the aryl arsonic acids. Subsequent incorporation of a dithiol gave the $\left[{ }^{77} \mathrm{As}\right]-$ dithioarylarsine in $95 \%$ radiochemical yield. The imaging counterpart, $\left[{ }^{72} \mathrm{As}\right]$-dithioarylarsine was synthesized using optimized conditions and reasonable radiochemical yield was accomplished (based on radioTLC). The reactions were carried out in high mercaptoacetate (monothiol) concentration and products remained intact over several days (based on radioTLC), suggesting these compounds will likely be stable to challenge by thiols found in vivo, such as glutathione and the sulfhydryl groups of albumin. Synthesis of a bifunctional chelate for conjugation to a suitable targeting vector is currently underway. 


\section{Chapter 4: Trithiol: a Potential Chelate for ${ }^{72,77}$ As Matched Pair Theranostic Complex with High in vivo Stability}

\section{Introduction}

Combined non-invasive radioimaging and radiotherapy (i.e., theranostic) agents are believed to have many advantages because the diagnostic information provided by the radioimaging potentially guides the strategy for radiotherapy.[4] Ideally the radioimaging and therapy counterparts are two radionuclides of the same nuclide and thus behave identically in vitro and in vivo, leading to investigation of a true "matched pair".[61] Two arsenic radionuclides $\left({ }^{72,77} \mathrm{As}\right)$ have suitable nuclear properties making them a true matched pair.[31] Arsenic-72 $\left(\beta^{+}\right.$emitter, 26 hour half-life) and ${ }^{77}$ As ( $\beta^{-}$emitter, 38.8 hour half-life) are suitable for PET imaging and radiotherapy, respectively, and compared to commonly used positron emitters (e.g., ${ }^{18} \mathrm{~F},{ }^{11} \mathrm{C},{ }^{64} \mathrm{Cu},{ }^{68} \mathrm{Ga}$ ) have sufficiently long half-lives making them useful in radiolabeling antibodies or peptides for radioimaging and therapy.[7]

The thiophilic nature has led to the investigation of thiol based ligands to achieve high in vivo stability. The aryl dithiol approach was discussed in Chapter 3. As a different approach, tridentate ligands were investigated because it was believed that the stability of radioarsenic complex could be improved by intramolecular binding thiols due to chelate effect. A trithiol ligand was synthesized and evaluated by DeGraffenreid et al..[32] A monothiol was used to reduce $\left[{ }^{77}\right.$ As $]$ arsenate to ${ }^{77}$ As (III), followed by trithiol radiolabeling. High radiolabeling yield (over 96\%) with nca ${ }^{77}$ As was achieved in a fairly short amount of time ( $\left.\sim 30 \mathrm{~min}\right)$. The 


\section{Yutian Feng}

high in vitro stability of As-trithiol complex made it a promising chelate for use in the preparation of radioarsenic radiopharmaceuticals.

To investigate the in vivo stability of the trithiol complex, a bifunctional chelate was developed and conjugated to the bombesin(7-14) $\mathrm{NH}_{2}\left(\mathrm{BBN}(7-14) \mathrm{NH}_{2}\right)$ peptide, which targets Gastrin-Releasing peptide (GRP) receptors highly expressed in prostate cancer cells.[33] The high binding affinity and selectivity towards GRP receptors, in vivo stability and established pharmacokinetics of bombesin(7-14) $\mathrm{NH}_{2}$ made it a promising targeting vector.[62-65] In this Chapter, we focused on the synthesis and characterization of a trithiol$\mathrm{BBN}$ conjugate and the biological evaluation of nca ${ }^{77} \mathrm{As}$ radiolabeled trithiol-BBN(714) $\mathrm{NH}_{2}$ in $\mathrm{CF}-1$ normal mice by comparing to the biodistribution of free nca ${ }^{77}$ As (arsenate) in normal mice.[66]

\section{Experimental}

\section{Materials}

Pentaerythritol, triethyl orthoacetate, $p$-toluene sulfonic acid monohydrate, propargyl bromide ( $80 \%$ in toluene), dioctyl phthalate, 3-bromopropionic acid, sodium azide, ethyl 3bromopropionoate, thioglycolic acid, tris(2-carboxyethyl)phosphine (TCEP), 2-(1Hbenzotriazol-1-yl)-1,1,3,3-tetramethyluronium hexafluorophosphate (HBTU), hydroxybenzotriazole (HOBt), $N$-ethyl- $N$-(propan-2-yl)propan-2-amine (DIEA), triisopropylsilane (TIS), protected amino acids, silica gel $60 \AA$, reversed phase C18 $125 \AA$, and aluminum backed C18-W TLC plates were purchased from Fisher Scientific or SigmaAldrich and used as received. Bacteriostatic saline was purchased from Hospira Inc. Sep-Pak C18 Plus Light Cartridges were purchased from Waters and used as received. All solvents, 


\section{Yutian Feng}

acids and bases were reagent grade, purchased from Fisher Scientific or Sigma-Aldrich and used without further purification. Only $18 \mathrm{M} \Omega$ water was used. CAUTION! Arsenic is highly toxic and should be handled with care.

Arsenic-77 was prepared by irradiation of $2-5 \mathrm{mg}$ of enriched ${ }^{76} \mathrm{GeO}_{2}(98.6 \%$; Trace Sciences International) in a thermal neutron flux of $2.4 \times 10^{14} \mathrm{n} / \mathrm{cm}^{2} / \mathrm{s}$ at the University of Missouri Research Reactor (MURR). [ ${ }^{77}$ As]arsenate was isolated in aqueous solution as previously reported. CAUTION! ${ }^{77}$ As and ${ }^{77} \mathrm{Ge}$ are radioactive and must be handled in laboratories outfitted and approved for work with radioactive materials. Arsenic-77: 38.9 h, $0.693 \mathrm{MeV}$ maximum $\beta^{-}, 239 \mathrm{keV} \gamma(1.65 \%) ;{ }^{77} \mathrm{Ge}: 11.3 \mathrm{~h}, 2.7 \mathrm{MeV}$ maximum $\beta^{-}, 211,215.6$, and 264.5 $\mathrm{keV} \gamma$ emissions.

\section{Physical Measurement}

${ }^{1} \mathrm{H}$ and ${ }^{13} \mathrm{C}$ NMR spectra were obtained in $\mathrm{CDCl}_{3}$ on a Bruker ARX-500 $\mathrm{MHz}$ spectrometer using TMS as an internal standard. Electrospray Ionization Mass Spectra (ESI-MS) were obtained on a Thermo Finnigan TSQ7000 triple-quadrupole instrument with an API2 source. Elemental analyses were performed by Atlantic Microlab, Inc. (Norcross, GA). An ORTEC HPGe detector outfitted with Genie multichannel analysis software was used to assay ${ }^{77} \mathrm{Ge}$ and ${ }^{77}$ As liquid samples. Reversed phase HPLC (RP-HPLC) was performed using a Shimadzu Prominence HPLC system equipped with a pump, controller, and Prominence UVVis detector (model SPD20-AV) set to 220 and $280 \mathrm{~nm}$, and coupled to a Beckman 170 $\mathrm{NaI}(\mathrm{Tl})$ radionuclide detector. The gradient system used for RP-HPLC run on a Phenomenex Jupiter C $18(5 \mu \mathrm{m}, 150 \mathrm{~mm}$ x $4.6 \mathrm{~mm})$ column was as follows: a linear gradient from 20/80 $\mathrm{ACN} / \mathrm{H}_{2} \mathrm{O}$ w/ $0.1 \%$ TFA to 50/50 ACN/ $\mathrm{H}_{2} \mathrm{O}$ w/ $0.1 \%$ TFA in 10 min, then from 50/50 


\section{Yutian Feng}

ACN/ $\mathrm{H}_{2} \mathrm{O}$ to $90 / 10 \mathrm{ACN} / \mathrm{H}_{2} \mathrm{O}$ in $3 \mathrm{~min}$, followed by a gradient from $90 / 10$ to $20 / 80$ $\mathrm{ACN} / \mathrm{H}_{2} \mathrm{O}$ over $5 \mathrm{~min}$, all at a flow rate of $1 \mathrm{~mL} / \mathrm{min}$. Peptide analysis and purification were performed on a Beckmann Coulter System Gold HPLC equipped with a 168 diode array detector, a 507e autoinjector and the 32 KARAT software package (Beckmann Coulter, Fullerton, CA) using a C-18 XBridge BEH, $250 \times 4.6$ mm, $5 \mu \mathrm{m}, 130 \AA$ from Waters, Milford, MA. The gradient for both analysis and purification was a linear gradient from $20 \%$ ACN to $50 \%$ ACN with $0.1 \%$ TFA in $45 \mathrm{~min}$. The flow rate was maintained at $1 \mathrm{~mL} / \mathrm{min}$ for analytical runs and $10 \mathrm{ml} / \mathrm{min}$ for semi-preparative purifications. All LC-MS analyses and MS assisted preparative purifications were performed with an LCQ Fleet from Thermo Fisher, Waltham, MA.

\section{Syntheses}

Many of these compounds were synthesized by Dr. Anthony DeGraffenreid and hence included in his Doctoral Dissertation.[52]

(1-Methyl-2,6,7-trioxabicyclo[2.2.2]octan-4-yl)methanol $\left[\mathrm{C}_{7} \mathrm{H}_{12} \mathrm{O}_{4}\right]$, 2. Synthesis of compound 2 was accomplished using a modified literature procedure.[67] Pentaerythritol (60 g, $440.7 \mathrm{mmol})$, was added to a stirring solution of dioctyl phthalate (100 mL) containing $p$ toluene sulfonic acid monohydrate $(\sim 15 \mathrm{mg}, 78 \mu \mathrm{mol})$. The reaction was heated to $120{ }^{\circ} \mathrm{C}$, triethyl orthoacetate $(71.685 \mathrm{~g}, 81 \mathrm{~mL}, 441.87 \mathrm{mmol})$ was added, and the reaction vessel outfitted with a distillation apparatus. After stirring for $22 \mathrm{~h}, 64 \mathrm{~mL}$ of ethanol had distilled, $83 \%$ of the theoretical amount. Triethylamine (TEA) $(2 \mathrm{~mL}, 14 \mathrm{mmol})$ was added, and the reaction mixture allowed to stir for 10 minutes. The reaction clarified upon heating to $160{ }^{\circ} \mathrm{C}$, at which time a vacuum was applied to remove the TEA and any remaining ethanol. The 


\section{Yutian Feng}

final product, a white solid, was isolated by vacuum distillation at $185{ }^{\circ} \mathrm{C}$ and recrystallized from benzene. Yield: 83\%, 58.64 g. ${ }^{1} \mathrm{H}$ NMR $\left(\mathrm{CDCl}_{3} ; 500 \mathrm{MHz}\right) \delta \mathrm{ppm}: 1.453\left(\mathrm{~s}, 3 \mathrm{H}, \mathrm{CH}_{3}\right)$, $1.58(\mathrm{t}, 1 \mathrm{H}, \mathrm{OH}), 3.454\left(\mathrm{~d}, 2 \mathrm{H}, \mathrm{CCH}_{2} \mathrm{OH}\right)$, and $4.015\left(\mathrm{~s}, 6 \mathrm{H}, \mathrm{OCH}_{2} \mathrm{C}\right) .{ }^{13} \mathrm{C} \mathrm{NMR}\left(\mathrm{CDCl}_{3}\right.$; $125.8 \mathrm{MHz}) \delta$ ppm: $23.53\left(\mathrm{CH}_{3}\right), 35.71\left(\mathrm{CH}_{2} \mathbf{C C H}_{2}\right), 61.50\left(\mathrm{CCH}_{2} \mathrm{OH}\right), 69.41\left(\mathrm{OCH}_{2} \mathrm{C}\right)$, and $108.67\left(\mathrm{OCCH}_{3}\right)$. ESI-MS (m/z): $161.06\left(161.07\right.$ calc'd for $\left.\mathrm{C}_{7} \mathrm{H}_{12} \mathrm{O}_{4}[\mathrm{M}+\mathrm{H}]^{+}\right)$. Elemental analysis calc'd (found) for $\mathrm{C}_{7} \mathrm{H}_{12} \mathrm{O}_{4}$ : C, 52.49 (51.58); $\mathrm{H}, 7.55$ (7.67).

1-Methyl-4-((prop-2-yn-1-yloxy)methyl)-2,6,7-trioxabicyclo[2.2.2]octane $\left[\mathrm{C}_{10} \mathrm{H}_{14} \mathrm{O}_{4}\right], 3$. Synthesis of compound $\mathbf{3}$ was accomplished using a modified literature procedure.[67] Compound 2 (5.43 g, $33.9 \mathrm{mmol})$ was added to a stirring solution of anhydrous dimethyl sulfoxide (DMSO) (30 mL) and powdered $\mathrm{KOH} \mathrm{(7.60} \mathrm{g,} 136 \mathrm{mmol})$. After stirring for 10 minutes, the reaction mixture was cooled in an ice bath $\left(0^{\circ} \mathrm{C}\right)$. Propargyl bromide $(4.04 \mathrm{~g}$, $3.02 \mathrm{~mL}, 33.9 \mathrm{mmol}$ ) was added drop-wise (Caution! Reaction becomes very hot!), and the reaction rapidly became dark brown. The reaction was stirred at room temperature for 95 minutes and poured into ice-cold water $(200 \mathrm{~mL})$. The off-white solid was collected by vacuum filtration, washed with water, and dried in vacuo to obtain the analytically pure product. X-ray quality crystals were obtained by slow evaporation from chloroform. Yield: $5.44 \mathrm{~g}, 81 \% .{ }^{1} \mathrm{H} \mathrm{NMR}\left(\mathrm{CDCl}_{3} ; 500 \mathrm{MHz}\right) \delta \mathrm{ppm}: 1.456\left(\mathrm{~s}, 3 \mathrm{H}, \mathrm{CH}_{3}\right), 2.442(\mathrm{t}, 1 \mathrm{H}, \mathrm{CCH})$, $3.286\left(\mathrm{~s}, 2 \mathrm{H}, \mathrm{CCH}_{2} \mathrm{O}\right), 4.006\left(\mathrm{~s}, 6 \mathrm{H},\left(\mathrm{CH}_{2}\right)_{3} \mathrm{C}\right)$, and $4.094\left(\mathrm{~d}, 2 \mathrm{H}, \mathrm{OCH} \mathbf{H}_{2} \mathrm{CCH}\right) .{ }^{13} \mathrm{C} \mathrm{NMR}$ $\left(\mathrm{CDCl}_{3} ; 125.8 \mathrm{MHz}\right) \delta$ ppm: $23.56\left(\mathrm{CH}_{3}\right), 34.85\left(\mathrm{CH}_{2} \mathrm{CCH}_{2}\right), 58.88\left(\mathrm{OCH}_{2} \mathrm{CCH}\right), 68.12$ $\left(\mathrm{CCH}_{2} \mathrm{O}\right), 69.55\left(\mathrm{OCH}_{2} \mathrm{C}\right), 75.34(\mathbf{C H}), 78.97\left(\mathrm{CH}_{2} \mathrm{CCH}\right), 108.72\left(\mathrm{OCCH}_{3}\right)$. ESI-MS $(\mathrm{m} / z)$ : 199.10 (199.09 calc'd for $\mathrm{C}_{10} \mathrm{H}_{14} \mathrm{O}_{4}[\mathrm{M}+\mathrm{H}]^{+}$). Elemental analysis calc'd (found) for $\mathrm{C}_{7} \mathrm{H}_{12} \mathrm{O}_{4}$ : C, 60.59 (59.06); H, 7.12 (7.23). 


\section{Yutian Feng}

2-(Hydroxymethyl)-2-((prop-2-yn-1-yloxy)methyl)propane-1,3-diol $\left[\mathrm{C}_{8} \mathrm{H}_{14} \mathrm{O}_{4}\right]$, 4. Synthesis

of compound 4 was prepared using a modified literature procedure.[67] Deprotection was accomplished by the addition of crude $3(2.225 \mathrm{~g}, 11.22 \mathrm{mmol})$ to $6 \mathrm{M} \mathrm{HCl}(12 \mathrm{~mL})$ in methanol $(40 \mathrm{~mL})$ at room temperature. After stirring overnight $(16 \mathrm{~h})$, potassium carbonate (5.6 g, $50 \mathrm{mmol}$ ) was added slowly. No more starting material was observed after 24 hours, based on TLC using ethyl acetate as the mobile phase $\left(4, \mathrm{R}_{\mathrm{f}} \approx 0.25\right)$. The solvent was removed by vacuum distillation to give the crude product, a thick dark yellow oil $(\sim 3 \mathrm{~g})$. This crude mixture was reconstituted in ethyl acetate, and filtered several times to remove any solids. The filtrate was taken to dryness, dissolved in ethyl acetate and loaded on a silica gel column. Ethyl acetate was used to elute the purified product. Removal of the solvent under vacuum gave the pure product, a thick light yellow oil. Yield: $84 \%, 1.6 \mathrm{~g} .{ }^{1} \mathrm{H} \mathrm{NMR}\left(\mathrm{CDCl}_{3}\right.$; $500 \mathrm{MHz}) \delta$ ppm: 2.148 (bs, 3H, OH), 2.465 (t, 1H, CH), 3.578 (s, 2H, CCH $\left.\mathbf{C H}_{2} \mathrm{O}\right), 3.722$ (s, 6 $\left.\mathrm{H}, \mathrm{OCH}_{2} \mathrm{C}\right)$, and $4.154\left(\mathrm{~d}, 2 \mathrm{H}, \mathrm{OCH}_{2} \mathrm{CCH}\right) .{ }^{13} \mathrm{C} \mathrm{NMR}\left(\mathrm{CDCl}_{3} ; 125.8 \mathrm{MHz}\right) \delta \mathrm{ppm}: 45.14$ (C), $58.98\left(\mathrm{CCH}_{2} \mathrm{O}\right), 64.70\left(\mathrm{HOCH}_{2} \mathrm{C}\right), 71.60\left(\mathrm{OCH}_{2} \mathrm{CCH}\right), 79.40\left(\mathrm{CH}_{2} \mathrm{CCH}\right)$, and 75.15 (CH). ESI-MS ( $/ / z)$ : 174.99 (175.09 calc'd for $\left.\mathrm{C}_{8} \mathrm{H}_{14} \mathrm{O}_{4}[\mathrm{M}+\mathrm{H}]^{+}\right)$. 2-((Prop-2-yn-1-yloxy)methyl)-2-((tosyloxy)methyl)propane-1,3-diyl bis(4methylbenzenesulfonate) $\left[\mathrm{C}_{29} \mathrm{H}_{32} \mathrm{O}_{10} \mathrm{~S}_{3}\right], 5$. Tosylation of compound 4 was accomplished by the slow addition of $p$-toluene sulfonyl chloride $(78.76 \mathrm{~g}, 413.1 \mathrm{mmol}$ ) to a stirring solution of pyridine $(90.3 \mathrm{~g}, 92 \mathrm{~mL}, 1.135 \mathrm{~mol})$, and $4(14.38 \mathrm{~g}, 82.56 \mathrm{mmol})$ at $-5{ }^{\circ} \mathrm{C}$. The reaction was allowed to slowly come to room temperature, and stirred for approximately 2 days. The reaction progress was followed by silica gel TLC with dichloromethane as the mobile phase and visualized using $\mathrm{KMnO}_{4}\left(\mathbf{5}, \mathrm{R}_{\mathrm{f}} \approx 0.55\right)$. The reaction mixture was poured into $2 \mathrm{M} \mathrm{HCl}$ (400 mL) at $5{ }^{\circ} \mathrm{C}$ to give a thick viscous white solid. Solids were washed with $2 \mathrm{M} \mathrm{HCl}(2 \mathrm{x}$ 


\section{Yutian Feng}

$100 \mathrm{~mL})$, and cold water $(2 \times 100 \mathrm{~mL})$. The solid was dissolved in ethyl acetate $(200 \mathrm{~mL})$ and washed with saturated sodium bicarbonate $(2 \times 50 \mathrm{~mL}), 2 \mathrm{M} \mathrm{HCl}(2 \times 100 \mathrm{~mL})$, and brine $(1 \times 50 \mathrm{~mL})$. The organic layer was dried over magnesium sulfate, filtered, and taken to dryness yielding a clear light yellow oil of the crude product. The crude product was recrystallized in a mixture of hexane/DCM (70/30), and then washed with hot hexanes $\left(50{ }^{\circ} \mathrm{C}\right)$ until the hexane wash revealed no UV active material. Residual hexane was removed in vacuo to give the product as a white solid. Yield: $92 \%, 48.21 \mathrm{~g} .{ }^{1} \mathrm{H} \mathrm{NMR}\left(\mathrm{CDCl}_{3} ; 500 \mathrm{MHz}\right)$ $\delta$ ppm: $2.408(\mathrm{t}, 1 \mathrm{H}, \mathrm{CH}), 2.468\left(\mathrm{~s}, 9 \mathrm{H}, \mathrm{CH}_{3}\right), 3.358\left(\mathrm{~s}, 2 \mathrm{H}, \mathrm{CCH}_{2} \mathrm{O}\right), 3.890(\mathrm{~m}, 8 \mathrm{H}$, $\mathrm{OCH}_{2} \mathrm{CCH}$ and $\left.\mathrm{OCH}_{2} \mathrm{C}\right), 7.357(\mathrm{~d}, 6 \mathrm{H}, \mathrm{ArH})$, and $7.716(\mathrm{~d}, 6 \mathrm{H}, \mathrm{ArH}) .{ }^{13} \mathrm{C} \mathrm{NMR}\left(\mathrm{CDCl}_{3}\right.$; $125.8 \mathrm{MHz}) \delta$ ppm: $21.87\left(\mathrm{CH}_{3}\right), 43.76\left(\mathrm{CH}_{2} \mathrm{CCH}_{2}\right), 66.11\left(\mathrm{OCH}_{2} \mathrm{CCH}\right), 66.89\left(\mathrm{OCH}_{2} \mathrm{C}\right)$, $75.51(\mathbf{C H}), 78.66\left(\mathrm{CH}_{2} \mathbf{C C H}\right), 128.16$ (ArC), 130.22 (ArC), 132.01 (ArC), and 145.50 (ArC). ESI-MS ( $m / z)$ : 659.10 (659.11 calc'd for $\mathrm{C}_{29} \mathrm{H}_{32} \mathrm{O}_{10} \mathrm{~S}_{3}[\mathrm{M}+\mathrm{Na}]^{+}$). Elemental analysis calc'd (found) for $\mathrm{C}_{29} \mathrm{H}_{32} \mathrm{O}_{10} \mathrm{~S}_{3}$ : C, 54.70 (54.48); H, 5.07 (5.12); S, 15.10 (15.01).

3-(3-Thiocyanatomethyl)propoxy)prop-1-yne $\left[\mathrm{C}_{11} \mathrm{H}_{11} \mathrm{~N}_{3} \mathrm{OS}_{3}\right], 6$. Synthesis of compound 6 was accomplished using a modified literature procedure.[67] To a $100 \mathrm{~mL}$ round bottom flask equipped with a condenser, 5 (10.02 g, $15.75 \mathrm{mmol}), \mathrm{KSCN}$ (19.86 g, $204.8 \mathrm{mmol})$ and anhydrous DMF (70 mL) were heated to $110{ }^{\circ} \mathrm{C}$ for 18 hours, $120{ }^{\circ} \mathrm{C}$ for 2 hours, and then an additional 8 hours at $110{ }^{\circ} \mathrm{C}$ while vigorously stirring. The reaction was monitored by silica gel TLC, using DCM as the mobile phase, until no starting material remained $\left(6, \mathrm{R}_{\mathrm{f}} \approx 0.4\right)$. The dark brown reaction mixture was poured over crushed ice water $(800 \mathrm{~mL})$ and placed in the freezer overnight $\left(-13^{\circ} \mathrm{C}\right)$ to precipitate the crude product, a dark brown solid. All of the solids were collected, combined, dissolved in ethyl acetate, and purified through a plug of silica gel. Pure product, a light yellow precipitate, was obtained by recrystallization from a 


\section{Yutian Feng}

mixture of ethyl ether and DCM using a dry ice/acetone bath. X-ray quality crystals were obtained by slow evaporation from ethyl ether. Yield: $2.79 \mathrm{~g}, 60 \% .{ }^{1} \mathrm{H}$ NMR $\left(\mathrm{CDCl}_{3} ; 500\right.$ MHz) $\delta$ ppm: $2.53(\mathrm{t}, 1 \mathrm{H}, \mathrm{CH}), 3.33\left(\mathrm{~s}, 6 \mathrm{H}, \mathrm{CH}_{2} \mathrm{SCN}\right), 3.70\left(\mathrm{~s}, 2 \mathrm{H}, \mathrm{CCH}_{2} \mathrm{O}\right)$, and $4.24(\mathrm{~d}$, $\left.2 \mathrm{H}, \mathrm{OCH} \mathrm{H}_{2} \mathrm{CCH}\right) .{ }^{13} \mathrm{C} \mathrm{NMR}\left(\mathrm{CDCl}_{3} ; 125.8 \mathrm{MHz}\right) \delta \mathrm{ppm}: 37.04\left(\mathrm{SCH}_{2} \mathrm{C}\right), 46.17\left(\mathrm{CH}_{2} \mathrm{CCH}_{2}\right)$, $58.69\left(\mathrm{CCH}_{2} \mathrm{O}\right), 68.97\left(\mathrm{OCH}_{2} \mathrm{CCH}\right), 76.42(\mathrm{CH}), 78.09\left(\mathrm{CH}_{2} \mathrm{CCH}\right)$, and $111.53(\mathrm{SCN})$. ESIMS (m/z): 298.73 (299.01 calc'd for $\left.\mathrm{C}_{11} \mathrm{H}_{11} \mathrm{~N}_{3} \mathrm{OS}_{3}[\mathrm{M}+\mathrm{H}]^{+}\right)$. Elemental analysis calc'd (found) for $\mathrm{C}_{11} \mathrm{H}_{11} \mathrm{~N}_{3} \mathrm{OS}_{3}$ : C, 44.42 (44.72); $\mathrm{H}, 3.73$ (3.67); N, 14.13 (13.86); S, 32.34 (32.51). Ethyl 3-azidopropionate $\left[\mathrm{C}_{5} \mathrm{H}_{9} \mathrm{~N}_{3} \mathrm{O}_{2}\right]$, 9. The product was prepared using a modified literature procedure.[68] To a stirring solution of DMSO (200 mL), and ethyl 3bromopropionate $(20.55 \mathrm{~g}, 113.5 \mathrm{mmol})$ at $0{ }^{\circ} \mathrm{C}, \mathrm{NaN}_{3}(9.71 \mathrm{~g}, 149.3 \mathrm{mmol})$ was added slowly. The reaction was allowed to slowly come to room temperature and stirred for 3 days. The reaction was poured into water $(600 \mathrm{~mL})$, and extracted with ethyl acetate $(3 \mathrm{x} 100 \mathrm{~mL})$. The combined ethyl acetate fractions were washed with saturated sodium bicarbonate $(2 \times 50$ $\mathrm{mL})$, water $(3 \times 50 \mathrm{~mL})$, brine $(1 \times 50 \mathrm{~mL})$, dried over sodium sulfate, filtered, and taken to dryness to give the pure product, a light yellow liquid. Yield: $71 \%, 11.5 \mathrm{~g} .{ }^{1} \mathrm{H} \mathrm{NMR}\left(\mathrm{CDCl}_{3}\right.$; $500 \mathrm{MHz}) \delta$ ppm: $1.468\left(\mathrm{t}, 3 \mathrm{H}, \mathrm{CH}_{3}\right), 2.54\left(\mathrm{t}, 2 \mathrm{H}, \mathrm{CH}_{2} \mathrm{C}\right), 3.54\left(\mathrm{t}, 2 \mathrm{H}, \mathrm{N}_{3} \mathrm{CH}_{2}\right)$, and $4.16(\mathrm{q}$,

$\left.2 \mathrm{H}, \mathrm{COOCH} \mathbf{H}_{2}\right) \cdot{ }^{13} \mathrm{C} \mathrm{NMR}\left(\mathrm{CDCl}_{3}: 125.8 \mathrm{MHz}\right) \delta \mathrm{ppm}: 14.28\left(\mathrm{CH}_{3}\right), 34.08\left(\mathbf{C H}_{2} \mathrm{COO}\right), 46.87$ $\left(\mathrm{N}_{3} \mathrm{CH}_{2}\right), 61.02\left(\mathrm{COOCH}_{2}\right)$, and $170.91(\mathbf{C})$.

Ethyl 3-(4-((3-thiocyanato-2,2-bis(thiocyanatomethyl)propoxy)methyl)-1H-1,2,3-triazol-1yl)propanoate $\left[\mathrm{C}_{16} \mathrm{H}_{20} \mathrm{~N}_{6} \mathrm{O}_{3} S_{3}\right]$, 7. Synthesis of compound 7 was accomplished using a modified literature procedure.[69, 70] Compounds 6 (1.19 g, $4 \mathrm{mmol})$ and 9 (1.76 g, 12 mmol) were added to a stirring solution of copper (II) sulfate pentahydrate $(21.9 \mathrm{mg}, 0.08$ mmol), sodium ascorbate $(270 \mathrm{mg}, 1.2 \mathrm{mmol})$, copper metal (1 g), THF (4 mL), ACN (4 mL), 


\section{Yutian Feng}

$\mathrm{H}_{2} \mathrm{O}(4 \mathrm{~mL})$, and $t-\mathrm{BuOH}(4 \mathrm{~mL})$ at $55{ }^{\circ} \mathrm{C}$. The reaction was monitored by silica gel TLC using DCM as the mobile phase $\left(9, \mathrm{R}_{\mathrm{f}} \approx 1 ; \mathbf{6}, \mathrm{R}_{\mathrm{f}} \approx 0.4 ; 7, \mathrm{R}_{\mathrm{f}} \approx 0\right)$. Once compound $\mathbf{6}$ was no longer observed, the solvents were removed by vacuum distillation. The residue was dissolved in DCM and loaded on a plug of silica gel. DCM was added as the mobile phase to remove impurities. Ethyl acetate was then added to elute the crude compound of interest. Further purification was accomplished by silica gel column chromatography ( 3 x $18 \mathrm{~cm}, 40 \mathrm{~g}$ ) using 40/60 hexanes/ethyl acetate to 20/80 hexanes/ethyl acetate to $100 \%$ ethyl acetate to obtain the compound of interest in the fractions containing $\geq 80 \%$ ethyl acetate as clear light yellow oil. Yield: $1.73 \mathrm{~g}, 98 \% .{ }^{1} \mathrm{H}$ NMR $\left(\mathrm{CDCl}_{3} ; 500 \mathrm{MHz}\right) \delta \mathrm{ppm}: 1.24(\mathrm{t}, 3 \mathrm{H}, \mathrm{CH}), 2.96(\mathrm{t}$, $2 \mathrm{H}, \mathrm{CH}_{2} \mathrm{COO}$ ), 3.28 (s, 6H, NCSCH $\left.\mathbf{H}_{2}\right), 3.65$ (s, 2H, $\left.\mathrm{CCH}_{2}\right), 4.15$ (q, 2H, COOCH $\left.\mathbf{H}_{2}\right), 4.64$ (t, $\left.2 \mathrm{H}, \mathrm{NCH}_{2}\right), 4.67\left(\mathrm{~s}, 2 \mathrm{H}, \mathrm{OCH}_{2} \mathrm{C}=\mathrm{C}\right)$, and $7.71(\mathrm{~s}, 1 \mathrm{H}, \mathrm{CH}) .{ }^{13} \mathrm{C} \mathrm{NMR}\left(\mathrm{CDCl}_{3} ; 125.8 \mathrm{MHz}\right)$ $\delta$ ppm: $14.22\left(\mathrm{CH}_{3}\right), 34.64\left(\mathrm{CH}_{2} \mathrm{COO}\right), 36.92\left(\mathrm{NCSCH}_{2}\right), 45.74\left(\mathrm{NCH}_{2}\right), 46.08(\mathbf{C}), 61.36$ $\left(\mathrm{COOCH}_{2}\right), 64.18\left(\mathrm{CCH}_{2} \mathrm{O}\right), 69.33\left(\mathrm{OCH}_{2}\right), 111.62(\mathrm{SCN}), 124.64(\mathrm{C}=\mathrm{C}), 143.11(\mathrm{C}=\mathrm{C})$, and $170.53(\mathbf{C}=\mathrm{O})$. ESI-MS $(\mathrm{m} / \mathrm{z})$ : $441.06\left(440.08\right.$ calc'd for $\left.\mathrm{C}_{16} \mathrm{H}_{20} \mathrm{~N}_{6} \mathrm{O}_{3} \mathrm{~S}_{3}[\mathrm{M}+\mathrm{H}]^{+}\right)$. 3-(4-((3-Thiocyanato-2,2-bis(thiocyanatomethyl)propoxy)methyl)-1H-1,2,3-triazol-1yl)propanoic acid $\left[\mathrm{C}_{14} \mathrm{H}_{16} \mathrm{~N}_{6} \mathrm{O}_{3} \mathrm{~S}_{3}\right], 8$. Concentrated sulfuric acid $(0.5 \mathrm{~mL})$ was added to a stirring solution of compound $7(0.40 \mathrm{~g}, 0.908 \mathrm{mmol})$ in $\mathrm{ACN}(5 \mathrm{~mL})$ and water $(25 \mathrm{~mL})$ at $70{ }^{\circ} \mathrm{C}$. The reaction was equipped with a reflux condenser, and monitored by silica gel TLC using a 20/80 mix of hexane/ethyl acetate as a mobile phase $\left(\mathbf{9}, \mathrm{R}_{\mathrm{f}} \approx 1 ; \mathbf{7}, \mathrm{R}_{\mathrm{f}} \approx 0.5 ; \mathbf{8}, \mathrm{R}_{\mathrm{f}} \approx\right.$ 0.25 ) until no starting material (compound 7) was observed. The ACN was removed via vacuum distillation, and the remaining material was extracted in DCM $(3 \times 50 \mathrm{~mL})$. The organic layers were combined, and taken to dryness by vacuum distillation. The residue oil was dissolved in DCM $(10 \mathrm{~mL})$ and applied to a plug of silica gel. DCM $(200 \mathrm{~mL})$ was 


\section{Yutian Feng}

added to remove any unwanted materials, and then ethyl acetate $(200 \mathrm{~mL})$ to elute the crude product. The ethyl acetate was removed and the product was further purified by reversed phase $\mathrm{C} 18$ chromatography $(3 \times 15 \mathrm{~cm})$ using $40 / 60 \mathrm{ACN} / \mathrm{H}_{2} \mathrm{O}$ as the mobile phase $\left(8, \mathrm{R}_{\mathrm{f}} \approx\right.$ 0.6 by reversed phase TLC with 40/60 $\mathrm{ACN} / \mathrm{H}_{2} \mathrm{O}$ ). The solvent was removed in vacuo to afford a light yellow oil. X-ray quality crystals were obtained by slow evaporation from a 40/60 mixture of $\mathrm{ACN}$ and $\mathrm{H}_{2} \mathrm{O}$. Yield: $50 \%, 0.187$ g. ${ }^{1} \mathrm{H} \mathrm{NMR}\left(\mathrm{CDCl}_{3} ; 500 \mathrm{MHz}\right) \delta \mathrm{ppm}$ : $3.03\left(\mathrm{t}, 2 \mathrm{H}, \mathrm{CH}_{2} \mathrm{COO}\right), 3.29$ (s, 6H, NCSCH$\left.)_{2}\right), 3.64\left(\mathrm{~s}, 2 \mathrm{H}, \mathrm{CCH}_{2}\right), 4.65\left(\mathrm{t}, 2 \mathrm{H}, \mathrm{NCH}_{2}\right), 4.67$ $\left(\mathrm{s}, 2 \mathrm{H}, \mathrm{OCH}_{2} \mathrm{C}=\mathrm{C}\right)$, and $7.76(\mathrm{~s}, 1 \mathrm{H}, \mathrm{CH}) .{ }^{13} \mathrm{C} \mathrm{NMR}\left(\mathrm{CDCl}_{3} ; 125.8 \mathrm{MHz}\right) \delta \mathrm{ppm}: 34.34$ $\left(\mathrm{CH}_{2} \mathrm{COO}\right), 36.95\left(\mathrm{NCSCH}_{2}\right), 45.79\left(\mathrm{NCH}_{2}\right), 46.05(\mathbf{C}), 63.94\left(\mathrm{CCH}_{2} \mathrm{O}\right), 69.38\left(\mathrm{OCH}_{2}\right)$, $111.77(\mathrm{SCN}), 124.95(\mathrm{C}=\mathbf{C}), 143.07(\mathbf{C}=\mathrm{C})$, and $173.92(\mathbf{C}=\mathrm{O})$. ESI-MS $(\mathrm{m} / \mathrm{z}): 412.02$ (412.04 calc'd for $\mathrm{C}_{14} \mathrm{H}_{16} \mathrm{~N}_{6} \mathrm{O}_{3} \mathrm{~S}_{3}[\mathrm{M}+\mathrm{H}]^{+}$). Elemental analysis calc'd (found) for $\mathrm{C}_{14} \mathrm{H}_{16} \mathrm{~N}_{6} \mathrm{O}_{3} \mathrm{~S}_{3}: \mathrm{C}, 37.07$ (37.15); H, 3.89 (3.94).

\section{Synthesis of Trithiocyanate-BBN Precursor}

Bombesin(7-14) $\mathrm{NH}_{2}$ was synthesized by solid phase peptide synthesis (model AAPPTEC 396 Omega, Louisville, KY) using Fmoc chemistry on Sieber Resin. All protected amino acids, as well as the solutions for coupling and deprotection reactions, were separately dissolved and arranged in the different specific vessels of the instrument. The protection groups used for the amino acid side chains were: Trityl (Trt) (Gln, His); tertbutyloxycarbonyl (Boc) (Trp); The Fmoc protecting groups were removed at every subsequent cycle by treatment with $20 \%$ piperidine for $10 \mathrm{~min}$. The peptide chain was assembled by sequential acylation (20 min for coupling) with "in situ" activated Fmoc-amino acids. Re-coupling was automatically performed at every cycle. The "in situ" activation of 


\section{Yutian Feng}

Fmoc-amino acids ( 3 eq. compared to the resin amount) were carried out using uronium salts (HBTU, 2.7 eq., HOBt 3 eq.) and DIEA (6 eq.). Compound 8 (700 mg, 2.4 mmol) was conjugated to the $\mathrm{N}$ terminus of the Bombesin (7-14) $\mathrm{NH}_{2}$ peptide on the resin using the same standard procedure used for the other amino acids. [71] The peptidyl-resin was cleaved and deprotected in a single reaction ( 2 hours) with the following mixture: TFA, phenol, water and TIS (85:5:5:5). Thiol scavengers were avoided as they react with thiocyanate groups. Precipitation and multiple washings with diethyl ether gave the final crude product. The product was HPLC purified as the trithiocyanate- $\mathrm{BBN}(7-14) \mathrm{NH}_{2}$ precursor, characterized by LC-MS ([M+H' $\left.\mathrm{H}^{+}\right] 1333,1333$ for $\left.\mathrm{C}_{57} \mathrm{H}_{79} \mathrm{O}_{11} \mathrm{~N}_{19} \mathrm{~S}_{4}\right)$, lyophilized and stored for further use.

\section{Synthesis of Trithiol-BBN(7-14) $\mathrm{NH}_{2}$}

The trithiocyanate-BBN(7-14) $\mathrm{NH}_{2}$ precursor $(1 \mathrm{mg}, 0.75 \mu \mathrm{mol}, 0.75 \mathrm{mM})$ was dissolved in $20 \% \mathrm{ACN}$ in water $(1 \mathrm{~mL}$ ), to which tris(2-carboxyethyl)phosphine (TCEP, $2 \mathrm{mg}, 7.5 \mu \mathrm{mol}$ ) was added. The solution was placed in a $55{ }^{\circ} \mathrm{C}$ water bath for $2 \mathrm{~h}$ to yield the trithiol-BBN(714) $\mathrm{NH}_{2}$ (TCEP residue remained), which was characterized by LC-MS $\left(\left[\mathrm{M}+\mathrm{H}^{+}\right] 1258,1258\right.$ for $\mathrm{C}_{54} \mathrm{H}_{82} \mathrm{O}_{11} \mathrm{~N}_{16} \mathrm{~S}_{4}, 90 \%$ yield) and used without further purification as the trithiol-BBN stock solution $(0.75 \mathrm{mM}, 1 \mathrm{mg} / \mathrm{mL})$.

\section{Synthesis of As-trithiol-BBN(7-14) $\mathrm{NH}_{2}$}

The As-trithiol-BBN(7-14) $\mathrm{NH}_{2}$ compound was synthesized with natural As $\left(\mathrm{As}_{2} \mathrm{O}_{3}\right)$ and characterized by LC-MS. The trithiol-BBN(7-14) $\mathrm{NH}_{2}$ stock solution $(500 \mu \mathrm{L}, 0.5 \mathrm{mg}, 0.4$ $\mu$ mol) was added to a vial. An arsenic trioxide stock solution was made by dissolving $\mathrm{As}_{2} \mathrm{O}_{3}$ (10.6 mg, $0.054 \mathrm{mmol})$ in water $\left(13.4 \mathrm{~mL}, \mathrm{As}_{2} \mathrm{O}_{3}\right.$ concentration $\left.4 \mathrm{mM}\right) . \mathrm{NaOH}$ solution $(50$ 


\section{Yutian Feng}

$\mu \mathrm{L}, 10 \mathrm{M}$ ) was added to assist the dissolution of $\mathrm{As}_{2} \mathrm{O}_{3}$. The arsenic trioxide stock solution (100 $\mu \mathrm{L}, 0.4 \mu \mathrm{mol})$ was added to the trithiol-BBN(7-14) $\mathrm{NH}_{2}$ stock solution $(0.4 \mu \mathrm{mol})$ at an 1:1 molar ratio and the reaction vial was placed in a $55{ }^{\circ} \mathrm{C}$ water bath for $40 \mathrm{~min}$. The Astrithiol-BBN(7-14) $\mathrm{NH}_{2}$ reaction solution was characterized by LC-MS $\left(\left[\mathrm{M}+\mathrm{H}^{+}\right]\right.$1330, 1330 for $\mathrm{C}_{54} \mathrm{H}_{79} \mathrm{O}_{11} \mathrm{~N}_{16} \mathrm{~S}_{4} \mathrm{As}$, over $95 \%$ yield). An HPLC comparison of trithiol-BBN(7-14) $\mathrm{NH}_{2}$ and As-trithiol-BBN(7-14) $\mathrm{NH}_{2}$ was carried out. The retention time of trithiol-BBN(7-14) $\mathrm{NH}_{2}$ and As-trithiol-BBN(7-14) $\mathrm{NH}_{2}$ were $12.3 \mathrm{~min}$ and $13.3 \mathrm{~min}$, respectively.

\section{X-ray Crystal Structures}

Crystallographic data of compound 3, 6 and $\mathbf{8}$ were acquired by Dr. Anthony DeGraffenreid and Dr. Charles Barnes and hence were included in Dr. Anthony DeGraffenreid's dissertation. [52] Intensity data for compounds $\mathbf{3 , 6}$, and $\mathbf{8}$ were obtained at $-100{ }^{\circ} \mathrm{C}$ or -173 ${ }^{\circ} \mathrm{C}$ on a Bruker SMART CCD Area Detector system using the $\omega$ scan technique with Mo Ka radiation from a graphite monochromator. Intensities were corrected for Lorentz and polarization effects. Equivalent reflections were merged, and absorption corrections were made using the multi-scan method. The structures were solved by direct methods with fullmatrix least-squares refinement, using the SHELX package.[55] All non-hydrogen atoms were refined with anisotropic thermal parameters. The hydrogen atoms were placed at calculated positions and included in the refinement using a riding model, with fixed isotropic $U$. Data were corrected for decay and absorption using the program SADABS.[56] Final difference maps contained no features of chemical significance. 


\section{Radiotracer synthesis of no carrier added ${ }^{77}$ As-trithiol-BBN}

No carrier added (nca) ${ }^{77} \mathrm{As}\left(\left[{ }^{77} \mathrm{As}\right] \mathrm{H}_{2} \mathrm{AsO}_{4}{ }^{-}, 370 \mathrm{MBq} / \mathrm{mL}, 10 \mathrm{mCi} / \mathrm{mL}\right)$ in aqueous solution was obtained from the University of Missouri Research Reactor (MURR) as a stock solution. An aliquot of the ${ }^{77}$ As stock solution $(200 \mu \mathrm{L}, 74 \mathrm{MBq}, 2 \mathrm{mCi})$ was added to a $2 \mathrm{~mL}$ sterile centrifuge tube along with a $30 \%$ ethanol/water solution $(581 \mu \mathrm{L})$. Ammonium mercaptoacetate $(18.2 \mu \mathrm{L}, 5.5 \mathrm{M}, 100 \mu \mathrm{mol})$ was then added, and the reaction was placed in a $55^{\circ} \mathrm{C}$ water bath for $45 \mathrm{~min}$. The trithiol-BBN(7-14) $\mathrm{NH}_{2}$ stock solution $(100 \mu \mathrm{L}, 0.75 \mathrm{mM}$, $0.1 \mathrm{mg}$ ) was added to the reaction mixture and heating continued in the $55^{\circ} \mathrm{C}$ water bath for $45 \mathrm{~min}$. The reaction was cooled to room temperature and diluted with $10 \mathrm{~mL}$ of water. A Sep-Pak® C18 Plus Light cartridge was preconditioned with ethanol and rinsed with water, and then the diluted reaction mixture was loaded on the cartridge, and washed with $10 \mathrm{~mL}$ of water. No carrier added ${ }^{77}$ As-trithiol-BBN was eluted from the cartridge with $1 \mathrm{~mL}$ of ethanol to which ascorbic acid $(30 \mu \mathrm{g})$ was added. The solution was brought to dryness under a gentle $\mathrm{N}_{2}$ stream at $25^{\circ} \mathrm{C}$, and then reconstituted with $5 \mathrm{~mL}$ of sterile saline solution. The final yield was determined to be $44.4 \mathrm{MBq}(1.2 \mathrm{mCi}, 60 \%)$ in $5 \mathrm{~mL}$ of bacteriostatic saline solution.

\section{Radiotracer synthesis of no carrier added ${ }^{72}$ As-trithiol-BBN}

Eluents from the ${ }^{72} \mathrm{Se} /{ }^{72}$ As generator were boiled to dryness and reconstituted with $1 \mathrm{~mL}$ of DI water $(0.555 \mathrm{MBq}, 15 \mu \mathrm{Ci}$ in $1 \mathrm{~mL})$ as the ${ }^{72} \mathrm{As}$ stock solution. An ethanol in water solution (30\% ethanol) $(345 \mu \mathrm{L})$ was added to a glass vial along with the ${ }^{72}$ As stock solution $(600 \mu \mathrm{L}, 0.33 \mathrm{MBq}, 9 \mu \mathrm{Ci})$. Ammonium mercaptoacetate solution $(9.1 \mu \mathrm{L}, 5.5 \mathrm{M}, 50 \mu \mathrm{M})$ was added to the vial and the reaction solution was heated at $55^{\circ} \mathrm{C}$ while stirring for 40 min. 


\section{Yutian Feng}

The trithiol-BBN(7-14) $\mathrm{NH}_{2}$ solution $(50 \mu \mathrm{L}, 0.75 \mathrm{mM}, 37.5 \mathrm{nM})$ was added and the reaction solution was heated at $55{ }^{\circ} \mathrm{C}$ while stirring for $40 \mathrm{~min}$. Then the reaction solution was filtered through a $0.2 \mu \mathrm{m}$ pore size syringe filter. The reaction solution was injected in the HPLC and the radiolabeling yield was determined to be over $96 \%$, with the same retention time as the non-radioactive standard As-trithiol-BBN(7-14) $\mathrm{NH}_{2}$.

\section{Biodistribution studies of no carrier added free ${ }^{77} \mathrm{As}$ and ${ }^{77} \mathrm{As}$-trithiol-BBN}

Male CF-1 mice at 5-6 weeks of age (Charles River Laboratories, Wilmington, MA) were used for pharmacokinetic studies. Mice were fed ad libitum rodent chow (Lab Diet 5008; Lab Diet, Inc., St. Louis, MO) and ad libitum acidified water in a humidified environment while housed four mice per cage in a ventilated rack system on a 12-hour light/12-hour dark light cycle in an AAALAC accredited facility. All studies were approved by the HS Truman Memorial Veteran's Hospital Subcommittee for Animal Studies (SAS).

Biodistribution studies of both uncomplexed ${ }^{77} \mathrm{As}\left(\left[{ }^{77} \mathrm{As}\right] \mathrm{H}_{2} \mathrm{AsO}_{4}{ }^{-}\right)$and $\left[{ }^{77} \mathrm{As}\right]$ As-trithiol$\mathrm{BBN}(7-14) \mathrm{NH}_{2}$ were performed in CF-1 mice. An ${ }^{77} \mathrm{As}\left(\left[{ }^{77} \mathrm{As}\right] \mathrm{H}_{2} \mathrm{AsO}_{4}{ }^{-}\right)$solution was prepared by diluting $60 \mu \mathrm{L}$ of nca ${ }^{77} \mathrm{As}\left(\left[{ }^{77} \mathrm{As}\right] \mathrm{H}_{2} \mathrm{AsO}_{4}{ }^{-}, 370 \mathrm{MBq} / \mathrm{mL}, 10 \mathrm{mCi} / \mathrm{mL}\right)$ stock solution with $2 \mathrm{~mL}$ of sterile saline solution. Animals were administered $100 \mu \mathrm{L}$ via the lateral tail vein. For the uncomplexed ${ }^{77} \mathrm{As}, 1.11 \mathrm{MBq}, 30 \mu \mathrm{Ci}$ in a $100 \mu \mathrm{L}$ syringe was measured with $0.67 \sim 0.78 \mathrm{MBq}(18 \sim 21 \mu \mathrm{Ci})$ of radioactivity administered. For ${ }^{77}$ As-trithiol$\mathrm{BBN}(7-14) \mathrm{NH}_{2}, 0.89 \mathrm{MBq}(24 \mu \mathrm{Ci})$ in $100 \mu \mathrm{L}$ were measured and $0.37 \mathrm{MBq}(10 \mu \mathrm{Ci})$ administered. Mice were sacrificed at $15 \mathrm{~min}, 1 \mathrm{~h}, 4 \mathrm{~h}$ and $24 \mathrm{~h}$ time points for uncomplexed

${ }^{77} \mathrm{As}$ and $1 \mathrm{~h}$ and $4 \mathrm{~h}$ time points for ${ }^{77} \mathrm{As}$-trithiol-BBN(7-14) $\mathrm{NH}_{2}$ post injection. Tissues and organs were collected, weighed, and residual radioactivity was quantified using a NaI(Tl) 


\section{Yutian Feng}

well detector. Data were analyzed to determine the percent injected dose (\%ID) and percent injected dose per gram (\% ID/g) of tissue/organ. Blood volume was calculated based on a blood volume of $6.5 \%$ of the body weight at sacrifice.

\section{Results and Discussion}

No carrier added ${ }^{72}$ As and ${ }^{77}$ As are of interest as a potential matched pair for theranostic radiopharmaceuticals.[31, 32] A linkable trithiol ligand was synthesized in several steps and then conjugated to the $\mathrm{N}$ terminus of the bombesin(7-14) $\mathrm{NH}_{2}$ peptide via solid phase peptide synthesis to afford the trithiocyanate-BBN precursor. The trithiol-BBN conjugate was readily generated by reducing the trithiocyanate-BBN precursor with TCEP, which was radiolabeled with ${ }^{77}$ As for in vivo stability evaluation in normal mice. Radiolabeling trithiol-BBN was also carried out with nca ${ }^{72}$ As eluted from the ${ }^{72} \mathrm{Se} /{ }^{72}$ As generator and similar results were achieved.

Trithiol Precursor Syntheses. The synthesis of the first trithiol precursors 3-(3thiocyanatomethyl)propoxy)prop-1-yne, 6, and 3-(4-((3-thiocyanato-2,2bis(thiocyanatomethyl) propoxy)methyl)-1H-1,2,3-triazol-1-yl)propanoic acid, 8, were prepared in yields of $31 \%$, and $50 \%$, respectively, using modified literature procedures (Scheme 4.1).[67] 


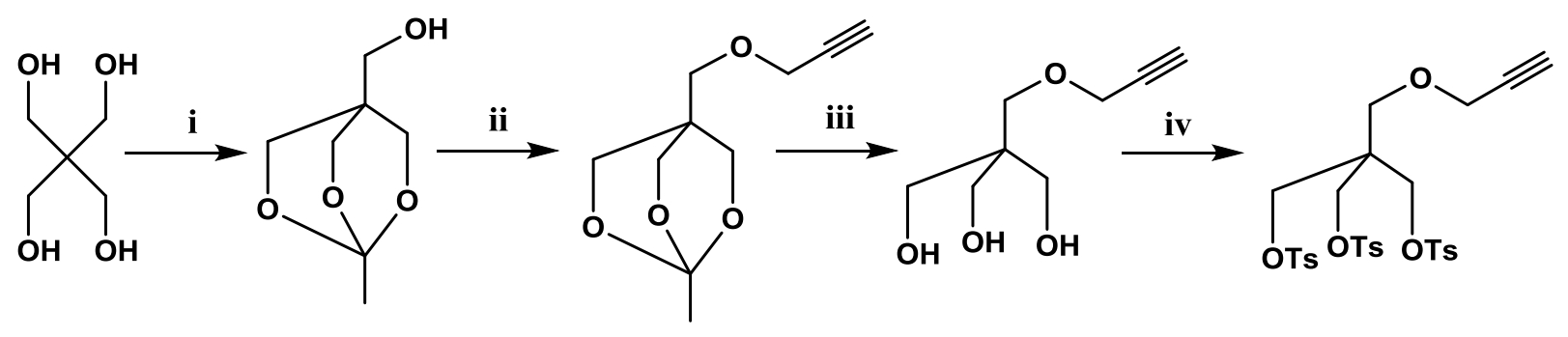

1

2

3

4

5

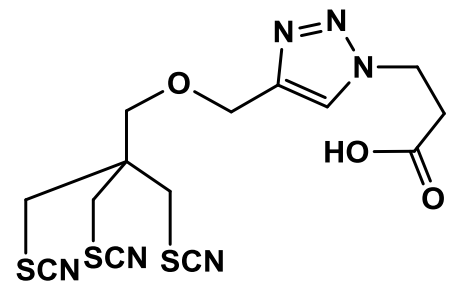

8

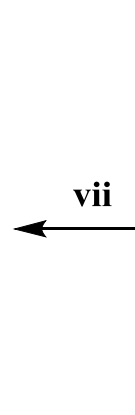

vii

7

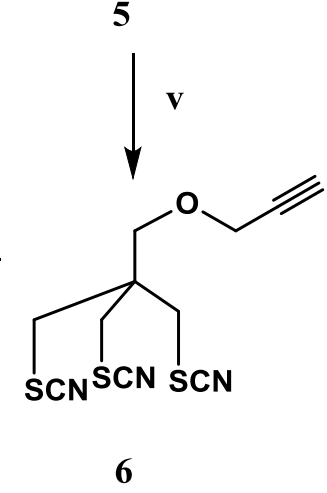

i: pentaerythritol, DOP, trace p-toluene sulfonic acid, triethyl orthoacetate (1 equiv.)

ii: DMSO, powdered $\mathrm{KOH}$, propargyl bromide (1 equiv.)

iii: $\mathrm{MeOH}, 2 \mathrm{M} \mathrm{HCl}$, then $\mathrm{K}_{2} \mathrm{CO}_{3}$

iv: pyridine (15.2 equiv.), p-toluene sulfonyl chloride (5.5 equiv.)

v: dry DMF, KSCN (13 equiv.)

vi: ACN, DI water, THF, t-butanol, copper (II) sulfate pentahydrate, sodium ascorbate, and ethyl 3-azidopropinoate (3 equiv) vii: DI water, $\mathrm{ACN}$, and $\mathrm{H}_{2} \mathrm{SO}_{4}$ (cat.)

Scheme 4.1. Synthetic scheme for the linkable trithiol precursor, compound $\mathbf{8}$.

(1-Methyl-2,6,7-trioxabic yclo[2.2.2]octan-4-yl)methanol, 2, was synthesized by the reaction of pentaerythritol, $\mathbf{1}$, with triethyl orthoacetate and a catalytic quantity $(0.025 \%$ wt.) of ptoluene sulfonic acid monohydrate in dioctyl phthalate at $120^{\circ} \mathrm{C}$. A key detail omitted in many literature preparations is the addition of TEA or another trialkyl amine base prior to distillation of the product. This compound is acid sensitive, therefore if the amine base is absent rapid decomposition occurs due to the catalytic quantity $(0.025 \%$ wt.) of p-toluene sulfonic acid present. Reaction of propargyl bromide with the bicyclic orthoester in dry DMSO containing powdered $\mathrm{KOH}$ yielded the bicyclic orthoester alkyne, 1-methyl-4-((prop- 


\section{Yutian Feng}

2-yn-1-yloxy)methyl)-2,6,7-trioxabic yclo[2.2.2]octane, 3. Attempts to purify this by silica gel proved futile because of the inherent acidity of silica. Recrystallization from benzene or ethyl ether is possible, however typically the crude product was immediately added to a stirring solution of methanol containing $\mathrm{HCl}$ followed by the addition of base, 24 hours later, to provide 2-(hydroxymethyl)-2-((prop-2-yn-1-yloxy)methyl)propane-1,3-diol, 4. Reaction of 4 with excess $p$-toluene sulfonyl chloride in pyridine yielded the 2-((prop-2-yn-1yloxy)methyl)-2-((tosyloxy)methyl)propane-1,3-diyl bis(4-methylbenzenesulfonate), 5. The first protected trithiol precursor, 3-(3-thiocyanatomethyl)propoxy)prop-1-yne, 6, was synthesized by reacting the tris-tosylate (5) with excess potassium thiocyanate in dry DMF. Further reaction of ethyl 3-azidopropionate, 9, with the alkyne, 6, through a Huisgen 1,3dipolar cycloaddition or 'click' reaction provided ethyl 3-(4-((3-thiocyanato-2,2bis(thiocyanatomethyl) propoxy)methyl)-1H-1,2,3-triazol-1-yl)propanoate, 7, in good yield. Subsequent acid catalyzed hydrolysis of the ester was carried out to give 3-(4-((3thiocyanato-2,2-bis(thiocyanatomethyl)propoxy)methyl)-1H-1,2,3-triazol-1-yl) propanoic acid, $\mathbf{8}$. Saponification of the ester was avoided due to the instability of the thiocyanate in alkali base.

The key intermediates, $\mathbf{2}, \mathbf{5}, \mathbf{6}$, and $\mathbf{8}$, were characterized by elemental analysis, while compounds, 2-8 were characterized by ${ }^{1} \mathrm{H}$ and ${ }^{13} \mathrm{C}$ NMR spectroscopy and ESI-MS. Compound 9 was characterized by ${ }^{1} \mathrm{H}$ and ${ }^{13} \mathrm{C}$ NMR spectroscopy. The molecular ions for compounds 2-8 were observed in the ESI-MS spectra at the calculated $m / z$ values. The ${ }^{1} \mathrm{H}$ and ${ }^{13} \mathrm{C}$ NMR of the compounds reported, 2-9, were characteristic of the functional groups present and comparable to available literature[72]. 


\section{Yutian Feng}

Single Crystal X-ray Structures. Compounds 3,6, and 8 were characterized by single crystal X-ray diffraction analysis. Crystal refinement data, bond angles, and distances are summarized in Tables 4.1 and 4.2. Figures 4.1-4.3 show the ORTEP structures of 3,6 and 8 .

Table 4.1. X-ray crystal Data, data collection parameters, and refinement parameters for $3, \mathbf{6}$, and 8. Many of these compounds were synthesized by Dr. Anthony DeGraffenreid and hence their crystallographic data were included in his Dissertation.[52]

\begin{tabular}{|c|c|c|c|}
\hline & $\begin{array}{l}\text { Bicyclic } \\
\text { Orthoester } \\
(3)\end{array}$ & $\begin{array}{c}\text { Alkyne } \\
\text { Trithiocyanate } \\
\text { (6) }\end{array}$ & $\begin{array}{c}\text { Trithiocyanate } \\
\text { COOH } \\
\text { (8) }\end{array}$ \\
\hline CCDC\# & 1585887 & 1585888 & 1585889 \\
\hline $\begin{array}{l}\text { Formula } \\
\text { F.W. }\end{array}$ & $\begin{array}{c}\mathrm{C}_{10} \mathrm{H}_{14} \mathrm{O}_{4} \\
198.21\end{array}$ & $\begin{array}{c}\mathrm{C}_{11} \mathrm{H}_{11} \mathrm{NOS}_{3} \\
297.41\end{array}$ & $\begin{array}{c}\mathrm{C}_{14} \mathrm{H}_{18} \mathrm{~N}_{6} \mathrm{O}_{4} \mathrm{~S}_{3} \\
430.52\end{array}$ \\
\hline $\begin{array}{l}\text { Crystal } \\
\text { System }\end{array}$ & Monoclinic & Triclinic & Monoclinic \\
\hline Space Group & P 21/c & P -1 & P 21/c \\
\hline $\mathrm{a}(\AA)$ & $7.9189(2)$ & $7.4212(9)$ & $12.3916(4)$ \\
\hline $\mathrm{b}(\AA)$ & $18.4612(5)$ & $9.2485(12)$ & $9.8148(3)$ \\
\hline c $(\AA)$ & $6.8206(2)$ & $10.4614(13)$ & $16.0906(5)$ \\
\hline$\alpha\left(^{\circ}\right)$ & 90 & $76.4950(10)$ & 90 \\
\hline$\beta\left(^{\circ}\right)$ & $103.7190(1)$ & $85.795(2)$ & $101.410(2)$ \\
\hline$\gamma\left({ }^{\circ}\right)$ & 90 & $78.1660(10)$ & 90 \\
\hline$V\left(\AA^{3}\right)$ & $968.67(5)$ & $683.08(15)$ & $1918.28(10)$ \\
\hline Z & 4 & 2 & 4 \\
\hline $\mathrm{r}_{\text {calc, }} \mathrm{g} / \mathrm{cm}^{3}$ & 1.359 & 1.446 & 1.491 \\
\hline $\mathrm{T}, \mathrm{K}$ & $173(2)$ & $100(2)$ & $100(2)$ \\
\hline$\mu, \mathrm{mm}^{-1}$ & 0.877 & 0.533 & 0.42 \\
\hline$\lambda$ source $(\AA)$ & 1.54178 & 0.71073 & 0.7173 \\
\hline $\mathrm{R}(\mathrm{F})$ & 0.0355 & 0.0252 & 0.0375 \\
\hline $\mathrm{R}_{\mathrm{w}}(\mathrm{F})^{2}$ & 0.0881 & 0.0646 & 0.076 \\
\hline GoF & 1.101 & 1.065 & 1.02 \\
\hline
\end{tabular}


Table 4.2. Selected bond angles $\left({ }^{\circ}\right)$ and distances $(\AA)$ for $\mathbf{3 , 6}$, and $\mathbf{8}$.

Bicyclic Orthoester (3)

\begin{tabular}{cccccc}
\hline & & & & \\
$\mathrm{O}(1)-\mathrm{C}(9)$ & $1.4082(1)$ & $\mathrm{C}(1)-\mathrm{C}(8)$ & $1.5454(18)$ & $\mathrm{S}(1)-\mathrm{C}(1)$ & $1.834(2)$ \\
$\mathrm{O}(1)-\mathrm{C}(1)$ & $1.4409(1)$ & $\mathrm{C}(3)-\mathrm{C}(4)$ & $1.472(2)$ & $\mathrm{S}(2)-\mathrm{C}(2)$ & $1.830(2)$ \\
$\mathrm{O}(2)-\mathrm{C}(9)$ & $1.4067(1)$ & $\mathrm{C}(4)-\mathrm{C}(5)$ & $1.185(2)$ & $\mathrm{S}(3)-\mathrm{C}(3)$ & $1.827(2)$ \\
$\mathrm{O}(2)-\mathrm{C}(2)$ & $1.4351(1)$ & $\mathrm{S}(1)-\mathrm{C}(6)$ & $1.8321(14)$ & $\mathrm{S}(1)-\mathrm{C}(6)$ & $1.696(2)$ \\
$\mathrm{O}(3)-\mathrm{C}(9)$ & $1.4046(1)$ & $\mathrm{S}(2)-\mathrm{C}(7)$ & $1.8302(14)$ & $\mathrm{S}(2)-\mathrm{C}(7)$ & $1.693(2)$ \\
$\mathrm{O}(3)-\mathrm{C}(3)$ & $1.4357(1)$ & $\mathrm{S}(3)-\mathrm{C}(8)$ & $1.8374(14)$ & $\mathrm{S}(3)-\mathrm{C}(8)$ & $1.697(2)$ \\
$\mathrm{O}(4)-\mathrm{C}(6)$ & $1.4228(1)$ & $\mathrm{S}(1)-\mathrm{C}(9)$ & $1.6958(16)$ & $\mathrm{N}(1)-\mathrm{C}(6)$ & $1.142(3)$ \\
$\mathrm{O}(4)-\mathrm{C}(5)$ & $1.4279(1)$ & $\mathrm{S}(2)-\mathrm{C}(10)$ & $1.6985(16)$ & $\mathrm{N}(2)-\mathrm{C}(7)$ & $1.149(3)$ \\
$\mathrm{C}(1)-\mathrm{C}(4)$ & $1.5224(2)$ & $\mathrm{S}(3)-\mathrm{C}(11)$ & $1.7004(16)$ & $\mathrm{N}(3)-\mathrm{C}(8)$ & $1.148(3)$ \\
$\mathrm{C}(2)-\mathrm{C}(4)$ & $1.5263(2)$ & $\mathrm{N}(1)-\mathrm{C}(9)$ & $1.147(2)$ & $\mathrm{N}(1)-\mathrm{C}(6)-\mathrm{S}(1)$ & $178.3(2)$ \\
$\mathrm{C}(3)-\mathrm{C}(4)$ & $1.5236(1)$ & $\mathrm{N}(2)-\mathrm{C}(10)$ & $1.146(2)$ & $\mathrm{N}(2)-\mathrm{C}(7)-\mathrm{S}(2)$ & $176.4(2)$ \\
$\mathrm{C}(4)-\mathrm{C}(5)$ & $1.5130(2)$ & $\mathrm{N}(3)-\mathrm{C}(11)$ & $1.148(2)$ & $\mathrm{N}(3)-\mathrm{C}(8)-\mathrm{S}(3)$ & $177.9(2)$ \\
$\mathrm{C}(6)-\mathrm{C}(7)$ & $1.4684(2)$ & $\mathrm{C}(5)-\mathrm{C}(4)-\mathrm{C}(3)$ & $178.25(16)$ & & \\
$\mathrm{C}(7)-\mathrm{C}(8)$ & $1.1858(2)$ & $\mathrm{N}(1)-\mathrm{C}(9)-\mathrm{S}(1)$ & $179.12(14)$ & & \\
$\mathrm{C}(9)-\mathrm{C}(10)$ & $1.4966(2)$ & $\mathrm{N}(2)-\mathrm{C}(10)-\mathrm{S}(2)$ & $176.55(14)$ & & \\
$\mathrm{C}(9)-\mathrm{O}(1)-\mathrm{C}(1)$ & $112.41(9)$ & $\mathrm{N}(3)-\mathrm{C}(11)-\mathrm{S}(3)$ & $176.85(14)$ & & \\
$\mathrm{C}(9)-\mathrm{O}(2)-\mathrm{C}(2)$ & $112.40(8)$ & & & & \\
$\mathrm{C}(9)-\mathrm{O}(3)-\mathrm{C}(3)$ & $112.18(8)$ & & & & \\
$\mathrm{C}(6)-\mathrm{O}(4)-\mathrm{C}(5)$ & $112.82(8)$ & & & & \\
$\mathrm{O}(1)-\mathrm{C}(1)-\mathrm{C}(4)$ & $108.38(9)$ & & & & \\
$\mathrm{O}(2)-\mathrm{C}(2)-\mathrm{C}(4)$ & $108.59(9)$ & & & & \\
$\mathrm{O}(3)-\mathrm{C}(3)-\mathrm{C}(4)$ & $108.89(9)$ & & & &
\end{tabular}




Yutian Feng | | Chapter 4

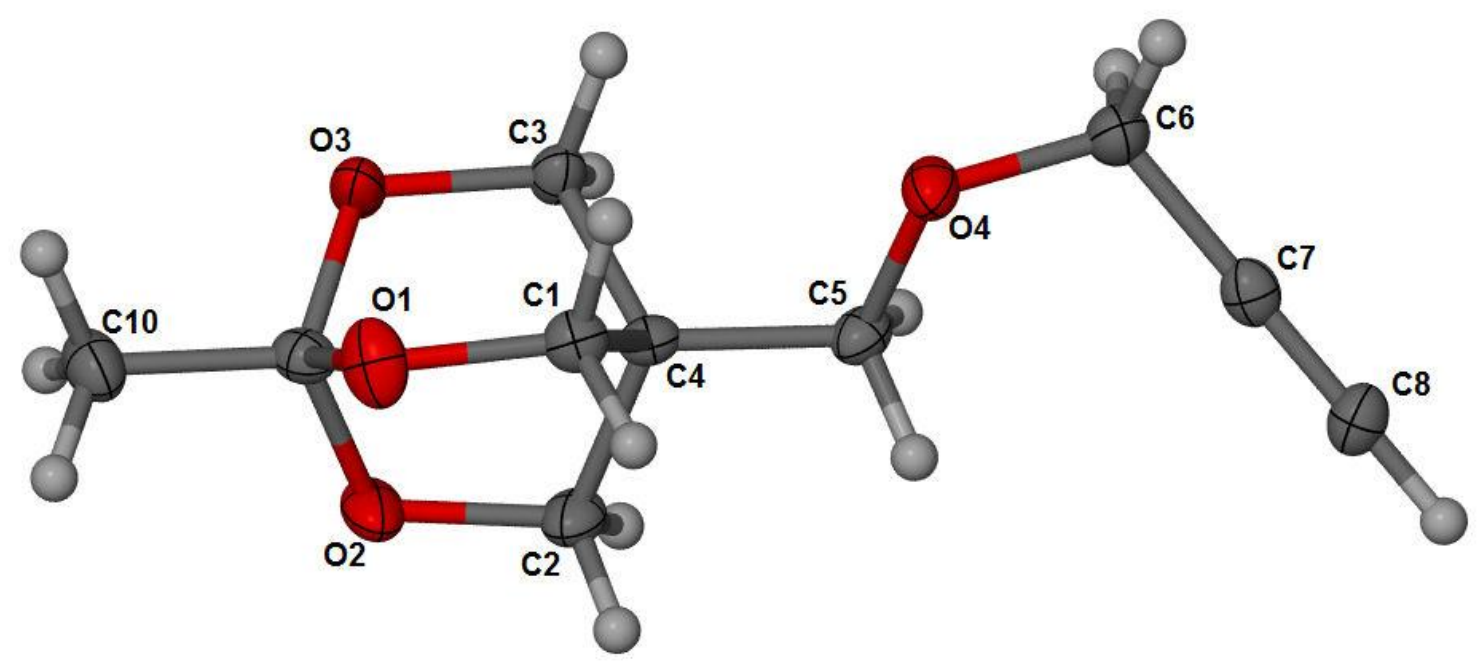

Figure 4.1. ORTEP representation of (3) (CCDC\# 1585887) with 50\% probability ellipsoids.[52]

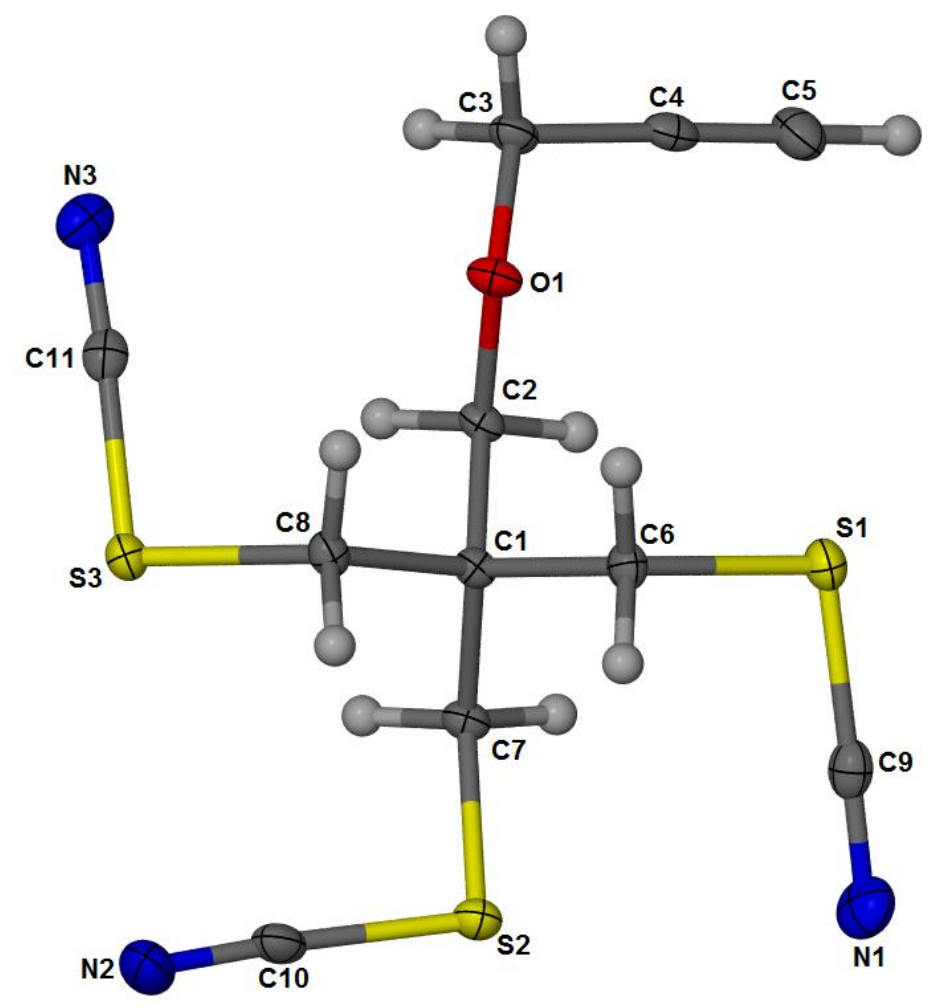

Figure 4.2. ORTEP representation of (6) (CCDC\# 1585888) with 50\% probability ellipsoids.[52] 


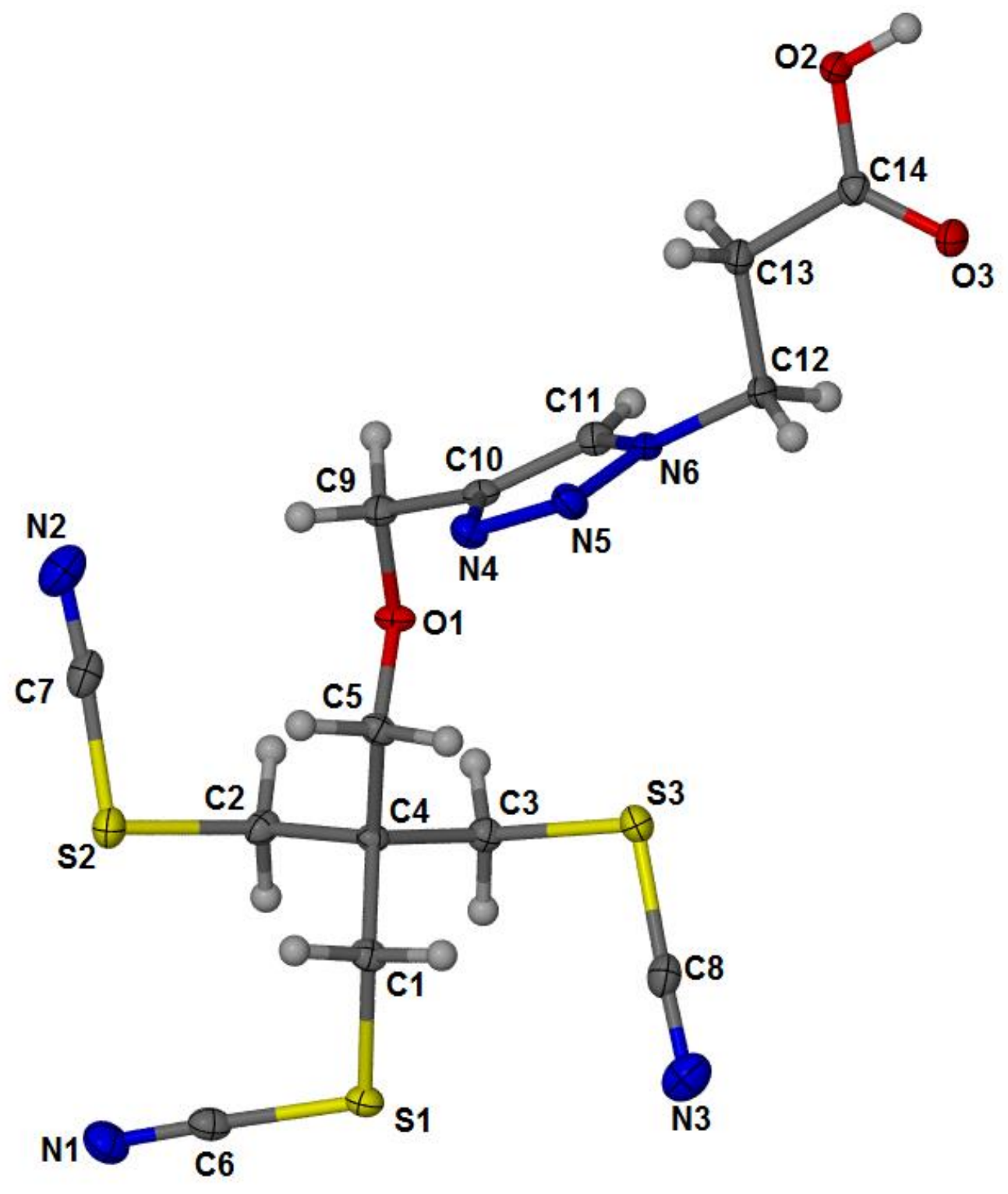

Figure 4.3. ORTEP representation of (8) (CCDC\# 1585889) with 50\% probability ellipsoids.[52]

Bond distances and angles for compounds 3, 6 and $\mathbf{8}$ were consistent with the literature[32, 73]. The average $\mathrm{CN}$ distances were $1.1472 \AA$, and $1.1466 \AA$ for compounds $\mathbf{6}$ and $\mathbf{8}$, respectively. This falls within the range of previously reported organic mono-thiocyanate

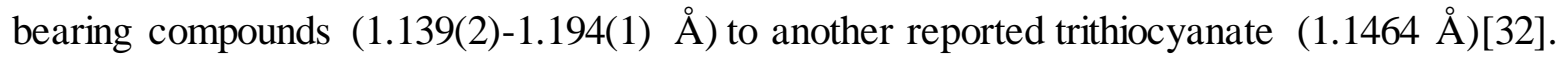




\section{Yutian Feng}

The average S-CN distances $1.6982 \AA$ and $1.6955 \AA$ reported here are slightly longer than reported for similar compounds (1.63 $\AA$ to 1.693(2) $\AA$ ), however are consistent with the reported trithiocyanate (S-CN bond distance of $1.695 \AA$ (1.6932(2) $\AA$ to 1.6977(2) $\AA$ )).[32] The $\mathrm{CH}_{2}$-SCN distances for compounds $\mathbf{6}$ and $\mathbf{8}$ have an average bond distance of $1.8332 \AA$, and 1.8303, respectively, which are in agreement with the distances reported for the trithiocyanate. The SCN angles reported here ranged from $176.4(2)^{\circ}$ to $179.12(14)^{\circ}$, and lie within the range of all reported organic thiocyanates $\left(172.3(1)^{\circ}\right.$ to $\left.197.7(3)^{\circ}\right)$.

Trithiol Precursor Bombesin analogue synthesis and Trithiol-Bombesin deprotection.

Bombesin (BBN) is an amphibian peptide analogue of the mammalian regulatory gastrinreleasing peptide (GRP)[74], which targets gastrin-releasing peptide receptors (GRPr) due to its high binding affinity, specificity and in vivo stability (Figure 4.4).[62] GRPr are found to be highly expressed in human prostate cancer cells. $[33,75]$ The $\mathrm{BBN}(7-14) \mathrm{NH}_{2}$ is the 7 amino acid peptide sequence, which is required for binding to the GRPr. Hence a trithiol$\mathrm{BBN}(7-14) \mathrm{NH}_{2}$ complex was synthesized for developing an ${ }^{77}$ As radiolabeled $\mathrm{BBN}$ analogue (Scheme 4.2). The trithiol-BBN(7-14) $\mathrm{NH}_{2}$ complex was stored as its protected precursor, trithiocyanate-BBN(7-14) $\mathrm{NH}_{2}$ because thiol groups have a tendency to oxidize over time. The synthesis of the trithiol-BBN(7-14) $\mathrm{NH}_{2}$ precursor followed standard procedures by coupling the trithiol ligand (compound 9) to the $\mathrm{BBN}(7-14) \mathrm{NH}_{2}$ peptide on resin (Figure 4.4).[71] An in situ activation with $\mathrm{HOBt}$ and $\mathrm{HBTU}$ was carried out and the trithiol ligand was coupled twice with a three times stoichiometric excess to the resin to ensure maximum coupling. The final product was cleaved from the resin using a TFA, phenol, water and TIS (85:5:5:5) mixture, purified by HPLC and lyophilized for storage. The product was characterized by LC-MS ([M+H $\left.{ }^{+}\right] 1333,1333$ calculated). 
<smiles>CSCC[C@H](NC(=O)[C@H](CC(C)C)NC(=O)[C@H](Cc1c[nH]cn1)NC(=O)CNC(=O)[C@@H](NC(=O)[C@H](C)NC(=O)[C@H](Cc1c[nH]c2ccccc12)NC(=O)[C@H](CCC(N)=O)N[Ge]C(C)C)C(C)C)C(N)=O</smiles><smiles>COC(C)C(N)=O</smiles>

Figure 4.4. The structure of trithiol-BBN(7-14) $\mathrm{NH}_{2}$ complex. (a) The structure of BBN(714) $\mathrm{NH}_{2}$ peptide. (b) The structure of trithiol-linker-BBN(7-14) $\mathrm{NH}_{2}$.

A trithiol-BBN(7-14) $\mathrm{NH}_{2}$ solution was prepared by reducing the trithiocyanate-BBN(714) $\mathrm{NH}_{2}$ precursor with tris(2-carboxyethyl)phosphine (TCEP), and evaluated for quality prior to radiolabeling. The yield of the trithiol-BBN(7-14) $\mathrm{NH}_{2}$ was determined to be greater than $90 \%$ so it was used in radiolabeling without further purification. 


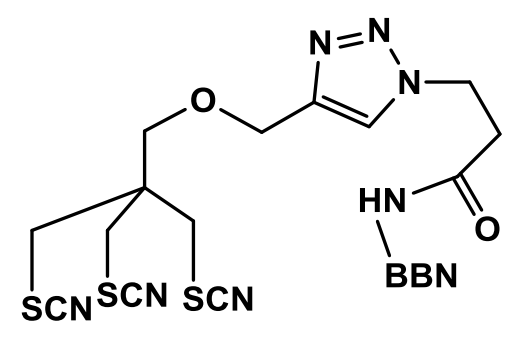

Trithiol-BBN precursor

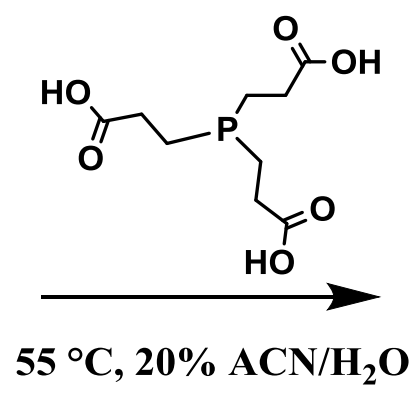

$55{ }^{\circ} \mathrm{C}, 20 \% \mathrm{ACN} / \mathrm{H}_{2} \mathrm{O}$

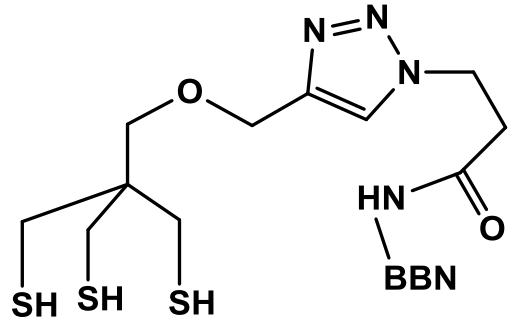

Trithiol-BBN

Scheme 4.2. Synthesis of trithiol-BBN(7-14) $\mathrm{NH}_{2}$ complex. The trithiol-BBN(7-14) $\mathrm{NH}_{2}$ precursor was deprotected.

Trithiol-BBN(7-14) $\mathbf{N H}_{2}$ radiolabeling. The nca ${ }^{77}$ As radiolabeling of trithiol-BBN(714) $\mathrm{NH}_{2}$ was carried out in $3 \mathrm{~h}$ following optimized conditions and over $90 \%$ radiochemical yield was achieved (Scheme 4.3)[32]. The radiolabeling reaction was analyzed by RP-HPLC and purified via a Sep-Pak® C18 cartridge. Compared to the concentration of nca ${ }^{77}$ As, the ammonium mercaptoacetate (monothiol) and trithiol-BBN were in great excess and hence no significant radiolysis was observed during radiolabeling. After radiolabeling, the solution was passed through a $0.2 \mu \mathrm{m}$ syringe filter, and approximately $30 \%$ of the radioactivity remained on the filter due to the hydrophobic nature of the ${ }^{77}$ As-trithiol-BBN. The syringe filter was then washed with $1 \mathrm{~mL}$ of $0.1 \%$ wt TWEEN@ 80 in water solution to remove the radioactivity and the eluent was injected in the HPLC. The remaining radioactivity on the syringe filter was proved to be the ${ }^{77}$ As-trithiol-BBN. The HPLC data is shown below (Figure 4.5). In Figure 4.5, purified ${ }^{77}$ As-trithiol-BBN(7-14) $\mathrm{NH}_{2}$ was injected and showed over $90 \%$ rradiolabeling yield and the radiochemical yield after the Sep-Pak purification was $60 \%$. Peaks at $3.28 \mathrm{~min}, 4.18 \mathrm{~min}, 4.4 \mathrm{~min}$ and $6.3 \mathrm{~min}$ were associated with the excess 


\section{Yutian Feng}

ammonium mercaptoacetate and TCEP. The peak at $12.4 \mathrm{~min}$ was associated with trithiolBBN(7-14) $\mathrm{NH}_{2}$, which was in good agreement with the standard trithiol-BBN(7-14) $\mathrm{NH}_{2}$ solution $(1 \mathrm{mg} / \mathrm{mL})$. A Sep-Pak® C18 cartridge was used to remove the excess ammonium mercaptoacetate and TCEP. Both radiolabeled ${ }^{77} \mathrm{As}$-trithiol-BBN(7-14) $\mathrm{NH}_{2}$ and trithiolBBN(7-14) $\mathrm{NH}_{2}$ were retained on the cartridge because of their high lipophilicities, while the monothiol and TCEP eluted in the mobile phase during loading and water wash. Purified ${ }^{77}$ As-trithiol-BBN(7-14) $\mathrm{NH}_{2}$ was eluted from the cartridge with ethanol, and the peaks associated with the monothiol and TCEP were much less intense (less than $0.1 \%$ remaining). Surprisingly the concentration of unlabeled trithiol-BBN(7-14) $\mathrm{NH}_{2}$ was also reduced because a significant amount ( $30 \%$ of total radioactivity) of both labeled and unlabeled trithiol$\mathrm{BBN}(7-14) \mathrm{NH}_{2}$ was retained on the cartridge. To further determine the total concentration of trithiol-BBN(7-14) $\mathrm{NH}_{2}$ in the product solution, the UV profile at $280 \mathrm{~nm}$ of purified ${ }^{77} \mathrm{As}-$ trithiol-BBN(7-14) $\mathrm{NH}_{2}$ solution was compared with a standard trithiol-BBN(7-14) $\mathrm{NH}_{2}$ solution $(1 \mathrm{mg} / \mathrm{mL})$ and the total trithiol-BBN(7-14)NH $\mathrm{NH}_{2}$ concentration was determined to be $6 \mu \mathrm{g} / \mathrm{mL}$. To the eluted ${ }^{77}$ As-trithiol-BBN(7-14) $\mathrm{NH}_{2}$ ethanol solution, ascorbic acid $(5 \mu \mathrm{g})$ was added to prevent radiolysis; significant radiolysis resulting in the formation of free ${ }^{77} \mathrm{As}$ was previously observed when the volume was reduced to near dryness. Upon addition of ascorbic acid, the ${ }^{77}$ As-trithiol-BBN(7-14) $\mathrm{NH}_{2}$ solution was brought to near dryness under a gentle $\mathrm{N}_{2}$ stream and reconstituted with bacteriostatic saline. Quality control was performed by RP-HPLC, with no sign of free ${ }^{77}$ As formation and the retention time of the product peak was in good agreement with ${ }^{77}$ As-trithiol-BBN(7-14) $\mathrm{NH}_{2}$ standard.

Due to the fairly low activity of the eluted nca ${ }^{72} \mathrm{As}$, no further evaluation was conducted following the radiolabeling of trithiol-BBN(7-14) $\mathrm{NH}_{2}$. The radioactivity of nca ${ }^{72} \mathrm{As}$ in the 


\section{Yutian Feng}

radiolabeling step was $(\sim 0.33 \mathrm{MBq}, 9 \mu \mathrm{Ci})$. Similar procedure for radiolabeling was conducted for ${ }^{72}$ As and over $95 \%$ radiochemical yield was observed by HPLC injections.

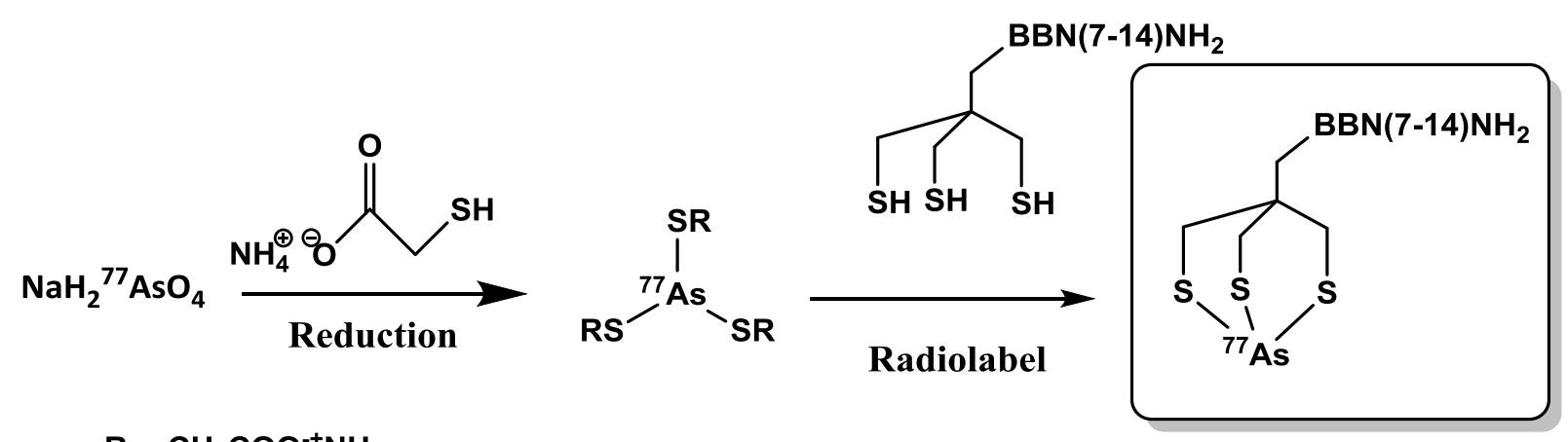

R: $-\mathrm{CH}_{2} \mathrm{COO}^{-+} \mathrm{NH}_{4}$

Scheme 4.3. Radiotracer synthesis of no carrier added ${ }^{77} \mathrm{As}$-trithiol-BBN(7-14) $\mathrm{NH}_{2}$. 


\section{Yutian Feng}

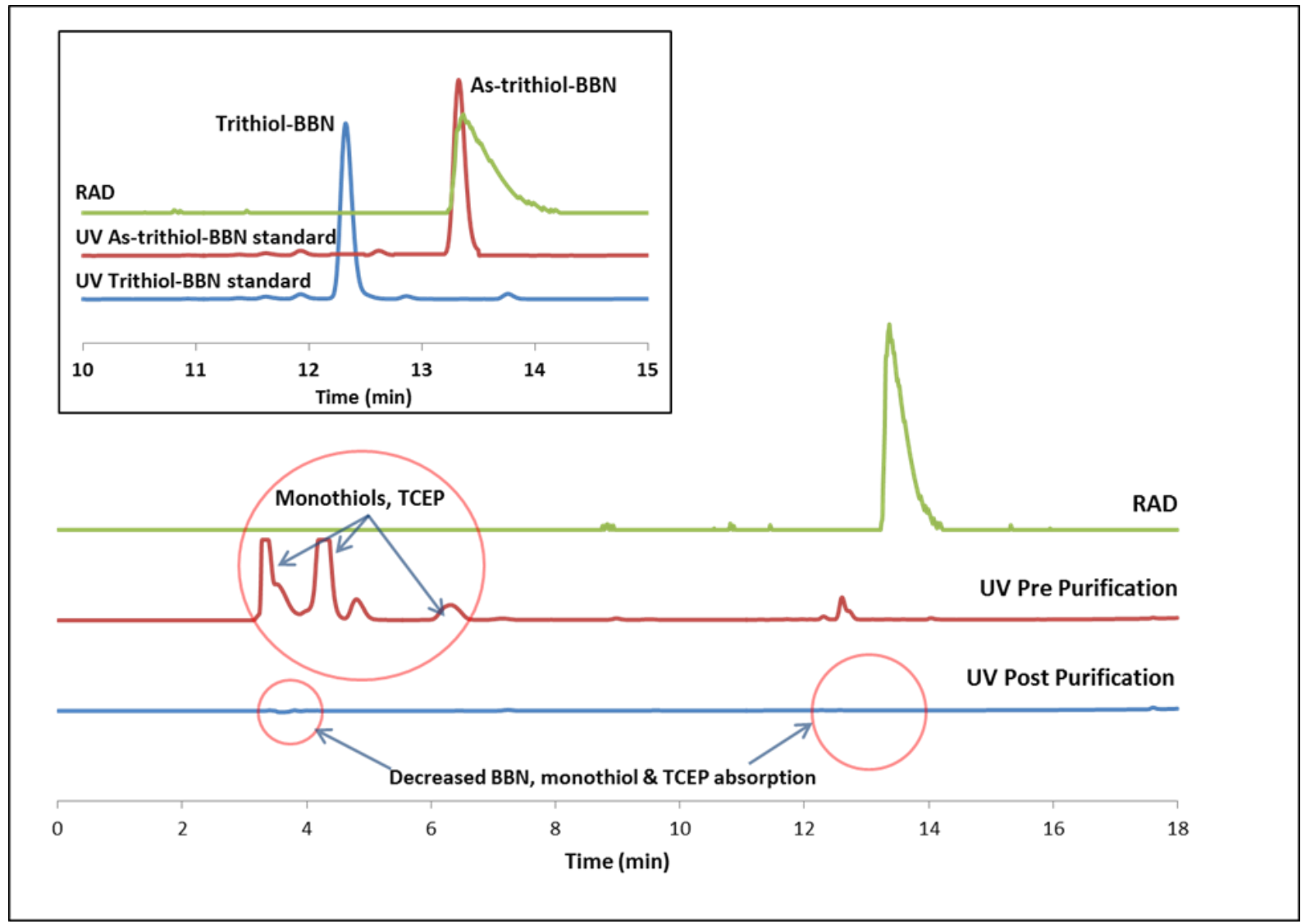

Figure 4.5. The ${ }^{77}$ As-trithiol-BBN(7-14) $\mathrm{NH}_{2}$ was analyzed by RP-HPLC and its signals from both the radiation detector and UV detectors (wavelengths $220 \mathrm{~nm}$ and $280 \mathrm{~nm}$ ) were compared with trithiocyanate-BBN(7-14) $\mathrm{NH}_{2}$, trithiol-BBN(7-14) $\mathrm{NH}_{2}$ and As-trithiol$\mathrm{BBN}(7-14) \mathrm{NH}_{2}$ standards. Injections of $25 \mu \mathrm{L}$ were carried out for all the injections.

In Figure 4.5., the upper left diagram: rad peak of ${ }^{77} \mathrm{As}$-trithiol-BBN(7-14) $\mathrm{NH}_{2}$ (first line) matched the UV peak of As-trithiol-BBN(7-14) $\mathrm{NH}_{2}$ standard (second line), and the wide peak width was due to the additional tubing inside of the radiation detector; the UV peak of trithiol-BBN(7-14) $\mathrm{NH}_{2}$ standard (third line) was distinguished from As-trithiol-BBN(714) $\mathrm{NH}_{2}$ peaks (first and second line); the unlabeled trithiol-BBN(7-14) $\mathrm{NH}_{2}$ was also reduced (second and third line). Lower diagram: UV signals of monothiols and TCEP impurities were 


\section{Yutian Feng}

reduced after purification (second and third line); no UV signals related to the rad signals of

${ }^{77}$ As-trithiol-BBN(7-14) $\mathrm{NH}_{2}$ (first line) were observed, indicating the low concentration of ${ }^{77}$ As-trithiol-BBN(7-14) $\mathrm{NH}_{2}$ in the product solution.

Biodistribution studies of no carrier added free ${ }^{77} \mathrm{As}$ and ${ }^{77} \mathrm{As}$-trithiol-B BN(7-14) $\mathrm{NH}_{2}$. A summary of the biodistribution of free ${ }^{77} \mathrm{As}$ (arsenate) and ${ }^{77} \mathrm{As}$-trithiol-BBN(7-14) $\mathrm{NH}_{2}$ is shown in Figure 4.6 and the detailed data are shown in Tables 4.3 and 4.4. A fast renal clearance of free As was expected.[14] Arsenate acts as a phosphate $\left(\mathrm{HPO}_{4}{ }^{-}\right)$mimic and can be reduced to As (III) in vivo.[76, 77] Generally arsenite has better in vivo retention due to multiple protein binding compared to arsenate, however a rapid renal excretion is usual for both.[77] ${ }^{77}$ As (arsenate) was excreted through the renal pathway with $40.8 \% \pm 5.52 \%$ injected dose per gram of weight (ID/g) at $15 \mathrm{~min}, 22.02 \% \pm 2.33 \%$ ID and $18.54 \% \pm 21.51 \%$ ID at 15 min observed in urine and bladder (radioactivity in urine and bladder is listed as ID), respectively. At $4 \mathrm{~h}, 83.77 \% \pm 7.27 \%$ ID was cleared to cage paper through urination and $1.74 \% \pm 0.41 \% \mathrm{ID} / \mathrm{g}$ remained in the kidneys, which indicates the majority of ${ }^{77} \mathrm{As}$ (arsenate) was not binding to free thiols from proteins present in blood plasma. The fast renal clearance of free ${ }^{77}$ As (arsenate) could potentially avoid radiotoxicity because if ${ }^{77}$ As was to dissociate from the chelate, it would be excreted in a short period of time $(4 \mathrm{~h})$. The biodistribution of ${ }^{77}$ As-trithiol-BBN(7-14) $\mathrm{NH}_{2}$ is vastly different from that of ${ }^{77} \mathrm{As}$ (arsenate); it was primarily cleared through the hepatobiliary system. At $1 \mathrm{hr}, 8.02 \% \pm 1.38 \% \mathrm{ID} / \mathrm{g}, 13.76 \% \pm 8.24 \%$ ID/g and $27.11 \% \pm 13.76 \%$ ID/g were observed in liver, small intestines and large intestines, respectively, while the biodistribution of free ${ }^{77}$ As showed the majority of radioactivity was excreted via renal clearance at the same time point $(13.77 \% \pm 1.41 \% \mathrm{ID} / \mathrm{g}$ remained in kidneys). 


\section{Yutian Feng}

Table 4.3. Biodistribution of free ${ }^{77} \mathrm{As}\left(\left[{ }^{77} \mathrm{As}\right] \mathrm{H}_{2} \mathrm{AsO}_{4}{ }^{-}\right)$in $\mathrm{CF}-1$ normal mice at $15 \mathrm{~min}, 1 \mathrm{~h}$,

$4 \mathrm{~h}$ and $24 \mathrm{~h}$ post injection, $\mathrm{n}=4$. Data are presented as $\% \mathrm{ID} / \mathrm{g} \pm \mathrm{SD}$.

\begin{tabular}{ccccc}
\hline Organ/Tissue & $15 \mathrm{~min}$ PI & $1 \mathrm{~h} \mathrm{PI}$ & $4 \mathrm{~h} \mathrm{PI}$ & $24 \mathrm{~h} \mathrm{PI}$ \\
\hline Heart & $1.21 \pm 1.73$ & $1.33 \pm 2.04$ & $0.65 \pm 1.14$ & $0.31 \pm 0.45$ \\
Lung & $3.43 \pm 2.81$ & $2.87 \pm 0.98$ & $0.60 \pm 1.10$ & $0.67 \pm 0.69$ \\
Liver & $4.39 \pm 0.73$ & $3.31 \pm 0.42$ & $0.42 \pm 0.07$ & $0.15 \pm 0.21$ \\
Kidneys & $40.80 \pm 5.52$ & $13.77 \pm 1.42$ & $1.74 \pm 0.42$ & $0.66 \pm 0.88$ \\
Spleen & 0.00 & $1.07 \pm 1.13$ & 0.00 & $0.57 \pm 1.14$ \\
Stomach & $0.82 \pm 1.03$ & $0.62 \pm 0.31$ & $0.16 \pm 0.32$ & $0.11 \pm 0.21$ \\
S. Intestine & $1.67 \pm 0.26$ & $1.59 \pm 0.17$ & $0.40 \pm 0.16$ & $0.13 \pm 0.18$ \\
L. Intestine & $1.28 \pm 0.28$ & $1.31 \pm 0.51$ & $1.02 \pm 0.37$ & $0.03 \pm 0.05$ \\
Muscle & $2.04 \pm 2.44$ & $1.02 \pm 0.70$ & $0.30 \pm 0.46$ & 0.00 \\
Bone & $0.95 \pm 1.89$ & $0.63 \pm 0.83$ & $0.50 \pm 0.99$ & 0.00 \\
Brain & 0.00 & $0.35 \pm 0.46$ & $0.50 \pm 0.38$ & $0.16 \pm 0.21$ \\
Pancreas & $2.29 \pm 1.95$ & $1.30 \pm 0.82$ & $0.25 \pm 0.25$ & 0.00 \\
Blood & $1.95 \pm 0.74$ & $0.52 \pm 0.19$ & $0.28 \pm 0.42$ & $0.38 \pm 0.32$ \\
Carcass & $2.26 \pm 0.19$ & $1.25 \pm 0.11$ & $0.41 \pm 0.15$ & $0.04 \pm 0.04$ \\
Excretion* & $22.79 \pm 2.20$ & $54.82 \pm 1.69$ & $86.90 \pm 2.53$ & $97.13 \pm 1.37$ \\
\hline
\end{tabular}

* Excretion includes the bladder, urine, cage paper, and feces $(24 \mathrm{~h})$ and is presented as $\% \mathrm{ID} \pm \mathrm{SD}$. 


\section{Yutian Feng}

Table 4.4. Biodistribution of ${ }^{77}$ As-trithiol-BBN(7-14) $\mathrm{NH}_{2}$ in $\mathrm{CF}-1$ normal mice at $1 \mathrm{~h}$ and 4

$\mathrm{h}$ post injection, $\mathrm{n}=5$. Data are presented as $\% \mathrm{ID} / \mathrm{g} \pm \mathrm{SD}$.

\begin{tabular}{ccc}
\hline Organ/Tissue & $1 \mathrm{~h} \mathrm{PI}$ & $4 \mathrm{~h} \mathrm{PI}$ \\
\hline Heart & $0.88 \pm 0.36$ & $0.28 \pm 0.39$ \\
Lung & $2.06 \pm 0.25$ & $2.65 \pm 0.63$ \\
Liver & $8.03 \pm 1.39$ & $3.53 \pm 1.14$ \\
Kidneys & $4.08 \pm 0.72$ & $1.67 \pm 0.85$ \\
Spleen & $2.09 \pm 0.53$ & $2.87 \pm 1.09$ \\
Stomach & $0.44 \pm 0.15$ & $0.80 \pm 1.04$ \\
S. Intestine & $13.77 \pm 8.24$ & $1.51 \pm 0.93$ \\
L. Intestine & $27.12 \pm 13.76$ & $30.45 \pm 10.05$ \\
Muscle & $0.60 \pm 0.27$ & $0.20 \pm 0.18$ \\
Bone & $0.50 \pm 0.60$ & $0.21 \pm 0.46$ \\
Brain & $0.54 \pm 0.78$ & $0.04 \pm 0.08$ \\
Pancreas & $1.51 \pm 0.52$ & $0.66 \pm 0.67$ \\
Blood & $0.58 \pm 0.21$ & $0.24 \pm 0.25$ \\
Carcass & $0.42 \pm 0.03$ & $0.44 \pm 0.11$ \\
Excretion* & $8.07 \pm 0.93$ & $38.04 \pm 8.76$ \\
\hline
\end{tabular}

* Excretion includes the bladder, urine and cage paper and is presented as $\%$ ID \pm SD. 
(A) Free ${ }^{77} \mathrm{As}$ (Arsenate)

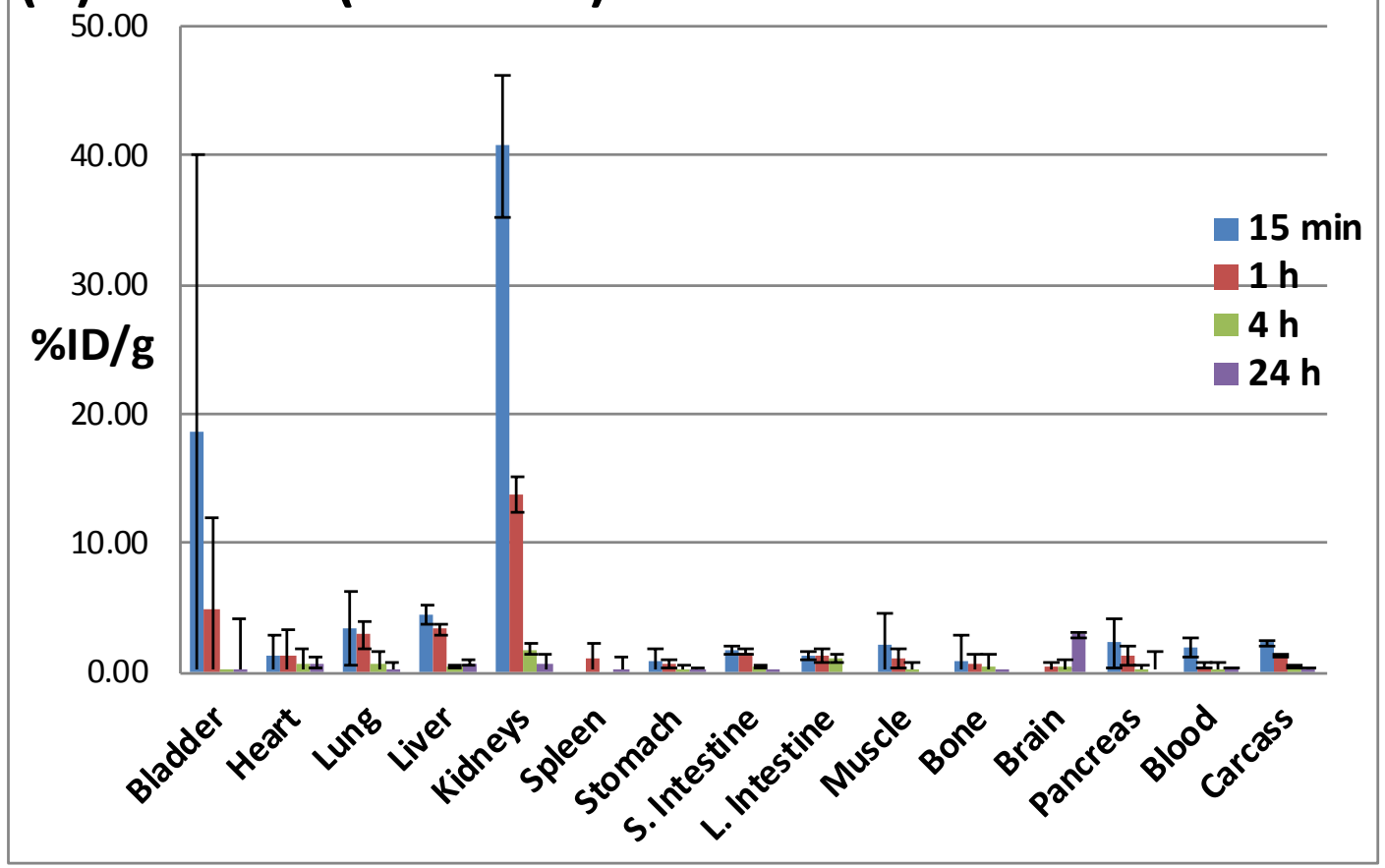

(B) ${ }_{50.00}^{77}$ As-trithiol-BBN(7-14) $\mathrm{NH}_{2}$

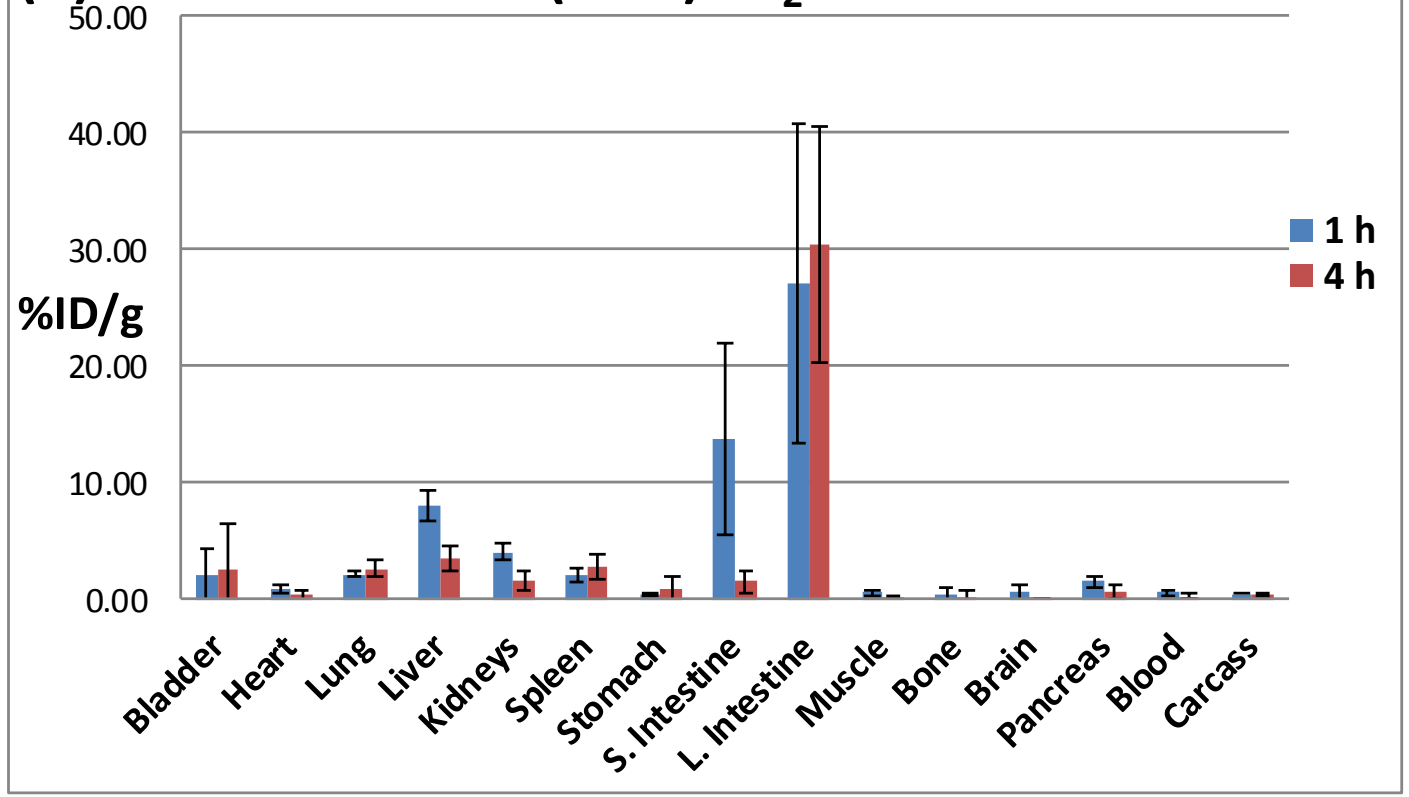

Figure 4.6. Biodistribution of free ${ }^{77} \mathrm{As}\left(\left[{ }^{77} \mathrm{As}\right] \mathrm{H}_{2} \mathrm{AsO}_{4}{ }^{-}\right)$and ${ }^{77} \mathrm{As}-$ trithiol-BBN(7-14) $\mathrm{NH}_{2}$ in CF-1 normal mice. (A) Free ${ }^{77}$ As at $15 \mathrm{~min}, 1 \mathrm{~h}, 4 \mathrm{~h}$ and $24 \mathrm{~h}, \mathrm{n}=4$. (B) ${ }^{77}$ As-trithiol-BBN(714) $\mathrm{NH}_{2}$ at $1 \mathrm{~h}$ and $4 \mathrm{~h}, \mathrm{n}=5$. 


\section{Yutian Feng}

The different clearance path of ${ }^{77}$ As-trithiol-BBN(7-14) $\mathrm{NH}_{2}$ indicates the high in vivo stability of ${ }^{77}$ As-trithiol-BBN(7-14) $\mathrm{NH}_{2}$ complex. At $4 \mathrm{hr}, 3.52 \% \pm 1.14 \% \mathrm{ID} / \mathrm{g}$ was retained in liver, which further indicates the high in vivo stability of ${ }^{77}$ As-trithiol-BBN(7-14) $\mathrm{NH}_{2}$. However the effective clearance via liver and intestines matched the high lipophilicity of ${ }^{77}$ As-trithiol-BBN(7-14) $\mathrm{NH}_{2}$.

\section{Conclusion}

A trithiol ligand and its ${ }^{77}$ As radiochemistry were reported previously[32]. An ${ }^{72,77}$ As trithiol complex, namely nca ${ }^{72,77}$ As-trithiol-BBN(7-14) $\mathrm{NH}_{2}$, was synthesized in $>90 \%$ radiochemical yield with nca ${ }^{72}$ As and ${ }^{77}$ As, respectively. To investigate the in vivo utility of the trithiol ligand framework for nca radioarsenic, the ${ }^{77}$ As-trithiol-BBN(7-14) $\mathrm{NH}_{2}$ was evaluated under in vivo conditions. Following Sep-Pak® purification, normal mouse biodistribution studies of uncomplexed ${ }^{77}$ As (arsenate) and ${ }^{77}$ As-trithiol-BBN(7-14) $\mathrm{NH}_{2}$ demonstrated that the trithiol framework is a promising ligand for developing ${ }^{72,77}$ As matched pair theranostic radiopharmaceuticals.[66] Development of a more hydrophilic linker to reduce the lipophilicity of the ${ }^{77}$ As complex will be discussed in the following section. 


\section{Synthesis of a linkable trithiol analogue with improved hydrophilicity}

\section{Introduction}

The high in vivo stability of the As-trithiol complex was discussed above. However the lack of accumulation of ${ }^{77}$ As-trithiol-BBN(7-14) $\mathrm{NH}_{2}$ in the pancreas was inconsistent with the literature since most of the radioactivity was excreted through liver, while ideally BBN analogues targeted GRP receptors expressed in pancreas in normal mice.[33] There are two

possible causes for loss of targeting efficacy of the ${ }^{77} \mathrm{As}$-trithiol-BBN(7-14) $\mathrm{NH}_{2}$ complex: the alkyl carbons between the trithiol chelates and the peptide, including the triazole ring structure, added to the lipophilicity of the complex, which was consistent with the fast hepatic clearance; the lack of structural flexibility of the triazole structure potentially led to the $\mathrm{As}(\mathrm{SR})_{3}$ unit affecting the binding sites on the peptide. [66] It was found that the rigidity of the chelate could potentially influence the binding affinity of the BBN peptide.[78, 79] The linkable trithiol (Figure 4.7) can be modified by incorporating several amino acids with high water solubility (e.g., serine) as a linker between the chelate and the targeting peptides, but it would increase the space between the chelate and peptide which would exceed the optimal length (6 to 9 carbon atoms) and result in loss of targeting efficacy.[79] However the trithiol-BBN(7-14) $\mathrm{NH}_{2}$ complex was used as a model molecule to evaluate the in vivo stability of As-trithiol complex. 


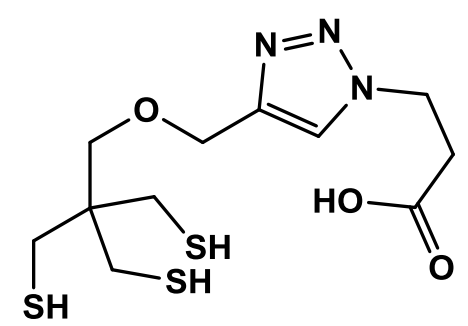

Figure 4.7. The structure of the linkable trithiol ligand containing a triazole unit.

A new trithiol was proposed and synthesized to meet the requirements of high hydrophilicity and flexibility in conjugating to targeting biomolecules (Figure 4.8). The trithiol moiety was conjugated to an isophthalic acid unit via an ether bridge. The two carboxylic acids could potentially act as incorporation sites for linking targeting biomolecules. They could also increase the hydrophilic ity and water solubility of the chelate because of the comparatively high acidity of the isophthalic acid (pKa 3.46, 4.46). The synthesis was carried out following a modified literature procedure.[80, 81] Radiolabeling the new trithiol, namely trithiolYF1, with nca ${ }^{77}$ As was carried out using the optimized conditions and the lipophilicity of the linkable trithiol (Figure 4.7) and the trithiolYF1 were compared.[32]<smiles>O=C(O)c1cc(OCC(CS)(CS)CS)cc(C(=O)O)c1</smiles>

Figure 4.8. The structure of the new trithiol chelate (trithiolYF1). 


\section{Experimental}

The synthesis of the trithiolYF1 is described in Scheme 4.4. The radiolabeling of the trithiolYF1 with nca ${ }^{77}$ As is described in Scheme 4.5. The synthesis of the previously evaluated trithiol chelate (linkable trithiol) and the radiolabeling of nca ${ }^{77} \mathrm{As}$ are described in Scheme 4.6.<smiles>COC(=O)c1cc(O)cc(C(=O)OC)c1</smiles>

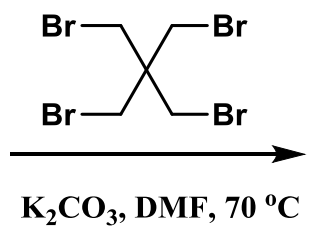<smiles>COC(=O)c1cc(OCC(CBr)(CBr)CBr)cc(C(=O)OC)c1</smiles>

9<smiles>COC(=O)c1cc(OCC(CS)(CS)C(C)(C)C)cc(C(=O)OC)c1</smiles>

10<smiles>O=C(O)c1cc(OCC(CS)(CS)CS)cc(C(=O)O)c1</smiles>

12
TCEP, $50{ }^{\circ} \mathrm{C} 2 \mathrm{~h}$

$90 \% \mathrm{EtOH} / \mathrm{H}_{2} \mathrm{O}$<smiles>O=C(O)c1cc(OCC2(CS)CSSC2)cc(C(=O)O)c1</smiles>

11

trithiolYF1<smiles>CC(=O)S[14CH3]</smiles>

Scheme 4.4. The synthesis of the new trithiol (trithiolYF1). 
<smiles>[R5][R5][R15]([R])[R5]</smiles>

Scheme 4.5. Radiolabeling of nca ${ }^{77}$ As with the new trithiol (trithiolYF1).

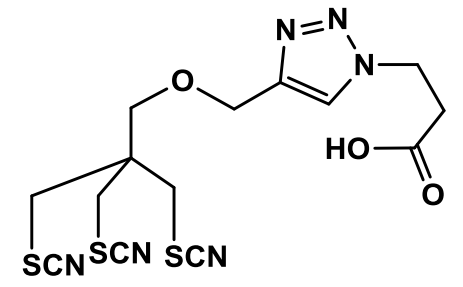

8<smiles>O=C(O)CCn1cc(COCC(CS)(CS)CS)nn1</smiles>

Linkable trithiol

13

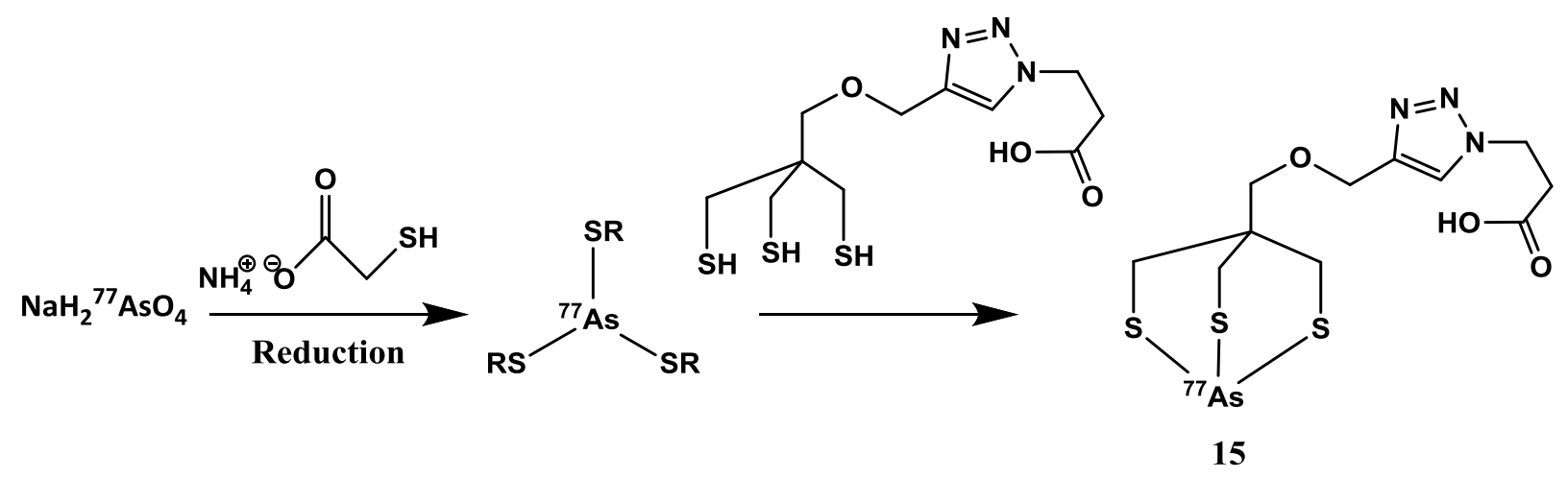

Scheme 4.6. The deprotection of the linkablec trithiol and radiolabeling with nca ${ }^{77}$ As. 


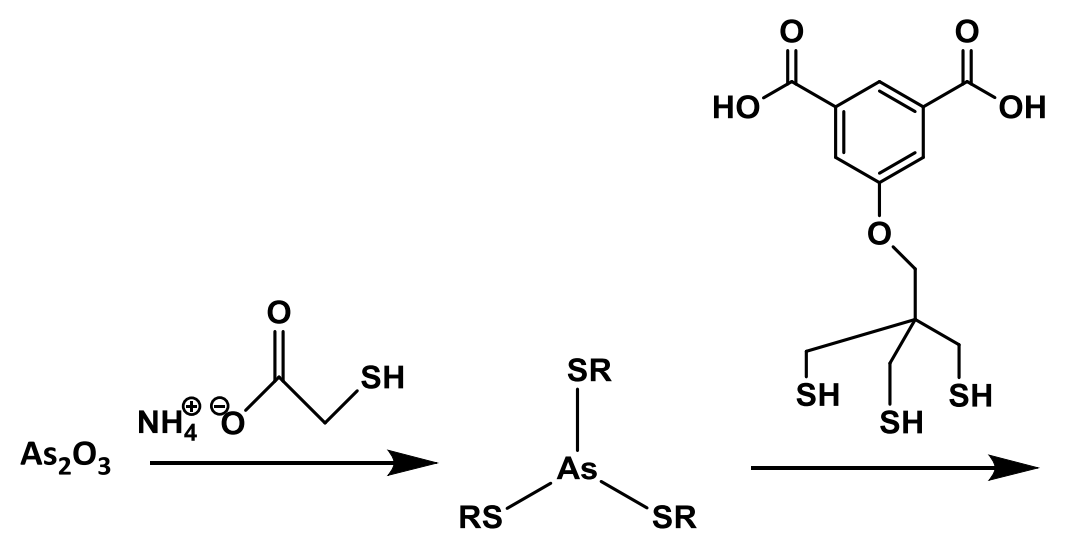

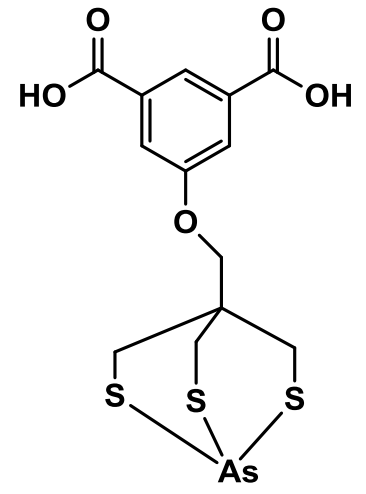

14

Scheme 4.7. The synthesis of the non-radioactive As-trithiol (As-trithiolYF1) complex.

Physical Measurements. ${ }^{1} \mathrm{H}$ and ${ }^{13} \mathrm{C}$ NMR spectra were obtained in $\mathrm{CDCl}_{3}$ and DMSO on a Bruker ARX-500 MHz spectrometer using TMS as an internal standard. Electrospray Ionization Mass Spectra (ESI-MS) were obtained on a Thermo Finnigan TSQ7000 triplequadrupole instrument with an API2 source. Elemental analyses were performed by Atlantic Microlab, Inc. (Norcross, GA). An ORTEC HPGe detector outfitted with Genie multichannel analysis software was used to assay ${ }^{77} \mathrm{Ge}$ and ${ }^{77}$ As liquid samples. Reversed phase HPLC (RP-HPLC) was performed using a Shimadzu Prominence HPLC system equipped with a pump, controller, and Prominence UV-Vis detector (model SPD20-AV) set to 220 and 280 $\mathrm{nm}$, and coupled to a Beckman $170 \mathrm{NaI}(\mathrm{Tl})$ radionuclide detector. The gradient system used for RP-HPLC run on a Phenomenex Jupiter C $18(5 \mu \mathrm{m}, 150 \mathrm{~mm}$ x $4.6 \mathrm{~mm})$ column was as follows: a linear gradient from 20/80 acetonitrile $(\mathrm{ACN}) / \mathrm{H}_{2} \mathrm{O}$ w/ $0.1 \%$ trifluoroacetic acid (TFA) to 80/20 ACN/H ${ }_{2} \mathrm{O}$ w/ $0.1 \% \mathrm{TFA}$ in $20 \mathrm{~min}$, then from 80/20 $\mathrm{ACN} / \mathrm{H}_{2} \mathrm{O}$ to 20/80 $\mathrm{ACN} / \mathrm{H}_{2} \mathrm{O}$ in $5 \mathrm{~min}$, all at a flow rate of $1 \mathrm{~mL} / \mathrm{min}$. All LC-MS analyses and MS assisted 


\section{Yutian Feng}

preparative purifications were performed with an LCQ Fleet from Thermo Fisher, Waltham, MA.

Dimethyl 5-(3-bromo-2,2-bis(bromomethyl)propoxy)isophthalate $\left[\mathrm{C}_{15} \mathrm{H}_{17} \mathrm{Br}_{3} \mathrm{O}_{5}\right], 9$.

Synthesis of compound $\mathbf{9}$ was accomplished using a modified literature procedure.[80]

Pentaerythritol tetrabromide $(13.8 \mathrm{~g}, 35.7 \mathrm{mmol})$ and dimethyl 5-hydroxyisophthalate (4.98 g, $23.7 \mathrm{mmol}$ ) were dissolved in $100 \mathrm{~mL}$ anhydrous dimethyl formamide (DMF) under a $\mathrm{N}_{2}$ atmosphere in a $500 \mathrm{~mL}$ round bottom flask. The reaction mixture was stirred and placed in a $70{ }^{\circ} \mathrm{C}$ bath for $24 \mathrm{~h}$. After the reaction was cooled to room temperature, DMF was re moved under vacuum. Deionized water $(500 \mathrm{~mL})$ was added to the reaction and the mixture was extracted with DCM (3 x $300 \mathrm{~mL})$. The organic layers were collected and combined, dried with anhydrous sodium sulfate solid, filtered and taken to dryness to afford the crude product. The crude product was purified via silica gel column chromatography using hexanes: DCM (3:1) as the mobile phase (dimethyl 5-hydroxyisophthalate, $\mathrm{R}_{\mathrm{f}} \approx 0$, pentaerythritol tetrabromide; $\left.\mathrm{R}_{\mathrm{f}} \approx 0.5 ; 9, \mathrm{R}_{\mathrm{f}} \approx 0.15\right)$. The product was eluted with $\mathrm{DCM}$ and the fractions were collected, combined and taken to dryness to afford the pure product as a white solid. Yield: 67\%, 8.2 g. ${ }^{1} \mathrm{H}$ NMR $\left(\mathrm{CDCl}_{3} ; 500 \mathrm{MHz}\right) \delta$ ppm: $3.680\left(\mathrm{~s}, 6 \mathrm{H}, \mathrm{CH}_{2} \mathrm{Br}\right), 3.956(\mathrm{~s}, 6 \mathrm{H}$, $\left.\mathrm{OCH}_{3}\right), 4.147$ (s, 2H, OCH $\left.\mathbf{H}_{2}\right), 7.779$ (d, 2H, CH), 8.333 (t, 1H, CH). ${ }^{13} \mathrm{C} \mathrm{NMR}\left(\mathrm{CDCl}_{3} ; 125.8\right.$

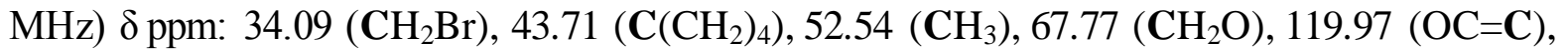
$123.93(\mathrm{O}=\mathrm{CC}=\mathbf{C}), 132.02(\mathrm{O}=\mathrm{CC}), 158.11(\mathrm{OC}=\mathrm{C}), 165.91(\mathbf{C O O})$. ESI-MS $(\mathrm{m} / \mathrm{z}): 516.98$ (517.01 calc'd for $\mathrm{C}_{15} \mathrm{H}_{17} \mathrm{Br}_{3} \mathrm{O}_{5}[\mathrm{M}+\mathrm{H}]^{+}$).

Dimethyl 5-(3-(acetylthio)-2,2-bis((acetylthio)methyl)propoxy)isophthalate $\left[\mathrm{C}_{21} \mathrm{H}_{26} \mathrm{O}_{8} \mathrm{~S}_{3}\right]$, 10. Synthesis of compound $\mathbf{1 0}$ was accomplished using a modified literature procedure.[81] Compound 9 ( $1 \mathrm{~g}, 1.9 \mathrm{mmol})$ and potassium thioacetate $(0.8 \mathrm{~g}, 7 \mathrm{mmol})$ were dissolved in 


\section{Yutian Feng}

anhydrous DMF (15 mL) under a $\mathrm{N}_{2}$ atmosphere in an $100 \mathrm{~mL}$ round bottom flask. The reaction mixture was stirred at room temperature for $72 \mathrm{~h}$. The reaction mixture was poured into a separatory funnel and extracted with ethyl acetate $(3 \times 50 \mathrm{~mL})$. The organic layer was washed with DI water $(3 \times 50 \mathrm{~mL})$, saturated $\mathrm{NaCl}$ solution $(1 \times 50 \mathrm{~mL})$ and dried with anhydrous sodium sulfate. The organic layer was then filtered and taken to dryness to afford the crude product. The crude product was purified via silica gel column chromatography using $\mathrm{DCM}$ as the mobile phase $\left(\mathbf{1 0}, \mathrm{R}_{\mathrm{f}} \approx 0.1\right)$. The fractions containing the product were combined and taken to dryness under vacuum to afford a light yellow solid. Yield: $90 \%, 858$ mg. ${ }^{1} \mathrm{H}$ NMR $\left(\mathrm{CDCl}_{3} ; 500 \mathrm{MHz}\right) \delta$ ppm: $2.346\left(\mathrm{~s}, 9 \mathrm{H}, \mathrm{COCH}_{3}\right), 3.194\left(\mathrm{~s}, 6 \mathrm{H}, \mathrm{CH}_{2} \mathrm{~S}\right), 3.874$ $\left(\mathrm{s}, 2 \mathrm{H}, \mathrm{OCH} \mathbf{H}_{2}\right), 3.946\left(\mathrm{~s}, 6 \mathrm{H}, \mathrm{OCH} \mathbf{H}_{3}\right), 7.718(\mathrm{~d}, 2 \mathrm{H}, \mathrm{CH}), 8.302(\mathrm{t}, 1 \mathrm{H}, \mathrm{CH}) .{ }^{13} \mathrm{C} \mathrm{NMR}$ $\left(\mathrm{CDCl}_{3} ; 125.8 \mathrm{MHz}\right) \delta$ ppm: $30.61\left(\mathrm{COCH}_{3}\right), 33.09\left(\mathrm{CH}_{2} \mathrm{~S}\right), 42.84\left(\mathbf{C}\left(\mathrm{CH}_{2}\right)_{4}\right), 52.48\left(\mathrm{CH}_{3}\right)$, $71.04\left(\mathbf{C H}_{2} \mathrm{O}\right), 119.92(\mathrm{OC}=\mathbf{C}), 123.64(\mathrm{O}=\mathrm{CC}=\mathbf{C}), 131.88(\mathrm{O}=\mathrm{CC}), 158.34(\mathrm{OC}=\mathrm{C})$, $166.02(\mathbf{C O O}), 194.31(\mathrm{SC}=\mathrm{O})$. ESI-MS $(\mathrm{m} / \mathrm{z})$ : 503.35 (503.61 calc'd for $\mathrm{C}_{21} \mathrm{H}_{26} \mathrm{O}_{8} \mathrm{~S}_{3}$ $\left.[\mathrm{M}+\mathrm{H}]^{+}\right)$. 5-((4-(Mercaptomethyl)-1,2-dithiolan-4-yl)methoxy)isophthalic acid $\left[\mathrm{C}_{13} \mathrm{H}_{14} \mathrm{O}_{5} \mathrm{~S}_{3}\right], 11$. Compound 10 was dissolved in $10 \mathrm{~mL}$ of absolute ethanol under a $\mathrm{N}_{2}$ atmosphere in a round bottom flask. $\mathrm{NaOH}(0.5 \mathrm{~g}, 12.3 \mathrm{mmol})$ was dissolved in $2 \mathrm{~mL}$ of DI water and this solution was added to the reaction mixture. The reaction mixture was placed in a $70{ }^{\circ} \mathrm{C}$ bath and a condenser was added. The reaction was stirred for $2 \mathrm{~h}$ and cooled to room temperature. The solution was taken to dryness and $100 \mathrm{~mL}$ of DI water was added to the residue. Ethyl ether was added to extract the crude product $(50 \mathrm{~mL}$ x 3). The organic layers were combined, dried with anhydrous $\mathrm{Na}_{2} \mathrm{SO}_{4}$, filtered and taken to dryness via vacuum to afford the crude product. The crude product was purified via silica gel column chromatography. A silica gel column 


\section{Yutian Feng}

was packed using DCM as the mobile phase. Impurities were washed off with DCM and the product was eluted with ethyl acetate/DCM (1:1). The retention values $\left(\mathrm{R}_{\mathrm{f}}\right)$ were measured on silica gel TLC plates in ethyl acetate/DCM $\left(1: 1,1 \%\right.$ acetic acid): impurities $\left(\mathrm{R}_{\mathrm{f}}=0.9\right)$ and product $\left(\mathrm{R}_{\mathrm{f}}=0.6\right)$. The fractions containing the product were dried to afford a pale yellow solid. Yield: 51\%, $700 \mathrm{mg} .{ }^{1} \mathrm{H}$ NMR (DMSO; $\left.500 \mathrm{MHz}\right) \delta$ ppm: 2.438 (t, 1H, SH), 2.684 (d, 2H, $\mathrm{CH}_{2} \mathrm{SH}$ ), 3.204 (m, 4H, CH $\left.\mathbf{H}_{2} \mathrm{~S}-\mathrm{S}\right), 4.162$ (s, 2H, OCH $), 7.711$ (d, 2H, CH), 8.092 (t, 1H, CH), 13.315 (s, 2H, COOH). ${ }^{13} \mathrm{C}$ NMR (DMSO; $\left.125.8 \mathrm{MHz}\right) \delta$ ppm: $26.46\left(\mathbf{C H}_{2} \mathrm{SH}\right), 42.87$ and $45.06\left(\mathrm{CH}_{2} \mathrm{~S}-\mathrm{S}\right), 55.99\left(\mathbf{C}\left(\mathrm{CH}_{2}\right)_{3}\right), 68.40\left(\mathrm{OCH}_{2}\right), 119.30(\mathbf{C H}), 122.66(\mathbf{C H}), 132.64$ (CCO), $158.55\left(\mathbf{C O C H}_{2}\right), 166.35(\mathbf{C O O H})$. ESI-MS $(\mathrm{m} / \mathrm{z})$ : 345.08 (347 calc'd for $\left.\mathrm{C}_{13} \mathrm{H}_{14} \mathrm{O}_{5} \mathrm{~S}_{3}[\mathrm{M}+\mathrm{H}]^{+}\right)$.

\section{5-(3-Mercapto-2,2-bis(mercaptomethyl)propoxy)isophthalic acid $\left[\mathrm{C}_{13} \mathrm{H}_{16} \mathrm{O}_{5} \mathrm{~S}_{3}\right], 12$.}

Compound 12 was produced by reducing compound 11 using tris(2-carboxyethyl)phosphine (TCEP). Compound 11 (100 mg, $0.289 \mathrm{mmol})$ was dissolved in 95\% ethanol in water (10 $\mathrm{mL}$ ), to which a TCEP solution (415.4 $\mathrm{mg}, 1.45 \mathrm{mmol}$, 5 eq.) was added. The reaction mixture was placed in a $55^{\circ} \mathrm{C}$ water bath and stirred for $2 \mathrm{~h}$. After the reaction was cooled to room temperature, it was dried in vacuum. Water $(20 \mathrm{~mL})$ and ethyl ether $(20 \mathrm{~mL})$ were added to the residue and poured into a separatory funnel. The organic layer was dried with anhydrous $\mathrm{Na}_{2} \mathrm{SO}_{4}$ and brought to dryness. No further purification was required. The product was afforded as a light yellow powder with quantitative yields. ${ }^{1} \mathrm{H}$ NMR (DMSO; $500 \mathrm{MHz}$ ) $\delta$ ppm: 2.438 (t, 3H, SH), 2.693 (d, 6H, $\mathrm{CH}_{2} \mathrm{SH}$ ), 3.992 (s, 2H, OCH $), 7.704$ (d, 2H, CH), 8.085 (t, 1H, CH), 13.303 (s, 2H, COOH). ${ }^{13} \mathrm{C}$ NMR (DMSO; $\left.125.8 \mathrm{MHz}\right) \delta$ ppm: 26.46 $\left(\mathrm{CH}_{2} \mathrm{SH}\right), 42.87\left(\mathbf{C}\left(\mathrm{CH}_{2}\right)_{3}\right), 68.36\left(\mathrm{OCH}_{2}\right), 119.29(\mathbf{C H}), 122.51(\mathbf{C H}), 132.58(\mathbf{C C O})$, $158.60\left(\mathrm{COCH}_{2}\right), 166.35(\mathbf{C O O H})$. 
5-((2,6,7-Trithia-1-arsabicyclo[2.2.2]octan-4-yl)methoxy)isophthalic acid $\left[\mathrm{C}_{13} \mathrm{H}_{13} \mathrm{AsO}_{5} \mathrm{~S}_{3}\right]$,

14. Arsenic trioxide (28.58 mg, $0.145 \mathrm{mmol})$ was suspended in $7 \mathrm{~mL}$ of $95 \%$ ethanol in water solution. Ammonium mercaptoacetate $(238 \mu \mathrm{L}, 5.5 \mathrm{M}, 1.31 \mathrm{mmol}, 9$ eq.) was added to that solution. Compound $12(100 \mathrm{mg}, 0.289 \mathrm{mmol})$ was added to the reaction mixture and placed in a $55{ }^{\circ} \mathrm{C}$ water bath and stirred for $40 \mathrm{~min}$. The reaction mixture was then placed in a freezer overnight. A precipitate was formed, filtered, washed with icy water (around $5{ }^{\circ} \mathrm{C}$ ) and ethyl ether and dried in vacuum to afford a while solid. ${ }^{1} \mathrm{H}$ NMR (DMSO; $\left.500 \mathrm{MHz}\right) \delta$ ppm: 3.139 (s, 6H, CH $\mathbf{H}_{2} \mathrm{~S}$ ), 3.944 (s, 2H, OCH $), 7.685$ (d, 2H, CH), 8.093 (t, 1H, CH), $13.266(\mathrm{~s}, 2 \mathrm{H}, \mathrm{COOH}) .{ }^{13} \mathrm{C}$ NMR (DMSO; $\left.125.8 \mathrm{MHz}\right) \delta \mathrm{ppm}: 28.59\left(\mathrm{CH}_{2} \mathrm{~S}\right), 42.87$ $\left(\mathbf{C}\left(\mathrm{CH}_{2}\right)_{3}\right), 75.21\left(\mathrm{OCH}_{2}\right), 119.29(\mathbf{C H}), 122.51(\mathbf{C H}), 132.60(\mathbf{C C O}), 158.60\left(\mathbf{C O C H}_{2}\right)$, 166.27 (COOH). ESI-MS ( $\mathrm{m} / \mathrm{z})$ : $421.15\left(421.34\right.$ calc'd for $\left.\mathrm{C}_{13} \mathrm{H}_{13} \mathrm{AsO}_{5} \mathrm{~S}_{3}[\mathrm{M}+\mathrm{H}]^{+}\right)$.

Radiotracer synthesis of no carrier added ${ }^{77} \mathrm{As}$-trithiol ( $\left.\left[{ }^{77} \mathrm{As}\right] 14\right)$. No carrier added (nca) ${ }^{77} \mathrm{As}\left(\left[^{77} \mathrm{As}\right] \mathrm{H}_{2} \mathrm{AsO}_{4}^{-}, 370 \mathrm{MBq} / \mathrm{mL}, 10 \mathrm{mCi} / \mathrm{mL}\right)$ in aqueous solution was obtained from the University of Missouri Research Reactor (MURR) as a stock solution. An aliquot of the ${ }^{77}$ As stock solution $(100 \mu \mathrm{L}, 37 \mathrm{MBq}, 1 \mathrm{mCi})$ was added to a $2 \mathrm{~mL}$ sterile centrifuge tube along with water $(581 \mu \mathrm{L})$ and acetonitrile $(100 \mu \mathrm{L})$. Ammonium mercaptoacetate $(18.2 \mu \mathrm{L}, 5.5 \mathrm{M}$, $100 \mu \mathrm{mol}$ ) was then added, and the reaction was placed in a $55^{\circ} \mathrm{C}$ water bath for $45 \mathrm{~min}$. The trithiolYF1 (12) stock solution in acetonitrile $(200 \mu \mathrm{L}, 5.7 \mathrm{mM}, 0.4 \mathrm{mg})$ was added to the reaction mixture and heating continued in the $55{ }^{\circ} \mathrm{C}$ water bath for $45 \mathrm{~min}$. The reaction was cooled to room temperature. The reaction mixture was filtered through a $0.2 \mu \mathrm{m}$ core size syringe filter, injected onto the HPLC, and compared with the cold As-trithiolYF1 standard $\left(\left[{ }^{77} \mathrm{As}\right] \mathbf{1 4}\right.$, retention time $=16.55 \mathrm{~min} ;\left[{ }^{\text {nat }} \mathrm{As}\right] \mathbf{1 4}$, retention time $\left.16.35 \mathrm{~min}\right)$. The radiochemical yield was determined to be over 95\% based on HPLC injections. 


\section{Yutian Feng}

Radiotracer synthes is of no carrier added ${ }^{77}$ As-trithiol ( $\left.\left[{ }^{77} \mathrm{As}\right] 15\right)$. Compound 8 was

prepared according to literature procedure.[66] The deprotection of compound $\mathbf{8}$ to afford compound 13 was carried out following literature procedures.[32, 66] No carrier added (nca) ${ }^{77} \mathrm{As}\left(\left[{ }^{77} \mathrm{As}\right] \mathrm{H}_{2} \mathrm{AsO}_{4}^{-}, 370 \mathrm{MBq} / \mathrm{mL}, 10 \mathrm{mCi} / \mathrm{mL}\right)$ in aqueous solution was obtained from the University of Missouri Research Reactor (MURR) as a stock solution. An aliquot of the ${ }^{77} \mathrm{As}$ stock solution (100 $\mu \mathrm{L}, 37 \mathrm{MBq}, 1 \mathrm{mCi})$ was added to a $2 \mathrm{~mL}$ sterile centrifuge tube along with water $(581 \mu \mathrm{L})$ and acetonitrile $(100 \mu \mathrm{L})$. Ammonium mercaptoacetate $(18.2 \mu \mathrm{L}, 5.5 \mathrm{M}$, $100 \mu \mathrm{mol}$ ) was then added, and the reaction was placed in a $55^{\circ} \mathrm{C}$ water bath for $45 \mathrm{~min}$. An aliquot of compound $\mathbf{1 3}(200 \mu \mathrm{L}, 5.7 \mathrm{mM}, 0.47 \mathrm{mg})$ was added to the reaction mixture and heating continued in the $55{ }^{\circ} \mathrm{C}$ water bath for $45 \mathrm{~min}$. The reaction was cooled to room temperature. The reaction solution was filtered with a $0.2 \mu \mathrm{m}$ core size syringe filter and injected onto the HPLC and retention time compared with the cold As-linkable trithiol standard $\left(\left[{ }^{77} \mathrm{As}\right] \mathbf{1 5}\right.$, retention time $=13.58 \mathrm{~min}$; $\left[{ }^{\text {nat }} \mathrm{As}\right) \mathbf{1 5}$, retention time $\left.13.45 \mathrm{~min}\right)$. The radiochemical yield was determined to be over 95\% based on HPLC analysis.

\section{Dis tribution coefficient $(\log D)$ studies comparing $\left[{ }^{77} \mathrm{As}\right] 15$ and $\left[{ }^{77} \mathrm{As}\right] 14$. PBS buffer} solution ( $2 \mathrm{~mL}, \mathrm{pH}=7.04,15 \mathrm{mM}$ ) was added to a centrifuge tube along with $2 \mathrm{~mL}$ of octanol. [ $\left.{ }^{77} \mathrm{As}\right] \mathbf{1 5}$ solution $(200 \mu \mathrm{L})$ was added to the centrifuge tube and the resultant solution mixed on a vortex mixer for $5 \mathrm{~min}$. The centrifuge tube was placed in a centrifuge (3200 rpm) for $2 \mathrm{~min}$. The aqueous $(1.5 \mathrm{~mL})$ and the organic layers $(1.5 \mathrm{~mL})$ were separated and counted on an HPGe detector. The experiment was carried out in triplicate. The distribution coefficient of $\left[{ }^{77} \mathrm{As}\right] \mathbf{1 4}$ was measured with the identical procedure. The log D values were calculated from the following equation:

$$
\log D=\log \frac{\text { Radioactivity in octanol }}{\text { Radioactivity in water }}
$$




\section{Yutian Feng}

\section{Results and Discussion}

The new trithiol chelate, namely the trithiolYF1, was proposed to improve the conjugating flexibility and hydrophilicity of the trithiol chelates. Syntheses of the trithiolYF1 was carried out following a modified procedure reported in the literature.[80, 81] Radiolabeling the new

trithiol with nca ${ }^{77}$ As was carried out using the optimized conditions for trithiol chelates and a high yield (over 96\%) was achieved similar to the trithiol chelate reported previously. [32] Distribution coefficient studies were performed to compare the lipophilicity of the linkable trithiol and the trithiolYF1.

Syntheses. Pentaerythritol tetrabromide was used as a starting material and precursors of the trithiol chelate design because alkyl bromides were considered good leaving groups. In the synthesis of compound $9, \mathrm{~K}_{2} \mathrm{CO}_{3}$ played a role as the base to deprotonate the hydroxyl group on the isophthalic acid to afford a nucleophile (Scheme 4.4). Pentaerythritol tetrabromide was present in excess to assure only one of the alkyl bromides was replaced by the nucleophile to afford compound 9 . The reaction was accomplished with a reasonable yield (67\%) and the unreacted starting material (pentaerythritol tetrabromide) was recovered using column chromatography. Compound $\mathbf{1 0}$ was afforded by reacting compound $\mathbf{9}$ with potassium thioacetate and replacing the tribromide with trithioacetate. The reaction was conducted at room temperature for $72 \mathrm{~h}$. Being a common protecting group for thiols, thioacetates can be deprotected to produce thiols via many methods.[82] Compound $\mathbf{1 0}$ was acquired in good yield (90\%). Methods of deprotection of compound $\mathbf{1 0}$ producing compound 12 were investigated. Ideally, free thiols would be produced after cleavage of the thioacetates. However, free thiols are readily oxidized to afford disulfides. Initially the deprotection was carried out using sodium methoxide in dry methanol under a $\mathrm{H}_{2}$ atmosphere. 


\section{Yutian Feng}

It was found that even though free thiols were produced in reasonable yield $(\sim 80 \%)$, they formed disulfides in the following work up, while the methyl esters remained intact (Scheme 4.4).[83] A simple deprotection was carried out using sodium hydroxide to cleave thioacetates and methyl esters spontaneously even though disulfides were formed after the deprotection, because thiols had a higher tendency to form disulfides under basic conditions. The target compound 12 was afforded by reducing compound 11 with tris(2carboxyethyl)phosphine (TCEP) quantitatively. The final product (12) was produced from compound 11 and used in situ in case the thiols form disulfides. In Scheme 4.7, the nonradioactive As-trithiol ( $\left.\left[{ }^{\text {nat }} A s\right] 14\right)$ was synthesized following a literature procedure using arsenic trioxide as starting material.[32]

Compounds $9-12$ were characterized by ${ }^{1} \mathrm{H}$ and ${ }^{13} \mathrm{C}$ NMR spectroscopy. The 6 protons of $\mathrm{CH}_{2} \mathrm{Br}$ were observed as a singlet signal at $3.68 \mathrm{ppm}$, which is consistent with literature values.[72] The protons of $\mathrm{CH}_{2} \mathrm{~S}$ in compound $\mathbf{1 0}$ were observed as a singlet at $3.194 \mathrm{ppm}$, which shifted up field compared to $\mathrm{CH}_{2} \mathrm{Br}$ in compound 9. After the deprotection of compound $\mathbf{1 0}$, compound $\mathbf{1 2}$ was produced but it readily oxidized during purification. The NMR spectra of compound 11 indicated a mixture between 11 and 12. In the ${ }^{1} \mathrm{H}$ NMR spectrum of 11, the multiplet at 3.198 ppm was associated with the 4 protons on $\mathrm{CH}_{2} \mathrm{~S}_{-}-\mathrm{SCH}_{2}$, resulting from the similarity between the difference in chemical shifts of $\mathrm{Ha}$ and $\mathrm{Hb}$ and their coupling constant. The proton signals of $\mathrm{CH}_{2} \mathrm{SH}$ were observed as 2 sets of doublet at 2.675 ppm and $2.865 \mathrm{ppm}$, respectively, indicating a mixture of compound 11 and 12. The doublet at $2.675 \mathrm{ppm}$ was associated with $\mathrm{CH}_{2} \mathrm{SH}$ of compound $\mathbf{1 1}$ and hence had higher integration, while the doublet at $2.865 \mathrm{ppm}$ was associated with 12. This also explained the split of the proton signals of $\mathrm{OCH}_{2}$ at $3.992 \mathrm{ppm}$ and $4.163 \mathrm{ppm}$. The ${ }^{1} \mathrm{H}$ and ${ }^{13} \mathrm{C}$ NMR characterization 


\section{Yutian Feng}

of the functional groups of compound $\mathbf{1 4}$ matched similar compounds previously reported.[32, 72]<smiles>CC1(C)SSCC1(CS)COc1cc(C(=O)O)cc(C(=O)O)c1</smiles>

Radiolabeling of nca ${ }^{77}$ As. The trithiolYF1 (12) was dissolved in an acetonitrile - water solution (50\% ACN in water). The solution was then treated with 5 equivalents of TCEP in a $55{ }^{\circ} \mathrm{C}$ water bath for $30 \mathrm{~min}$ to reduce all disulfides that could potentially form due to oxidation. The production of nca ${ }^{77}$ As and the radiolabeling conditions for trithiol chelates were discussed in Chapter 2 and Chapter 4, respectively. After the radiolabeling step, the reaction mixture was filtered through a syringe filter but it was observed that a significant amount of radioactivity remained on the filter. The situation was improved by adding $0.01 \%$ $w t$. Tween 80 to the reaction solution prior to filtration. A high radiolabeling yield was observed based on HPLC and comparison with the non-radioactive standard (over 96\%). Dis tribution coefficient $(\log D)$ studies. The $\log \mathrm{D}$ value represents the distribution of the nca ${ }^{77}$ As-trithiol in aqueous and organic solutions. It is usually determined with two immiscible phases such as water and 1-octanol, and may indicate the lipophilicity of a compound.[84] By comparing the concentration of the compound in water and 1-octanol, a $\log \mathrm{D}$ value was calculated based on the equation:

$$
\log D=\log \frac{\text { Radioactivity in octanol }}{\text { Radioactivity in water }}
$$




\section{Yutian Feng}

The $\log \mathrm{D}$ values also depend on the $\mathrm{pH}$ of the aqueous solution. A PBS buffer was normally used instead of DI water to maintain a certain pH.[84] Radiolabeling was conducted using both the $\left[{ }^{77} \mathrm{As}\right] \mathbf{1 4}$ and $\left[{ }^{77} \mathrm{As}\right] \mathbf{1 5}$. The log D studies were carried out using $15 \mathrm{mM} \mathrm{pH=7} \mathrm{PBS}$ buffer and 1-octanol. It is important to note that due to the large excess of monothiol present in the radiolabeling solution, when the ${ }^{77}$ As-trithiol (both 14 and 15) was added to the two phases of PBS buffer and 1-octanol, the monothiol exceeded the capacity of the PBS buffer and hence the $\mathrm{pH}$ of the aqueous phase was measured to be 4 . The aqueous solution

containing the ${ }^{77}$ As-trithiol was mixed with 1-octanol for $5 \mathrm{~min}$ and centrifuged for $2 \mathrm{~min}$ at $32000 \mathrm{rpm}$. Portions of both the aqueous and organic phases were taken out and counted on an HPGe counter. The $\log \mathrm{D}$ value of the $\left[{ }^{77} \mathrm{As}\right] 15$ was measured $1.27 \pm 0.02(n=3)$ and that of the $\left[{ }^{77} \mathrm{As}\right] 14$ was measured $0.32 \pm 0.03(n=3)$. This indicated an improvement in hydrophilicity for the trithiolYF1 (12) and its $\log$ D value would potentially be lower at a higher $\mathrm{pH}$, since the isophthalic acids were mostly protonated at $\mathrm{pH}=4$.

\section{Conclusion}

An improved trithiol chelate was proposed, synthesized and characterized, namely the trithiolYF1. Radiolabeling the trithiolYF1 with nca ${ }^{77}$ As was carried out following the reported procedure.[32] The distribution coefficient (log D) studies were conducted using PBS buffer and 1-octanol to compare the hydrophilicity of the previously reported trithiol (linkable trithiol, 13) and the trithiolYF1. The results indicated a higher hydrophilicity for the trithiolYF1. Further improvement could be accomplished by adding hydrophilic spacers between the trithiolYF1 and targeting biomolecules. Future studies include the conjugation of 


\section{Yutian Feng}

the trithiolYF1 chelate to targeting biomolecules and the evaluation of the trithiolYF1 conjugate under in vivo conditions. 


\section{Structural and stability analysis of an arsenic trihydroxyl compound: 4 - ethyl-2,6,7-trioxa-1-arsabicyclo[2.2.2]octane}

\section{Introduction}

Radionuclides of arsenic have the potential to be useful as imaging and therapeutic radionuclides.[5] Two promising arsenic radionuclides, As-72 and As-77, are considered a "matched pair" because of their useful nuclear properties for PET imaging and radiotherapy, respectively.[32] In order to utilize arsenic radionuclides, ligands stabilizing As(III) at high dilution under in vivo conditions are required. Sulfur and oxygen donors are commonly observed in arsenic chemistry based on the metalloid nature of arsenic. Due to the chelate effect, cyclic multidentate ligands are capable of increasing the binding stability. Several successful examples are DOTA, NOTA and NODAGA.[85-87] However oxygen and sulfur based cyclic tridentate ligands that are suitable for complexing arsenic are required. The bicyclic 4-methyl-2,6,7-trioxa-1-arsabicyclo[2.2.2] octane has been reported.[88-90] However no further analysis was reported. A bicyclic arsenic complex 4-ethyl-2,6,7-trioxa-1arsabicyclo[2.2.2] octane was synthesized, and fully characterized, including its crystal structure. Its stability under conditions similar to biological conditions was investigated. Arsenic has a strong affinity for thiol containing molecules such as dimercaptosuccinic acid and British anti-Lewisite, which are approved to treat arsenic poisoning. [46] Arsenic toxicity is believed to involve binding to thiols in proteins. The total thiol concentration in the body has been estimated to be $0.4-0.5 \mathrm{mM}$ in plasma, and $8-10 \mu \mathrm{M}$ in cells; these concentrations are fairly high compared to the concentration of radiopharmaceuticals (nM).[47, 48] Radiopharmaceuticals must survive the complex in vivo environment to be effective. The 
$\mathrm{As}(\mathrm{OR})_{3}$ bicyclic complex was challenged with 1-ethanethiol in the presence of triethylamine.[38]

\section{Experimental}

Ge ne ral remarks. ${ }^{1} \mathrm{H}$ and ${ }^{13} \mathrm{C}$ NMR spectra were obtained in $d_{1}-\mathrm{CDCl}_{3}$ with $1 \%$ TMS. The NMR signals were calibrated with the TMS reference at $0.00 \mathrm{ppm}$, using a Bruker DRX 500 MHz Spectrometer. 2-ethyl-2-(hydroxymethyl)propane-1,3-diol was obtained from SigmaAldrich and arsenic trioxide was obtained from Thermo Fisher Scientific. 1-ethanethiol and triethylamine (TEA) were obtained from Sigma-Aldrich. All solvents used were reagent grade. All reagents were employed without further purification. Chloroform-D (0.1\% TMS) was obtained from Cambridge Isotopes Laboratories.

4-Ethyl-2,6,7-trioxa-1-arsabicyclo[2.2.2]octane. 1,1,1-Tris(hydroxymethyl)propane (1.3 g, $9.7 \mathrm{mmol})$ and arsenic trioxide $(1.0 \mathrm{~g}, 5.1 \mathrm{mmol})$ were heated to $125{ }^{\circ} \mathrm{C}$ in toluene $(25 \mathrm{~mL})$ in a 2-necked round bottom flask equipped with a short vigreux distillation head. After stirring overnight, water had distilled off from the reaction. The reaction mixture was filtered, taken to dryness by vacuum distillation, and recrystallized from hexanes to obtain the pure product as a white solid. X-ray quality crystals were obtained by slow evaporation from hexanes. Yield: $1.5 \mathrm{~g}, 70 \% .{ }^{1} \mathrm{H} \mathrm{NMR}\left(\mathrm{CDCl}_{3} \mathrm{~d}_{1} ; 500 \mathrm{MHz}\right) \delta \mathrm{ppm}: 0.790\left(\mathrm{t}, 3 \mathrm{H}, \mathrm{CH}_{2} \mathrm{CH}_{3}\right)$,

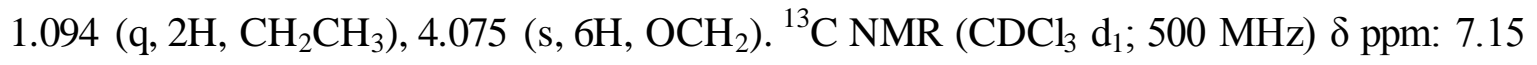
$\left(\mathrm{CH}_{2} \mathrm{CH}_{3}\right), 25.1\left(\mathrm{CH}_{2} \mathrm{CH}_{3}\right), 35.62\left(\mathrm{CCH}_{2}\right), 72.36\left(\mathrm{CH}_{2} \mathrm{O}\right)$.

Stability study. 4-ethyl-2,6,7-trioxa-1-arsabicyclo[2.2.2]octane (20 mg, $0.097 \mathrm{mmol})$ was dissolved in $1 \mathrm{~mL}$ of deuterated chloroform in a sealed glass vial (solution $\mathrm{A}, 97 \mathrm{mM}$ ). Ethanethiol $(17.8 \mu \mathrm{L}, 15.3 \mathrm{mg}, 0.24 \mathrm{mmol})$ and TEA (34 $\mu \mathrm{L}, 24.7 \mathrm{mg}, 0.24 \mathrm{mmol})$ were 


\section{Yutian Feng}

dissolved in $947.2 \mu \mathrm{L}$ of deuterated chloroform in a sealed glass vial (solution $\mathrm{B}, 240 \mathrm{mM}$ ). Three NMR tubes were prepared: 1) $500 \mu \mathrm{L}$ each of solution A and deuterated chloroform; 2) $500 \mu \mathrm{L}$ each of solution B and deuterated chloroform; 3) $500 \mu \mathrm{L}$ each of solution $\mathrm{A}$ and solution B. All solutions were monitored by ${ }^{1} \mathrm{H}$ NMR at $0,4,24$, and $72 \mathrm{~h}$. X-ray determination of 4-ethyl-2,6,7-trioxa-1-ars abicyclo[2.2.2]octane. The crystal structure data for the $\mathrm{As}(\mathrm{OR})_{3}$ bicyclic complex was obtained at $-100{ }^{\circ} \mathrm{C}$ on a Bruker SMART CCD Area Detector system using the $\omega$ scan technique with Mo K $\alpha$ radiation from a graphite monochromator. The crystal size was approximately $0.450 \times 0.250 \times 0.005 \mathrm{~mm}^{3}$. Intensities were corrected for Lorentz and polarization effects. The structure was solved by direct methods with full-matrix least-squares refinement, using the SHELX package.[55] All non-hydrogen atoms were refined with anisotropic thermal parameters. The hydrogen atoms were placed at calculated positions and included in the refinement using a riding model, with fixed isotropic U. Other crystal refinement data are reported in Table 4.5. Final difference maps contained no features of chemical significance.

\section{Results and Discussion}

The development of the chemistry of As(III) for radiopharmaceutical applications requires the identification of chelates that will stabilize the As(III) at high dilution under in vivo conditions. To this end, a trithiol ligand was investigated. The bicyclic arsenic(III) complex, 4-ethyl-2,6,7-trioxa-1-arsabicyclo[2.2.2] octane $\left(\mathrm{As}\left(\mathrm{O}_{3} \mathrm{R}\right)\right)$, was synthesized in a manner similar to the previously reported 4-methyl-2,6,7-trioxa-1-arsabicyclo[2.2.2] octane analogue (Scheme 4.8). [89, 90] 


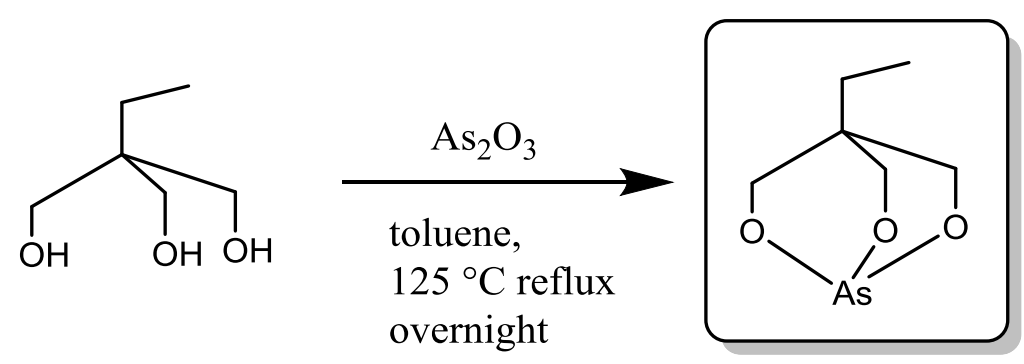

Scheme 4.8. The synthesis of the $\mathrm{As}\left(\mathrm{O}_{3} \mathrm{R}\right)$ complex 4-ethyl-2,6,7-trioxa-1arsabicyclo[2.2.2] octane.

A search of the Cambridge Structural Database (Version 5.36) revealed no crystal structures of 4-ethyl-2,6,7-trioxa-1-arsabicyclo[2.2.2] octane.[91] Crystal data, data collection and structure refinement details are summarized in Table 4.5. The C-bound $\mathrm{H}$ atoms were included in calculated positions and treated as riding: $\mathrm{C}-\mathrm{H}=0.95-0.99 \AA$ with $\mathrm{Uiso}(\mathrm{H})=$ 1.2 $\mathrm{Ueq}(\mathrm{C})$. The final least-squares cycle for the crystal structure of 4-ethyl-2,6,7-trioxa-1arsabicyclo[2.2.2] octane was calculated with $\mathrm{R}=0.0722$ and $\mathrm{R}_{\mathrm{w}}=0.2069$ (Figure 4.9). The bond angles and distances are summarized in Table 4.6. The As-O bond lengths for 4-ethyl2,6,7-trioxa-1-arsabicyclo[2.2.2] octane range from $1.7777(13)$ to $1.7858(14)$, with an average of $1.7827(\AA)$ (Table 4.6). These bond lengths are in good agreement with the As(III)-O bond distance of $1.77 \pm 0.03(\AA)$ reported in the Cambridge Structural Database.[92] The crystal structure shows no sign of an As=O double bond, however existence of such species have been reported (no crystal structures).[93] In the crystal, molecules pack as dimers about inversion centers, with a close intermolecular contact of 2.868(2) $\AA$ between O3 and As1, which is accompanied by a contact distance of 2.823(3) $\AA$ between $\mathrm{O} 3$ and the symmetry generated $\mathrm{O} 3$. Such close interactions are common in the 


\section{Yutian Feng}

packing of similar metal-O systems. These dimer pairs are then stacked into columns along the a direction, as shown in Figure 4.10.

Table 4.5. X-ray crystal Data, data collection parameters, and refinement parameters for 4ethyl-2,6,7-trioxa-1-arsabicyclo[2.2.2] octane.

\begin{tabular}{|c|c|}
\hline Empirical formula & $\mathrm{C}_{6} \mathrm{H}_{11} \mathrm{AsO}_{3}$ \\
\hline Formula weight & 206.07 \\
\hline Temperature & $100(2) \mathrm{K}$ \\
\hline Wavelength & $0.71073 \AA$ \\
\hline Crystal system & Monoclinic \\
\hline Space group & P 21/n \\
\hline Unit cell dimensions & $\mathrm{a}=6.0059(10) \AA \quad \square=90^{\circ}$ \\
\hline & $\begin{array}{c}\mathrm{b}=11.602(2) \AA \quad \square=92.272(2)^{\circ} . \\
\mathrm{c}=10.6270(18) \AA \quad \square=90^{\circ} .\end{array}$ \\
\hline Volume & $739.9(2) \AA^{3}$ \\
\hline $\mathbf{Z}$ & 4 \\
\hline Density (calculated) & $1.850 \mathrm{Mg} / \mathrm{m}^{3}$ \\
\hline Absorption coefficient & $4.537 \mathrm{~mm}^{-1}$ \\
\hline F $(000)$ & 416 \\
\hline Crystal size & $0.500 \times 0.250 \times 0.150 \mathrm{~mm}^{3}$ \\
\hline The ta range for data collection & 2.600 to $27.538^{\circ}$ \\
\hline Index ranges & $-7 \leq \mathrm{h} \leq 7,-14 \leq \mathrm{k} \leq 14,-13 \leq 1 \leq 13$ \\
\hline Reflections collected & 8432 \\
\hline Inde pe ndent reflections & $1691[\mathrm{R}($ int $)=0.0230]$ \\
\hline Completeness to theta $=25.242^{\circ}$ & $99.9 \%$ \\
\hline Absorption correction & Semi-empirical from equivalents \\
\hline Max. and min. transmission & 0.55 and 0.40 \\
\hline Refinement me thod & Full-matrix least-squares on $\mathrm{F}^{2}$ \\
\hline Data / restraints / parameters & $1691 / 0 / 92$ \\
\hline Goodness-of-fit on $F^{2}$ & 1.079 \\
\hline Final $R$ indices $[I>2 \operatorname{sigma}(I)]$ & $\mathrm{R} 1=0.0211, w \mathrm{R} 2=0.0546$ \\
\hline $\mathbf{R}$ indices (all data) & $\mathrm{R} 1=0.0234, \mathrm{wR} 2=0.0555$ \\
\hline Extinction coefficient & $\mathrm{n} / \mathrm{a}$ \\
\hline
\end{tabular}




\section{Yutian Feng}

\section{Largest diff. peak and hole $\quad 0.677$ and -0.542 e. $\AA^{-3}$}

Computer programs: APEX2 and SAINT (Bruker, 2008), SHELXS2014.[55]

Table 4.6. Selected bond angles $\left({ }^{\circ}\right)$ and distances $(\AA)$ for 4-ethyl-2,6,7-trioxa-1arsabicyclo[2.2.2]octane.

\begin{tabular}{|c|c|c|c|}
\hline \multicolumn{2}{|c|}{ Selected distance $(\AA)$} & \multicolumn{2}{|c|}{ Selected bond angles $\left(^{\circ}\right)$} \\
\hline$\overline{\mathrm{As}(1)-\mathrm{O}(1)}$ & $1.7777(13)$ & $\mathrm{O}(1)-\mathrm{As}(1)-\mathrm{O}(2)$ & $96.23(6)$ \\
\hline $\mathrm{As}(1)-\mathrm{O}(2)$ & $1.7847(14)$ & $\mathrm{O}(1)-\mathrm{As}(1)-\mathrm{O}(3)$ & $97.51(6)$ \\
\hline $\mathrm{As}(1)-\mathrm{O}(3)$ & $1.7858(14)$ & $\mathrm{O}(2)-\mathrm{As}(1)-\mathrm{O}(3)$ & $96.03(6)$ \\
\hline $\mathrm{O}(1)-\mathrm{C}(1)$ & $1.450(2)$ & $\mathrm{C}(1)-\mathrm{O}(1)-\mathrm{As}(1)$ & $114.93(10)$ \\
\hline $\mathrm{O}(2)-\mathrm{C}(2)$ & $1.451(2)$ & $\mathrm{C}(2)-\mathrm{O}(2)-\mathrm{As}(1)$ & $114.84(11)$ \\
\hline $\mathrm{O}(3)-\mathrm{C}(3)$ & $1.446(2)$ & $\mathrm{C}(3)-\mathrm{O}(3)-\mathrm{As}(1)$ & $115.51(11)$ \\
\hline$C(1)-C(4)$ & $1.535(2)$ & $\mathrm{O}(1)-\mathrm{C}(1)-\mathrm{C}(4)$ & $112.22(14)$ \\
\hline$C(2)-C(4)$ & $1.537(2)$ & $\mathrm{O}(2)-\mathrm{C}(2)-\mathrm{C}(4)$ & $112.63(15)$ \\
\hline $\mathrm{C}(3)-\mathrm{C}(4)$ & $1.533(2)$ & $\mathrm{O}(3)-\mathrm{C}(3)-\mathrm{C}(4)$ & $112.19(14)$ \\
\hline$C(4)-C(5)$ & $1.536(2)$ & $C(3)-C(4)-C(1)$ & $109.02(14)$ \\
\hline \multirow{6}{*}{$\mathrm{C}(5)-\mathrm{C}(6)$} & $1.532(3)$ & $C(3)-C(4)-C(5)$ & $110.93(15)$ \\
\hline & & $C(1)-C(4)-C(5)$ & $110.87(15)$ \\
\hline & & $C(3)-C(4)-C(2)$ & $108.43(15)$ \\
\hline & & $C(1)-C(4)-C(2)$ & $109.12(15)$ \\
\hline & & $C(5)-C(4)-C(2)$ & $108.42(15)$ \\
\hline & & $C(6)-C(5)-C(4)$ & $115.51(15)$ \\
\hline
\end{tabular}




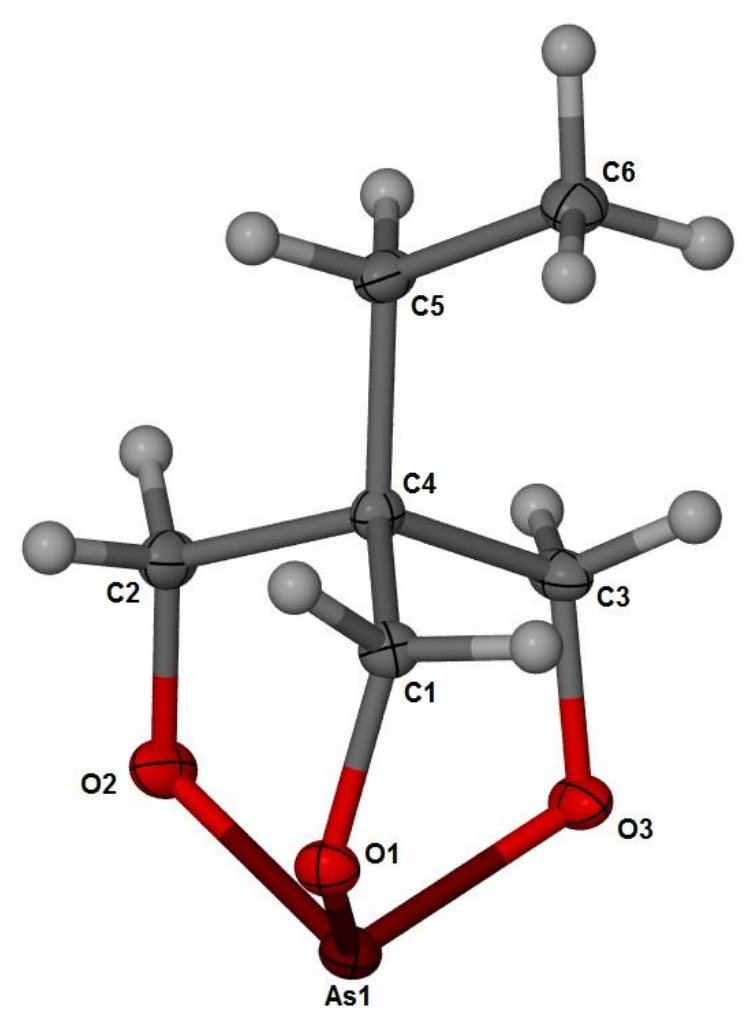

Figure 4.9. ORTEP representation of 4-ethyl-2,6,7-trioxa-1-arsabicyclo[2.2.2] octane with 50\% probability ellipsoids. 


\section{Yutian Feng}

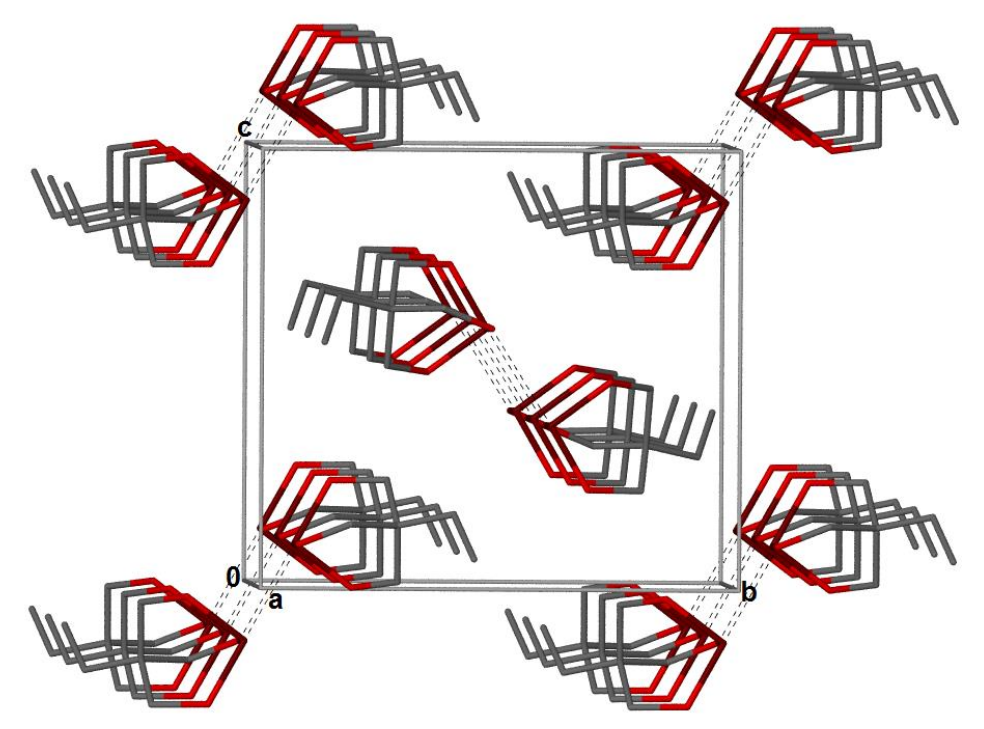

Figure 4.10. The packing diagram of 4-ethyl-2,6,7-trioxa-1-arsabicyclo[2.2.2]octane.

The ${ }^{1} \mathrm{H}$ NMR and ${ }^{13} \mathrm{C}$ NMR spectra of the As $(\mathrm{OR})_{3}$ bicyclic complex are shown in Figures 4.11 and 4.12. A singlet observed at $4.07 \mathrm{ppm}$ by ${ }^{1} \mathrm{H}$ NMR was assigned to the six methylene protons adjacent to the $\mathrm{O}-\mathrm{As}$, which is consistent with the $4.23 \mathrm{ppm}$ chemical shift for the analogous protons reported by Neunhoeffer et al. for 4-methyl-2,6,7-trioxa-1arsabicyclo[2.2.2] octane.[72, 89] The remaining 5 protons for the pendant ethyl group were observed as a quartet ( 2 protons) at $1.10 \mathrm{ppm}$ and a triplet ( 3 protons) at $0.78 \mathrm{ppm}$. Four carbon signals were observed in the ${ }^{13} \mathrm{C}$ NMR spectrum, with chemical shifts at $7.31 \mathrm{ppm}$ and $25.20 \mathrm{ppm}$ assigned to the methyl and methylene carbons of the ethyl group, respectively, and the $35.62 \mathrm{ppm}$ and $72.47 \mathrm{ppm}$ chemical shifts attributed to the quaternary carbon and methylene carbons adjacent to the oxo groups, respectively. These chemical shifts are 


\section{Yutian Feng}

consistent with those reported in similar environments $\left(\mathrm{RCH}_{2} \mathrm{R}^{\prime}=20-45 \mathrm{ppm}, \mathrm{RCH}_{3}=0-30\right.$ ppm, $\mathrm{C}=67-77 \mathrm{ppm}$, and $\left.\mathrm{RCH}_{2} \mathrm{OR}^{\prime}=30-50 \mathrm{ppm}\right) .[72]$

The stability of this compound to "thiol challenge" was evaluated by ${ }^{1} \mathrm{H}$ NMR using ethanethiol. The ${ }^{1} \mathrm{H}$ NMR and ${ }^{13} \mathrm{C}$ NMR spectra of the starting material, 1,1,1tris(hydroxymethyl)propane, are shown in Figures 4.13 and 4.14. The stability of 4-ethyl2,6,7-trioxa-1-arsabicyclo[2.2.2] octane to challenge by ethanethiol was monitored by ${ }^{1} \mathrm{H}$ NMR. The spectra of the individual compounds, as well as the reaction mixture were followed by ${ }^{1} \mathrm{H}$ NMR over 72 hours (Figures 4.15-4.17). The stability was assessed following the change in the proton signal associated with the As-OR linkage $\left(\mathrm{CH}_{2} \mathrm{OAs}\right)$. In Figure 4.17-A, a potential mechanism for the thiol challenge is shown. The lower electronegativity of arsenic compared to oxygen polarizes the As-O bond (partial positive charge on arsenic) facilitating nucleophilic attack on arsenic by a thiolate and resulting in breaking of the As-O bond and formation of an As-SR bond. This bond breaking and formation is observed in the various ${ }^{1} \mathrm{H}-\mathrm{NMR}$ spectra shown in Figure 4.17-B. At the $0 \mathrm{~h}$ time point following addition of ethanethiol, protons associated with the $\mathrm{CH}_{2}-\mathrm{O}$ As are observed as a split peak at $4.07 \mathrm{ppm}$, which is observed as a singlet at the same chemical shift at the $4 \mathrm{~h}$ time point. A possible explanation for this observation is that an intermediate forms before the As-O bond breaks, and results in a different chemical environment around the protons of $\mathrm{CH}_{2}-\mathrm{O}-\mathrm{As}$. The alkoxide, $\mathrm{RO}^{-}$, formed is protonated to generate a hydroxyl group. The formation of the hydroxyl group changes the chemical environment as well as the chemical shifts of the protons adjacent to the oxygen in the ${ }^{1} \mathrm{H}$ NMR spectra. At the $72 \mathrm{~h}$ time point, a peak at $3.68 \mathrm{ppm}$ has grown in size while the peak at 4.05 ppm has diminished. The peak observed at $3.68 \mathrm{ppm}$ correlates with protons of the 


\section{Yutian Feng}

$\mathrm{CH}_{2} \mathrm{OH}$ group consistent with the formation of a hydroxyl group (Figure 4.17-B). The appearance and growth of this signal indicates the decomposition of the As-trialkoxy complex, during which As-O bonds are replaced with As-S bonds from ethanethiol. 


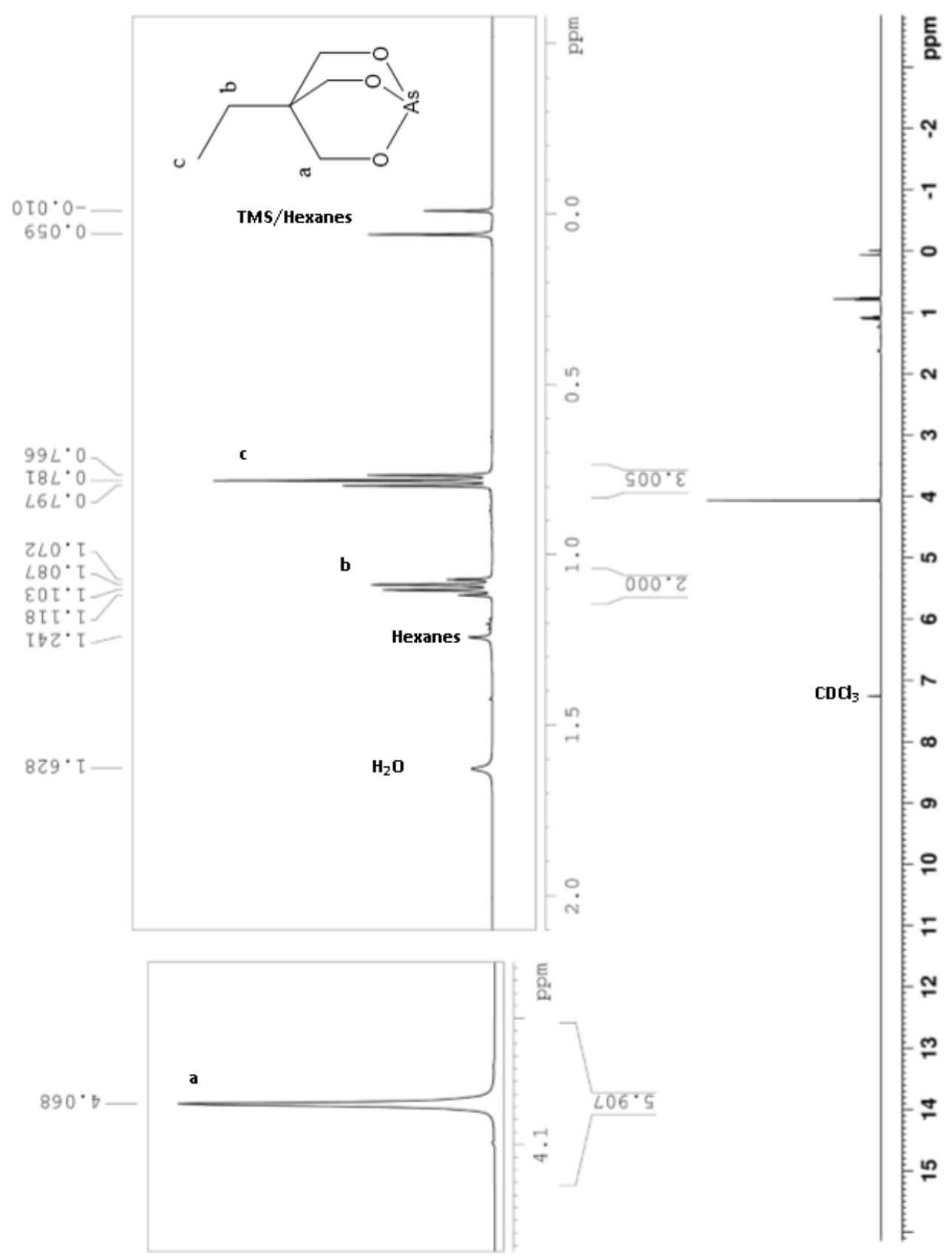

Figure 4.11. ${ }^{1} \mathrm{H}$ NMR spectrum of 4-ethyl-2,6,7-trioxa-1-arsabic yclo[2.2.2] octane $\left(\mathrm{CDCl}_{3} \mathrm{~d}_{1}\right.$; $500 \mathrm{MHz}$ ). 


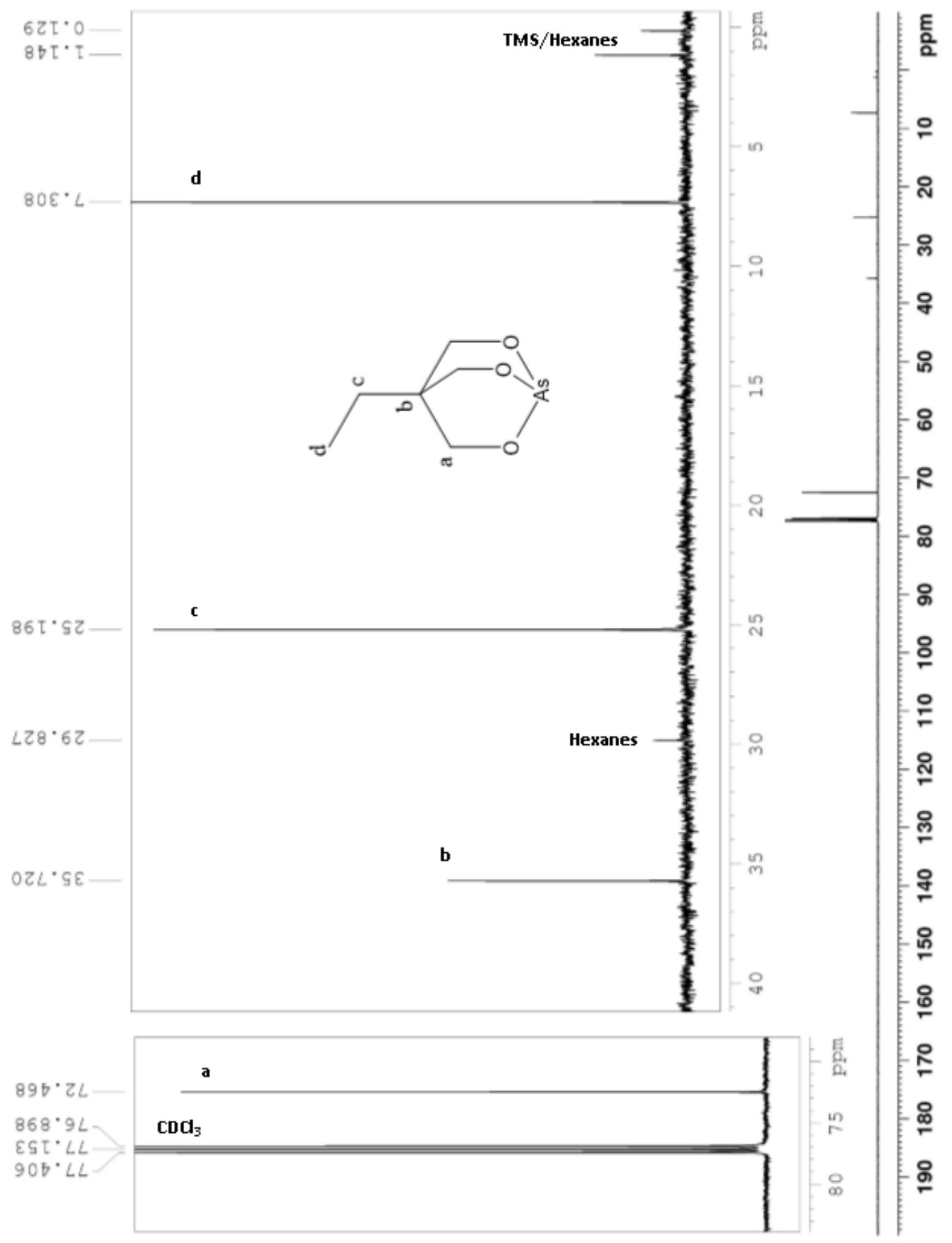

Figure 4.12. ${ }^{13} \mathrm{C}$ NMR spectrum of 4-ethyl-2,6,7-trioxa-1-arsabic yclo[2.2.2] octane $\left(\mathrm{CDCl}_{3}\right.$ $\left.\mathrm{d}_{1} ; 500 \mathrm{MHz}\right)$. 


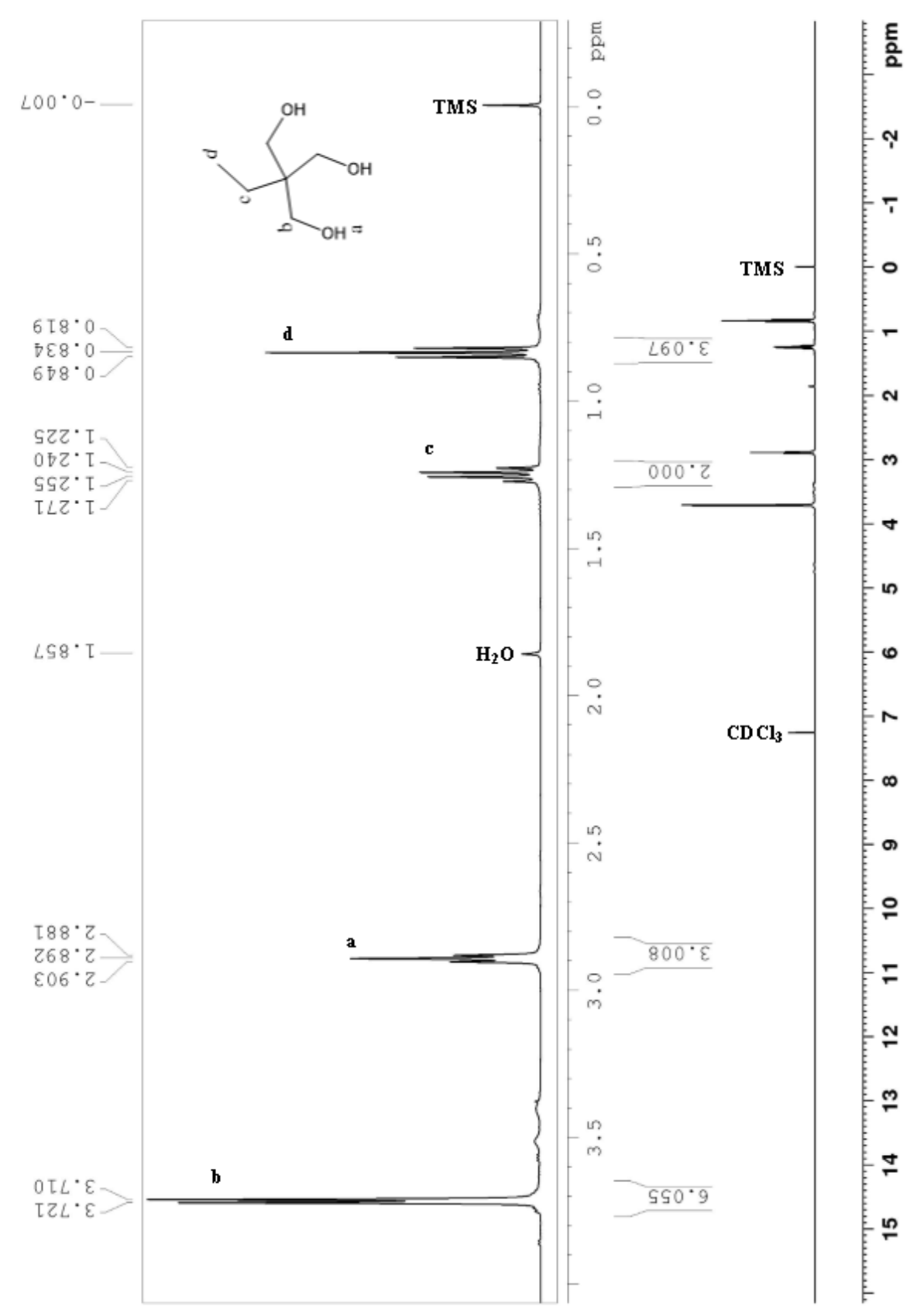

Figure 4.13. ${ }^{1} \mathrm{H}$ NMR spectrum of 2-ethyl-2-(hydroxymethyl)propane-1,3-diol $\left[\mathrm{C}_{6} \mathrm{H}_{14} \mathrm{O}_{3}\right]$ $\left(\mathrm{CDCl}_{3} \mathrm{~d}_{1} ; 500 \mathrm{MHz}\right)$. 


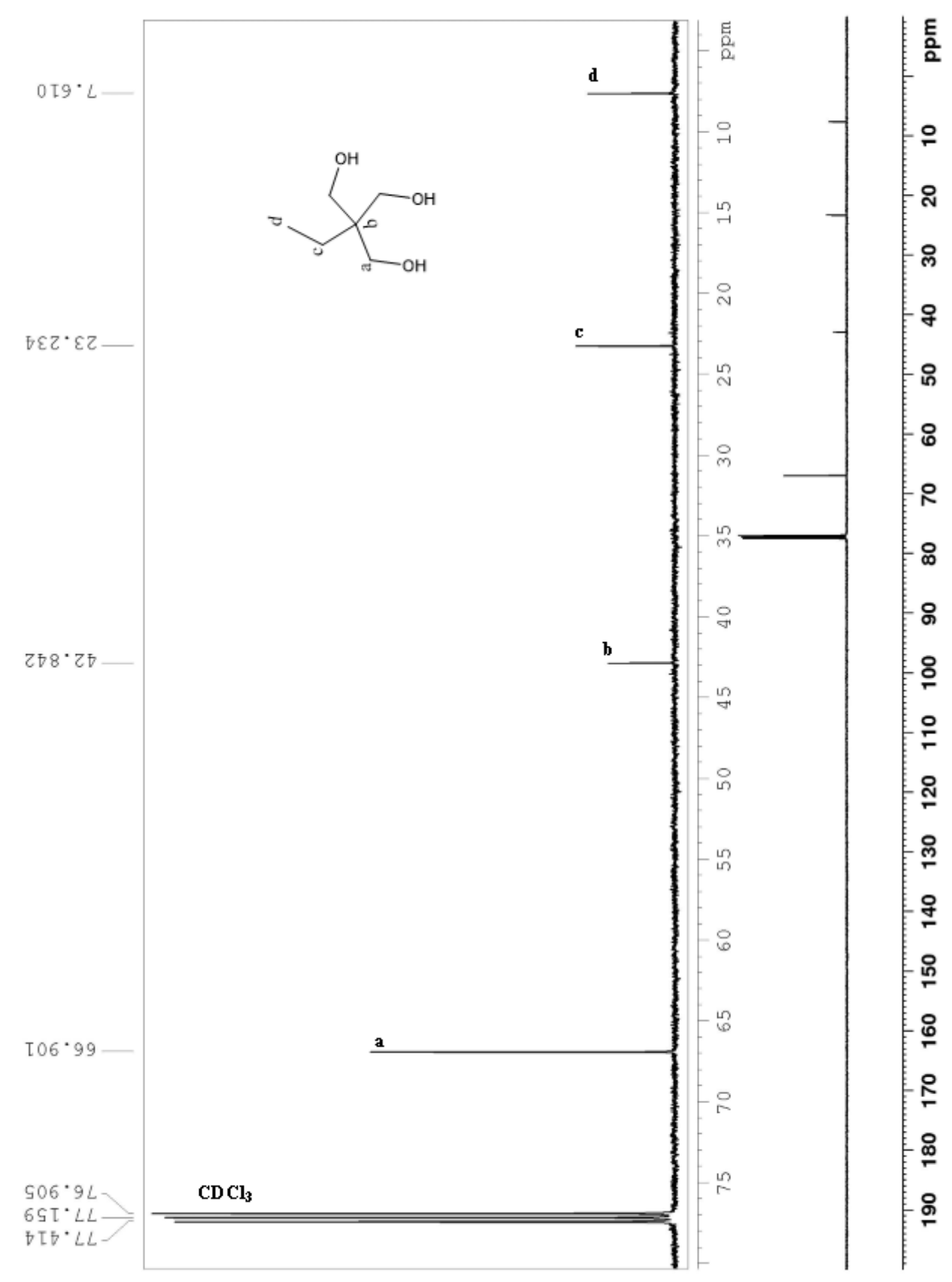

Figure 4.14. ${ }^{13} \mathrm{C}$ NMR spectrum of 2-ethyl-2-(hydroxymethyl)propane-1,3-diol $\left(\mathrm{CDCl}_{3} \mathrm{~d}_{1}\right.$; $500 \mathrm{MHz})$. 

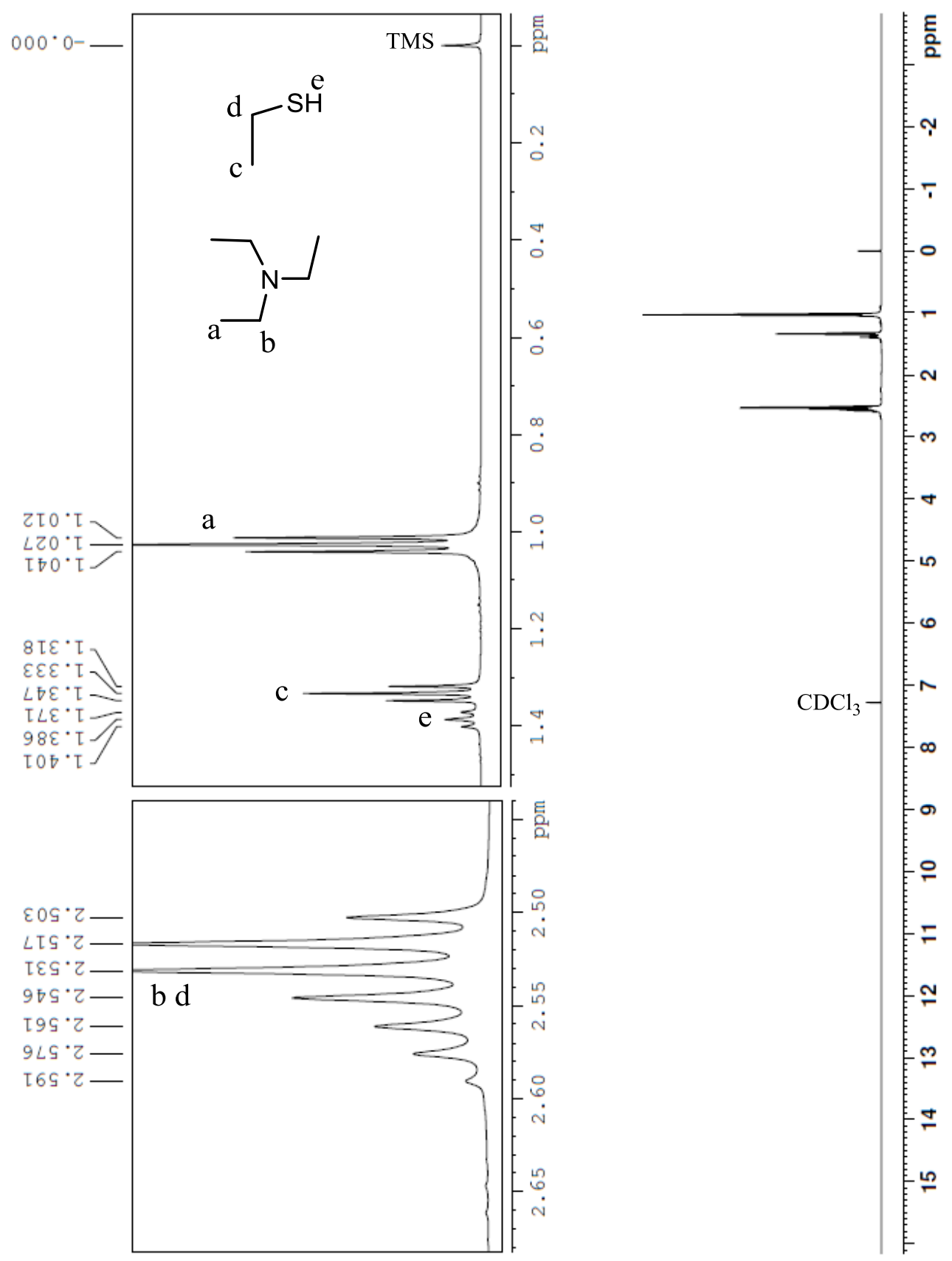

Figure 4.15. ${ }^{1} \mathrm{H}$ NMR spectrum of a mixture of ethanethiol and triethylamine (stock solution $\mathrm{B}, 0.24 \mathrm{mmol}$, 1:1 ratio, affording thiolates); this is the reference spectrum for the $\mathrm{t}=0 \mathrm{~h}$ time point $\left(\mathrm{CDCl}_{3} \mathrm{~d}_{1} ; 500 \mathrm{MHz}\right)$. 

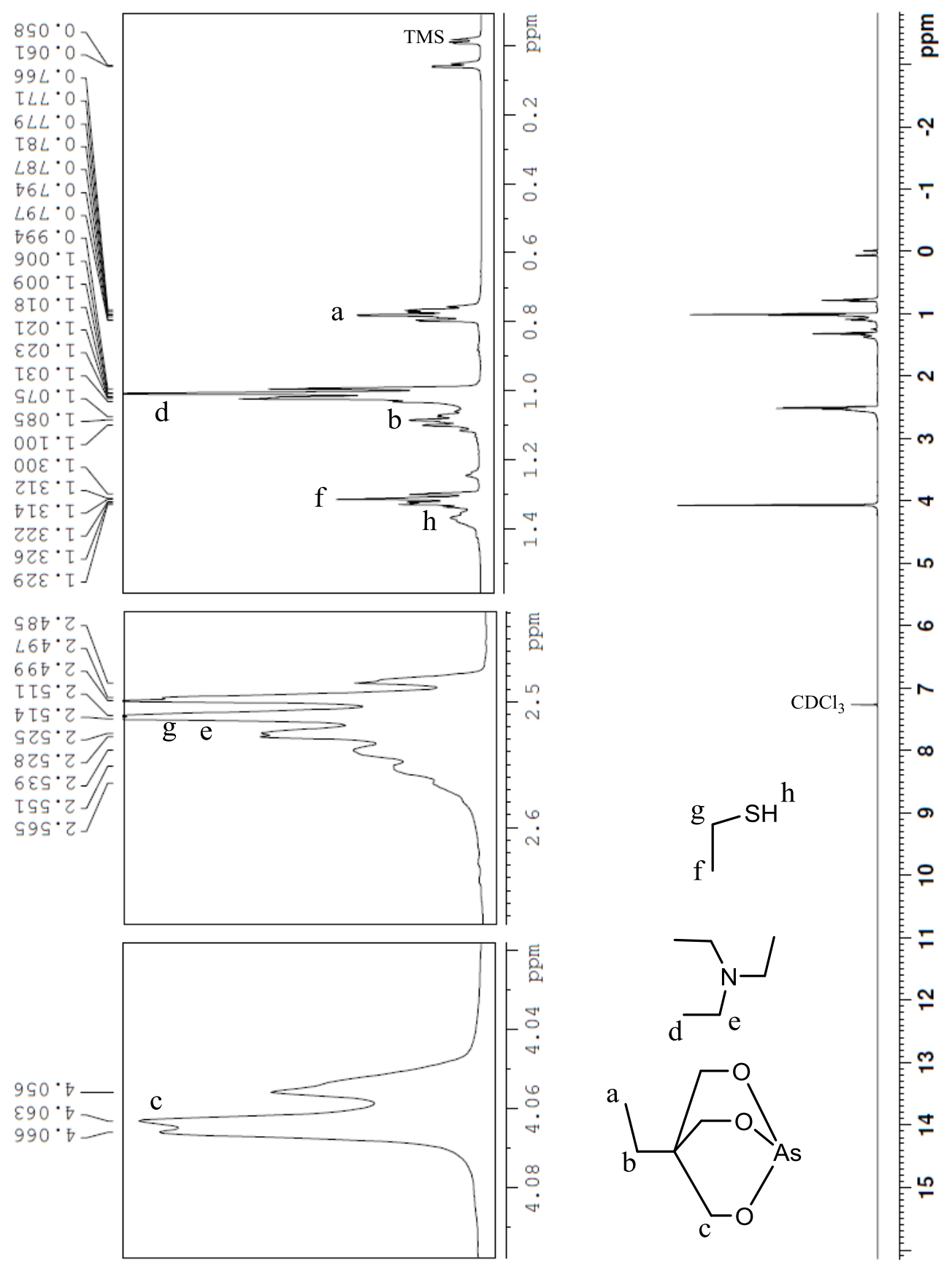

Figure 4.16. ${ }^{1} \mathrm{H}$ NMR spectrum of a mixture of ethanethiol, triethylamine and 4-ethyl-2,6,7trioxa-1-arsabicyclo[2.2.2]octane (thiol challenge study; free thiol: As complex 2.5: 1); this is the $\mathrm{t}=0 \mathrm{~h}$ time point spectrum. 


\section{Yutian Feng}
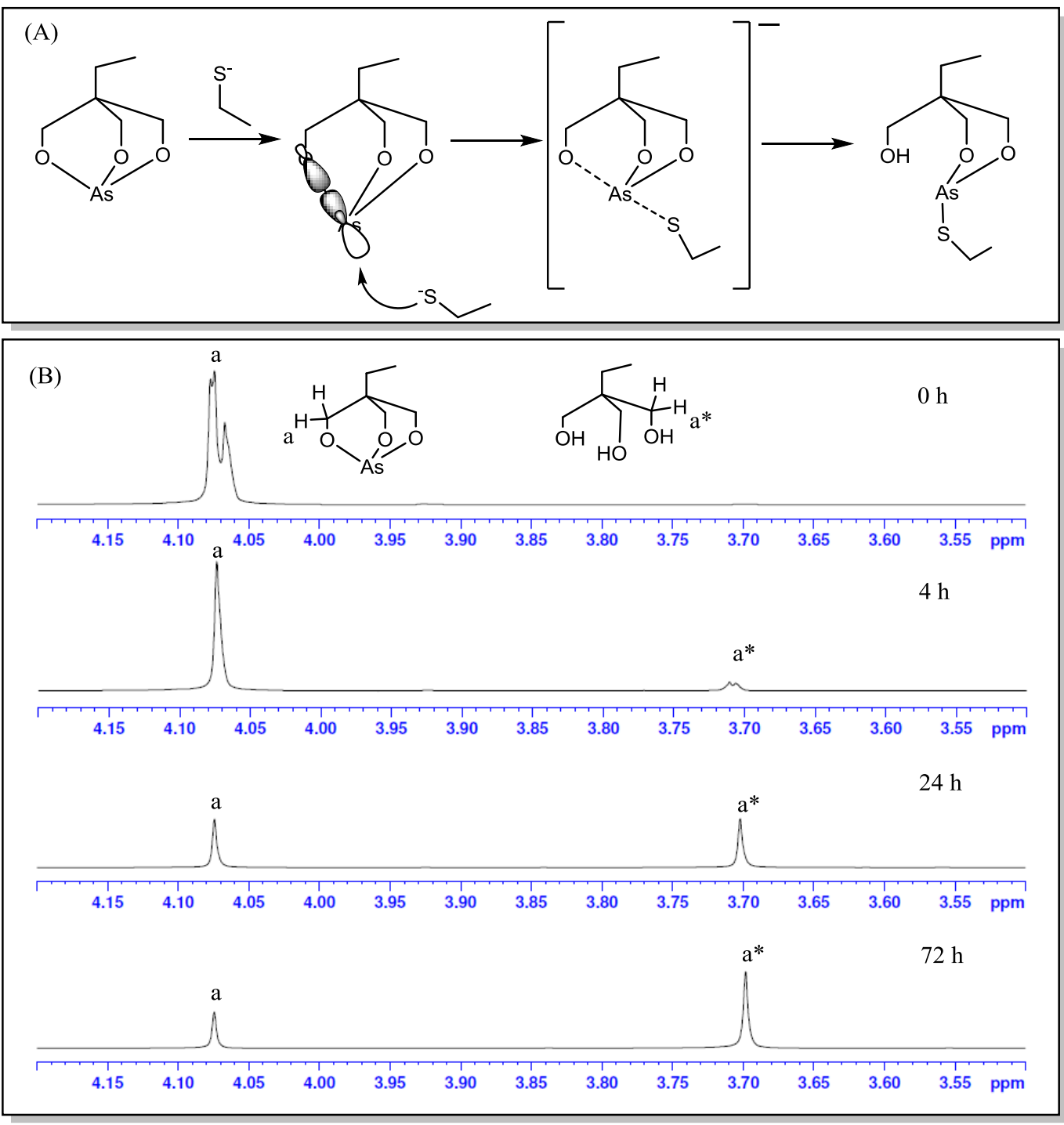

Figure 4.17. (A) Proposed mechanism of a free thiol approaching the As metal center from As-O $\sigma^{*}$ orbital as a nucleophile, resulting in the As-O bond breaking and formation of a free hydroxyl group and As-S bonds. (B) ${ }^{1} \mathrm{H}$ NMR spectra ( $\delta$ from 3.5 to $4.2 \mathrm{ppm}$ ) showing the thiol challenge mixture at $\mathrm{t}=0 \mathrm{~h}, \mathrm{t}=4 \mathrm{~h}, \mathrm{t}=24 \mathrm{~h}$, and $\mathrm{t}=72 \mathrm{~h}$, respectively. a represents ${ }^{1} \mathrm{H}$ NMR signals of $\mathrm{CH}_{2} \mathrm{OAs}$, while $\mathbf{a}^{*}$ represents ${ }^{1} \mathrm{H}-\mathrm{NMR}$ signals for a free hydroxyl group $\mathrm{CH}_{2} \mathrm{OH}$. A singlet $\left(\mathbf{a}^{*}\right)$ grew in overtime indicating the decomposition of the $\mathrm{As}(\mathrm{OR})_{3}$ bicyclic complex. 


\section{Yutian Feng}

\section{Conclusion}

A new $\mathrm{As}(\mathrm{OR})_{3}$ bicyclic complex was synthesized for evaluating $\mathrm{O}$ donors as ligands for As(III) for potential in vivo use. The crystal structure of the $\mathrm{As}(\mathrm{OR})_{3}$ bicyclic complex revealed no sign of an $\mathrm{As}=\mathrm{O}$ bond indicating that $\mathrm{As}$ was in the +3 oxidation state. After exposure to air, the arsenic in the $\mathrm{As}(\mathrm{OR})_{3}$ bicyclic complex remained in the +3 oxidation state showing the possible stability of As(III) complex. The full interpretation of NMR spectra of this complex and its precursor provided a method for investigating the stability of this complex by "thiol challenge". The diminishment of the proton peak associated with $\mathrm{CH}_{2-}$ O-As revealed decomposition of the $\mathrm{As}(\mathrm{OR})_{3}$ bicyclic complex, and the growing proton peak associated with $\mathrm{CH}_{2} \mathrm{OH}$ confirmed the formation of a free hydroxyl group, which indicated decomposition of the complex. Therefore the stability of As complex surviving in vivo conditions needs to be improved. The approach is to use sulfur donor based ligands. Ligands with higher stability are required in order to develop radioarsenic radiopharmaceuticals. 


\section{Yutian Feng}

\section{Chapter 5: Conclusions}

All the work discussed in this dissertation is supported by the collaboration between the University of Missouri Chemistry Department, the MU Research Reactor, Harry S. Truman VA Hospital and the University of Washington. It focuses on the development of radioarsenic as a matched pair radionuclide for imaging and radiotherapy from the production of no carrier added ${ }^{72,77} \mathrm{As}$, its radiochemistry via two approaches and the initial evaluation under in vivo conditions.

The production and separation of nca ${ }^{77}$ As has been developed previously but an improvement of the separation method regarding separation capacity was discussed in Chapter 2. The production of a ${ }^{72} \mathrm{Se} /{ }^{72} \mathrm{As}$ generator via the ${ }^{70} \mathrm{Ge}(\alpha, 2 \mathrm{n}){ }^{72} \mathrm{Se}$ nuclear reaction has not been reported previously. Preliminary studies of the ${ }^{72} \mathrm{Se} /{ }^{72}$ As separation parameters were discussed in Chapter 2. Using the optimized generator parameters a larger scale production will be carried out in the near future.

Synthesis of no carrier added $\left[{ }^{77} \mathrm{As}\right]$ dithioarylarsines was conducted and optimized as an approach to stabilize nca radioarsenic under in vivo conditions. A series of dithioarylarsines were synthesized and characterized as macroscopic standards. The synthesis and characterization of the macroscopic dithioarylarsines and nca $\left[{ }^{77}\right.$ As]dithioarylarsines were discussed in Chapter 3.

A trithiol chelate as another approach for arsenic radiolabeling was reported previously. [32] A linkable trithiol chelate was synthesized and characterized to evaluate the stability of the Astrithiol complex in vivo. The trithiol-BBN(7-14) $\mathrm{NH}_{2}$ bioconjugate was radiolabeled with nca ${ }^{77}$ As, purified and the biodistribution of ${ }^{77}$ As-trithiol-BBN(7-14) $\mathrm{NH}_{2}$ was evaluated in mice. It displayed high in vivo stability but poor targeting efficacy due to the high lipophilicity and 


\section{Yutian Feng}

rigidity of the trithiol chelate. A dicarboxylic trithiol analogue was proposed, synthesized and characterized to improve the lipophilic ity and rigidity. Comparison of the dicarboxylic trithiol with the previous trithiol chelates showed promising results as high hydrophilicity was observed. Future work will include the evaluation of the dicarboxylic trithiol in vivo. As an alternative, a triol (trihydroxyl) chelate was evaluated. The As-triol compound was synthesized and characterized at the macroscopic level. Its stability was investigated via a "thiol challenge" and poor stability was observed when the complex was treated with high thiol concentrations, which indicates that sulfur donor based chelates are better choices for radioarsenic. This work was discussed in Chapter 4.

The chemistry of arsenic at the tracer level has not been well explored, but it is the foundation for developing radiopharmaceuticals using radioarsenic. This dissertation emphasizes the radiochemistry of nca ${ }^{72,77}$ As and includes the chemistry of arsenic in aqueous solutions, the interactions of arsenic with thiol based ligands, and the evaluation of conjugates using radioarsenic for potential radiopharmaceuticals. The work described in this dissertation was inspired by arsenic chemistry at the macroscopic level, but it covers both the similarities and differences between the macroscopic level and the tracer level. This dissertation provides feasible methods to produce, radiolabel and conjugate a bifunctional chelate to radioarsenic, and hence pave the way for developing ${ }^{72,77}$ As as a matched pair for radiopharmaceutical development. 


\section{Yutian Feng}

\section{Appendix A: Supplemental Data for Chapter 3}

The ${ }^{1} \mathrm{H}$ and ${ }^{13} \mathrm{C}$ NMR data of the compounds $\mathbf{1 - 3}$ in the Chapter 3 were listed in the Appendix A. The structures of the compounds were attached to their NMR data. The NMR signals were interpreted and labeled according to the structures. 


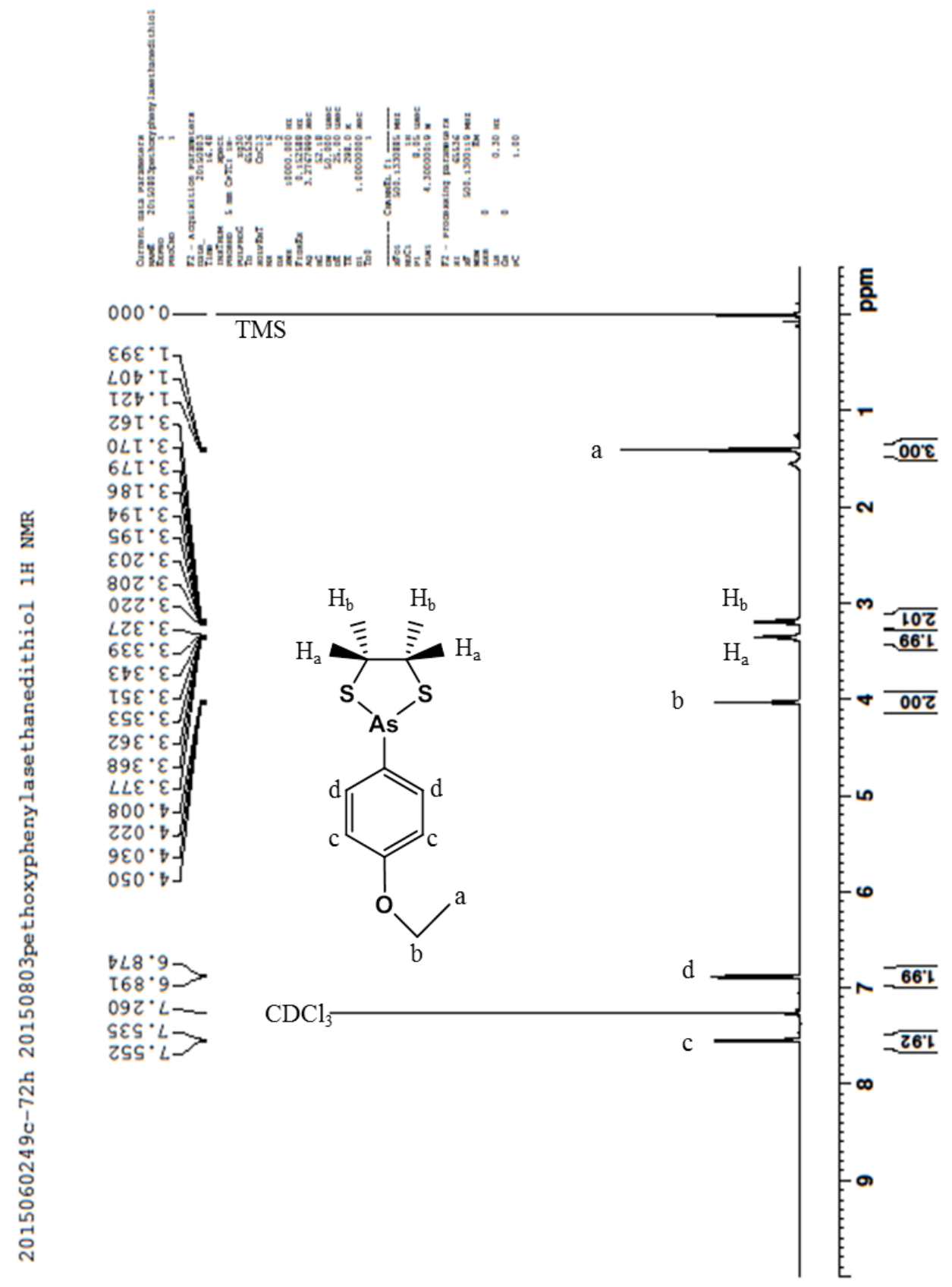

Figure A-1. ${ }^{1} \mathrm{H}$ NMR of 2-(4-ethoxyphenyl)-1,3,2-dithiaarsolane $\left[\mathrm{CH}_{3} \mathrm{CH}_{2} \mathrm{OC}_{6} \mathrm{H}_{4} \mathrm{As}\left(\mathrm{SCH}_{2} \mathrm{CH}_{2} \mathrm{~S}\right)\right]$, compound 1. 


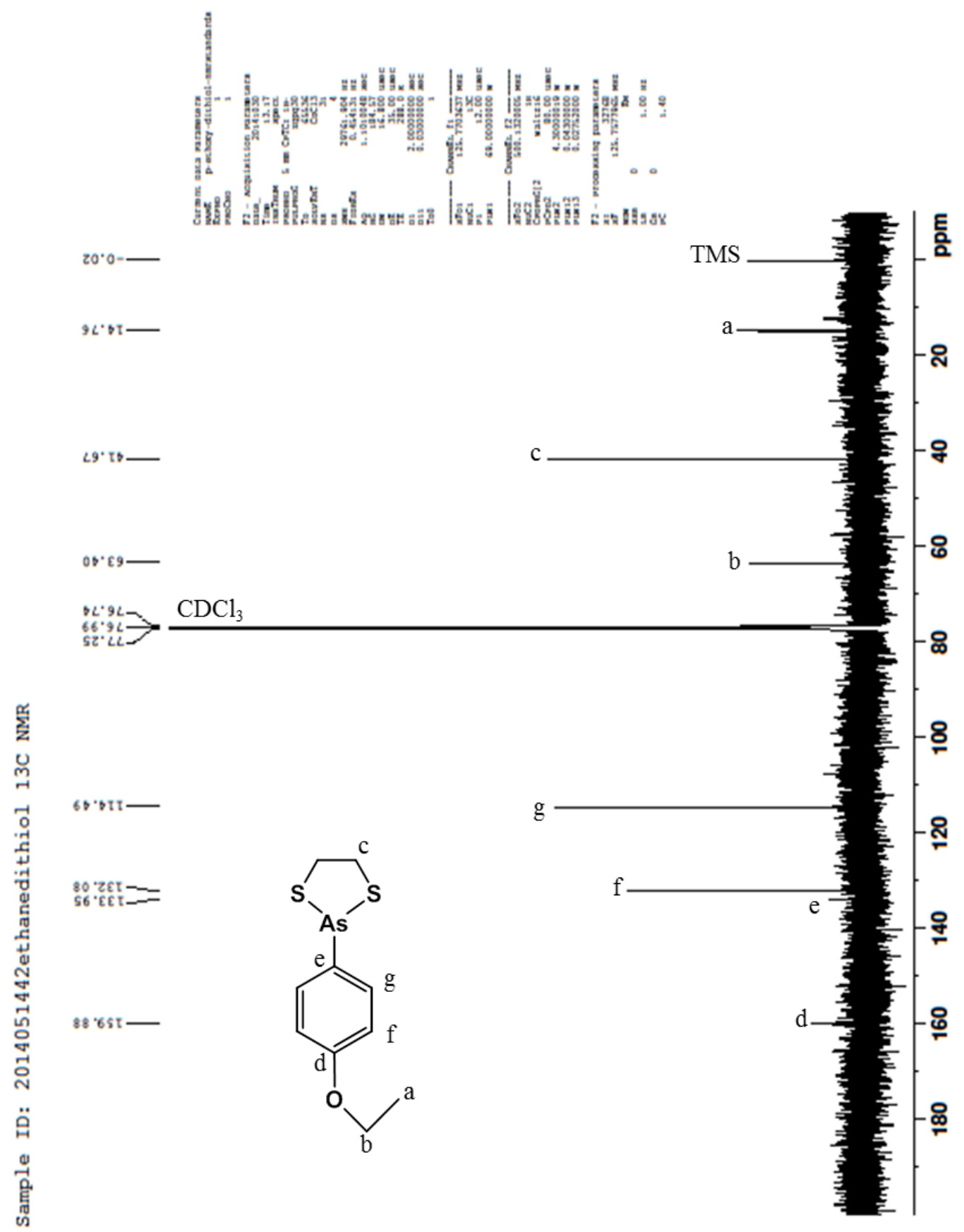

Figure A-2. ${ }^{13} \mathrm{C}$ NMR of 2-(4-ethoxyphenyl)-1,3,2-dithiaarsolane $\left[\mathrm{CH}_{3} \mathrm{CH}_{2} \mathrm{OC}_{6} \mathrm{H}_{4} \mathrm{As}\left(\mathrm{SCH}_{2} \mathrm{CH}_{2} \mathrm{~S}\right)\right]$, compound 1. 

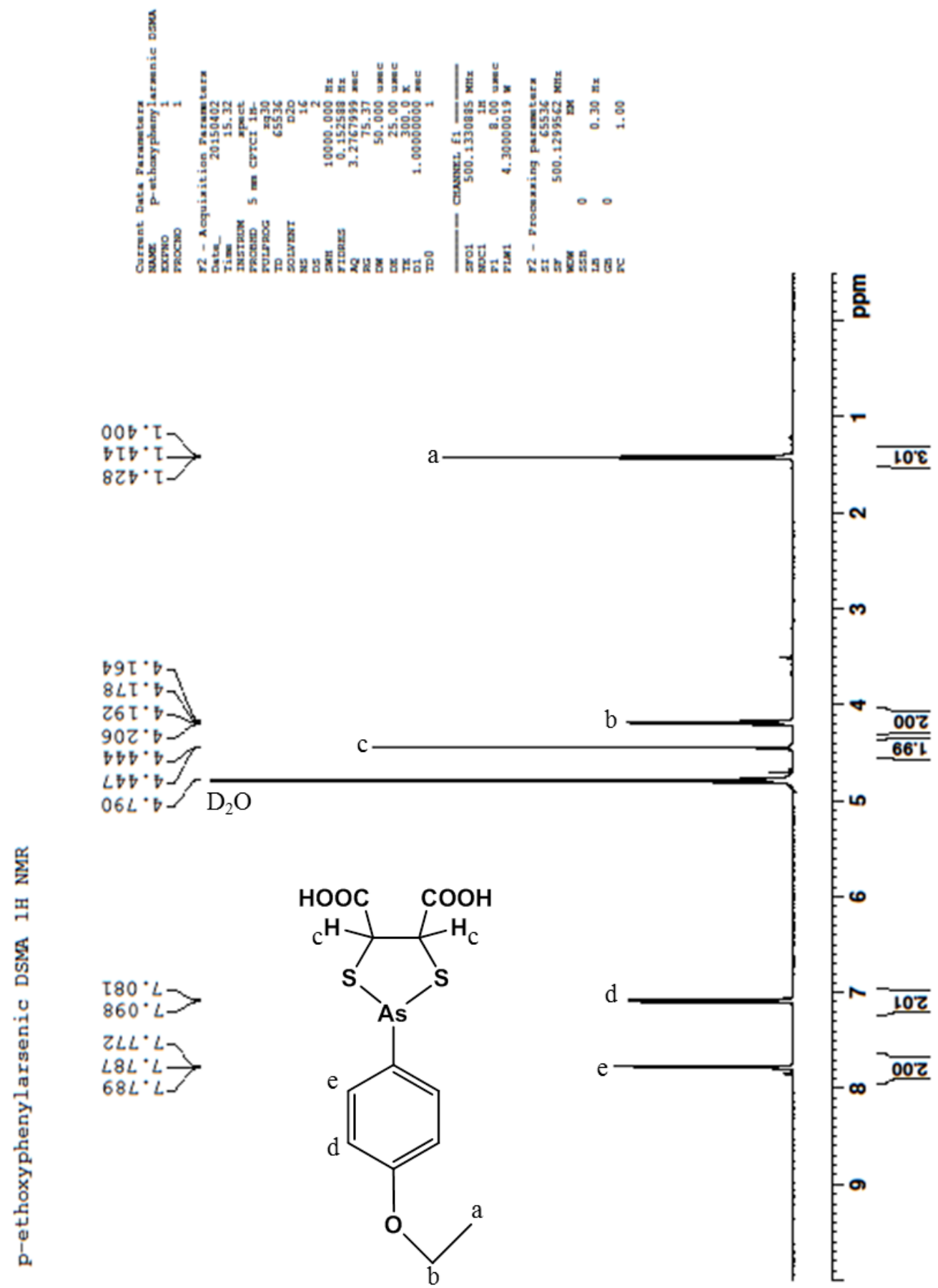

Figure A-3. ${ }^{1}$ H NMR of 2-(4-ethoxyphenyl)-1,3,2-dithiaarsolane-4,5-dicarboxylic acid, $\left(\mathrm{NH}_{4}\right)_{2}\left[\mathrm{CH}_{3} \mathrm{CH}_{2} \mathrm{O} \mathrm{C} \mathrm{H}_{4} \mathrm{As}(\mathrm{SCH}(\mathrm{COO}) \mathrm{CH}(\mathrm{COO}) \mathrm{S})\right]$, compound 2. 


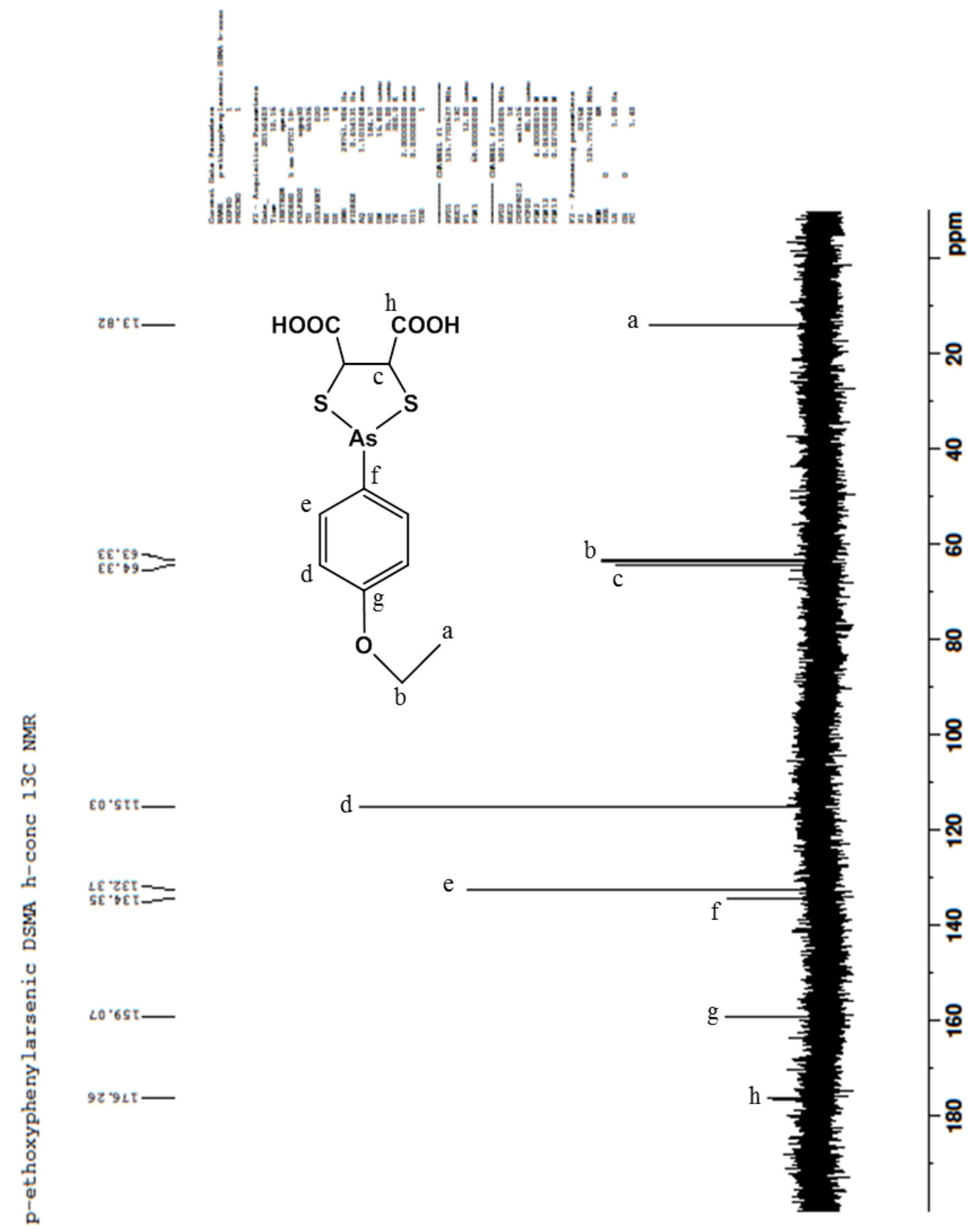

Figure A-4. ${ }^{13} \mathrm{C}$ NMR of 2-(4-ethoxyphenyl)-1,3,2-dithiaarsolane-4,5-dicarboxylic acid, $\left(\mathrm{NH}_{4}\right)_{2}\left[\mathrm{CH}_{3} \mathrm{CH}_{2} \mathrm{O} \mathrm{C} \mathrm{H}_{4} \mathrm{As}(\mathrm{SCH}(\mathrm{COO}) \mathrm{CH}(\mathrm{COO}) \mathrm{S})\right]$, compound 2. 


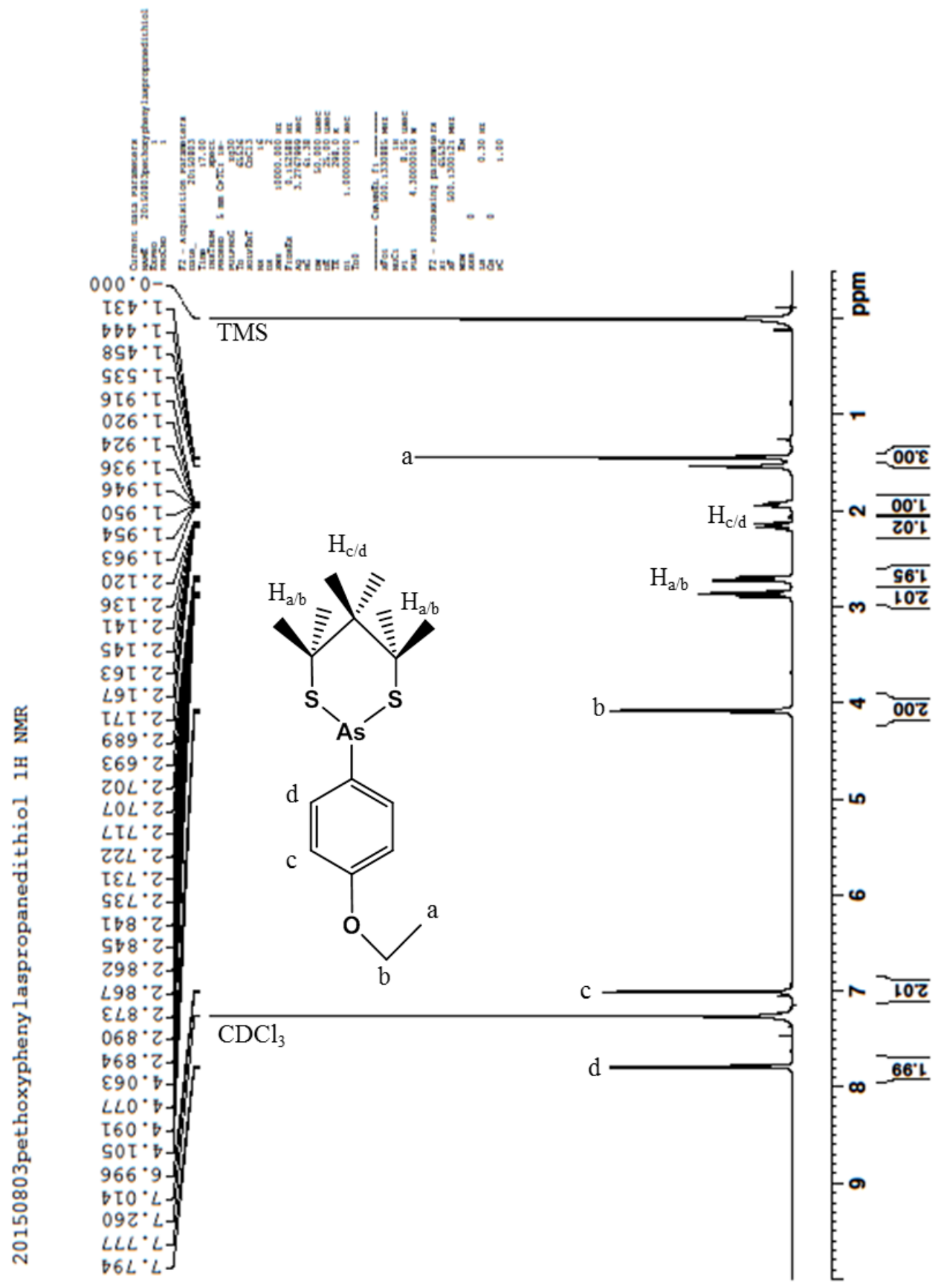

Figure A-5. ${ }^{1} \mathrm{H}$ NMR of 2-(4-ethoxyphenyl)-1,3,2-dithiaarsinane $\left[\mathrm{CH}_{3} \mathrm{CH}_{2} \mathrm{OC}_{6} \mathrm{H}_{4} \mathrm{As}\left(\mathrm{SCH}_{2} \mathrm{CH}_{2} \mathrm{CH}_{2} \mathrm{~S}\right)\right]$, compound 3. 


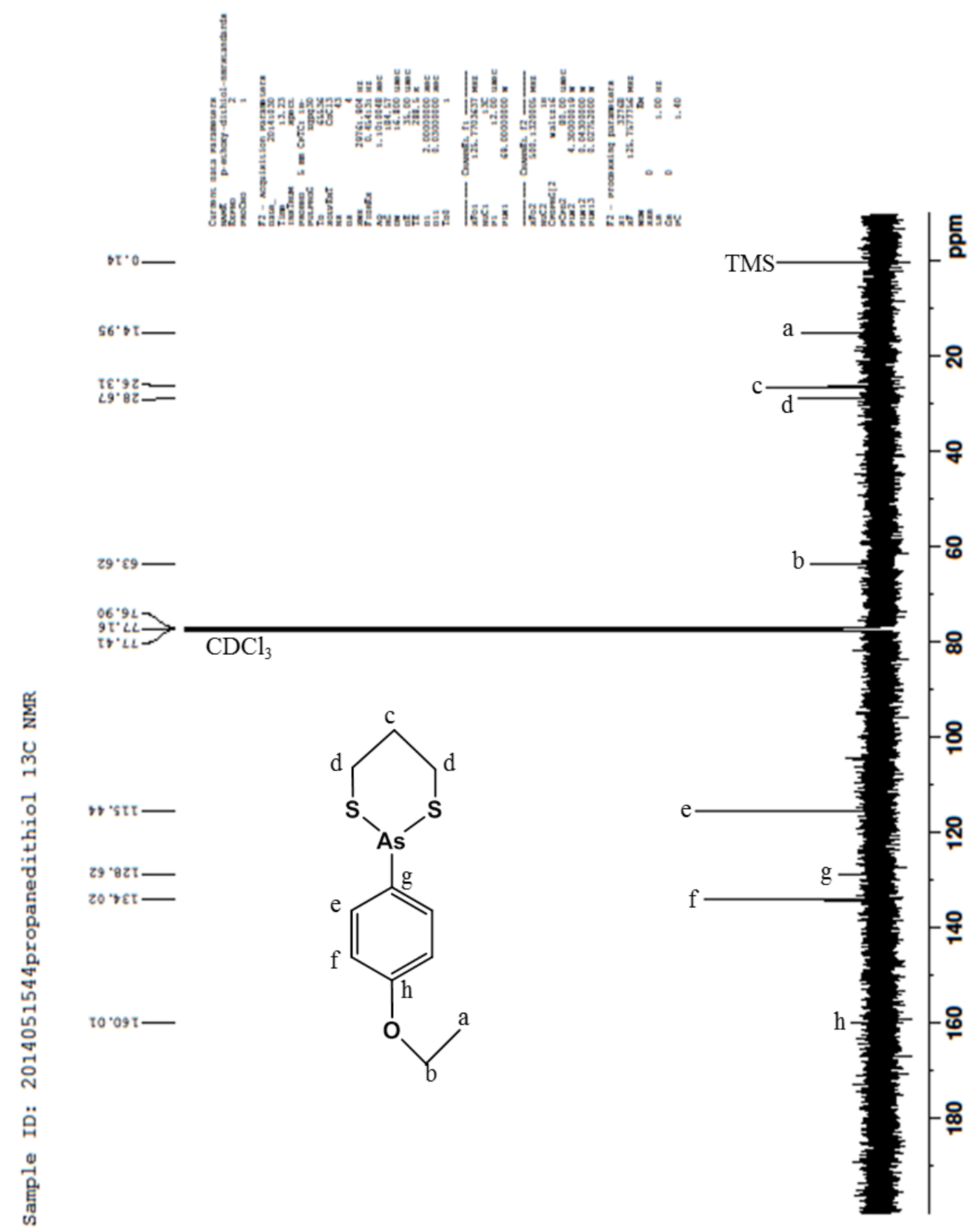

Figure A-6. ${ }^{13} \mathrm{C}$ NMR of 2-(4-ethoxyphenyl)-1,3,2-dithiaarsinane $\left[\mathrm{CH}_{3} \mathrm{CH}_{2} \mathrm{OC}_{6} \mathrm{H}_{4} \mathrm{As}\left(\mathrm{SCH}_{2} \mathrm{CH}_{2} \mathrm{CH}_{2} \mathrm{~S}\right)\right]$, compound 3. 


\section{Appendix B: Supplemental Data for Chapter 4}

The ${ }^{1} \mathrm{H}$ and ${ }^{13} \mathrm{C}$ NMR data of the compounds included in the Chapter 4 were listed in the Appendix B. The structures of the compounds were attached to their NMR data. The NMR signals were interpreted and labeled according to the structures. 


\section{Yutian Feng}

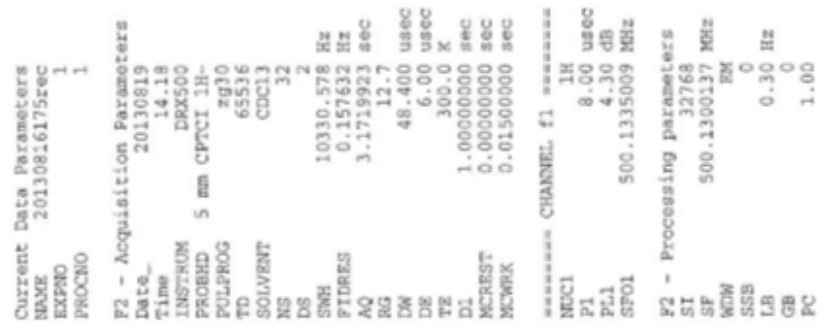

$600^{\circ} 0-$
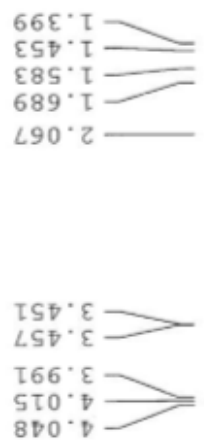

b

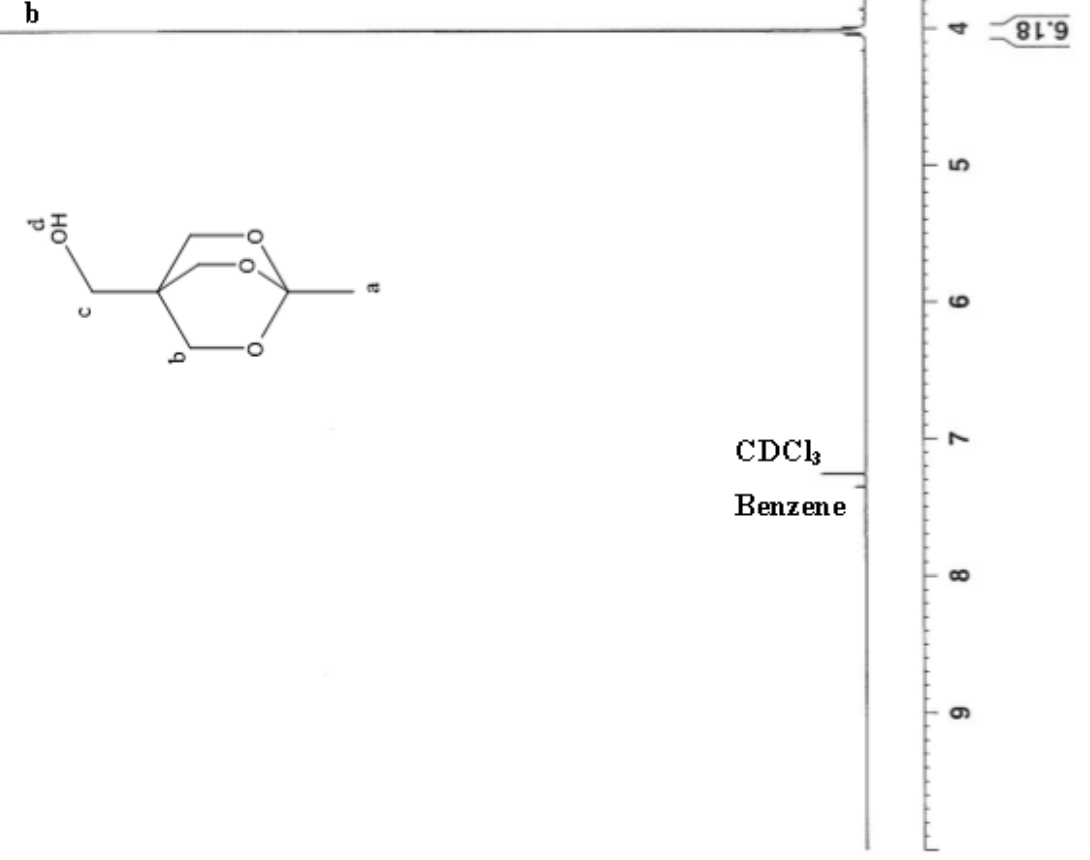

$092^{\circ} L$

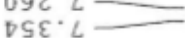

Figure

B-1. ${ }^{1} \mathrm{H}$ NMR of (1-methyl-2,6,7-trioxabicyc lo[2.2.2] octan-4-yl)methanol $\left[\mathrm{C}_{7} \mathrm{H}_{12} \mathrm{O}_{4}\right]$, compound 2. 


\section{Yutian Feng}
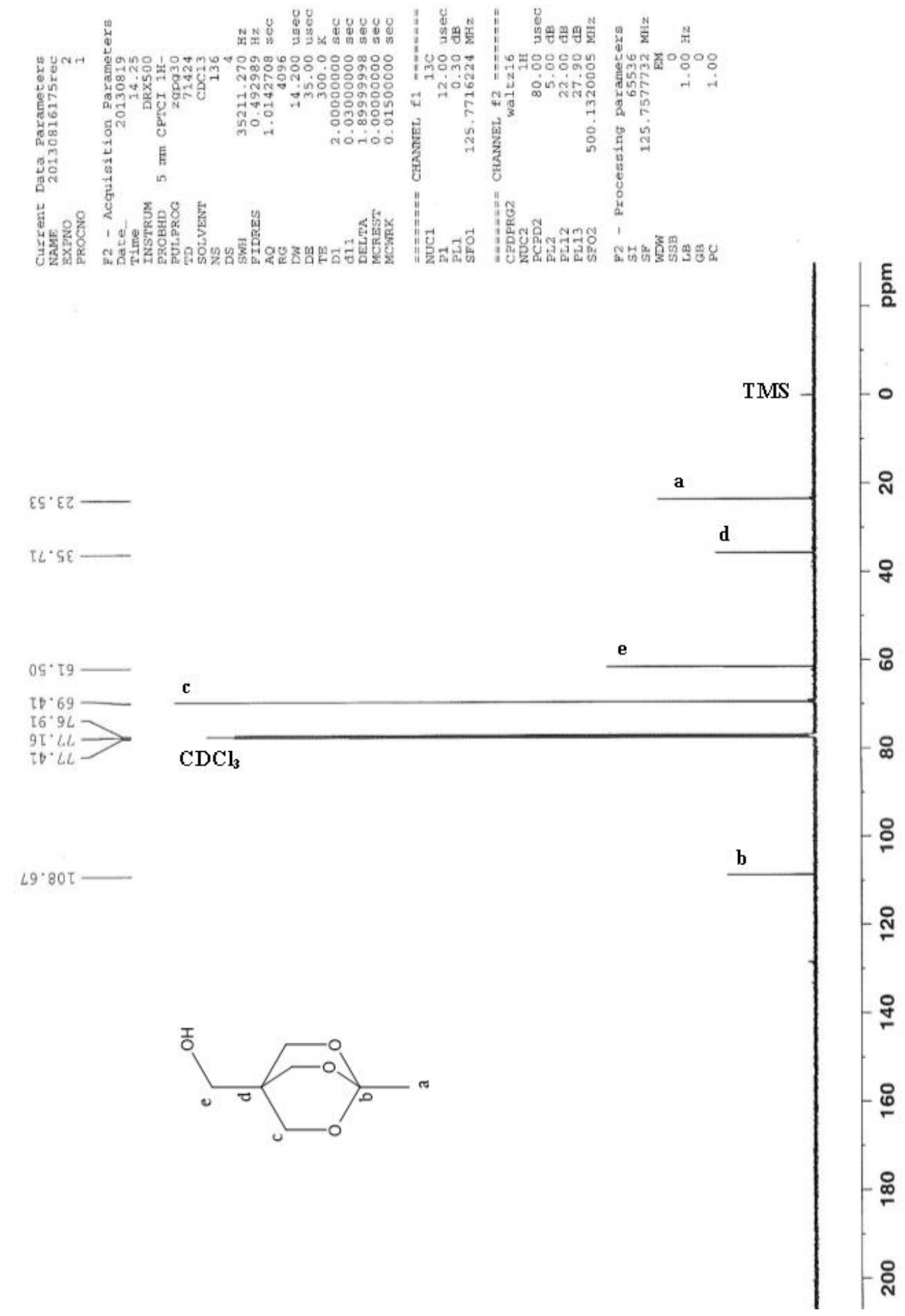

Figure B-2. ${ }^{13} \mathrm{C}$ NMR of (1-methyl-2,6,7-trioxabicyclo[2.2.2] octan-4-yl)methanol $\left[\mathrm{C}_{7} \mathrm{H}_{12} \mathrm{O}_{4}\right]$, compound 2 . 


\section{Yutian Feng}
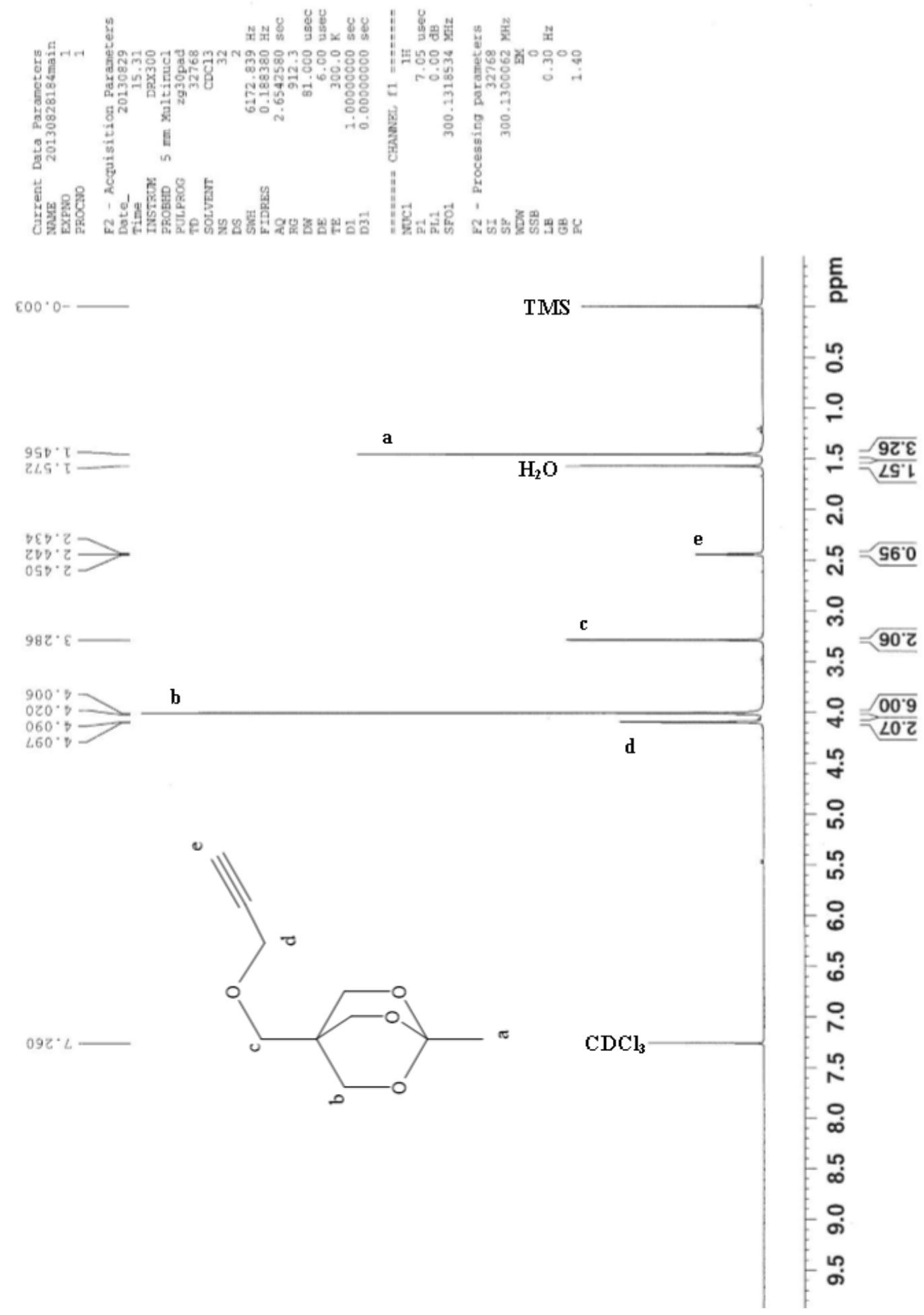

Figure B-3. ${ }^{1}$ H NMR of 1-methyl-4-((prop-2-yn-1-yloxy)methyl)-2,6,7-

trioxabicyclo[2.2.2] octane $\left[\mathrm{C}_{10} \mathrm{H}_{14} \mathrm{O}_{4}\right]$, compound 3 . 

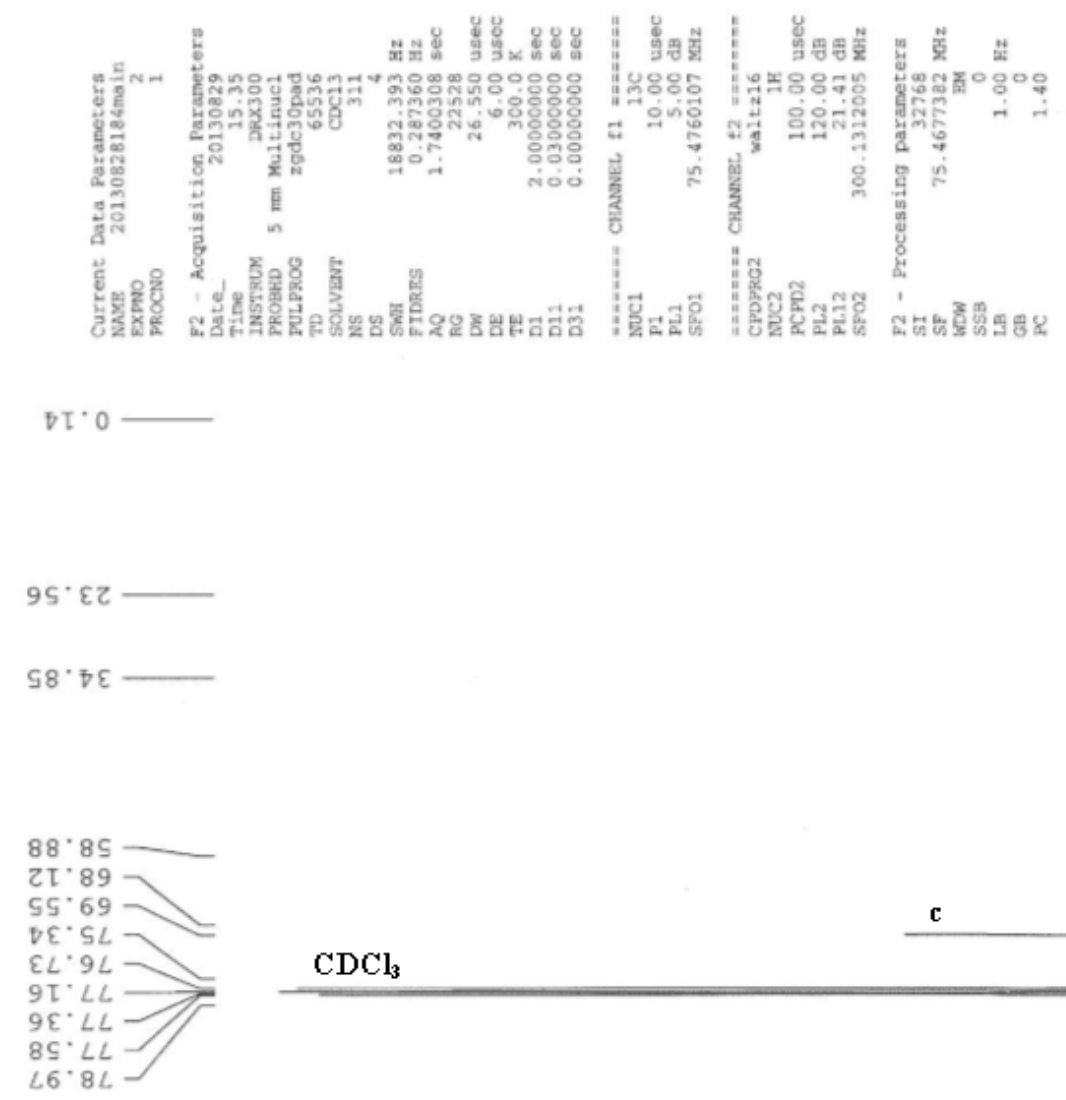

$2 L \cdot 80 \tau$

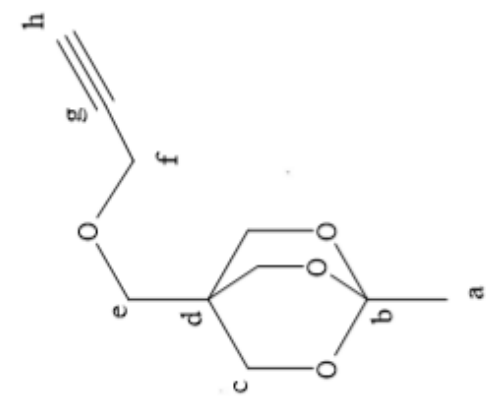

Figure

B-4. ${ }^{13} \mathrm{C}$ NMR of 1-methyl-4-((prop-2-yn-1-yloxy) methyl)-2,6,7-trioxabic yclo[2.2.2]octane

$\left[\mathrm{C}_{10} \mathrm{H}_{14} \mathrm{O}_{4}\right]$, compound 3 . 


\section{Yutian Feng}

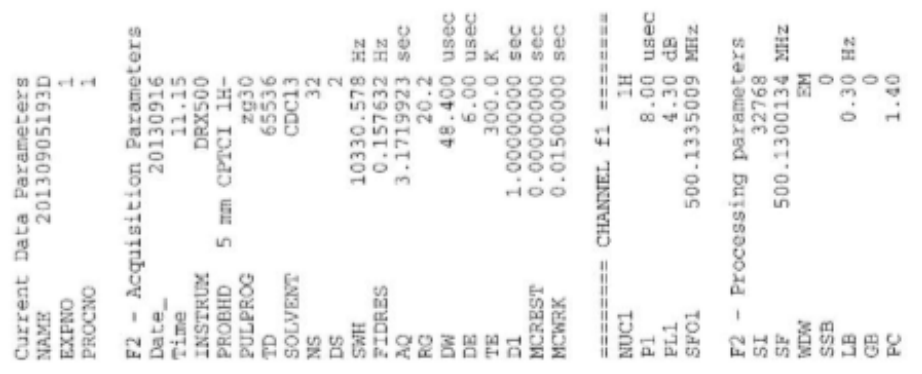

$\mathrm{S} 00^{\circ} \mathrm{O}^{-}$

政

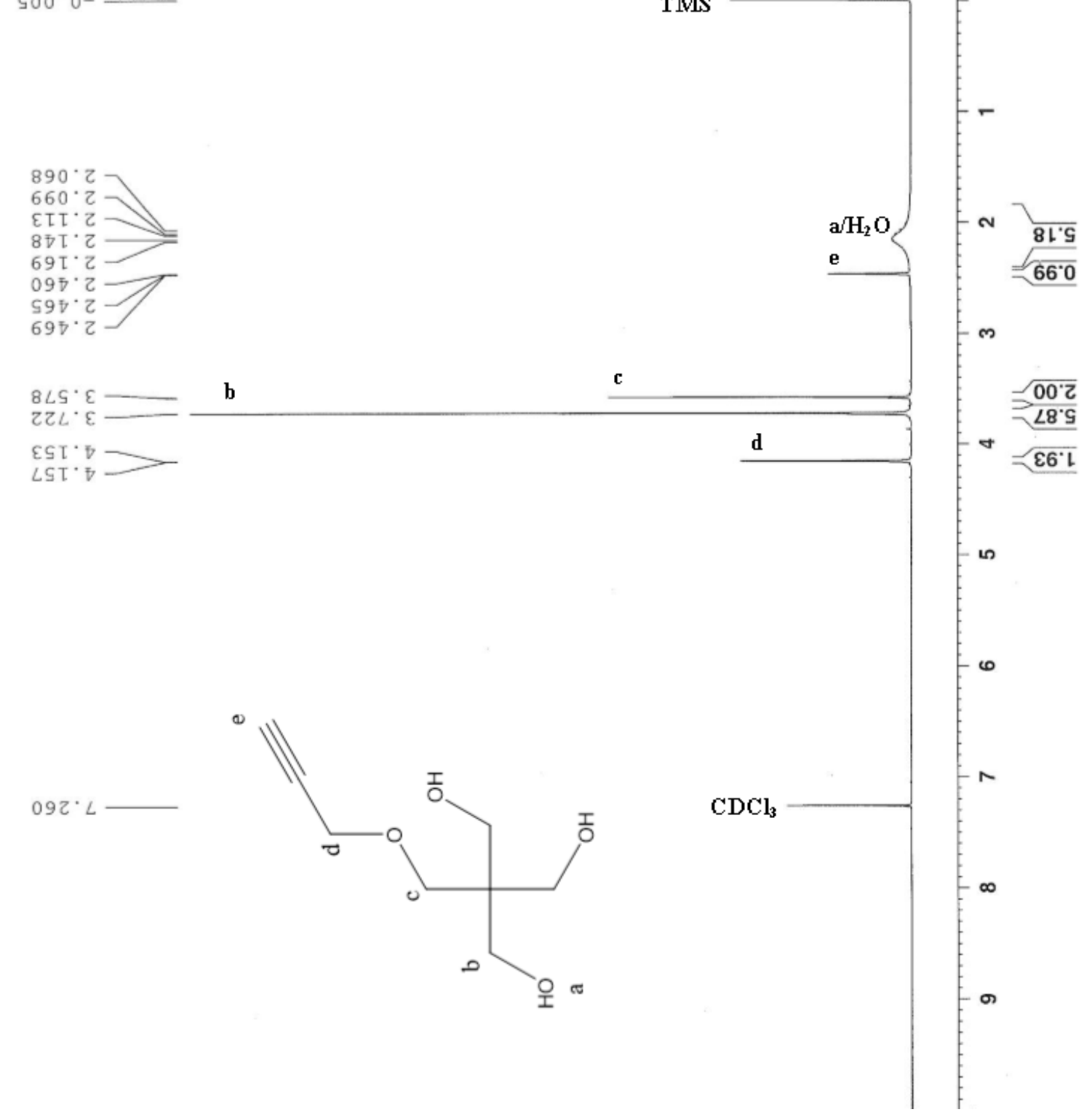

Figure B-5. ${ }^{1}$ H NMR of 2-(hydroxymethyl)-2-((prop-2-yn-1-yloxy)methyl)propa ne-1,3-diol $\left[\mathrm{C}_{8} \mathrm{H}_{14} \mathrm{O}_{4}\right]$, compound 4 . 

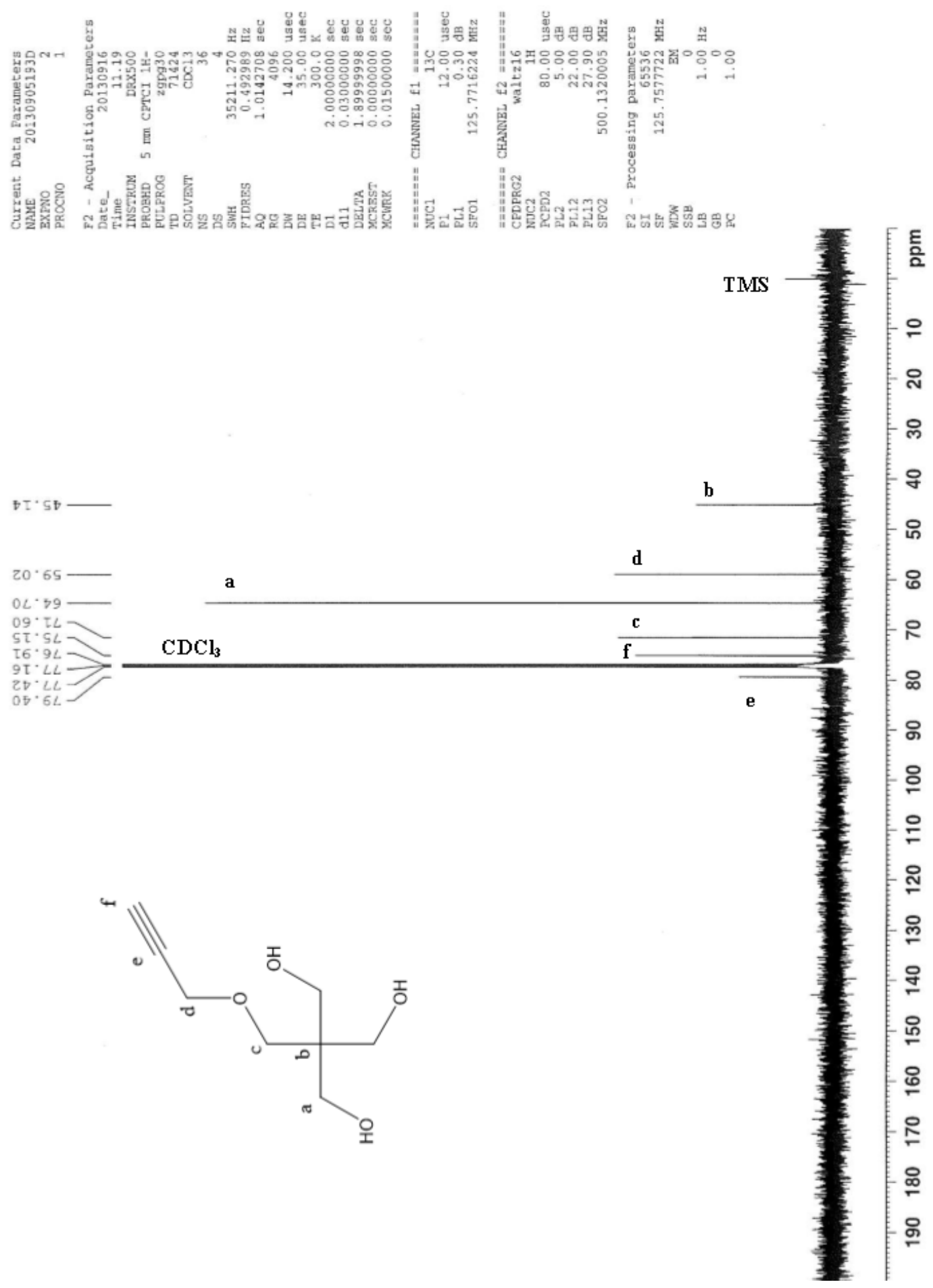

Figure B-6. ${ }^{13} \mathrm{C}$ NMR of 2-(hydroxymethyl)-2-((prop-2-yn-1-yloxy)methyl) propane-1,3-diol $\left[\mathrm{C}_{8} \mathrm{H}_{14} \mathrm{O}_{4}\right]$, compound 4 . 


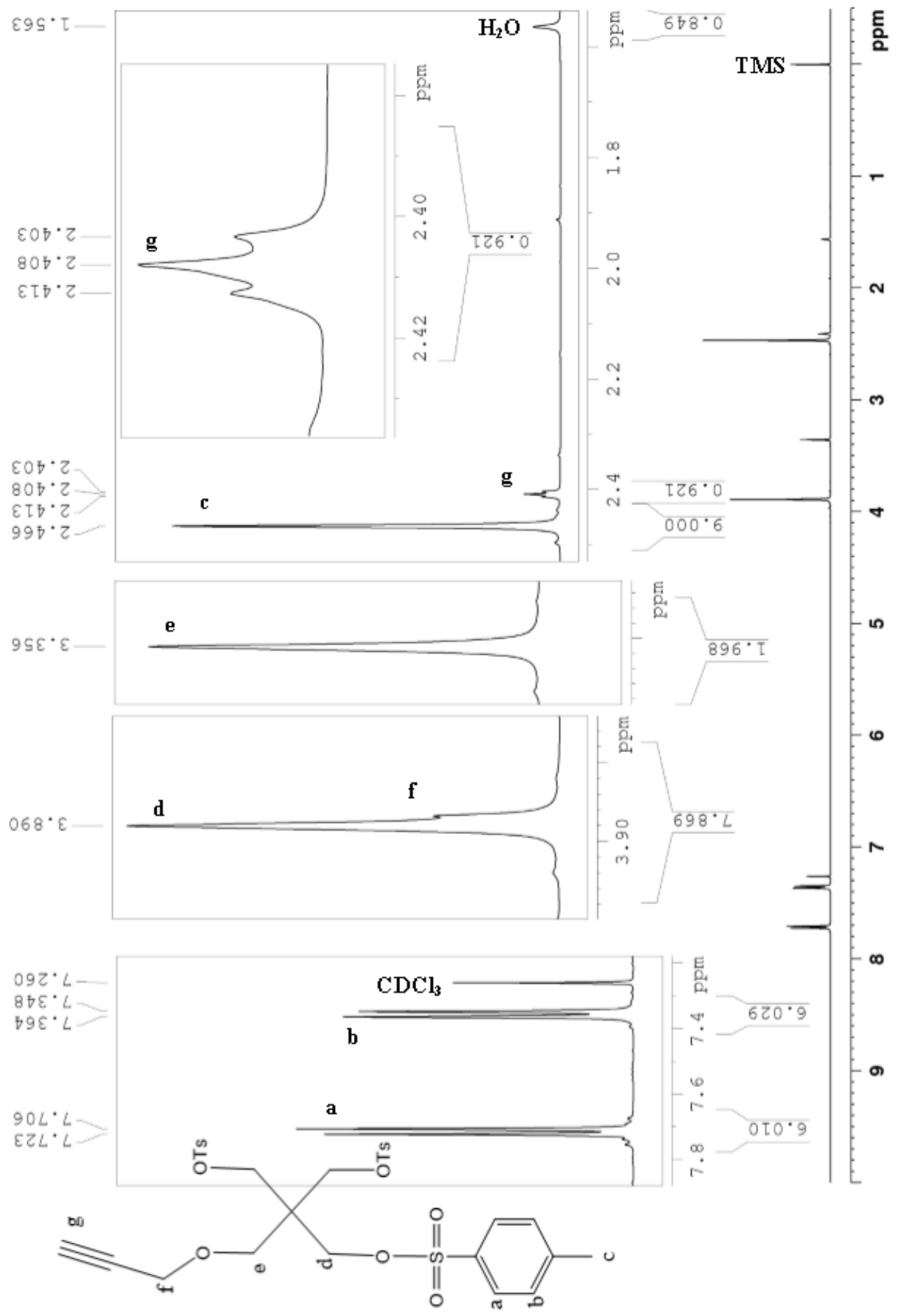

Figure B -7. ${ }^{1} \mathrm{H}$ NMR of 2-((prop-2-yn-1-yloxy)methyl)-2-((tosyloxy)methyl)propane-1,3diyl bis(4-methylbenzenesulfonate) $\left[\mathrm{C}_{29} \mathrm{H}_{32} \mathrm{O}_{10} \mathrm{~S}_{3}\right]$, compound 5 . 


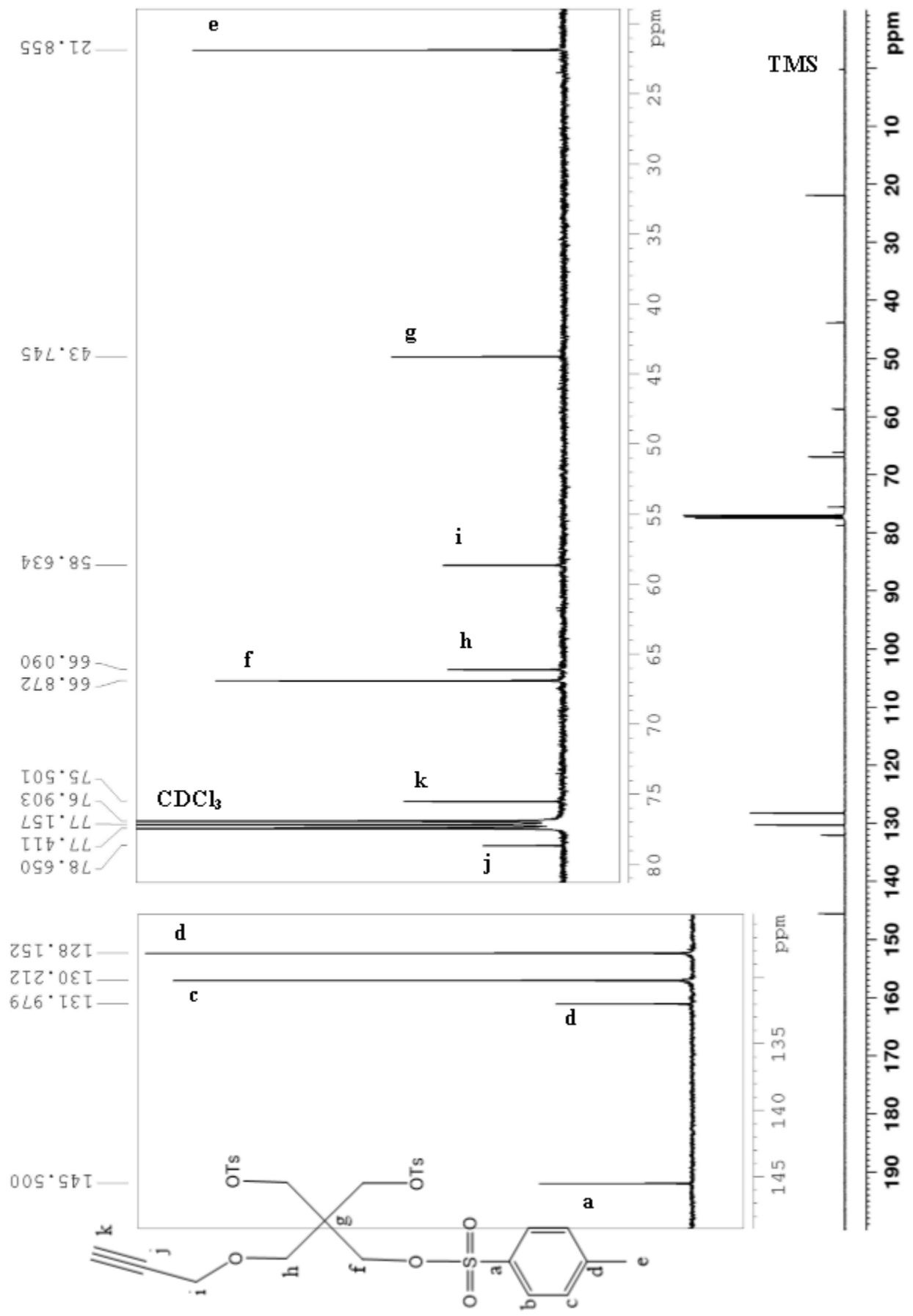

Figure B-8. ${ }^{13} \mathrm{C}$ NMR of 2-((prop-2-yn-1-yloxy)methyl)-2-((tosyloxy) methyl)propane-1,3diyl bis(4-methylbenzenesulfonate) $\left[\mathrm{C}_{29} \mathrm{H}_{32} \mathrm{O}_{10} \mathrm{~S}_{3}\right]$, compound $\mathbf{5}$. 


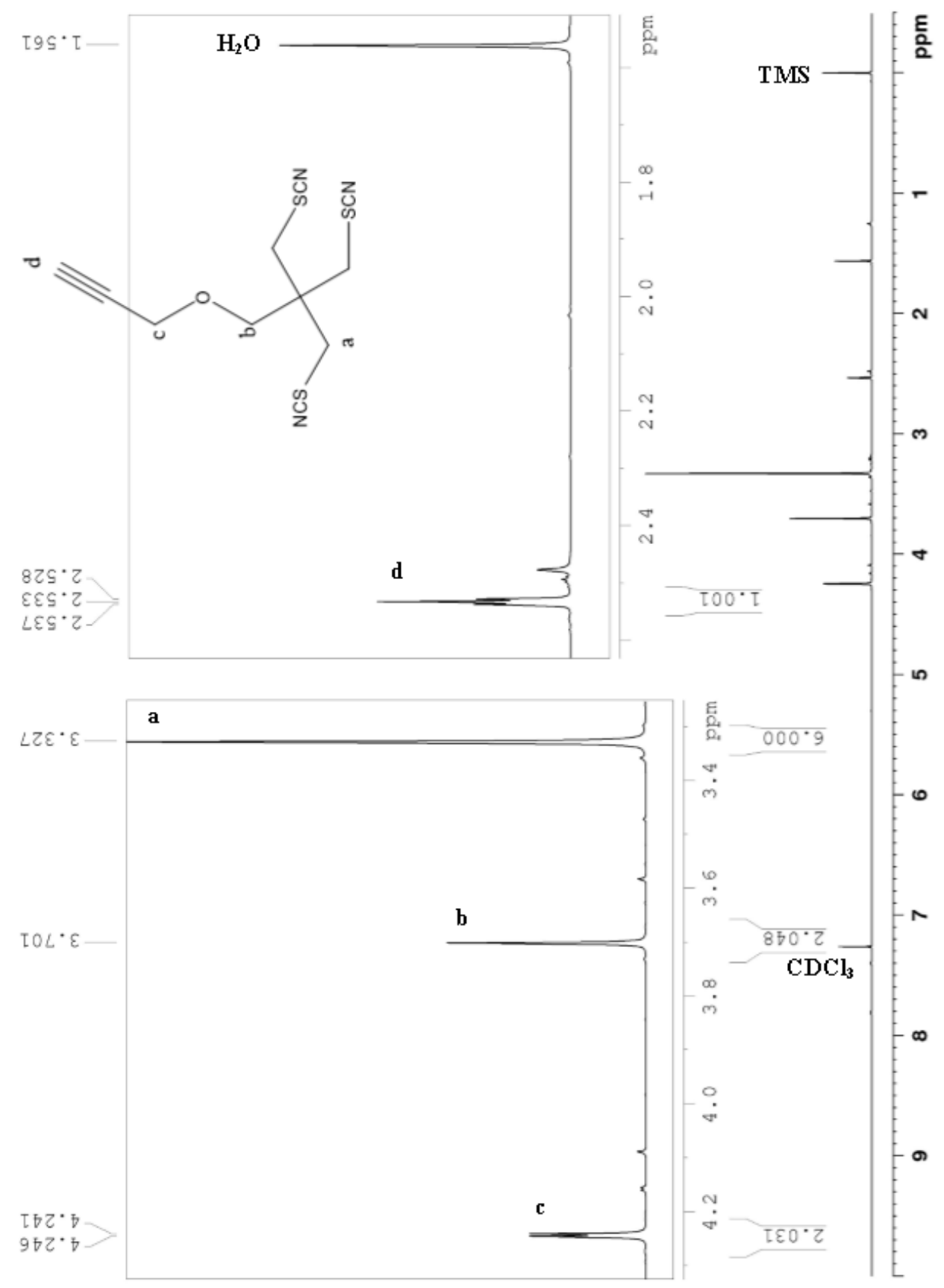

Figure B-9. ${ }^{1} \mathrm{H}$ NMR of 3-(3-thiocyanatomethyl)propoxy)prop-1-yne $\left[\mathrm{C}_{11} \mathrm{H}_{11} \mathrm{~N}_{3} \mathrm{OS}_{3}\right]$, compound 6 . 


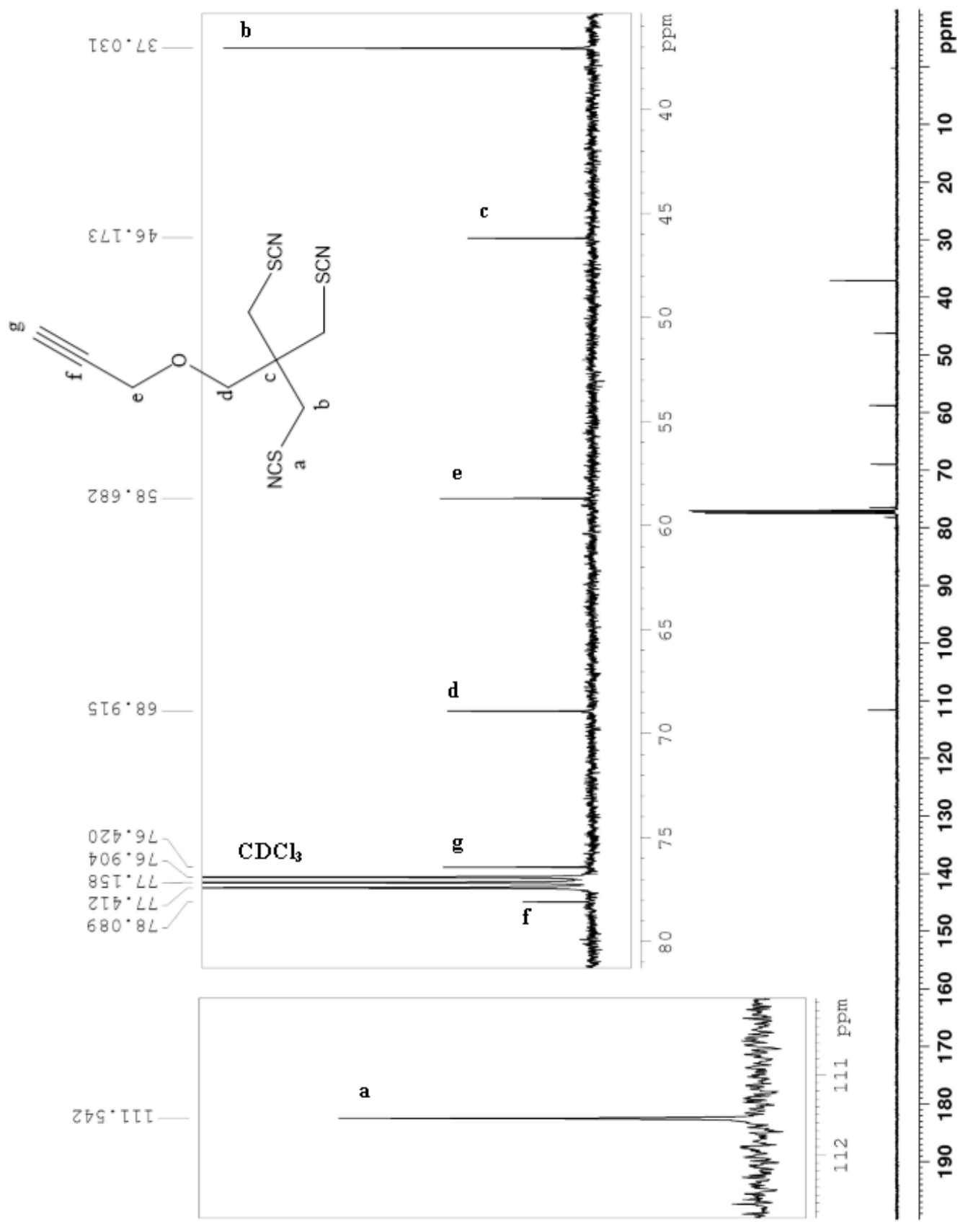

Figure B-10. ${ }^{13} \mathrm{C}$ NMR of 3-(3-thiocyanatomethyl) propoxy) prop-1-yne $\left[\mathrm{C}_{11} \mathrm{H}_{11} \mathrm{~N}_{3} \mathrm{OS}_{3}\right]$, compound 6. 

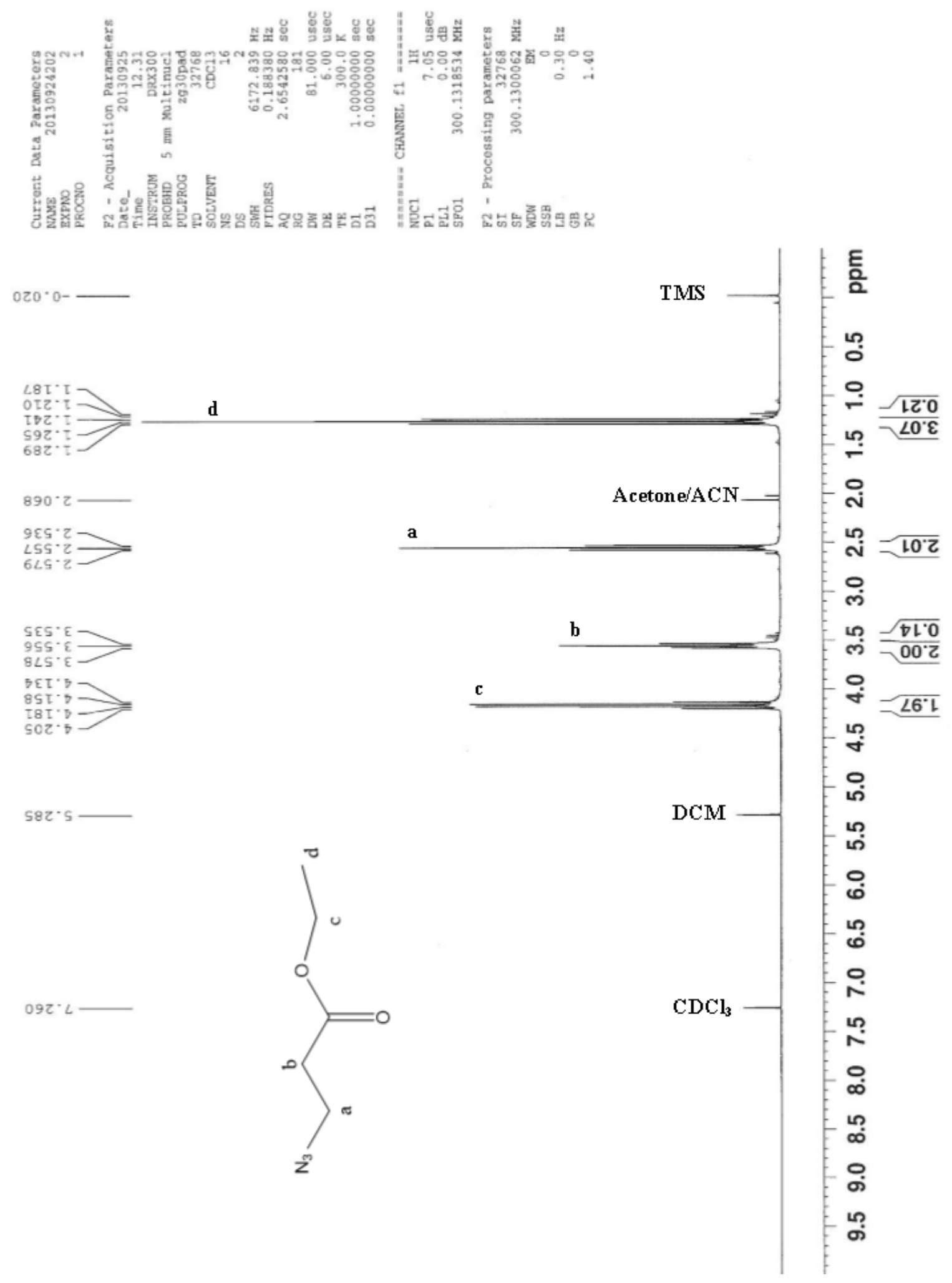

Figure B-11. ${ }^{1} \mathrm{H}$ NMR of ethyl 3-azidopropionate $\left[\mathrm{C}_{5} \mathrm{H}_{9} \mathrm{~N}_{3} \mathrm{O}_{2}\right]$, compound 9. 

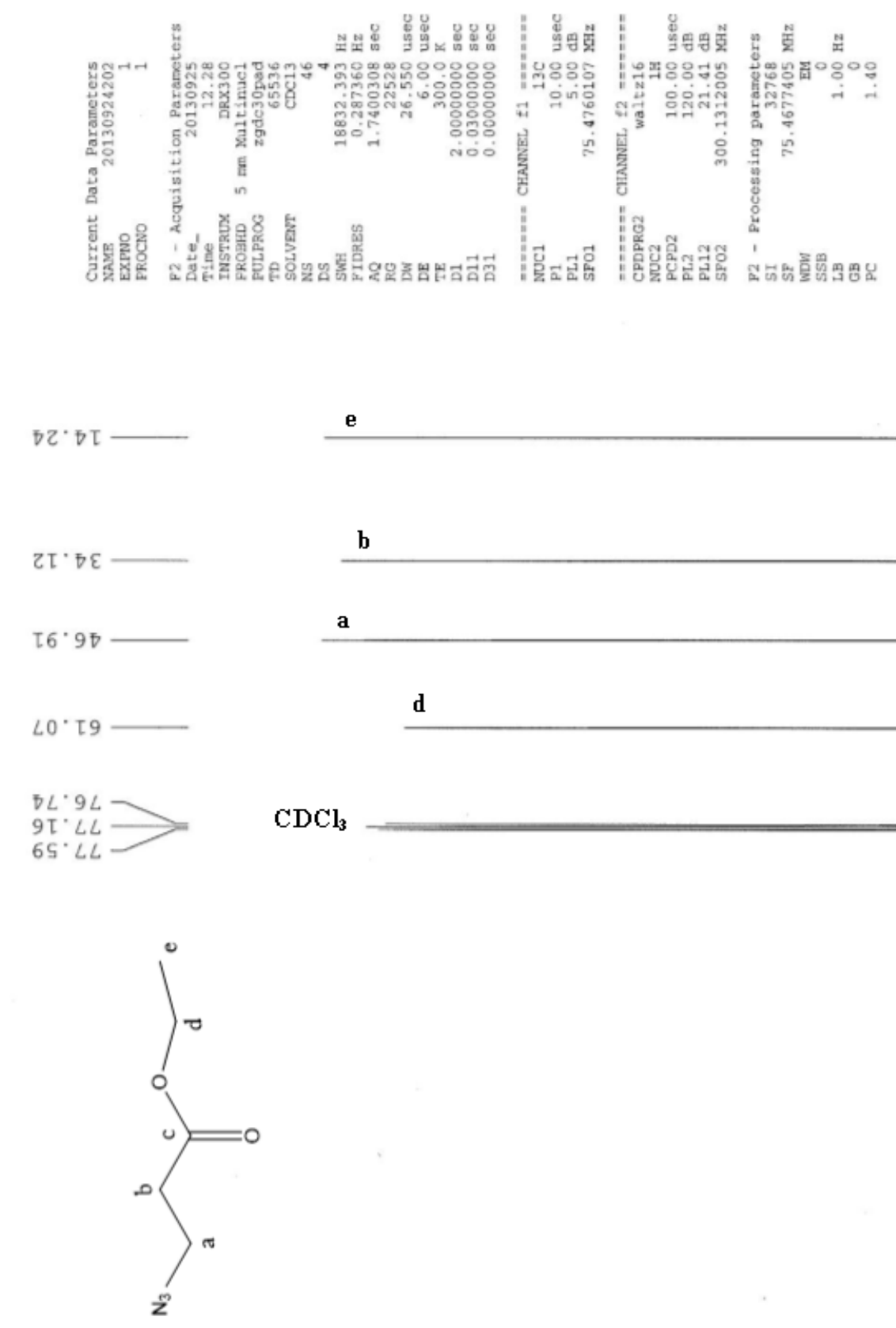

$\angle 6^{\circ} 0 \angle \tau$
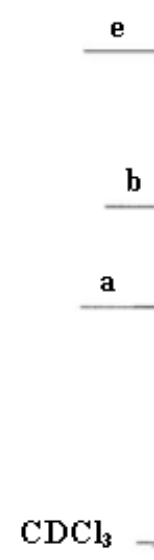

a

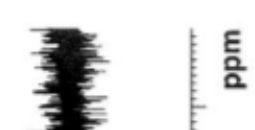

을

으

ㅇำ

ㅇ

웅

으

- 으

웃

- 이

으

응

은

오ํ

옹

운

음

응

c

운

음

우

Figure B-12. ${ }^{13} \mathrm{C}$ NMR of ethyl 3-azidopropionate $\left[\mathrm{C}_{5} \mathrm{H}_{9} \mathrm{~N}_{3} \mathrm{O}_{2}\right]$, compound 9 . 


\section{Yutian Feng}

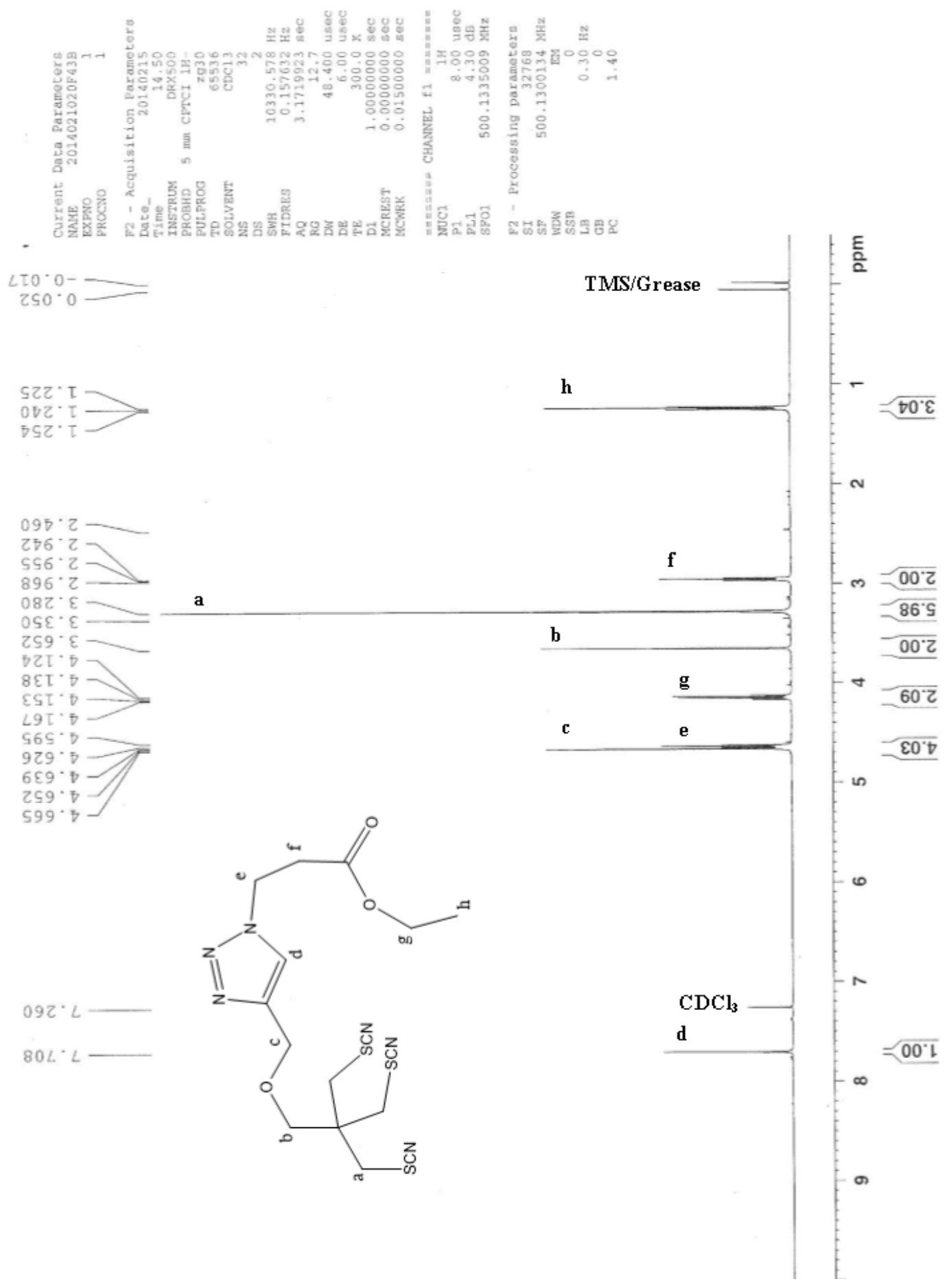

Figure B-13. ${ }^{1} \mathrm{H}$ NMR of ethyl 3-(4-((3-thiocyanato-2,2-

bis(thiocyanatomethyl) propoxy)methyl)-1H-1,2,3-triazol-1-yl)propanoate $\left[\mathrm{C}_{16} \mathrm{H}_{20} \mathrm{~N}_{6} \mathrm{O}_{3} \mathrm{~S}_{3}\right]$, compound 7. 


\section{Yutian Feng}
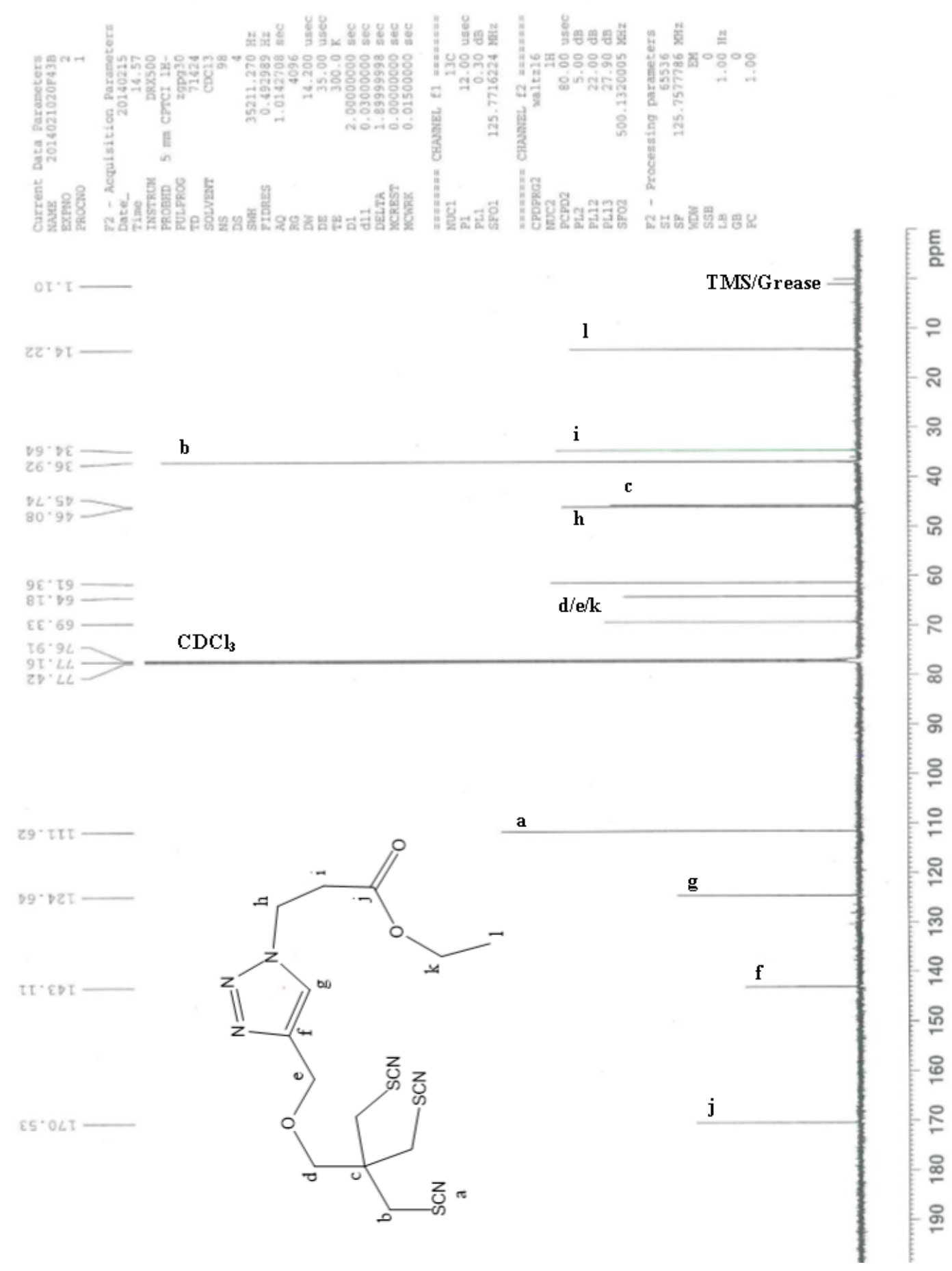

Figure B-14. ${ }^{13} \mathrm{C}$ NMR of ethyl 3-(4-((3-thiocyanato-2,2-

bis(thiocyanatomethyl) propoxy)methyl)-1H-1,2,3-triazol-1-yl)propanoate $\left[\mathrm{C}_{16} \mathrm{H}_{20} \mathrm{~N}_{6} \mathrm{O}_{3} \mathrm{~S}_{3}\right]$, compound 7. 


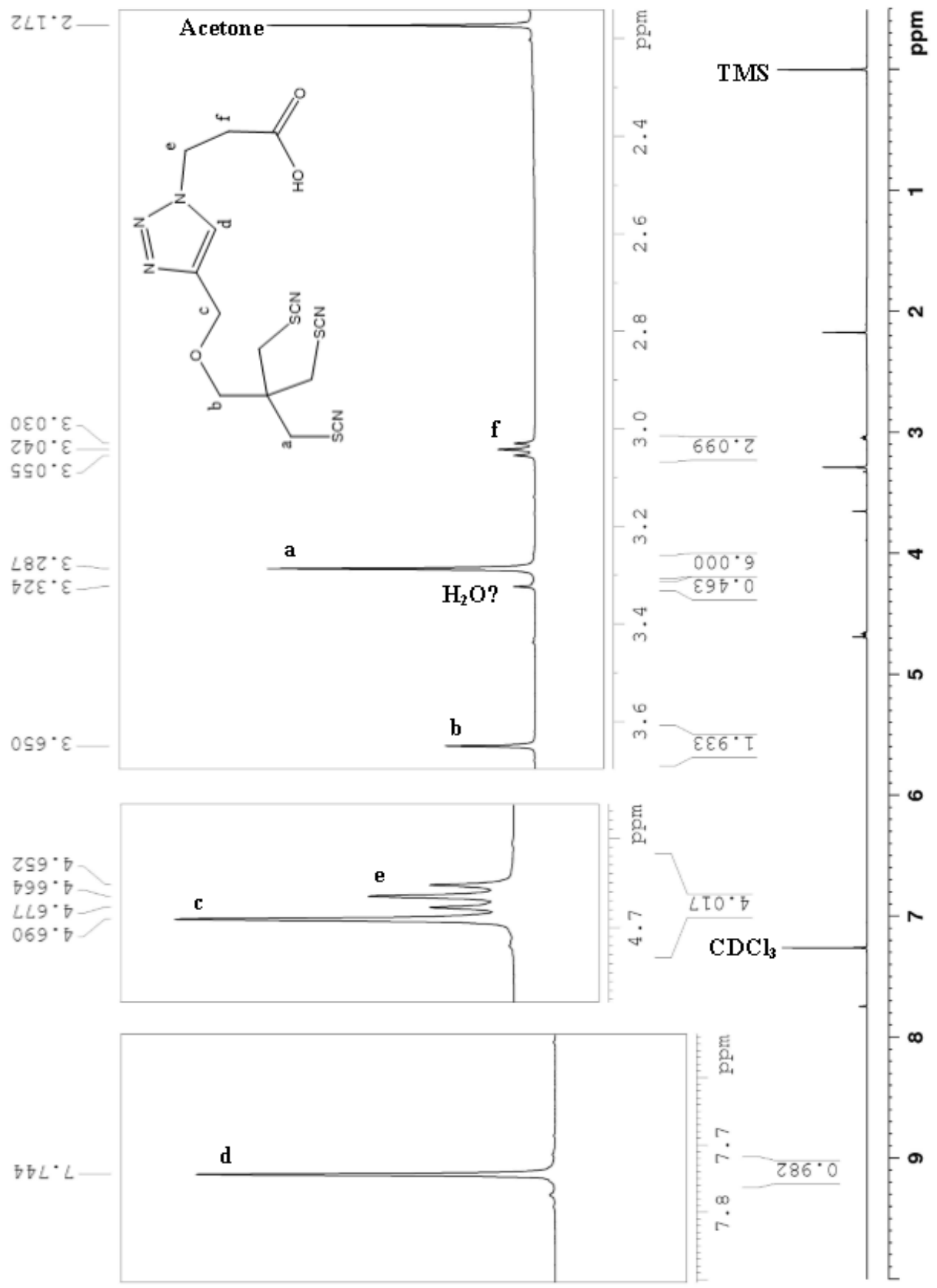

Figure B-15. ${ }^{1} \mathrm{H}$ NMR of 3-(4-((3-thiocyanato-2,2-bis(thiocyanatomethyl)propoxy)methyl)1H-1,2,3-triazol-1-yl)propanoic acid $\left[\mathrm{C}_{14} \mathrm{H}_{16} \mathrm{~N}_{6} \mathrm{O}_{3} \mathrm{~S}_{3}\right]$, compound 8 . 


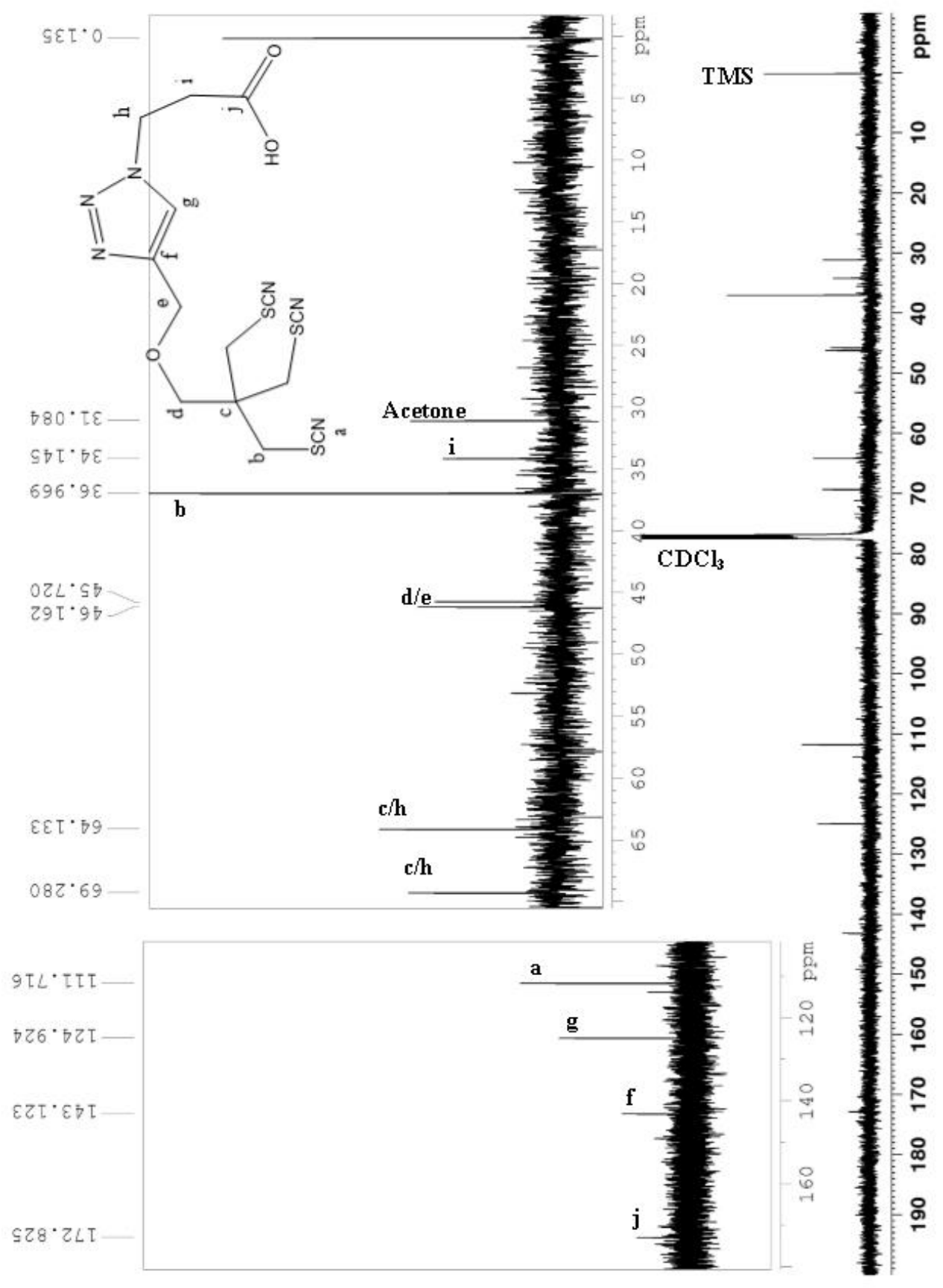

Figure B-16. ${ }^{13} \mathrm{C}$ NMR of 3-(4-((3-thiocyanato-2,2-bis(thiocyanatomethyl)propoxy) methyl)1H-1,2,3-triazol-1-yl)propanoic acid $\left[\mathrm{C}_{14} \mathrm{H}_{16} \mathrm{~N}_{6} \mathrm{O}_{3} \mathrm{~S}_{3}\right]$, compound 8 . 


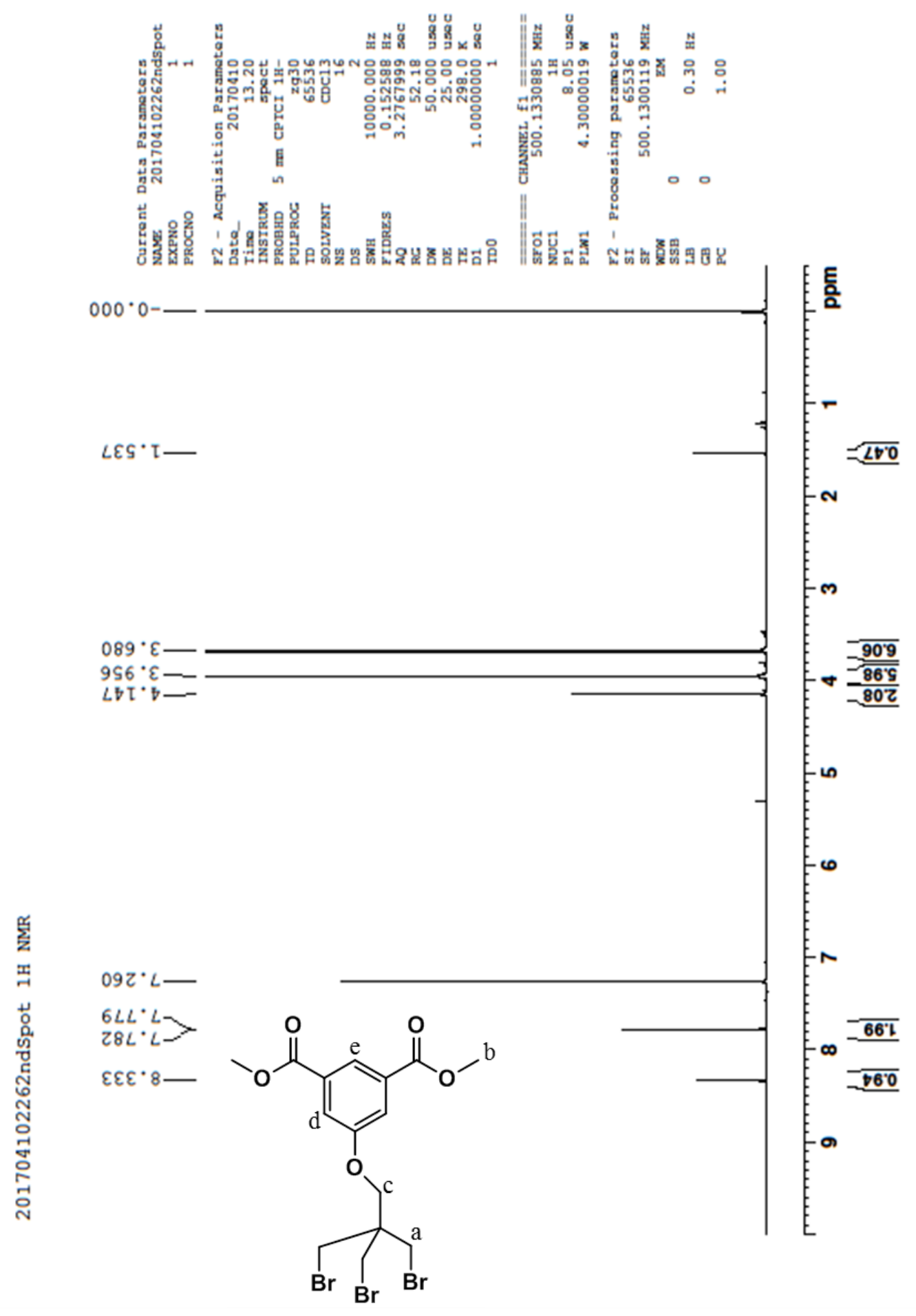

Figure B-17. ${ }^{1} \mathrm{H}$ NMR of dimethyl 5-(3-bromo-2,2-bis(bromomethyl)propoxy)isophthalate $\left[\mathrm{C}_{15} \mathrm{H}_{17} \mathrm{Br}_{3} \mathrm{O}_{5}\right]$, compound 9. 


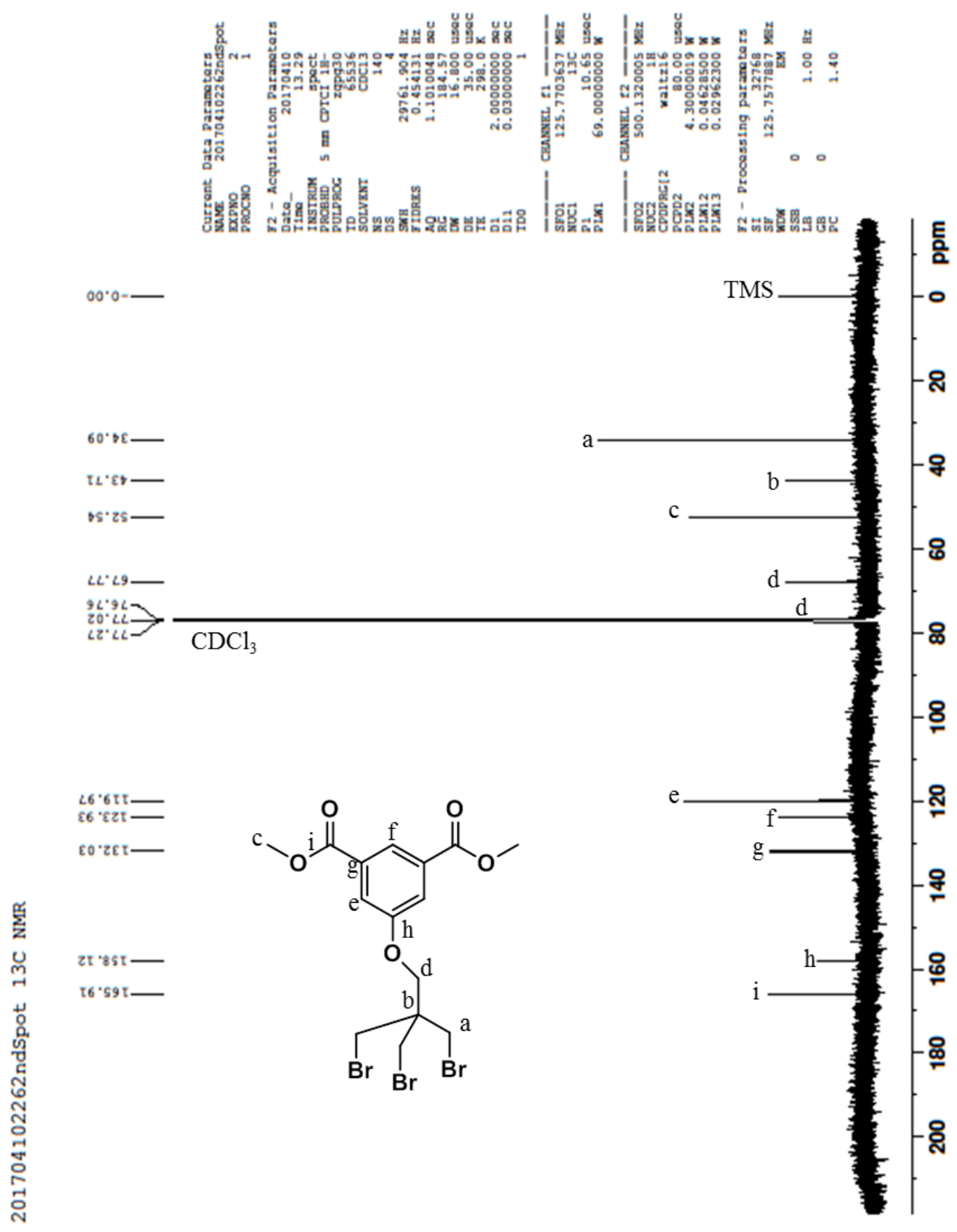

Figure B-18. ${ }^{13} \mathrm{C}$ NMR of dimethyl 5-(3-bromo-2,2-bis(bromomethyl)propoxy)isophthalate $\left[\mathrm{C}_{15} \mathrm{H}_{17} \mathrm{Br}_{3} \mathrm{O}_{5}\right]$, compound 9. 


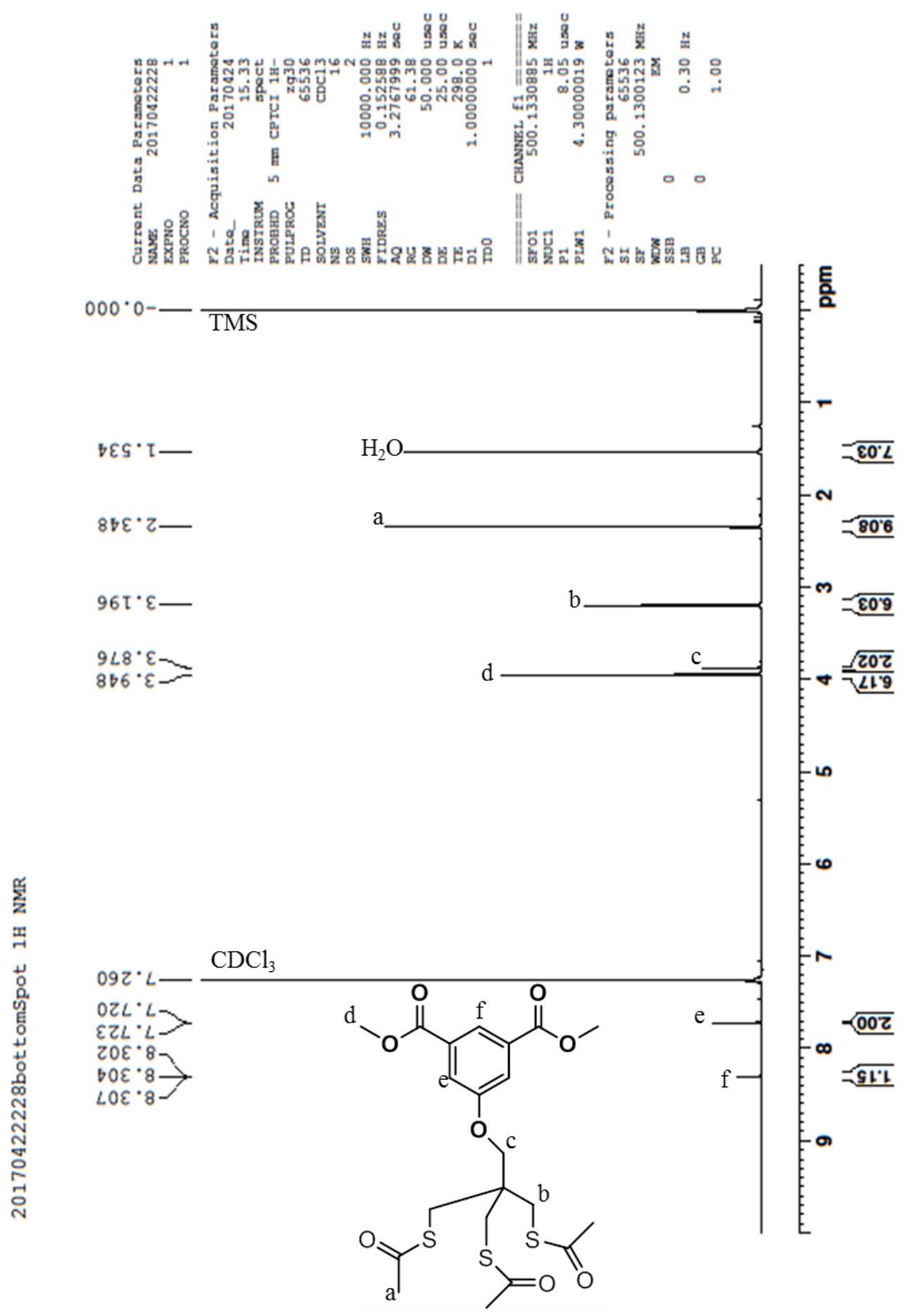

Figure B-19. ${ }^{1}$ H NMR of dimethyl 5-(3-(acetylthio)-2,2-

bis((acetylthio)methyl) propoxy) is ophthalate $\left[\mathrm{C}_{21} \mathrm{H}_{26} \mathrm{O}_{8} \mathrm{~S}_{3}\right]$, compound $\mathbf{1 0}$. 


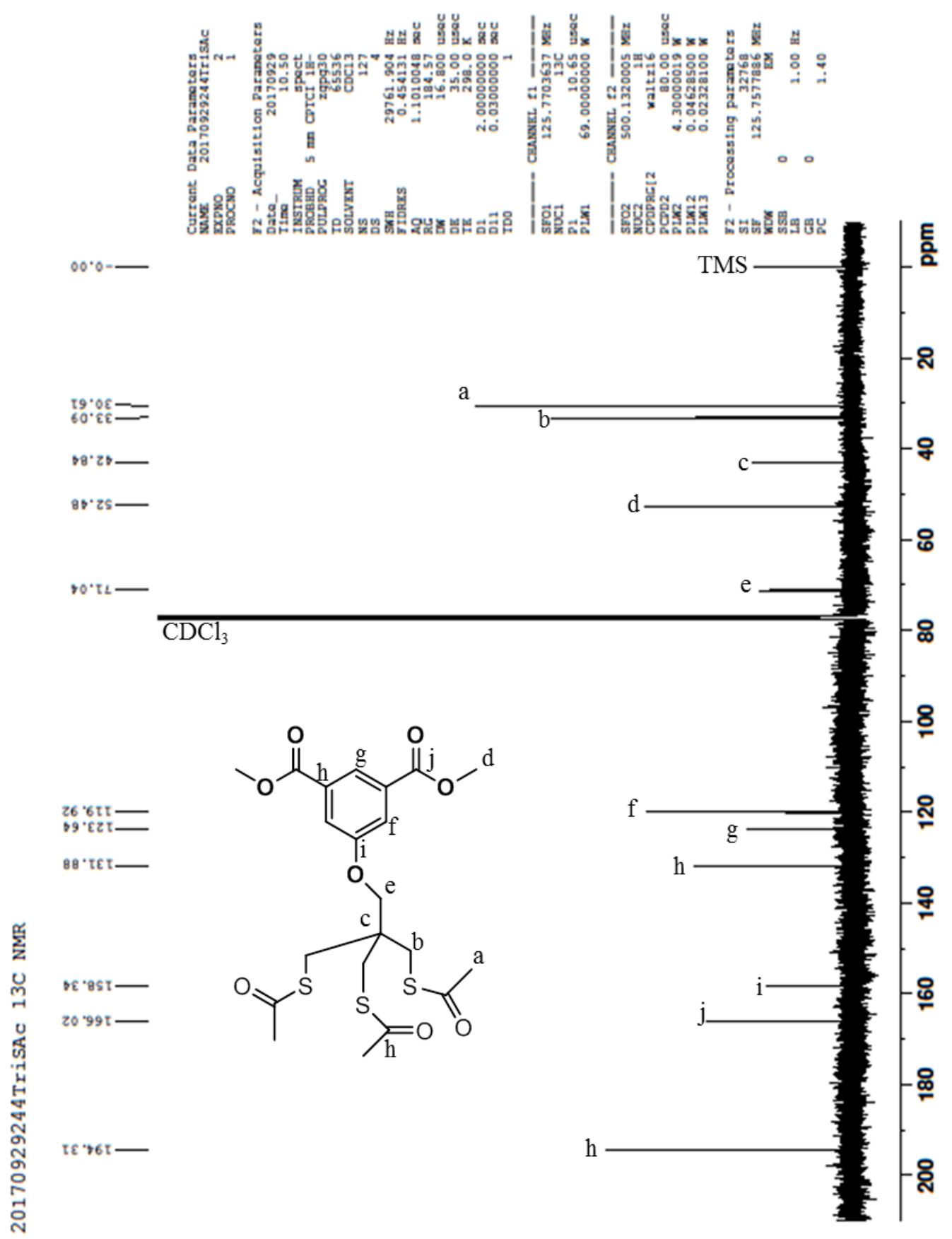

Figure B-20. ${ }^{13} \mathrm{C}$ NMR of dimethyl 5-(3-(acetylthio)-2,2-

bis((acetylthio)methyl) propoxy) is ophthalate $\left[\mathrm{C}_{21} \mathrm{H}_{26} \mathrm{O}_{8} \mathrm{~S}_{3}\right]$, compound $\mathbf{1 0}$. 


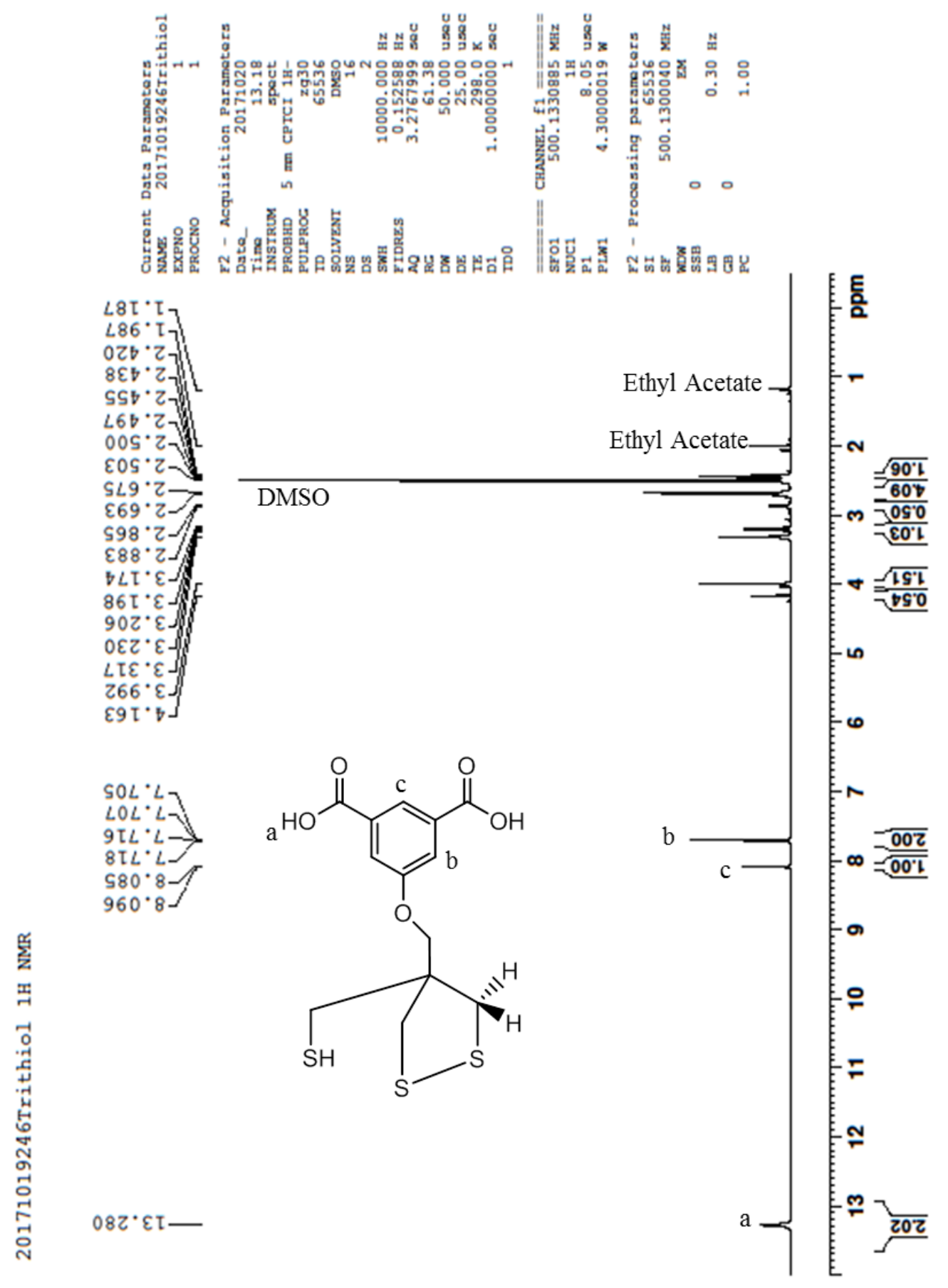

Figure B-21a. ${ }^{1}$ H NMR of 5-((4-(mercaptomethyl)-1,2-dithiolan-4-yl)methoxy) is ophthalic acid $\left[\mathrm{C}_{13} \mathrm{H}_{14} \mathrm{O}_{5} \mathrm{~S}_{3}\right]$, compound 11. 

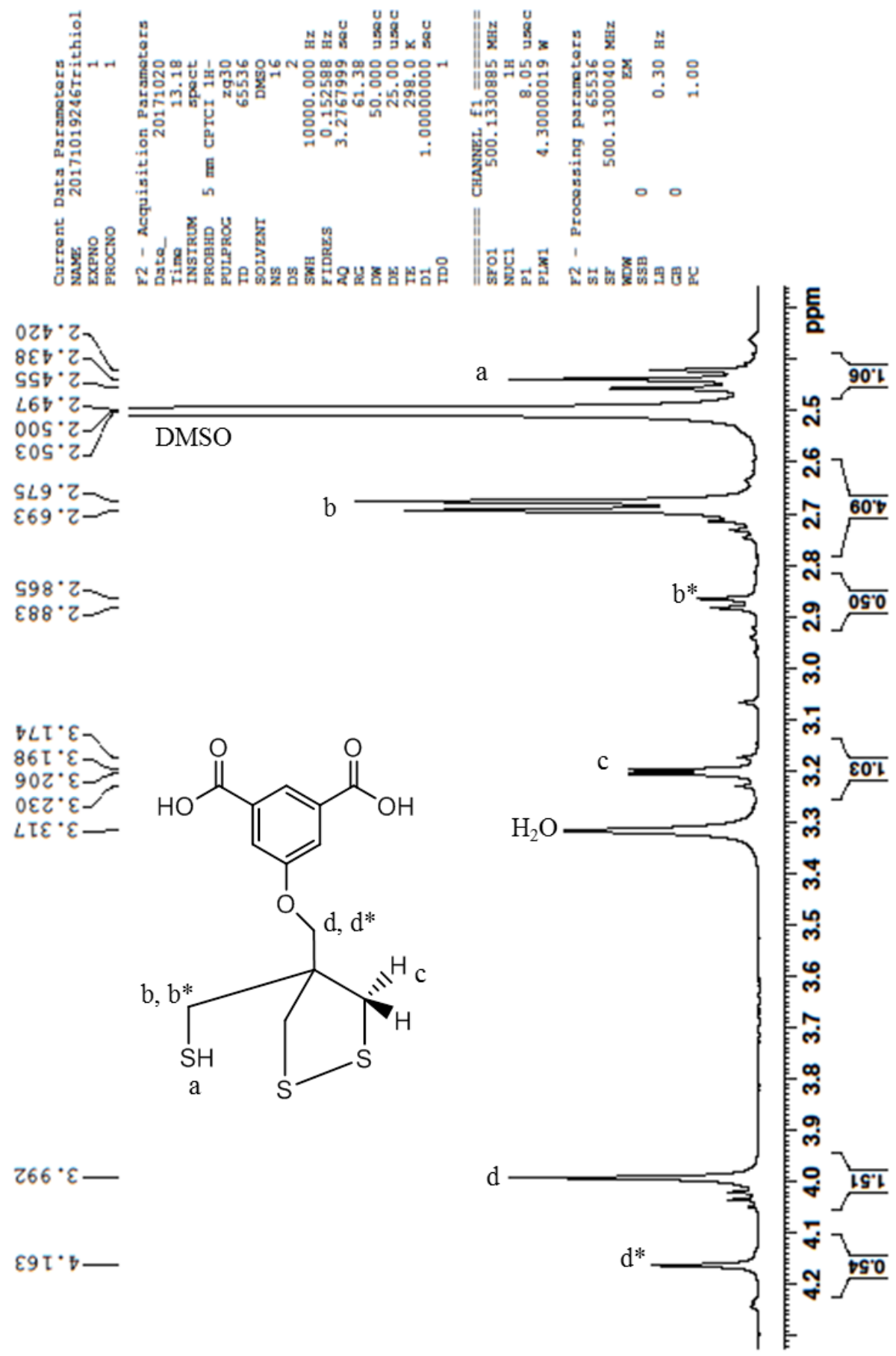

Figure B-21b. ${ }^{1} \mathrm{H}$ NMR of 5-((4-(mercaptomethyl)-1,2-dithiolan-4-yl) methoxy) isophthalic acid $\left[\mathrm{C}_{13} \mathrm{H}_{14} \mathrm{O}_{5} \mathrm{~S}_{3}\right]$, compound $\mathbf{1 1}$. 


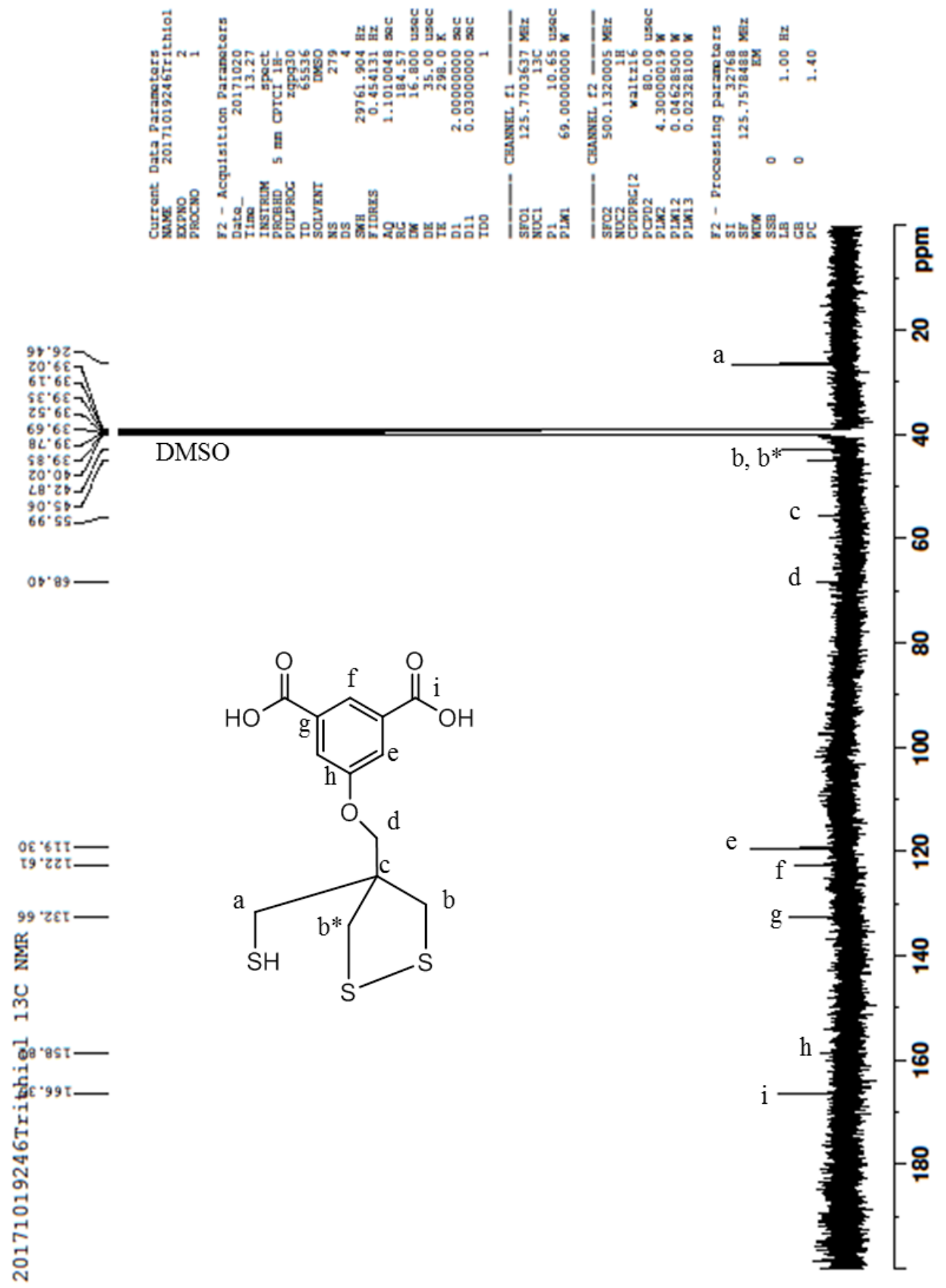

Figure B-22. ${ }^{13} \mathrm{C}$ NMR of 5-((4-(mercaptomethyl)-1,2-dithiolan-4-yl) methoxy) isophthalic acid $\left[\mathrm{C}_{13} \mathrm{H}_{14} \mathrm{O}_{5} \mathrm{~S}_{3}\right]$, compound $\mathbf{1 1}$. 

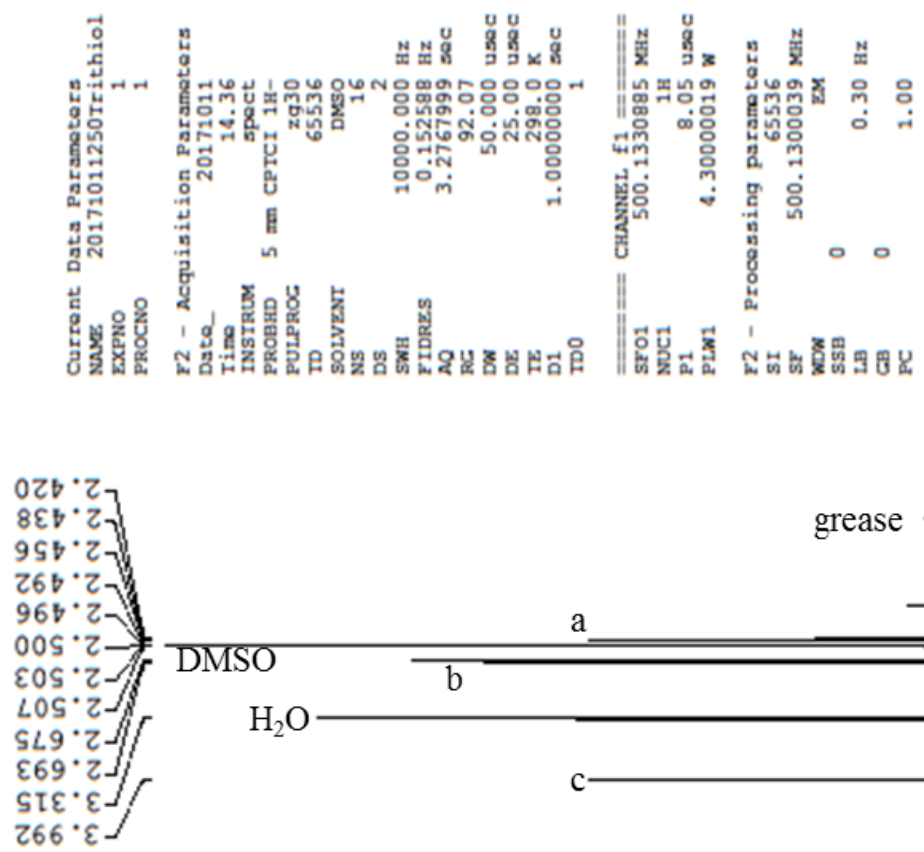

$\checkmark 0 L^{\circ} L$

$90 L^{\circ} \mathrm{L}-\mathrm{L}$

$280^{\circ} 8-$

$\mathrm{S} 80^{\circ} 8-$

$880^{\circ} 8-$

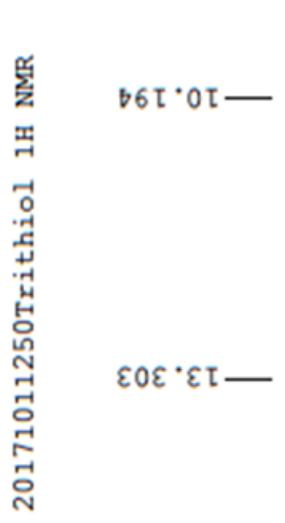

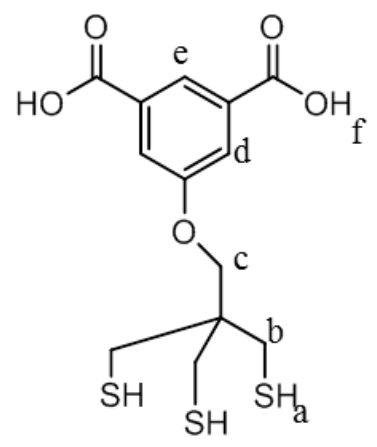

d

a

$\mathrm{H}_{2} \mathrm{O}$
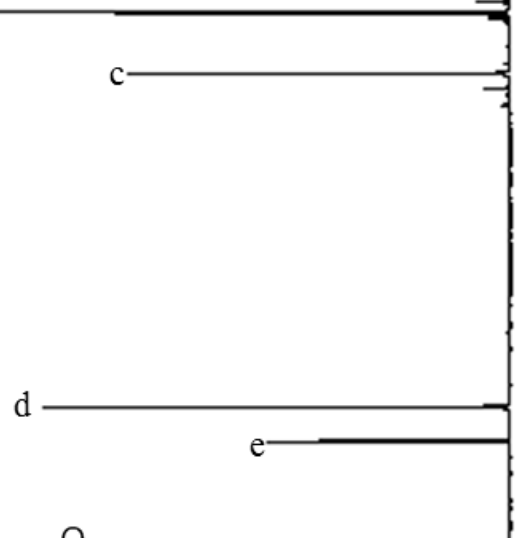

(

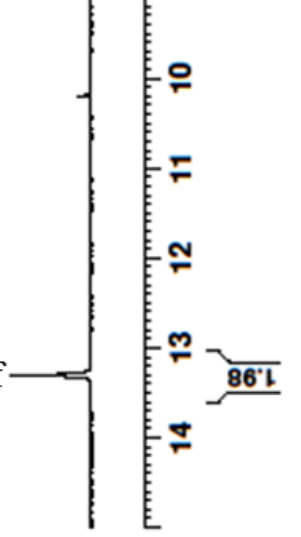

Figure B-23. ${ }^{1} \mathrm{H}$ NMR of 5-(3-mercapto-2,2-bis(mercaptomethyl)propoxy)isophthalic acid $\left[\mathrm{C}_{13} \mathrm{H}_{16} \mathrm{O}_{5} \mathrm{~S}_{3}\right]$, compound $\mathbf{1 2}$. 

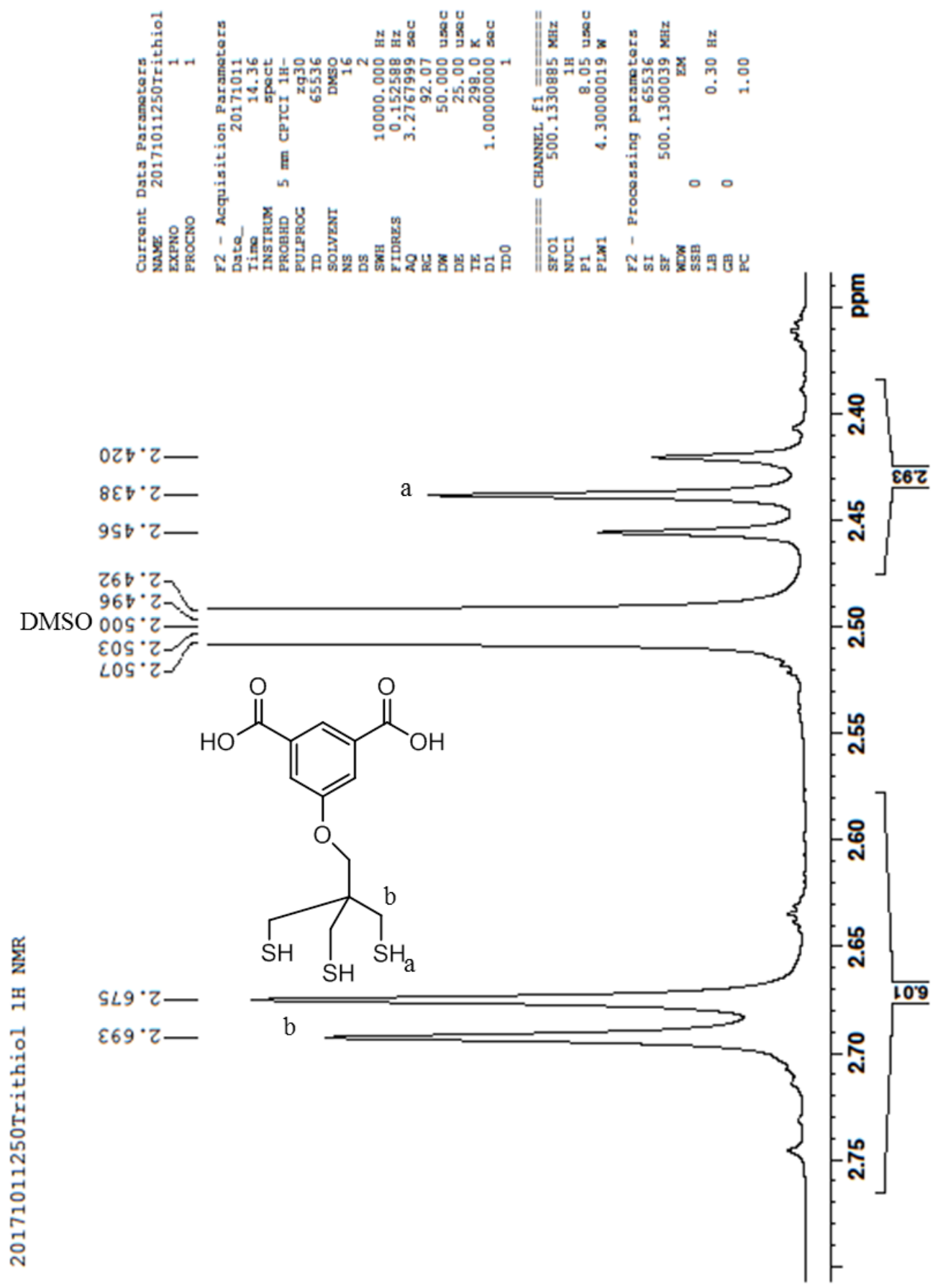

Figure B-24. ${ }^{1} \mathrm{H}$ NMR of 5-(3-mercapto-2,2-bis(mercaptomethyl)propoxy) isophthalic acid $\left[\mathrm{C}_{13} \mathrm{H}_{16} \mathrm{O}_{5} \mathrm{~S}_{3}\right]$, compound 12 . 


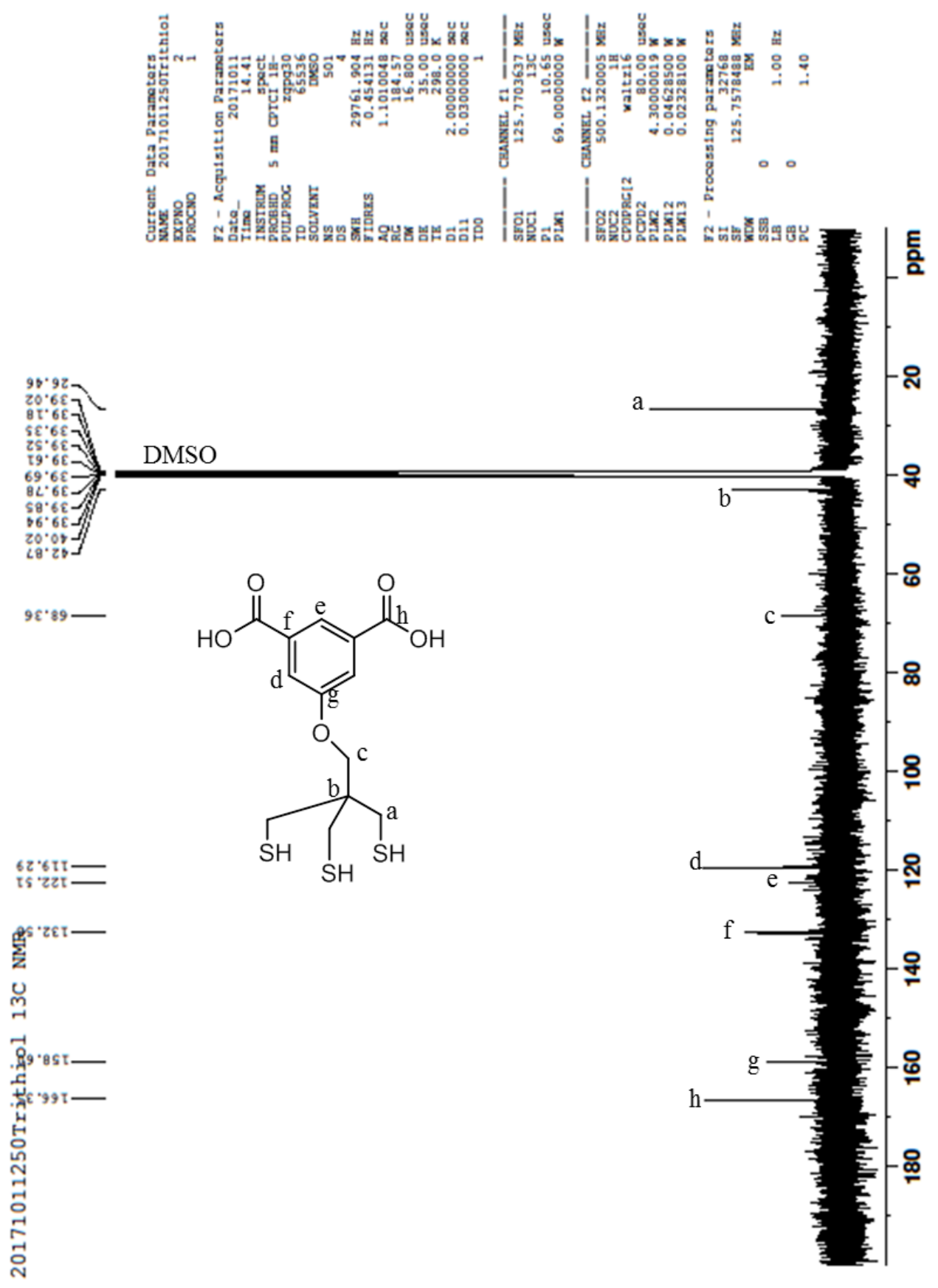

Figure B-25. ${ }^{13} \mathrm{C}$ NMR of 5-(3-mercapto-2,2-bis(mercaptomethyl)propoxy) is ophthalic acid $\left[\mathrm{C}_{13} \mathrm{H}_{16} \mathrm{O}_{5} \mathrm{~S}_{3}\right]$, compound 12 . 

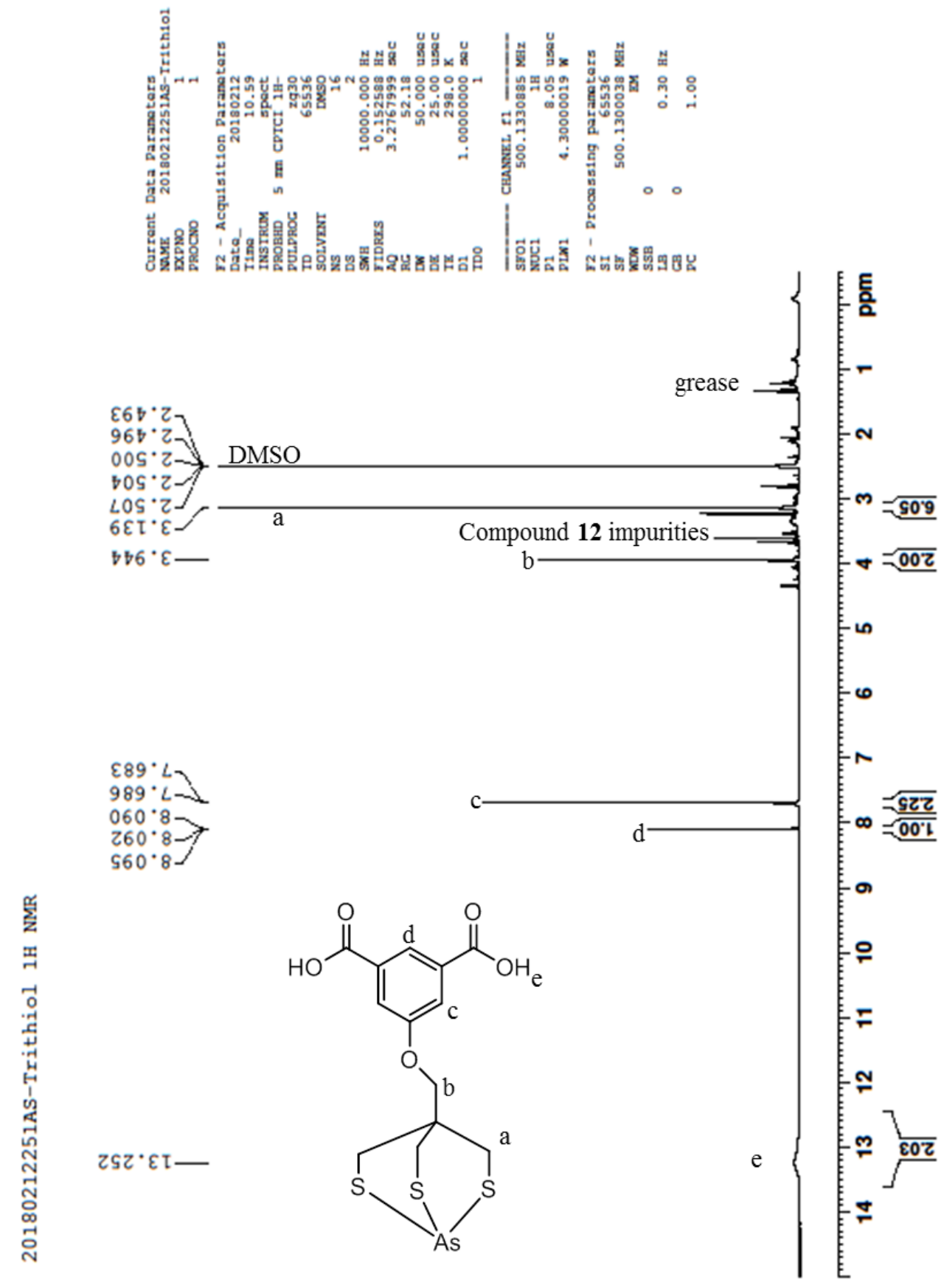

Figure B-26. ${ }^{1} \mathrm{H}$ NMR of 5-((2,6,7-trithia-1-arsabicyclo[2.2.2] octan-4-

yl)methoxy)is ophthalic acid $\left[\mathrm{C}_{13} \mathrm{H}_{13} \mathrm{AsO}_{5} \mathrm{~S}_{3}\right]$, compound 14. 

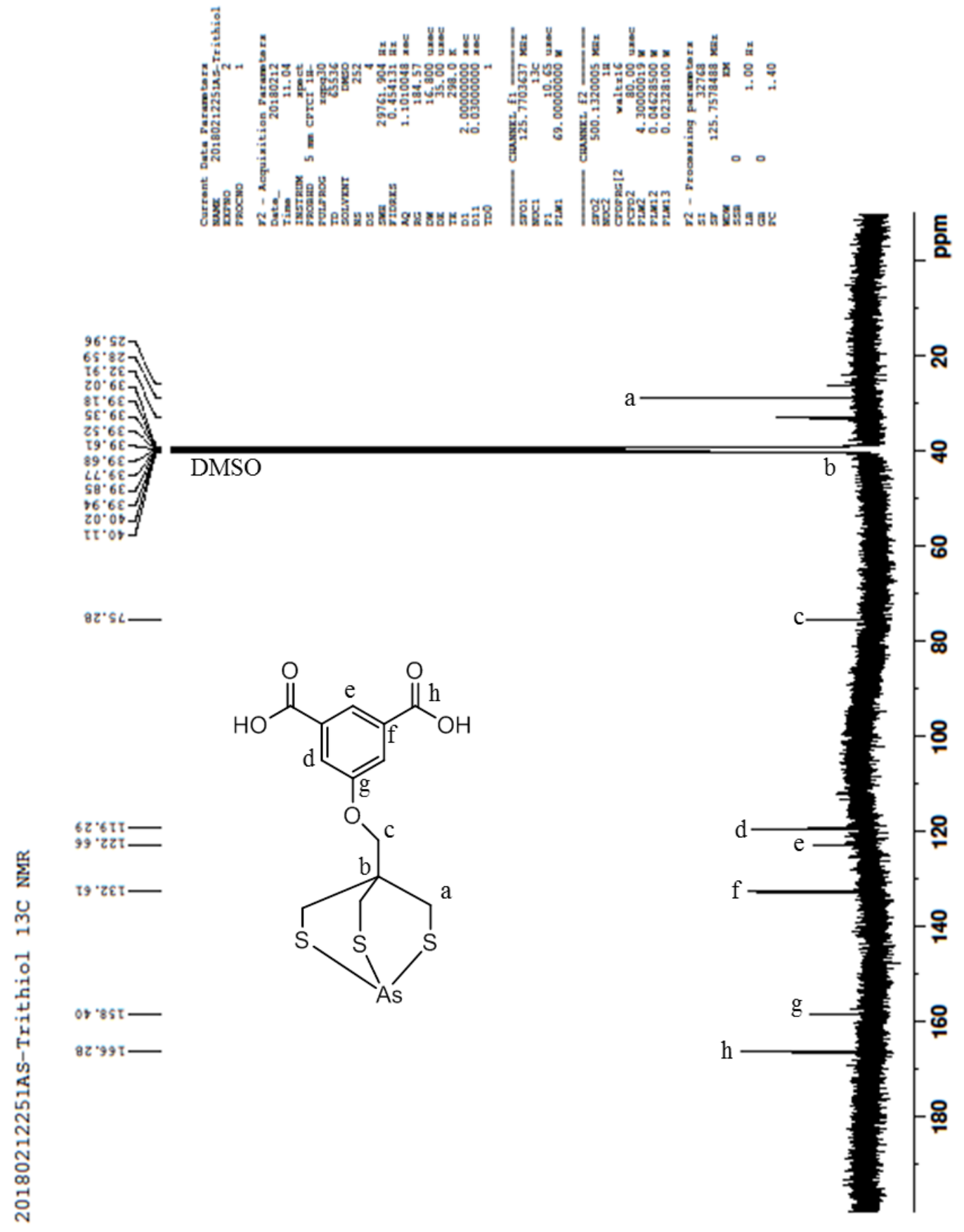

Figure B-27. ${ }^{13} \mathrm{C}$ NMR of 5-((2,6,7-trithia-1-arsabicyclo[2.2.2]octan-4-

yl)methoxy)is ophthalic acid $\left[\mathrm{C}_{13} \mathrm{H}_{13} \mathrm{AsO}_{5} \mathrm{~S}_{3}\right]$, compound 14. 


\section{References}

1. Gott, M.D., et al., Chromatographic separation of germanium and arsenic for the production of high purity 77 As. Journal of Chromatography A, 2016. 1441: p. 68-74.

2. Hevesy, G., Application of isotopes in biology. Journal of the Chemical Society (Resumed), 1939: p. $1213-1223$.

3. Liu, S. and D.S. Edwards, 99mTc-labeled small peptides as diagnostic radiopharmaceuticals. Chemical reviews, 1999. 99(9): p. 2235-2268.

4. Del Vecchio, S., et al., Nuclear imaging in cancer theranostics. The Quarterly Journal of Nuclear Medicine and Molecular Imaging, 2007. 51(2): p. 152.

5. Cutler, C.S., et al., Radiometalsfor Combined Imaging and Therapy. Chemical Reviews, 2013. 113(2): p. 858-883.

6. Wycoff, D.E., et al., Chromatographic separation of selenium and arsenic: a potential $72 \mathrm{Se} / 72$ As generator. Journal of Chromatography A, 2014. 1340: p. 109-114.

7. Nayak, T.K. and M.W. Brechbiel, Radioimmunoimaging with longer-lived positron-emitting radionuclides: potentials and challenges. Bioconjugate chemistry, 2009. 20(5): p. 825-841.

8. Kitchin, K.T. and K. Wallace, The role of protein binding of trivalent arsenicals in arsenic carcinogenesis and toxicity. Journal of inorganic biochemistry, 2008. 102(3): p. 532-539.

9. Pott, W.A., S.A. Benjamin, and R.S. Yang, Pharmacokinetics, metabolism, and carcinogenicityof arsenic, in Reviews of environmental contamination and toxicology. 2001, Springer. p. 165-214.

10. Aposhian, H.V., DMSA and DMPS-water soluble antidotes for heavy metal poisoning. Annual Review of Pharmacology and Toxicology, 1983. 23(1): p. 193-215. 


\section{Yutian Feng}

11. Jennewein, M., et al., A new method for radiochemical separation of arsenic from irradiated germanium oxide. Applied radiation and isotopes, 2005. 63(3): p. 343-351.

12. Jennewein, M., et al., Vascular imaging of solid tumors in rats with a radioactive arsenic-labeled antibody that binds exposed phosphatidy/serine. Clinical Cancer Research, 2008. 14(5): p. 13771385.

13. Herth, M.M., et al., 72/74 As-labeling of HPMA based polymers for long-term in vivo PET imaging. Bioorganic \& medicinal chemistry letters, 2010. 20(18): p. 5454-5458.

14. Ellison, P.A., et al., High yield production and radiochemical isolation of isotopically pure arsenic72 and novel radioarsenic labeling strategies for the development of theranostic radiopharmaceuticals. Bioconjugate chemistry, 2015. 27(1): p. 179-188.

15. Kitchin, K.T. and K. Wallace, Dissociation of arsenite - peptide complexes: Triphasic nature, rate constants, half - lives, and biological importance. Journal of biochemical and molecular toxicology, 2006. 20(1): p. 48-56.

16. Rahmim, A. and H. Zaidi, PET versus SPECT: strengths, limitations and challenges. Nuclear medicine communications, 2008. 29(3): p. 193-207.

17. Bateman, T.M., Advantages and disadvantages of PET and SPECT in a busy clinical practice. Journal of Nuclear Cardiology, 2012. 19(1): p. 3-11.

18. Richards, P., W.D. Tucker, and S.C. Srivastava, Technetium-99m: an historical perspective. The International journal of applied radiation and isotopes, 1982. 33(10): p. 793-799.

19. Mansi, L., et al., Basic premisesto molecular imaging and radionuclide therapy. Journal of Diagnostic Imaging and Therapy, 2014. 1(1): p. 137-156.

20. Liu, Z., et al., One-step 18F labeling of biomolecules using organotrifluoroborates. Nature protocols, 2015. 10(9): p. 1423-1432. 


\section{Yutian Feng}

21. Strebhardt, K. and A. Ullrich, Paul Ehrlich's magic bullet concept: 100 years of progress. Nature Reviews Cancer, 2008. 8(6): p. 473-480.

22. Brucer, M., The heritage of nuclear medicine. 1979: Society of Nuclear Medicine, Incorporated.

23. Gamelin, E., et al., Individual fluorouracil dose adjustment based on pharmacokinetic follow-up compared with conventional dosage: results of a multicenter randomized trial of patients with metastatic colorectal cancer. Journal of clinical oncology, 2008. 26(13): p. 2099-2105.

24. Jensen, C., Controversy and consensus: nuclear beta decay 1911-1934. Vol. 24. 1999: Springer Science \& Business Media.

25. Jahn, M., et al., Separation and purification of no carrier added arsenic from bulk amounts of germanium being adequate to radiopharmaceutical labeling chemistry.

26. Shehata, M., et al., Separation of radioarsenic from irradiated germanium oxide targetsfor the production of 71As and 72As. Journal of Radioanalytical and Nuclear Chemistry, 2011. 287(2): p. 435-442.

27. Tolmachev, V. and H. Lundqvist, Separation of arsenic from germanium oxide targets by dry distillation. Journal of Radioanalytical and Nuclear Chemistry, 2001. 247(1): p. 61-66.

28. Ballard, B., et al., Selenium-72 formation via natBr $(p, x)$ induced by 100 MeV Protons: Steps towards a novel 72Se/72As generator system. Applied Radiation and Isotopes, 2012. 70(4): p. 595-601.

29. Jennewein, M., et al., A no-carrier-added 72Se/72As radionuclide generator based on distillation. Radiochimica Acta, 2004. 92(4-6): p. 245-249.

30. Jennewein, M., et al., A no-carrier-added 72Se/72As radionuclide generator based on solid phase extraction. Radiochimica Acta, 2005. 93(9-10): p. 579-583.

31. DeGraffenreid, A.J., et al., Dithiol Aryl Arsenic Compounds as Potential Diagnostic and Therapeutic Radiopharmaceuticals. Inorganic Chemistry, 2016. 55(16): p. 8091-8098. 


\section{Yutian Feng}

32. DeGraffenreid, A.J., et al., Trithiols and their arsenic compounds for potential use in diagnostic and therapeutic radiopharmaceuticals. Nuclear medicine and biology, 2016. 43(5): p. 288-295.

33. Reubi, J.C., Neuropeptide receptors in health and disease: the molecular basis for in vivo imaging. Journal of nuclear medicine, 1995. 36(10): p. 1825-1835.

34. Selim, H.M., Dynamics and bioavailability of heavy metals in the rootzone. 2011: CRC Press.

35. Chinol, M., et al., Production of GMP-compliant lutetium-177: radiochemical precursor for targeted cancer therapy. Nuclear Medicine and Biology, 2010. 37(6): p. 717.

36. Goeckeler, W., et al., Skeletal localization of samarium-153 chelates: potential therapeutic bone agents. Journal of nuclear medicine, 1987. 28(4): p. 495-504.

37. Volkert, W.A. and T.J. Hoffman, Therapeutic radiopharmaceuticals. Chemical reviews, 1999. 99(9): p. 2269-2292.

38. Feng, Y., et al., Chemistry and radiochemistry of $A s$, Re and $R h$ isotopes relevant to radiopharmaceutical applications: high specific activity radionuclides for imaging and treatment. Dalton Transactions, 2017. 46(42): p. 14677-14690.

39. Jennewein, M., et al., A no-carrier-added 72Se/72As radionuclide generator based on distillation. Radiochimica Acta, 2004. 92(4-6): p. 245-249.

40. Al-Kouraishi, S.H. and G.G.J. Boswell, An isotope generator for 72As. The International Journal of Applied Radiation and Isotopes, 1978. 29(11): p. 607-609.

41. Wycoff, D.E., et al., Chromatographic separation of selenium and arsenic: A potential 72Se/72As generator. Journal of Chromatography A, 2014. 1340: p. 109-114.

42. Bateman, H. The solution of a system of differential equations occurring in the theory of radioactive transformations. in Proc. Cambridge Philos. Soc. 1910. 


\section{Yutian Feng}

43. Levin, C.S. and E.J. Hoffman, Calculation of positron range and its effect on the fundamental limit of positron emission tomography system spatial resolution. Physics in Medicine \& Biology, 1999. 44(3): p. 781.

44. Conti, M. and L. Eriksson, Physics of pure and non-pure positron emittersfor PET: a review and a discussion. EJNMMI physics, 2016. 3(1): p. 8.

45. Chattopadhyay, S., et al., A versatile technique for radiochemical separation of medically useful no-carrier-added (nca) radioarsenic from irradiated germanium oxide targets. Applied Radiation and Isotopes, 2007. 65(11): p. 1202-1207.

46. Ezeh, V.C. and T.C. Harrop, A sensitive and selective fluorescence sensor for the detection of arsenic (III) in organic media. Inorganic chemistry, 2012. 51(3): p. 1213-1215.

47. Pike, V.W., PET radiotracers: crossing the blood-brain barrier and surviving metabolism. Trends in pharmacological sciences, 2009. 30(8): p. 431-440.

48. Mungli, P., et al., Total thiols: biomedical importance and their alteration in various disorders. Online journal of health and allied sciences, 2009. 8(2).

49. Heredia-Moya, J. and K.L. Kirk, An improved synthesis of arsenic-biotin conjugates. Bioorganic \& medicinal chemistry, 2008. 16(10): p. 5743-5746.

50. Adams, E., et al., Chemistry of organometalloid complexes with potential antidotes: structure of an organoarsenic (III) dithiolate ring. Inorganic Chemistry, 1990. 29(8): p. 1500-1503.

51. Hamilton, C.S. and J.F. Morgan, The preparation of aromatic arsonic and arsinic acids by the Bart, Bechamp, and Rosenmund Reactions. Organic Reactions, 1944.

52. DeGraffenreid, A.J., Arsenic for Potential Diagnostic Imaging and Radiotherapy. 2015: University of Missouri-Columbia.

53. Lloyd, N.C., et al., Substituted phenylarsonic acids; structures and spectroscopy. Journal of Organometallic Chemistry, 2008. 693(14): p. 2443-2450. 


\section{Yutian Feng}

54. Starkey, E., $p$ - Dinitrobenzene. Organic Syntheses, 1943: p. 40-40.

55. Sheldrick, G.M., A short history of SHELX. Acta Crystallographica Section A: Foundations of Crystallography, 2008. 64(1): p. 112-122.

56. Sheldrick, G., Sadabs. 1996, University of Göttingen, Germany Program for Empirical Absorption Correction of Area Detector Data.

57. Loiseau, P.M., P. Lubert, and J.-G. Wolf, Contribution of dithiol ligands to in vitro and in vivo trypanocidal activities of dithiaarsanes and investigation of ligand exchange in an aqueous solution. Antimicrobial agents and chemotherapy, 2000. 44(11): p. 2954-2961.

58. Gibaud, S., et al., (2-Phenyl-[1, 3, 2] dithiarsolan-4-yl)-methanol derivatives show in vitro antileukemic activity. Journal of organometallic chemistry, 2006. 691(5): p. 1081-1084.

59. von Döllen, A. and H. Strasdeit, Models for the Inhibition of Dithiol - Containing Enzymes by Organoarsenic Compounds: Synthetic Routes and the Structure of [PhAs (HlipS2)](HlipS22-= Reduced Lipoic Acid). European Journal of Inorganic Chemistry, 1998. 1998(1): p. 61-66.

60. Shaikh, T.A., et al., Structural characteristics of 2-halo-1, 3, 2-dithiarsenic compounds and tris(pentafluorophenylthio)-arsen. Journal of organometallic chemistry, 2006. 691(9): p. 1825-1833.

61. Bockisch, A., Matched pairs for radionuclide-based imaging and therapy. European journal of nuclear medicine and molecular imaging, 2011. 38(1): p. 1-3.

62. Ohki-Hamazaki, H., M. Iwabuchi, and F. Maekawa, Development and function of bombesin-like peptides and their receptors. International Journal of Developmental Biology, 2003. 49(2-3): p. 293-300.

63. Abd-Elgaliel, W.R., et al., Design, Synthesis, and Biological Evaluation of an AntagonistBombesin Analogue as Targeting Vector. Bioconjugate chemistry, 2008. 19(10): p. 2040-2048.

64. Hoffman, T.J. and C.J. Smith, True radiotracers: Cu-64 targeting vectors based upon bombesin peptide. Nuclear medicine and biology, 2009. 36(6): p. 579-585. 


\section{Yutian Feng}

65. Lane, S.R., et al., Optimization, biological evaluation and microPET imaging of copper-64-labeled bombesin agonists, [64 Cu-NO2A-(X)-BBN (7-14) NH 2], in a prostate tumor xenografted mouse model. Nuclear medicine and biology, 2010. 37(7): p. 751-761.

66. Feng, Y., et al., A Trithiol Bifunctional Chelate for 72, 77 As: a Matched Pair Theranostic Complex with High in vivo Stability. Nuclear Medicine and Biology, 2018.

67. Camerano, J.A., et al., A trithiol protio-ligand and its fixation to the periphery of a carbosilane dendrimer as scaffolds for polynuclear rhodium and iridium complexes and metallodendrimers. Organometallics, 2005. 24(21): p. 5147-5156.

68. Alvarez, S.G. and M.T. Alvarez, A practical procedure for the synthesis of alkyl azides at ambient temperature in dimethyl sulfoxide in high purity and yield. Synthesis, 1997. 1997(04): p. 413-414.

69. Rostovtsev, V.V., et al., A stepwise huisgen cycloaddition process: copper (I) - catalyzed regioselective "ligation" of azides and terminal alkynes. Angewandte Chemie, 2002. 114(14): p. $2708-2711$.

70. Meldal, M. and C.W. Tornøe, Cu-catalyzed azide-alkyne cycloaddition. Chemical reviews, 2008. 108(8): p. 2952-3015.

71. Chan, W.C. and P.D. White, Fmoc solid phase peptide synthesis. 2000: Oxford University Press.

72. Field, L.D., S. Sternhell, and J.R. Kalman, Organic structuresfrom spectra. 2012: John Wiley \& Sons.

73. Zhdanko, A.G. and V.G. Nenajdenko, Nonracemizable isocyanoacetates for multicomponent reactions. The Journal of organic chemistry, 2008. 74(2): p. 884-887.

74. Anastasi, A., V. Erspamer, and M. Bucci, Isolation and structure of bombesin and alytesin, two analogous active peptides from the skin of the European amphibiansBombina andAlytes. Experientia, 1971. 27(2): p. 166-167. 


\section{Yutian Feng}

75. Markwalder, R. and J.C. Reubi, Gastrin-releasing peptide receptors in the human prostate relation to neoplastic transformation. Cancer research, 1999. 59(5): p. 1152-1159.

76. Hughes, M.F., Arsenic toxicity and potential mechanisms of action. Toxicology letters, 2002. 133(1): p. 1-16.

77. Shen, S., et al., Arsenic binding to proteins. Chemical reviews, 2013. 113(10): p. 7769-7792.

78. Li, Y., et al., 18F-click labeling of a bombesin antagonist with an alkyne-18F-ArBF3-: in vivo PET imaging of tumors expressing the GRP-receptor. American journal of nuclear medicine and molecular imaging, 2013. 3(1): p. 57.

79. Hoffman, T.J., et al., Novel series of 111/n-labeled bombesin analogs as potential radiopharmaceuticalsfor specific targeting of gastrin-releasing peptide receptors expressed on human prostate cancer cells. Journal of Nuclear Medicine, 2003. 44(5): p. 823-831.

80. Hou, Y.-L., et al., Metalation triggers single crystalline order in a porous solid. Journal of the American Chemical Society, 2016. 138(45): p. 14852-14855.

81. Chabre, Y.M., et al., Expeditive synthesis of glycodendrimer scaffolds based on versatile TRIS and mannoside derivatives. The Journal of organic chemistry, 2008. 73(14): p. 5602-5605.

82. Wuts, P.G. and T.W. Greene, Greene's protective groups in organic synthesis. 2006: John Wiley \& Sons.

83. Zervas, L., I. Photaki, and N. Ghelis, On Cysteine and Cystein Peptides. II. S-Acylcysteines in Peptide Synthesis. Journal of the American Chemical Society, 1963. 85(9): p. 1337-1341.

84. Meyer, J.-P., et al., Exploring Structural Parameters for Pretargeting Radioligand Optimization. Journal of medicinal chemistry, 2017. 60(19): p. 8201-8217.

85. Garrison, J.C., et al., In vivo evaluation and small-animal PET/CT of a prostate cancer mouse model using 64Cu bombesin analogs: side-by-side comparison of the CB-TE2A and DOTA chelation systems. Journal of Nuclear Medicine, 2007. 48(8): p. 1327-1337. 


\section{Yutian Feng}

86. Prasanphanich, A.F., et al., [64CU-NOTA-8-Aoc-BBN (7-14) NH2] targeting vector for positronemission tomography imaging of gastrin-releasing peptide receptor-expressing tissues. Proceedings of the National Academy of Sciences, 2007. 104(30): p. 12462-12467.

87. Bartholomä, M.D., Recent developments in the design of bifunctional chelators for metal-based radiopharmaceuticals used in Positron Emission Tomography. Inorganica Chimica Acta, 2012. 389: p. 36-51.

88. Verkade, J.G., R.W. King, and C.W. Heitsch, Phosphorus Complexes of Group III Acids. IV. B11, F19, H1, and P31 Nuclear Magnetic Resonance Studies of Boron Complexes of Polycyclic Phosphites. Inorganic Chemistry, 1964. 3(6): p. 884-889.

89. Neunhoeffer, O. and W. Maiwald, Bicyclische Ester des 1.1.1 - Tris - hydroxymethyl - propans mit dreibasigen anorganischen Säuren. Chemische Berichte, 1962. 95(1): p. 108-110.

90. Cooper, G., et al., Structure-activity relations in 2, 6, 7-trioxa-1-phosphabicyclo (2, 2, 2) octanes and related compounds. EUROPEAN JOURNAL OF MEDICINAL CHEMISTRY, 1978. 13(3): p. 207212.

91. Groom, C.R. and F.H. Allen, The Cambridge Structural Database in retrospect and prospect. Angewandte Chemie International Edition, 2014. 53(3): p. 662-671.

92. Ramírez-Solís, A., et al., Experimental and theoretical characterization of arsenite in water: insights into the coordination environment of As-O. Inorganic chemistry, 2004. 43(9): p. 29542959.

93. Supavilai, P., et al., Anion-dependent modulation of [3 $\mathrm{H}]$ muscimol binding and of GABAstimulated [3 H] flunitrazepam binding by picrotoxin and related CNS convulsants. European journal of pharmacology, 1982. 81(4): p. 687-691. 


\section{Yutian Feng}

\section{Vita}

Yutian Feng was born on November 8, 1989 in Xi'an, China to Xiaoyan Feng and Jianwei Feng. He graduated from Xi' an No.1 High School in 2008 and then went to the Huazhong University of Science and Technology (HUST) in Wuhan, China. During his undergraduate education, he worked at the Wuhan National Laboratory for Optoelectronics (WNLO) as a research assistant. He earned his B.S. in chemistry in 2012 and enrolled in the master program in biochemistry in the HUST in 2012. One year later he enrolled in the Ph.D. program in the Department of Chemistry, University of Missouri-Columbia. He joined Professor Silvia S. Jurisson's research group in 2013 and focused on the research of the chemistry and radiochemistry of Arsenic. He was awarded the Outstanding Graduate Teaching Award and David E. Troutner Radiochemistry Fellowship in 2017, and the Outstanding Graduate Research Award in 2018. He believes he may be the only graduate student to date who was awarded all three awards in the Department of Chemistry. In May 2018 he earned his Ph.D. in radiochemistry and will continue his research as a Postdoctoral associate at Duke University under the mentorship of Professor Michael R. Zalutsky.

The same as his favorite character in the book "A Song of Ice and Fire" (by George R. R. Martin), he likes to call himself: Yutian Feng of the House of Arsenic, First of His Name, Protector of Thiols, Breaker of Beakers, Bearer of the Burnt Nasal Receptors, Grey Warden of Germanium and $\mathrm{PhD}$ of radiochemistry. 